NBSIR 78-1420-2 R

\title{
NBS Minimal BASIC Test Programs - Version 1 User's Manual
}

Volume 2 - General Program Structure, Output, Assignment, Simple Control Structures, Simple Expressions

David E. Gilsinn

Charles L. Sheppard

Systems and Software Division

Institute for Computer Sciences and Technology

National Bureau of Standards

Washington, D.C. 20234

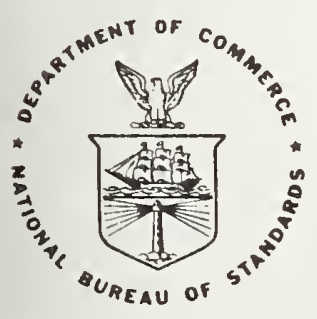

U.S. DEPARTMENT OF COMMERCE

NATIONAL BUREAU OF STANDARDS 

NBSIR 78-1420-2

NBS MINIMAL BASIC TEST

PROGRAMS - VERSION 1

USER'S MANUAL

Volume 2 - General Program Structure, Output, Assignment, Simple Control Structures, Simple Expressions

David E. Gilsinn

Charles L. Sheppard

Systems and Software Division

Institute for Computer Sciences and Technology

National Bureau of Standards

Washington, D.C. 20234

U.S. DEPARTMENT OF COMMERCE, Juanita M. Kreps, Secretary

Dr. Sidney Harman, Under Secretary

Jordan J. Baruch, Assistant Secretary for Science and Technology

NATIONAL BUREAU OF STANDARDS, Ernest Ambler, Acting Director 
This volume is the second of four volumes that comprise the user's guide to the NBS Minimal BASIC test programs. The programs test whether a BASIC processor accepts the syntactical forms and produces semantically meaningful results according to the specifications given in BSR X3.60 Proposed American National Standard for Minimal BASIC. The object of this volume is to introduce elementary variable, control and expression forms and exercise them by using a large sample of variations of the appropriate statements. There are thirty three programs in this volume. They cover specifically the tests for output, simple assignment of variables, elementary control structures, general program structure, formulating simple expressions, and the hierarchy of operators. The entire set of test programs is available on magnetic tape.

Key Words: BASIC, BASIC standard, BASIC validation, compiler validation, computer programming language, computer standards. 
D. Introduction . . . . . . . . . . . . . 1

1. Output and Assignment of Strings ......... . 2 Program Listing . . . . . . . . 4 Sample Output . . . . . . . . 8

2. Exception Test for Printing TAB Beyond the Left Margin . . . . . . . . . . . . . . 12 Program Listing . . . . . . . . 12 Sample Output ........ . . 13

3. Using Empty Print Items to Space Over Print

Zones . . . . . . . . . . . . 15 Program Listing . . . . . . . . 15 Sample Output ........ . 16

4. Printing Integer and Fixed Point Constants . . 17 Program Listing . . . . . . . . . 20 Sample Output . . . . . . . 23

5. Printing Floating Point Constants . . . . . 26 Program Listing . . . . . . . . . 27 Sample Output . . . . . . . 31

6. Printing of Floating Point Numbers (cont.) and Assignment of Integer and Fixed Point Values . 36 Program Listing . . . . . . . 38 Sample Output . . . . . . . 42

7. Assignment of Floating Point Constants . . . . 45 Program Listing . . . . . . . 46 Sample Output . . . . . . . 48

8. Testing the Minimal Limits in Magnitude of

Numerical Constants . . . . . . . . 51 Program Listing . . . . . . . 52 Sample Output . . . . . . . 56

9. The REM and GOTO Statements . . . . . . 60 Program Listing ........ . 61 Sample Output . . . . . . . 64

10. Test for Goro with Illegal statement

Label . . . . . . . . . . 66

Program Listing . . . . . . . 66

Sample Output . . . . . . . 67

11. The IF-THEN Statement Used to Compare Positive Numerical Constants . . . . . . . . 68 Program Listing . . . . . . . . . 70 Sample Output . . . . . . . 74 
12. The IF-THEN Statement Used to Compare Negative Numerical Constants... . . . . . . . 76 Program Listing . . . . . . . . 77 Sample Output . . . . . . . . 81

13. IF-THEN Comparison of Negative Constant (cont.) and Variables Avoiding Parentheses . 82 Program Listing ........ . . 82 Sample Output . . . . . . . . 83

14. Comparing Quoted Strings and String Variables. 84 Program Listing . . . . . . . 85 Sample Output . . . . . . . . 90

15. Test of IF-THEN Transfer to Illegal Line Number . . . . . . . . . . . . . . 9 91 Program Listing .......... . 91 Sample Output . . . . . . . . 91

16. Line Labels with and Without Leading Zeroes. . 93 Program Listing . . . . . . . . 93 Sample Output . . . . . . . 94

17. Order of Lines - Two Lines with the Same Line Number . . . . . . . . . . 9 95 Program Listing . . . . . . . . 95 Sample output. . . . . . . . . 96

18. Order of Lines - Lines out of

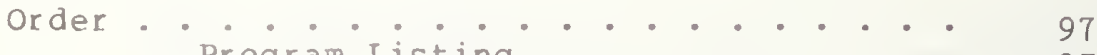

Program Listing . . . . . . . . 97

Sample Output . . . . . . . . 97

19. The ABS Function and Elementary Numerical

Expressions using Constants . . . . . . . . 99

Program Listing ......... . 100

Sample Output . . . . . . . 104

20. Elementary Numerical Expressions Using

Constants (Continued) . . . . . . . . . 107

Program Listing ... . . . . . . 107

Sample Output .. . . . . . . 110

21. Elementary Numerical Expressions Using

Constants (Continued) . . . . . . . . . 113

Program Listing ... . . . . . . 113

Sample Output . . . . . . . . 116

22. Elementary Expressions Using Simple Varjables . 119

Program Listing . . . . . . . . 119

Sample output . . . . . . . . 122

23. Elementary Expressions Using Simple Variables

(Continued) ............... . . . . 125

Program Listing . . . . . . . . 125

Sample Output . . . . . . . . 130 
24. Elementary Operations on Mixed Type Constants . 133

Program Listing . . . . . . . 133

Sample Output . . . . . . . 136

25. Elementary Operations on Mixed Type Constants

(Continued) . . . . . . . . . . . 139

Program Listing . . . . . . . . 139

Sample Output . . . . . . . . 144

26. Elementary Operations on Variables Assigned

Mixed Type Constants . . . . . . . . . 147

Program Listing ........ . 147

Sample Output . . . . . . . 151

27. Elementary Operations on Variables Assigned

Mixed Type Constants (Continued) . . . . . 154

Program Listing ........ . 154

Sample Output . . . . . . . 160

28. Addition of Three or More Terms . . . . . . 163

Program Listing . . . . . . . . 163

Sample Output . . . . . . . 166

29. Multiplication of Three or More Factors . . . I68

Program Listing .......... 168

Sample Output . . . . . . . . 171

30. Hierarchy of Operators and Parentheses . . . 173

Program Listing ......... 174

Sample Output . . . . . . . . 178

31. Hierarchy of Operators and Parentheses

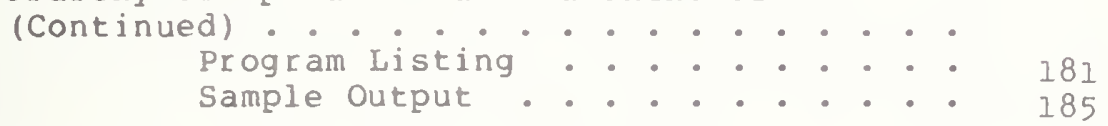

32. Evaluation of Expressions Having a Variety of

Operators.............. . . 188

Program Listing . . . . . . . . 188

Sample Output . . . . . . . . 191

33. Insertion of Spaces Between Elements of Numeric

Expressions . . * *. . . . . . . . 193

Program Listing . . . . . . . 193

Sample Output . . . . . . . 194 


\section{Introduction}

This volume is the second in a set of four volumes that comprise the user's guide to the NBS Minimal BASIC test programs. There are thirty three routines in this volume that cover the topics of output, simple assignment of variables, some preliminary control structures, general program structure, formulating simple expressions and determining the hierarchy of operators. The user should be familiar with volume $l$ of this series before executing the programs because it describes the general system logic and environmental assumptions made by the authors. Furthermore, in order to understand the terminology, the user should also be familiar with the Minimal BASIC standard BSR $\times 3.60$.

Except for routines that concentrate on evaluating processor diagnostic capabilities, most routines have more than one individual test within them. These tests are delineated within the body of the routine by a BEGIN TEST statement on input and are terminated by an END TEST statement on output. Each of the individual tests has been titled with a section number in its program listing that identifies it with the appropriate documentation section.

The authors, in using the tests themselves, have found it useful to proceed by first reading the test documentation paragraphs and noting the appropriate sections within the standard that are covered by them. This correspondence can be found in the overview volume. Next execute a program file and compare the results with the sample output. Then, proceed with the next routine. This allows orderly progression from one test to the next, with the user keeping track of discrepancies as they occur.

There is one source code for each major section in the documentation (e.g. 1.0. 2.0, etc.). The subsections (e.g. 1.2.1, 2.2, etc.) are descriptive paragraphs of specific tests within the one source code associated with the major section. For example, there is a portion of the code NBS FILE 1 that is subtitled with a subsection number 1.2.1. This means that portion of the code is associated with subsection 1.2.1 in the documention.

Within this and the subsequent volumes we have used the word "type" not in the sense of a variable type but in the sense of a difference in form. Thus we speak of one type of numerical constant over another in order to differentiate say between an integer or " $E$ " format numerical constant. Our use of the word "type" does not imply different compiler representation. 


\subsection{OUTPUT AND ASSIGNMENT OF STRINGS}

This test unit executes some of the basic print-list forms which use such print-items as quoted strings, string variables, tab-calls, and nulls. The test unit also executes the case of an empty-print-list. This section uses specifications from sections $3,4,5,6,9$, and 12 of the Minimal BASIC standard $\times 3.60$.

\section{1.l An Empty Print List}

The objective of this test is to verify that a completely empty print-list will generate an end-of-print-line, thereby completing the current line of output. That is, if a PRINT statement contains no print list, then a blank line results. The test generates the empty print-list by following the keyword PRINT with an end-of-line character. The output informs the user where the blank I ines should be.

\subsection{Printing and Assigning Quoted Strings}

\subsection{Allowed ASCII Characters}

The objective of this test is to print the character set for BASIC which is described in terms of the ASCII character set. The letters are the set of upper-case Roman letters referenced by the ASCII character set in positions $4 / 1$ through 5/10. The digits are the set of Arabic digits referenc sd by the ASCII character set in positions $3 / 0$ through $3 / 9$. The remaining string-characters consist of: space, exclamation-point, quote, number-sign, dollar, percent, ampersand, apostrophe, open-parenthesis, close-parenthesis, asterisk, plus, comma, minus, period, slant, colon, semicolon, less-than, equals, greater-than, question-mark, circumflex, and underline. The output should show the letters first, then the digits and finally the remaining quoted string-characters.

\subsubsection{Spaces in Quoted Strings}

The objective of this test is to show that an implementation will not ignore spaces embedded in quoted strings. The output of the test illustrates this by two lines of alphabetically ordered letters. As a comparison to show that the embedded spaces were retained, the second line has blank spaces where the letters $B, E, F, I, J, K, N, O, P, Q, T, U, V, W$, and $X$ should be.

\subsubsection{End-of-Line Test for Quoted Strings}

This test determines whether omitting the print-separator at the end of a print-Iist will be recognized as an indicator to start the next-line. That is, an end- of-print-line should be generated and added to the characters generated by the evaluation of the print-list. The test is constructed to inform the user how each printed statement should begin and which lines should be blank as a result of an empty string or a null-print.

\subsubsection{Semicolon Separator for Quoted Strings}


The objective of this test is to verify that the evaluation of the semicolon separator generates the null string (i.e. a string of zero length). The test generates as output the digits "123" on five successive lines. To generate the five lines, the test is constructed to perform:

(1) one print item followed by no separator,

(2) three print items separated by semicolons on one line,

(3) two print items separated by a semicolon on different $l$ ines,

(4) two print items separated by a semicolon but on

different lines, with different string lengths from (3),

(5) three separate print statements

separated by semicolons.

\subsubsection{Printing 72 Characters}

The objective of this test is to verify that up to 72 characters may be printed on one line. Since the total length of program lines, including the keyword, has been limited to 72 characters, it is not possible to create a single 72-character output string. Therefore, the test uses the semicolon separator to concatenate two sets of two strings each. The first string of each set has 50 characters and the second has 22 characters. On output the two lines of digits form column indices from 1 to 72. This test, of course, assumes the availability of a 72 column output device or terminal.

\subsubsection{Comma Separator for Quoted Strings}

The objective of this test is to verify that coma separators generate enough spaces to fill out the current print zone. The length of each zone is implementation dependent but should have a width of at least d+e+6 spaces, where $d$ is the significance-width, and e is the exrad-width (see section 12.4 of BSR X3.60). All the print zones should have the same length, except possibly the last. The number of zones and length is implementation dependent. The test is constructed to output three sets of three letters XYZ which should appear in a consistently spaced periodic manner. Each triplet of letters should be separated by spaces and appear in separate print zones. The numbers printed above the letters specify print column, and the difference between the column number of one of the letters, say $x$, and its next appearance on the line is the zone width. This number should be greater than or equal to $d+e+6$. The difference between the column number of the second and third X's should be the same as the first zone width. Three groups were used in order not to exceed the 72 character maximum output line for some implementations.

\subsubsection{Tabbing Quoted Strings within the Margin}

The objective of this test is to show that TAB-calling will set the columnar position of the current line to the specified value prior to printing the next print-item. The TAB-calls are not made beyond the margin in this test. The term "current line" refers to the (possibly empty) string of characters generated since the last end-of-print-line was generated. The "margin" is the number of characters that can be printed on one line and is defined by the implementation. The "columnar position" of the current line is the print position that will be occupied by the next character output to that line. Print positions are numbered consecutively from left to right, 
starting with position one. The test uses the semicolon print-separator in the print-list to effect the generating of the null string. The test output begins by printing a string of digits for counting the columnar positions. This string of digits should then be followed by the printing of the digits 1. 2, and 3 on three different consecutive lines. Each of the digits should be printed in columns 24,48 , and 72 , respectively.

\subsubsection{Assignment of Quoted Strings}

The objective of this test is to verify the assignment of strings to string variables by assignments of the maximum assignable string length for a standard conforming program (18 characters). The test prints a phrase of 18 characters in length as a verification that the assignment of the maximum assignable string length in a standard conforming program is possible for all string-variables.

\subsubsection{Semicolon Separator for Assigned Strings}

This test is similar to test 1.2.4. For this test the print-items in the print-list are assigned to string-variables. The output should be the same as that in test 1.2 .4 .

\subsubsection{Comma Separator for Assigned Strings}

This test is similar to test 1.2.6. For this test the print-items in the print-list are assigned to string-variables. The output should be the same as that in test 1.2 .6 .

\subsubsection{Tabbing Assigned Strings Within the Margin}

This test is similar to test 2.2.7. For this test the print-item following a TAB-call in a print-list is a string-variable. The output is the same as that of test 1.2.7.

10 PRINT "PROGRAM FILE 1"
20 PRINT
30 PRINT
40 PRINT
50 PRINT "
60 PRINT "
70 PRINT "


80 PRINT "

90 PRINT

100 PRINT "

110 PRINT "

120 PRINT

130 PRINT

140 PRINT

150 PRINT

160 PRINT

220 PRINT

230 PRINT

240 PRINT

250 PRINT

260 PRINT

270 PRINT

280 PRINT

290 PRINT

300 PRINT

310 PRINT

320 PRINT "

330 PRINT

340 PRINT

350 PRINT

360 PRINT

370 PRINT

380 PRINT

390 PRINT "

400 PRINT

410 PRINT

420 PRINT "

430 PRINT *

440 PRINT"

450 PRINT "

460 PRINT

470 PRINT

480 PRINT

490 PRINT

500 PRINT *

510 PRINT

520 PRINT "

530 PRINT

540 PRINT "

550 PRINT *

560 PRINT

570 PRINT *

580 PRINT

590 PRINT "

600 PRINT

610 PRINT "

620 PRINT

630 PRINT

640 PRINT"

650 PRINT *

660 PRINT

670 PRINT -

680 PRINT "

690 PRINT

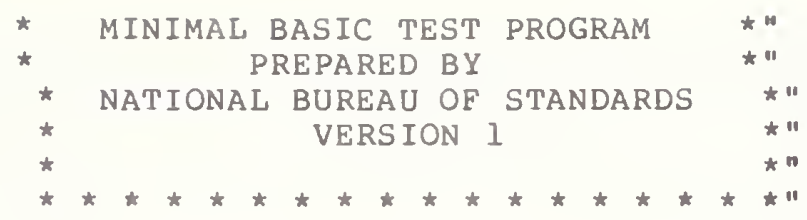

SECTION 1.1: NULL PRINT."

THIS IS LINE 1."

BEGIN TEST."

THIS IS LINE 2."

THIS IS LINE 4,3 SHOULD HAVE BEEN SKIPPED." THIS IS LINE 5."

THIS IS LINE 8, 6 AND 7 SHOULD HAVE BEEN SKIPPED." END TEST."

SECTION 1.2: PRINT OF AND ASSIGNMENT OF QUOTED STRINGS." SECTION 1.2.1: ALLOWED CHARACTERS."

BEGIN TEST."

ABCDEFGHI JKLMNOPQRSTUVWXYZ "

$1234567890^{\prime \prime}$

() \&! \# 80 ?

$+,-/<{ }^{n} \cdot "$

: i_"

END TEST."

SECTION 1.2.2: SPACES IN QUOTED STRINGS."

BEGIN TEST."

ABCDEFGHI JKLMNOPQRSTUVWXYZ "

$A C D$ GH LM RS YZ"

END TEST."

SECTION 1.2.3.: END-OF-LINE TEST, QUOTED STRINGS."

BEGIN TEST."

THIS LINE COMES FROM ONE QUOTED STRING PRINT."

THIS LINE IS THE OUTPUT OF THE NEXT PRINT."

PAST TWO PRINT LINES MUST BEGIN WITH: THIS LINE..."

LINE ABOVE THIS MUST BE BLANK (AN EMPTY STRING)."

LINE BELOW THIS MUST BE BLANK (NULL PRINT)." 


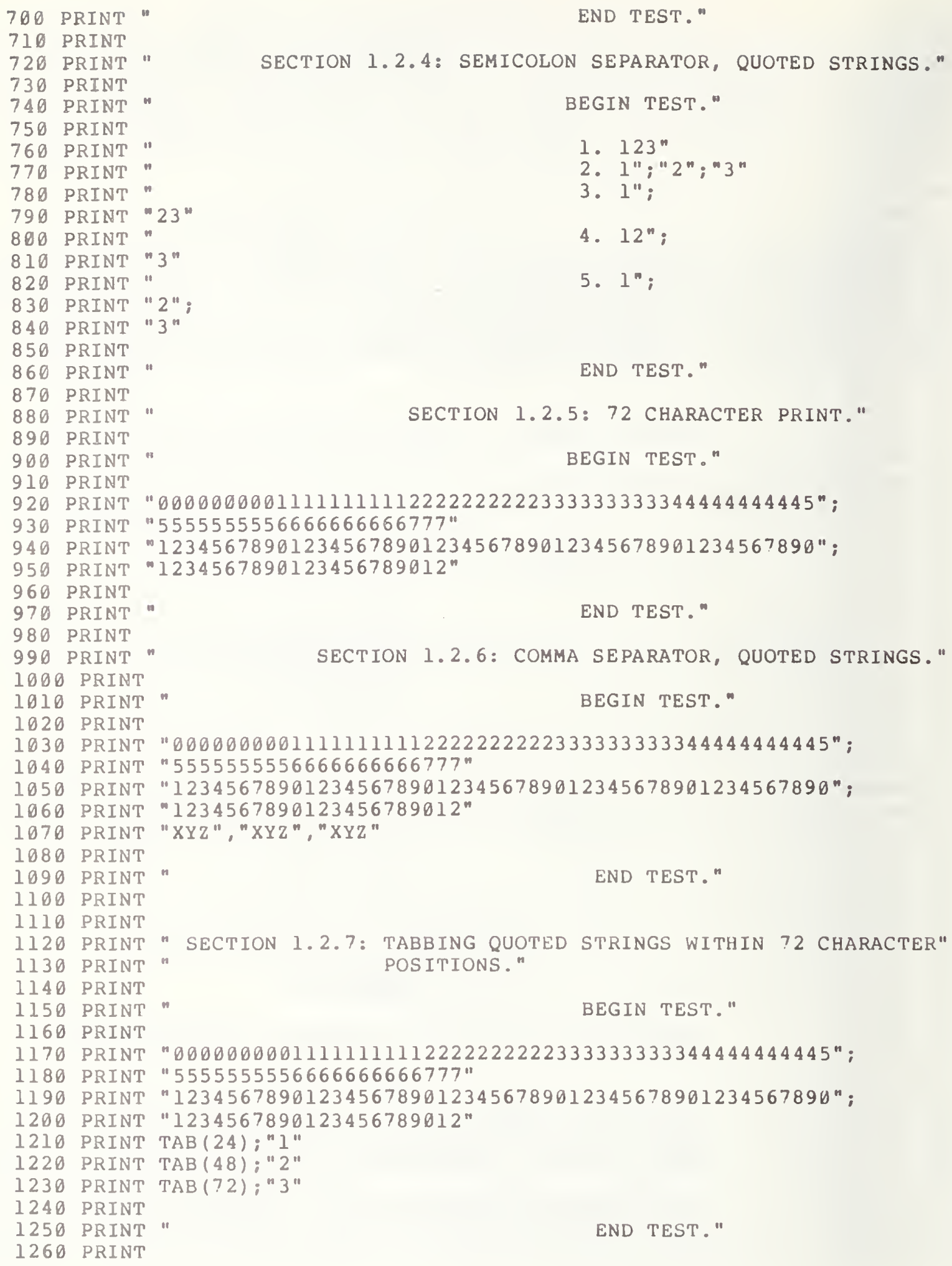




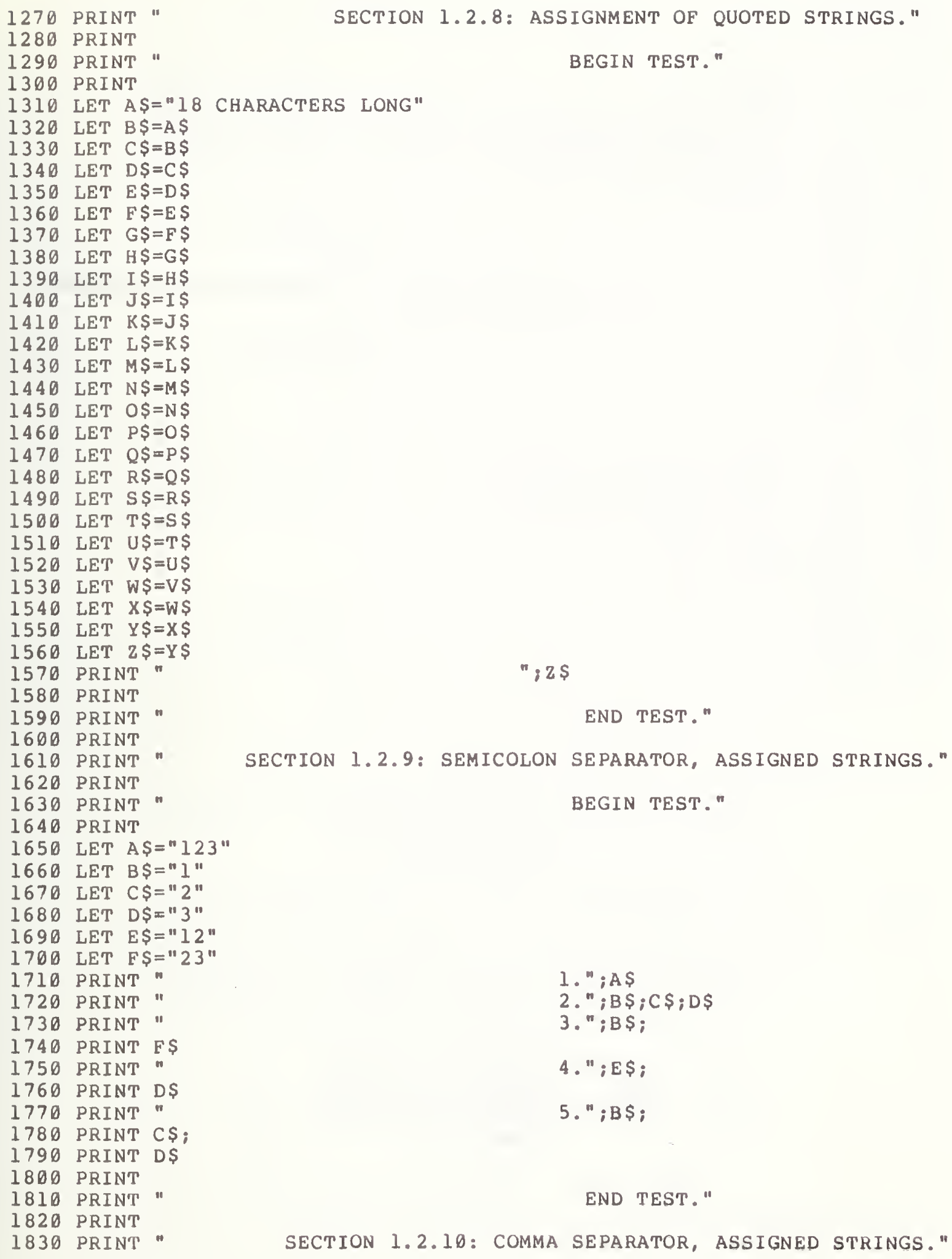




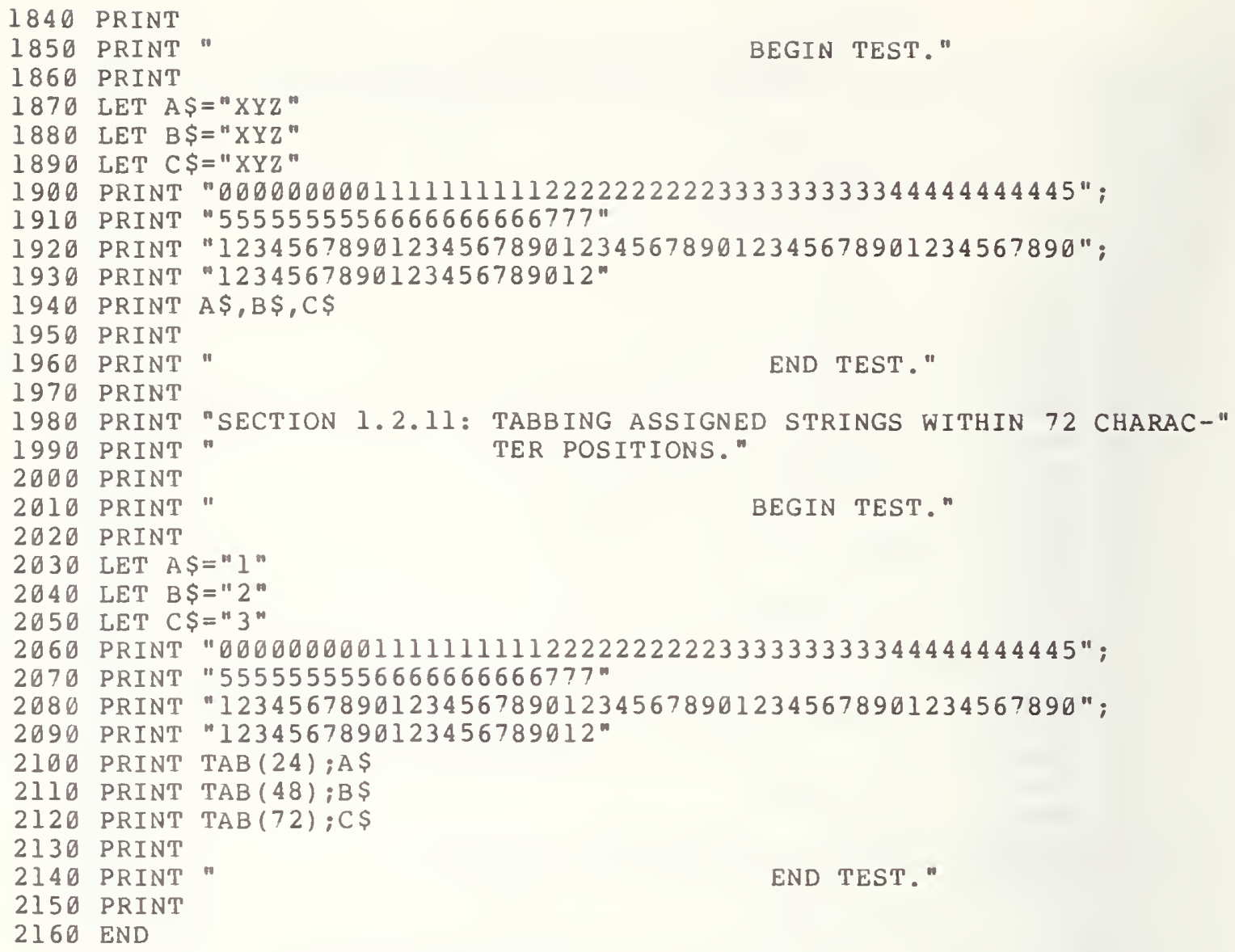

PROGRAM FILE 1
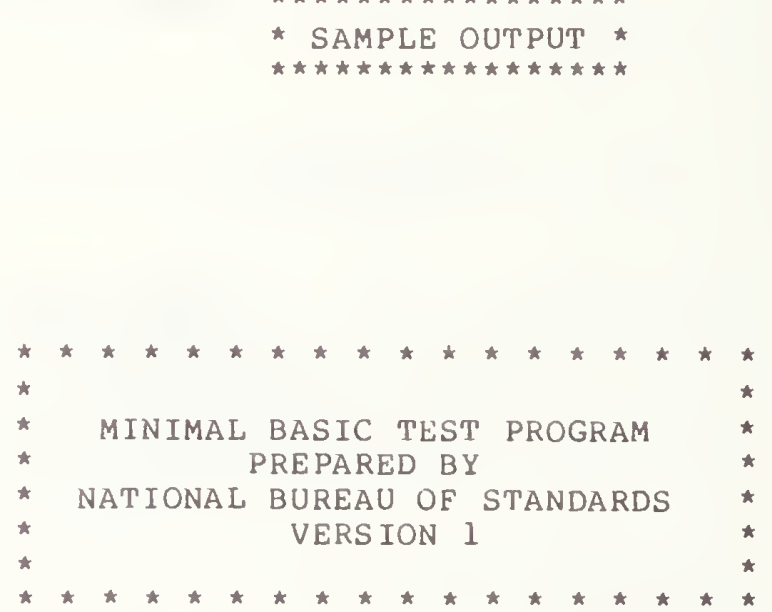
SECTION 1.1: NULL PRINT.

THIS IS LINE 1.

BEGIN TEST.

THIS IS LINE 2.

THIS IS LINE 4,3 SHOULD HAVE BEEN SKIPPED.

THIS IS LINE 5 .

THIS IS LINE 8,6 AND 7 SHOULD HAVE BEEN SKIPPED. END TEST .

SECTION 1.2: PRINT OF AND ASSIGNMENT OF QUOTED STRINGS.

SECTION 1.2.1: ALLOWED CHARACTERS.

BEGIN TEST.

ABCDEFGH I JKLMNOPQRSTUVWXYZ

1234567890

() $\& ! \# 88^{\circ} ? * \$$

,$+-/ \Leftrightarrow{ }^{\circ}$.

$: \quad ;$

END TEST.

SECTION 1.2.2: SPACES IN QUOTED STRINGS.

BEGIN TEST.

ABCDEFGH I JKLMNOPQRSTUVWXYZ

$\begin{array}{llllll}A & C D & G H & \text { LM } & \text { RS } & \text { YZ }\end{array}$

END TEST.

SECTION 1.2.3.: END-OE-LINE TEST, QUOTED STRINGS.

BEGIN TEST.

THIS LINE COMES EROM ONE QUOTED STRING PRINT.

THIS LINE IS THE OUTPUT OF THE NEXT PRINT.

PAST TWO PRINT LINES MUST BEGIN WITH: THIS LINE...

LINE ABOVE THIS MUST BE BLANK (AN EMPTY STRING).

LINE BELOW THIS MUST BE BLANK (NULL PRINT).

END TEST.

SECTION 1.2.4: SEMICOLON SEPARATOR, QUOTED STRINGS.

BEGIN TEST.

1. 123

2. 123

3. 123 


\author{
4. 123 \\ 5. 123 \\ END TEST. \\ SECTION 1.2.5: 72 CHARACTER PRINT. \\ BEGIN TEST.
}

$00000000011111111112222222222333333333344444444445555555555666666666677 ?$ 123456789012345678901234567890123456789012345678901234567890123456789012

END TEST.

SECTION 1.2.6: COMMA SEPARATOR, QUOTED STRINGS.

BEGIN TEST.

ด00000000111111111122222222223333333333444444444455555555556666666666777 123456789012345678901234567890123456789012345678901234567890123456789012 XYZ XYZ XYZ

END TEST.

SECTION 1.2.7: TABBING QUOTED STRINGS WITHIN 72 CHARACTER POSITIONS.

BEGIN TEST.

000000000111111111122222222223333333333444444444455555555556666666666777 123456789012345678901234567890123456789012345678901234567890123456789012 1

2

END TEST.

SECTION 1.2.8: ASSIGNMENT OF QUOTED STRINGS.

BEGIN TEST.

18 CHARACTERS LONG

END TEST .

SECTION 1.2.9: SEMICOLON SEPARATOR, ASSIGNED STRINGS. BEGIN TEST.

1.123

2.123

3.123

4.123

5.123

END TEST. 
SECTION 1.2.10: COMMA SEPARATOR, ASSIGNED STRINGS.

BEGIN TEST.

000000000111111111122222222223333333333444444444455555555556666666666777 123456789012345678901234567890123456789012345678901234567890123456789012 $\mathrm{XYZ}$ XYZ $X Y Z$

END TEST.

SECTION 1.2.11: TABBING ASSIGNED STRINGS WITHIN 72 CHARACTER POSITIONS.

BEGIN TEST.

000000000111111111122222222223333333333444444444455555555556666666666777 123456789012345678901234567890123456789012345678901234567890123456789012 1

END TEST. 


\section{E EXEPTION TEST FOR PRINTING TAB BEYOND THE LEFT MARGIN}

The objective of this routine is to execute error tests on improper numeric arguments for the TAB-call (see section 12.5 of BSR X3.60). This testing is performed as follows:

\section{1 TAB Argument is 0}

First, it verifies that when the rounded argument of the TAB-call is less than one, the implementation supplies an argument value of one and continues program execution. This part of the test uses an argument value of zero in the TAB-call. On output there should be an $x$ in the first column position.

\subsection{TAB Argument is Negative}

This part of the test further verifies the procedure specified in test 2.1. However, for this test -10 is the argument of the TAB-call. The output should be the same as in 2.1 .

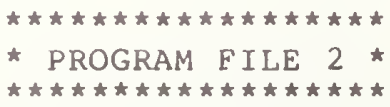

10 PRINT "PROGRAM FILE 2"

60 PRINT

70 PRINT

80 PRINT

90 PRINT "

100 PRINT

110 PRINT

120 PRINT

130 PRINT

140

140 PRINT "THE CASE WHEN A ROUNDED TAB ARGUMENT haPPENS TO HAVE A VALUE"

150 PRINT "LESS THAN ONE. IN SUCH A CASE THIS SHOULD BE HANDLED AS A"

160 PRINT "NON-FATAL ERROR WHEREBY A VALUE OF 1 IS TO BE SUPPLIED FOR"

170 PRINT "THE TAB ARGUMENT AND THE PROGRAM SHOULD CONTINUE."

180 PRINT

190 PRINT

200 PRINT

210 PRINT

220 PRINT

230 PRINT

240 PRINT

250 PRINT "ด0000000011111111112222222222333333333344444444445"; 


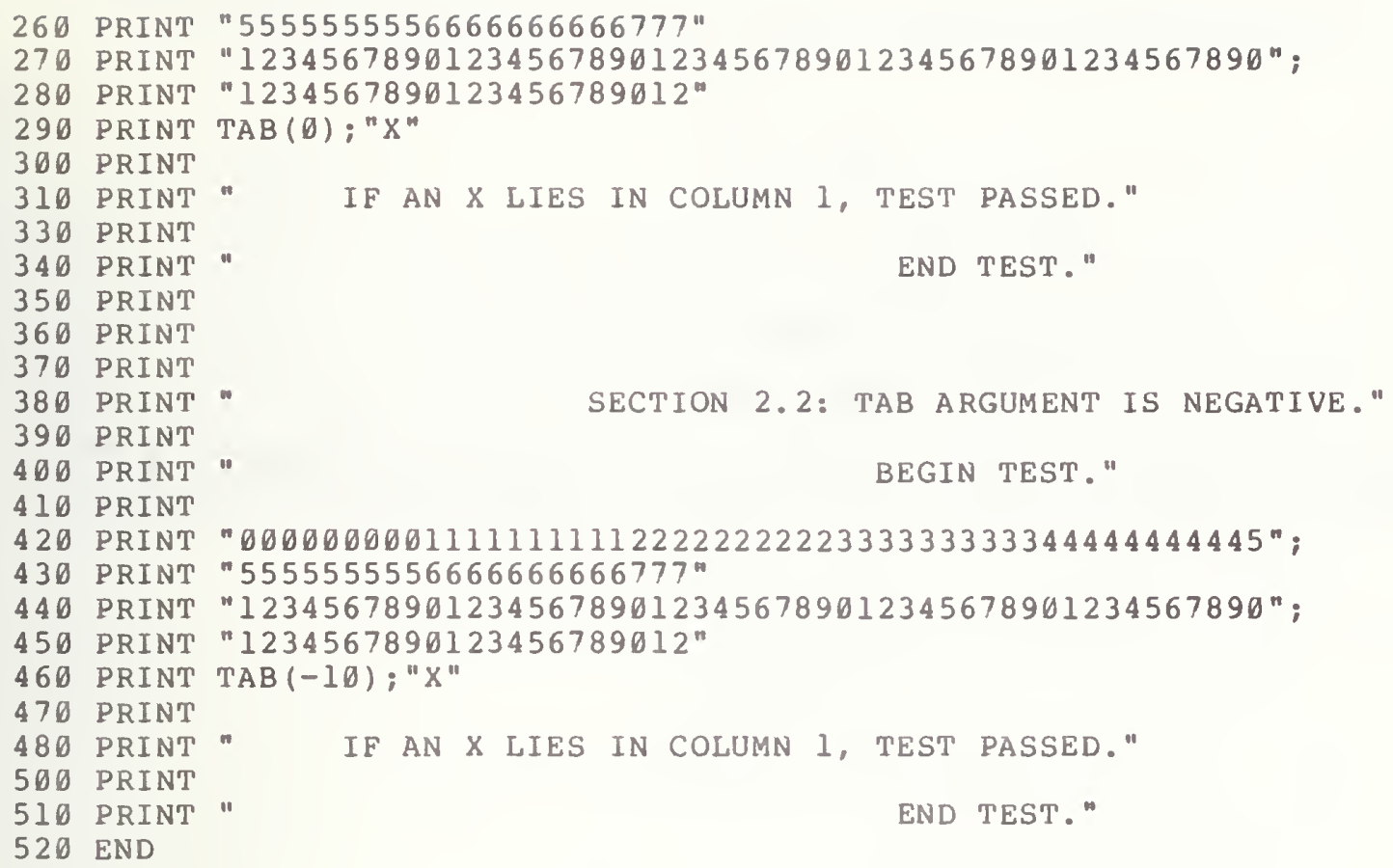

PROGRAM FILE 2

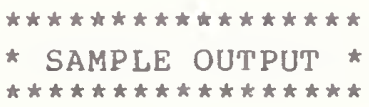

SECTION 2. O: ERROR TEST ON PRINT TAB.

THIS SECTION USES TWO DIFFERENT TAB ARGUMENTS TO TEST THE CASE WHEN A ROUNDED TAB ARGUMENT HAPPENS TO HAVE A VALUE LESS THAN ONE. IN SUCH A CASE THIS SHOULD BE HANDLED AS A NON-FATAL ERROR WHEREBY A VALUE OF 1 IS TO BE SUPPLIED FOR THE TAB ARGUMENT AND THE PROGRAM SHOULD CONTINUE. 


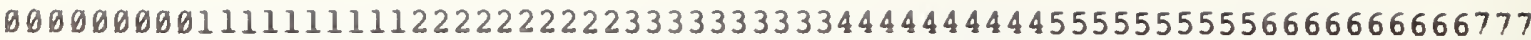
123456789012345678901234567890123456789012345678901234567890123456789012 $\mathrm{x}$

IF AN $X$ LIES IN COLUMN 1, TEST PASSED.

END TEST .

SECTION 2.2: TAB ARGUMENT IS NEGATIVE.

BEGIN TEST.

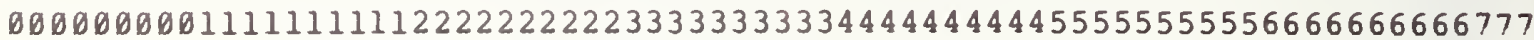
123456789012345678901234567890123456789012345678901234567890123456789012 $\mathrm{x}$

IF AN $X$ LIES IN COLUMN 1, TEST PASSED.

END TEST. 


\section{O USING EMPTY PRINT ITEMS TO SPACE OVER PRINT ZONES}

The objective of this test is to verify that the comma separator allows users to produce automatically positioned output in a tabular format as determined by the print zones (see section 12.4 of BSR X3.60).

Furthermore, it verifies that null print items can be used in the print-list. The term "null" refers to the space character. The test uses a print-list which has three single space characters and a quoted string as print-items. Each print-item is separated by a comma print-separator. The output for this test should show an A in the first column position of the fourth print zone assuming the implementation has four print zones. This is a reasonable assumption for most systems.

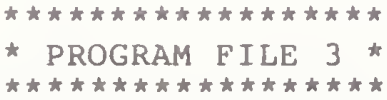

10 PRINT "PROGRAM FILE 3"

60 PRINT

70 PRINT

86 PRINT

90 PRINT "

SECTION 3.0: NULL PRINT ITEMS."

100 PRINT

110 PRINT

120 PRINT

130 PRINT $" \star \star \star \star \star *$ NOTE: THE FIRST THREE PRINT ITEMS ARE NULL, THEREFORE"

140 PRINT "THE FOURTH PRINT ITEM WHICH IS A STRING EXPRESSION SHOULD"

150 PRINT "APPEAR IN THE BEGINNING COLUMN OF THE FOURTH PRINT ZONE FOR"

160 PRINT "THIS SYSTEM (THAT IS, IF THE SYSTEM PARTITIONS FOUR OR MORE"

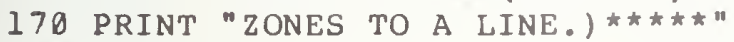

180 I'RINT

190 PRINT

200 PRINT

210 PRINT

220 PRINT

230 PRINT "00000000011111111112222222222333333333344444444445";

240 PRINT "5555555556666666666777"

250 PRINT "I2345678901234567890123456789012345678901234567890";

260 PRINT " $1234567890123456789012^{\text {" }}$

270 PRINT, , "A"

280 PRINT

290 PRINT " IF THE A IS IN THE BEGINNING COLUMN OF THE FOURTH"

300 PRINT "PRINT ZONE FOR THIS SYSTEM, THEN THE SYSTEM WILL HAVE PASSED"

310 PRINT "THE TEST."

320 PRINT

330 PRINT

340 PRINT

END TEST." 


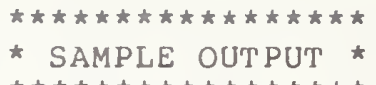

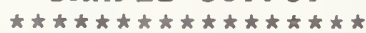

PROGRAM FILE 3

\author{
SECTION 3.0: NULL PRINT ITEMS.
}

\begin{abstract}
*****NOTE: THE FIRST THREE PRINT ITEMS ARE NULL, THEREFORE THE FOURTH PRINT ITEM WHICH IS A STRING EXPRESSION SHOULD APPEAR IN THE BEGINNING COLUMN OF THE FOURTH PRINT ZONE FOR THIS SYSTEM (THAT IS, IF THE SYSTEM PARTITIONS FOUR OR MORE

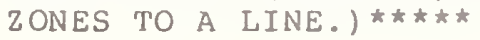

\title{
BEGIN TEST.
}

000000000111111111122222222223333333333444444444455555555556666666666777 123456789012345678901234567890123456789012345678901234567890123456789012

A

IF THE A IS IN THE BEGINNING COLUMN OF THE FOURTH PRINT ZONE FOR THIS SYSTEM, THEN THE SYSTEM WILL HAVE PASSED THE TEST. 


\section{1 PRINTING INTEGER AND EIXED POINT CONSTANTS}

\subsection{Printing Constants with Six Significant Digits}

The Minimal BASIC standard specifies that a program can contain numeric constants that have an arbitrary number of digits. However, the specification allows implementations to round the values of the constants to an implementation-defined precision of not less than six significant decimal digits. Therefore in general we have restricted our concern to the proper handing of numbers with six significant digits. The user is referred to section 5 and 12 of BSR $\times 3.60$ for the required specifications.

In order to clarify some of the notation used we take NRl to mean an integer constant or implicit point representation form and NR2 to mean a fixed point form or explicit point unscaled representation. We must make it clear that the standard does not specify internal machine representation so that NRI and NR2 refer only to external character appearance or graphical appearance and not to internal machine representation.

\subsubsection{Constants in NRI Form (Integers)}

This section verifies that the test implementation recognizes and prints numbers that appear in the integer or NRI format. In recognizing the NRI format, the particular implementation should maintain at least six significant digits of precision on output. The test uses columnar output to show, in the first column, how the numbers should appear according to standard form, and in the second column, how the numbers are printed by the system being tested. The print-lists, in the source code, which contain the print-items for the numerical output use both signed and unsigned NRI constants.

\subsubsection{NRI Constants Separated by Commas}

The objective of this test is similar to that of test 1.2.6. However, for this test, the print-items in the print-list are numerical constants in NRl form. On output there is a string of digits used as column counters. This string of digits is followed by two lines of integers. The integers on the first line are $1,-12$, and 123 in their respective print zones. The second line of integers contains -1234, 12345, and -123456 in their respective print zones.

\subsubsection{Space Allotment for Integers, in Compact Form}

The objective of this test is to verify that there is a sufficjent amount of spacing upon output of NRI constants. That is, the evaluation of each NRI constant should produce a string of characters consisting of a leading space if the number is positive or a leading minus sign if the number is negative, followed by the decimal representation of the number and a trajling space. This implies that $d+2$ spaces are the minimal required for printing NRl constants. The "d" is the significance-width for the number of significant decimal digits printed in numeric representations. For NRl constants "d" is required to have a minimal value of at least six digits. 
The output of the test generates four columns of NRI constants. Each print-list, contains numbers to be printed, and quoted strings containing asterisks. These strings are separated from the constants by semicolons and are used to delineate spacing generated around the numeric output. Since semicolons generate no spaces, the four columns of numbers should be surrounded by asterisks to identify the number of spaces allocated for an NRI representation by the implementation. The output is headed by strings of digits that can be used as column counters. Beneath these strings of digits should be the four columns of numbers. The first column is an example of standard conformance for the implementation's second column of numbers. The third column is an example of standard conformance for the fourth column of numbers which are printed by the implementation.

\subsubsection{NRI Constants Separated by Semicolons}

The objective here is two-fold: the test should show that the evaluation of the semicolon separator generates the null string, and at the same time, the test should show on output a minimum of two spaces between each pair of numbers. On output there should be a string of digits which can be used as column counters in determining whether the printed numbers have a minimum of two spaces between each pair.

\section{1 .5 Constants in NR2 Form (Reals)}

There are two conditions under which numbers are to be printed in NR2 format. Let $d$ be the number of significant digits of accuracy of the machine. Then, the first condition arises when the number is not representable as an integer, i.e., NRl, yet falls in the interval

$$
0.1-(0.5) *\left(10^{\wedge}(-d-1)\right) \text { to }\left(10^{\wedge} d\right)-(1 / 2) \text {. }
$$

Notice that as d increases both endpoints increase. The left hand endpoint is never greater than 0.1 , however. Next, since the minimal precision requirement is $d=6$, then $\left(10^{\wedge} 6\right)-(1 / 2)$ is the smallest right hand endpoint. Therefore, all numbers on all implementations that are not representable as integers, yet fall between 0.1 and 999999 in absolute value, must be printed in NR2 format. Notice that with systems having six digits of precision one can only get numbers with fractional parts up to 99999.9 without rounding. All numbers from 100000 to 999999 should be rounded to the nearest integer and output in NRI if only 6 digits of precision are being carried by the system.

The second case occurs when a number is less than $0.1-(0.5){ }^{\star}\left(1 \theta^{\wedge}\left(-d^{-1}\right)\right)$ in absolute value yet can be represented exactly with d digits after the decimal point. For example, if $\mathrm{d}=6$ then $10^{\wedge}(-6)$ must be printed as .000001.

The actual test is divided into two parts. In the first part a set of numbers, both signed and unsigned, with absolute values between $\emptyset .1$ and 99999.9 are printed for testing the NR2 printing format. The numbers printed should have at least six significant figures. The numbers printed should all be representable exactly without roundoff. Specific roundoff tests will be conducted in a subsequent test. The distribution of numbers is as follows: 1) 14 numbers of absolute value between $\theta .1$ and 1.0 were chosen. Of these, 5 have been entered with trailing zeroes. The outputs should have trailing zeroes deleted. 2) 5 numbers of absolute value between 1.0 and 10000 . 3) 10 
numbers of absolute value between 10000 and 99999.9. Columns one and three should fall in print zones one and three. These represent the minimal required output formats. Column three should have a leading minus sign, as well as column four. The first and third columns are the standard output forms requiring $d+3$ characters counting minus sign or leading blank for positive number, period and trailing space. For systems with d>6 the standard numbers as given would be numbers with the 6 characters as specified and $d-6$ trailing zeroes which would be required to be suppressed. Columns two and four may have more than $d+3$ spaces allocated. The point of the test is that however many spaces are allocated by the implementation, the minimal requirement is $d+3$. For example, implementations may choose to line up decimal points for all NR2 numbers and allow more than d spaces on either side of the decimal. This is acceptable. The listing of column two contains numbers that are alternately signed and unsigned positively. The output of column two should be unsigned. The second part of the test outputs numbers less than $0.1-(0.5) *\left(1 \theta^{\wedge}(-7)\right)$ that are exactly representable with d digits after the decimal. Since $d=6$ is the minimal requirement, all numbers chosen are based on this. The test for other values of $d$ will appear in the roundoff test.

\subsubsection{NR2 Constants Separated by Commas}

The objective of this test is similar to test 1.2.6. However, for this test the print-items in the print-list are numeric constants, in NR2 form. On output there should be a string of digits which can be used as column counters. This string of digits should be followed by two lines of numerals. The numerals on the first 1 ine should be: $123456,-99999.9$, and 91234.5 in their respective print zones. The second line of numerals should be $-1.23456,89123.4$, and -2.34567 in their respective print zones.

\subsubsection{Space Allotment for Reals, in Compact Form}

The object of this test section is to print a set of numbers in packed form under a column index scheme to assess the conformance with the minjmal $\mathrm{d}+3$ character rule for NR2 numbers. As in the test for section 4.1 .3 , there are four columns of numbers. Columns one and three are minimal conformance numbers for the case $d=6$. These numbers have 9 characters. Columns two and four which would be generated by the test system might have more spaces allocated for the number than the minimal conformance requirement. The rule in general is that there should be at least $d+3$ characters allocated. In order to determine the actual number of characters allowed by the system the columns have been bracketed by asterisks. Again, columns two and four are the system generated columns. These are the columns to which the rule must be applied. There must be at least one trajling space for all numbers and a leading space if the number printed is positive.

\subsubsection{NR2 Constants Separated by Semicolons}

The objective of this test is the same as test 4.1.4. However, for this test NR2 constants are being used as the print-items. The output should be similar in format to that of test 4.1 .4 except that explicit point unscaled constants should appear. The user should examine the spacing between numbers in a line. There should be a trailing space for all numbers and a leading space if the number is positive. 

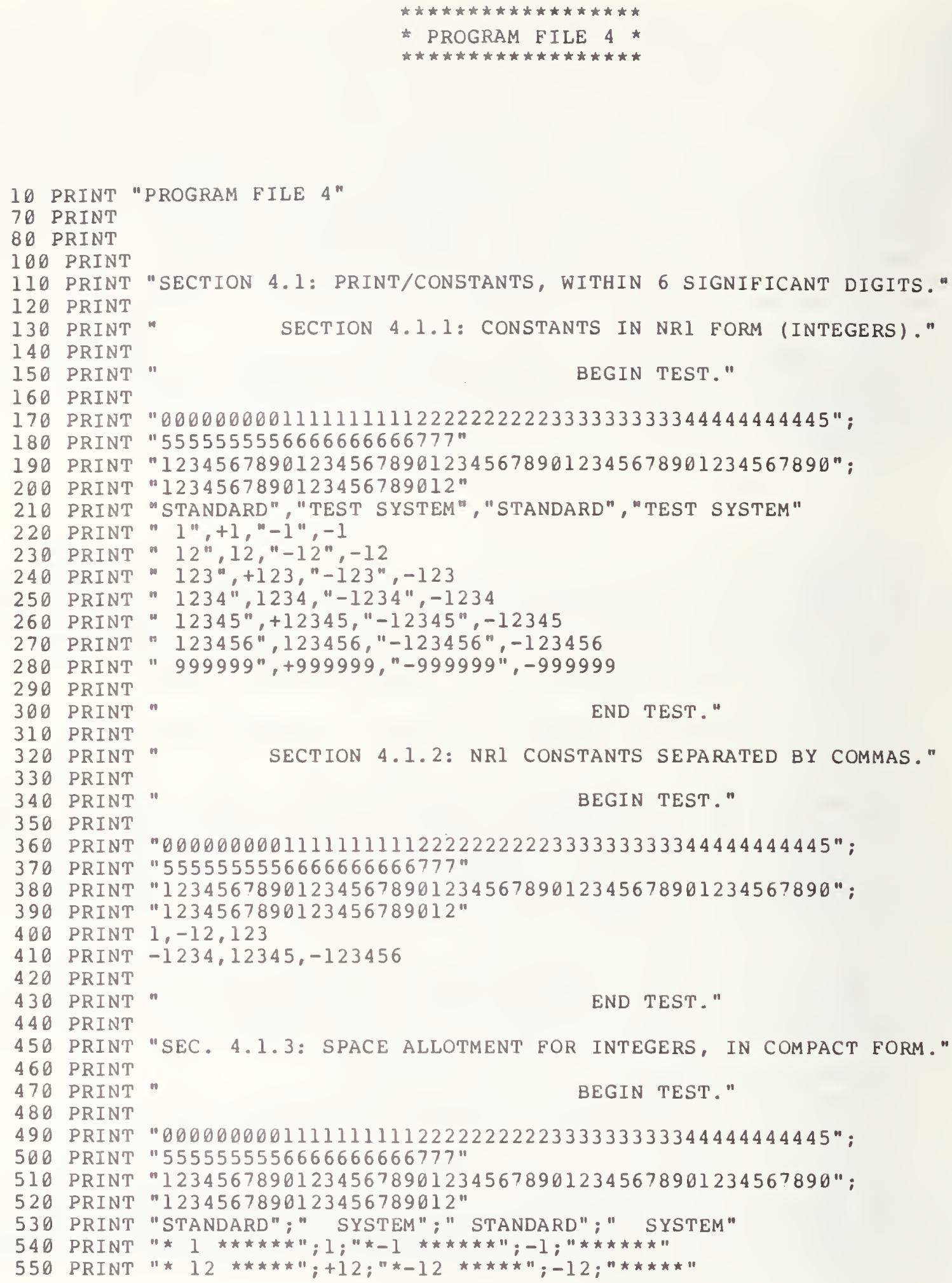


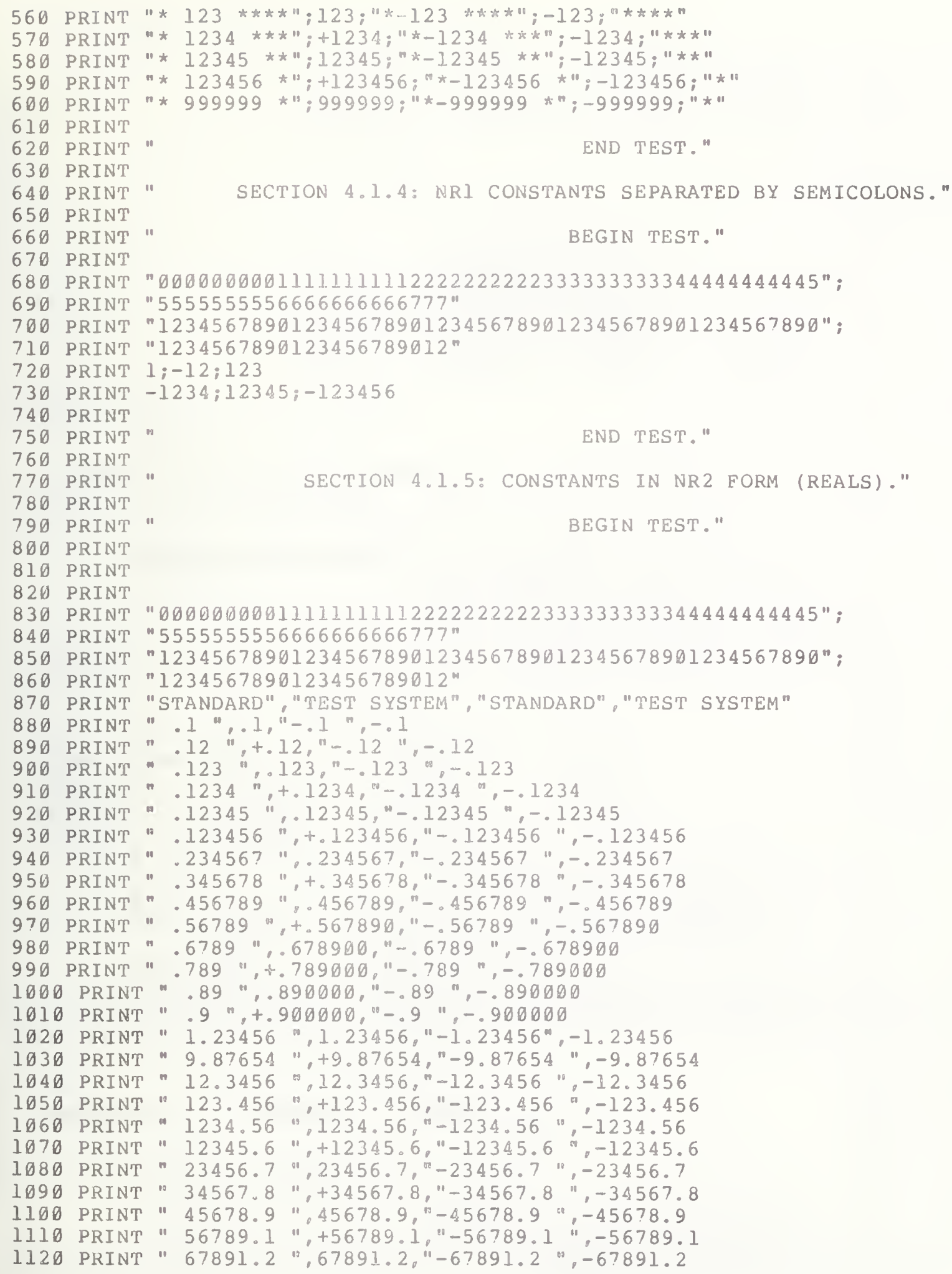




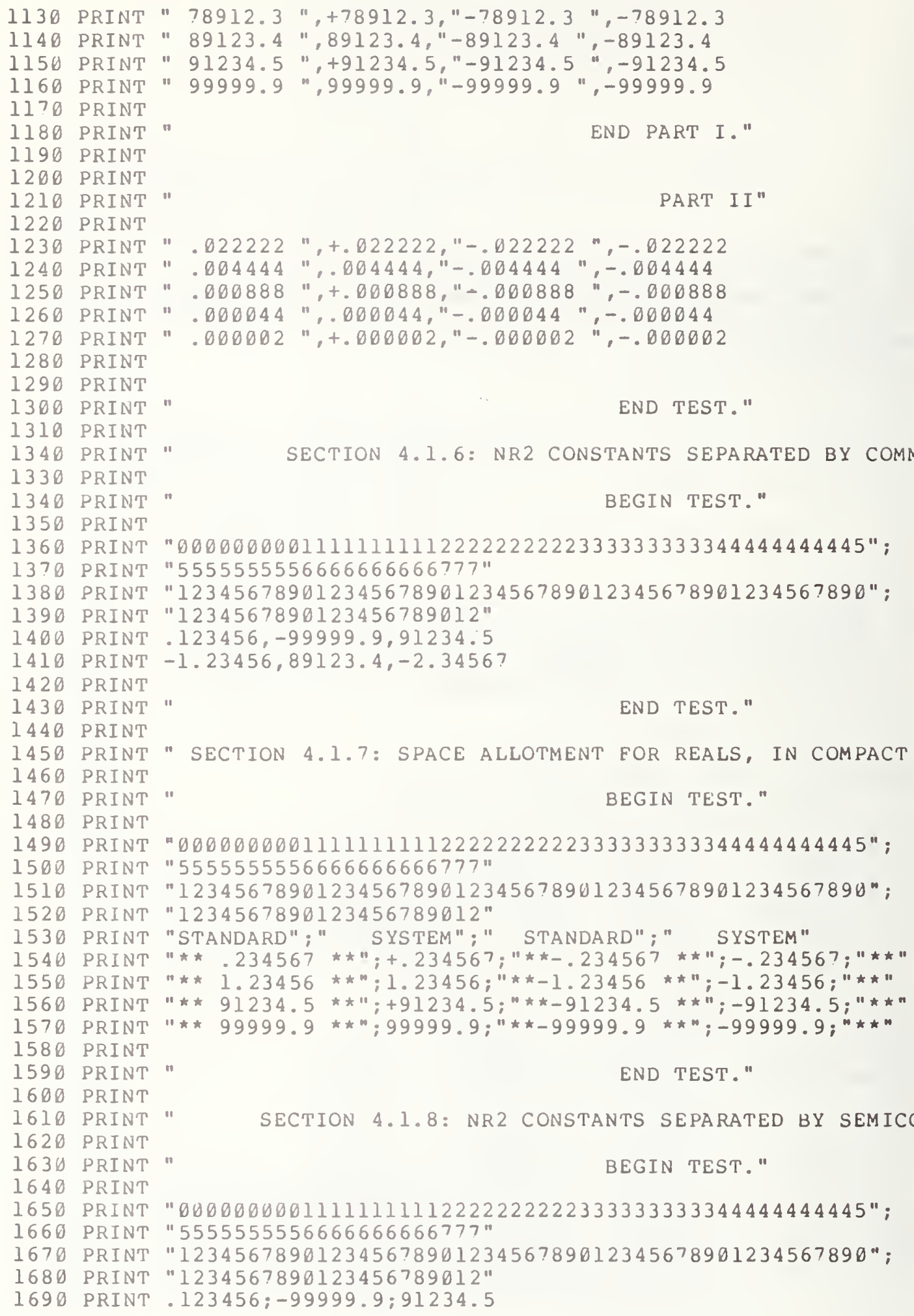


1700 PRINT $-1.23456 ; 89123.4 ;-2.34567$

1710 PRINT

1720 PRINT "

END TEST."

1730 PRINT

1740 END

PROGRAM FILE 4

SECTION 4.1: PRINT/CONSTANTS, WITHIN 6 SIGNIFICANT DIGITS.

SECTION 4.1.1: CONSTANTS IN NRI FORM (INTEGERS).

BEGIN TEST.

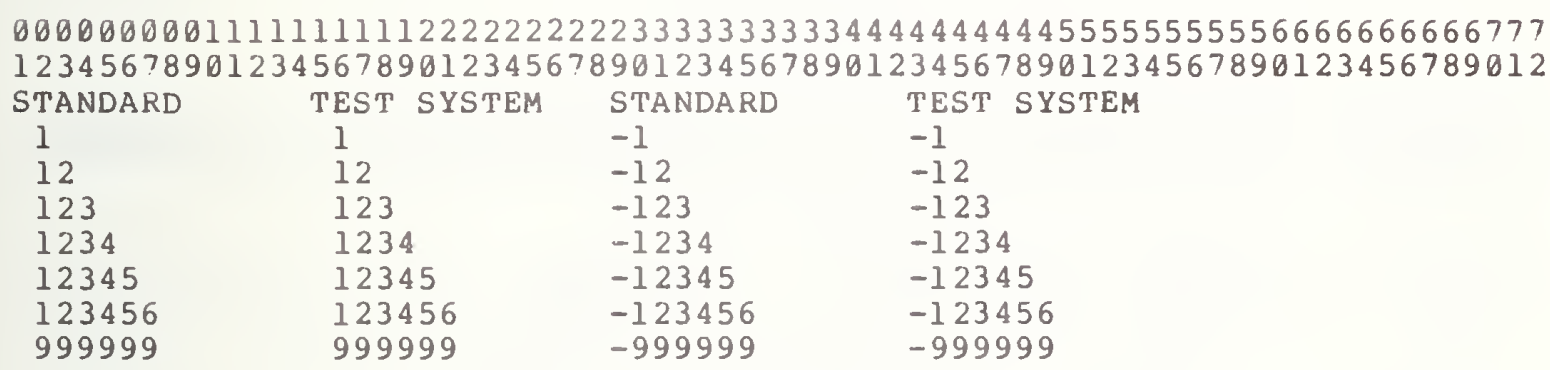

END TEST.

SECTION 4.1.2: NRI CONSTANTS SEPARATED BY COMMAS.

BEGIN TEST .

000000000111111111122222222223333333333444444444455555555556666666666777 123456789012345678901234567890123456789012345678901234567890123456789012

$1 \quad-12 \quad 123$

$\begin{array}{lll}-1234 & 12345 & -123456\end{array}$

END TEST .

SEC. 4.1.3: SPACE ALLOTMENT FOR INTEGERS, IN COMPACT FORM.

BEGIN TEST.

000000000111111111122222222223333333333444444444455555555556666666666777 
123456789012345678901234567890123456789012345678901234567890123456789012 STANDARD SYSTEM STANDARD SYSTEM

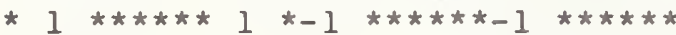

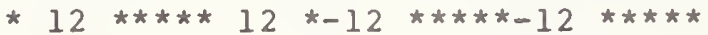

$\star 123 * * * * 123 *-123 * * * *-123 * * * *$

* $1234 * \star * 1234 *-1234 * * *-1234 * * *$

* $12345 * \star 12345 *-12345 * \star-12345 * \star$

* 123456 * $123456 *-123456 *-123456$ *

* $999999 * 999999 *-999999 *-999999 *$

END TEST.

SECTION 4.1.4: NRI CONSTANTS SEPARATED BY SEMICOLONS.

BEGIN TEST.

000000000111111111122222222223333333333444444444455555555556666666666777 123456789012345678901234567890123456789012345678901234567890123456789012 $1-12 \quad 123$

$-1234 \quad 12345-123456$

END TEST.

SECTION 4.1.5: CONSTANTS IN NR2 FORM (REALS).

BEGIN TEST.

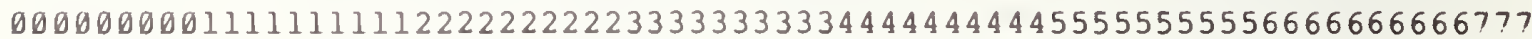
123456789012345678901234567890123456789012345678901234567890123456789012

STANDARD

. 1

.12

.123

.1234

.12345

.123456

.234567

. 345678

.456789

.56789

.6789

.789

.89

.9

1. 23456

9.87654

12.3456

123.456

1234.56

12345.6

23456 . 7

34567.8

45678.9

56789.1

67891.2

\section{TEST SYSTEM STANDARD}

. 1

.12

.123

.1234

.12345

.123456

.234567

.345678

.456789

.56789

.6789

.789

.89

.9

1. 23456

9.87654

12.3456

123.456

1234.56

12345.6

23456 .?

34567.8

45678.9

56789.1

67891.2
-. 1

$-.12$

$-.123$

-. 1234

$-.12345$

-. 123456

$-.234567$

$-.345678$

$-.456789$

$-.56789$

$-.6789$

$-.789$

$-.89$

$-.9$

$-1.23456$

$-9.87654$

$-12.3456$

$-123.456$

$-1234.56$

$-12345.6$

$-23456.7$

$-34567.8$

$-45678.9$

$-56789.1$

$-67891.2$
TEST SYSTEM

$-.1$

$-.12$

$-.123$

-. 1234

-. 12345

-. 123456

$-.234567$

$-.345678$

$-.456789$

$-.56789$

$-.6789$

$-.789$

$-.89$

$-.9$

$-1.23456$

$-9.87654$

$-12.3456$

$-123.456$

$-1234.56$

$-12345.6$

$-23456.7$

$-34567.8$

$-45678.9$

$-56789.1$

$-67891.2$ 


$\begin{array}{llll}78912.3 & 78912.3 & -78912.3 & -78912.3 \\ 89123.4 & 89123.4 & -89123.4 & -89123.4 \\ 91234.5 & 91234.5 & -91234.5 & -91234.5 \\ 99999.9 & 99999.9 & -99999.9 & -99999.9 \\ & & & \\ & & \\ & & \\ & & \\ .022222 & & & \\ .004444 & .022222 & -.022222 & -.022222 \\ .000888 & .004444 & -.004444 & -.004444 \\ .000044 & .000888 & -.000888 & -.000888 \\ .000002 & .000044 & -.000044 & -.000044 \\ & .000002 & -.000002 & -.000002\end{array}$

\section{END TEST.}

SECTION 4.1.6: NR2 CONSTANTS SEPARATED BY COMMAS.

BEGIN TEST.

000000000111111111122222222223333333333444444444455555555556666666666777 123456789012345678901234567890123456789012345678901234567890123456789012 .123456

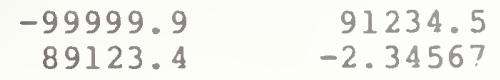

91234.5

89123.4

-2.3456 ?

$-1.23456$

END TEST.

SECTION 4.1.7: SPACE ALLOTMENT FOR REALS, IN COMPACT FORM.

BEGIN TEST.

000000000111111111122222222223333333333444444444455555555556666666666777 123456789012345678901234567890123456789012345678901234567890123456789012 STANDARD SYSTEM STANDARD SYSTEM

$\star * .234567 * * .234567 * *-.234567 * *-.234567 * *$

$\star * 1.23456 * * 1.23456 * *-1.23456 * *-1.23456 * *$

** $91234.5 * * 91234.5 * *-91234.5 * *-91234.5 * *$

* * 99999.9** 99999.9**-99999.9**-99999.9**

END TEST.

SECTION 4.1.8: NR2 CONSTANTS SEPARATED BY SEMICOLONS.

BEGIN TEST.

000000000111111111122222222223333333333444444444455555555556666666666777 123456789012345678901234567890123456789012345678901234567890123456789012

$.123456-99999.9 \quad 91234.5$

$-1.23456 \quad 89123.4-2.34567$

END TEST. 


\subsection{PRINTING FLOATING POINT CONSTANTS}

As in the previous section the words "floating point" refer to the external character appearance, as for example, on input or output. It does not mean that internal representation is required to be floating point, although this is sometimes the case and software is sometimes used to perform the required conversions for input and output formatting. The user should refer to sections 5 and 12 of BSR X3.60 for the specifications appropriate to this section.

\section{1 Constants in NR3 Form (E-Format)}

The objective of this part is to print constants that require the use of an explicit print scaled representation form. There are two cases in which this should occur. First, if the number has a magnitude greater than $\left(1 \theta^{\wedge} d\right)-(1 / 2)$ and secondly, if the number is less than $\theta .1-(\theta .5) *\left(1 \theta^{\wedge}(-d-1)\right)$ and cannot be expressed exactly with d decimal digits following a period. The minimal upper and maximal lower bounds for the absolute value of numbers are 1.E38 and 1.E-38, respectively. This is the range of the magnitude of numbers that rust be recognized by all systems supporting Minimal Basic. Larger ranges containing this range are acceptable. Note that for NR3 representations on output, the significand, represented by $x$, must lie in the range $l<=x<10$ which means that there must be one digit to the left of the decimal point.

The first part of this test subsection will print groups of large numbers. The optional exrad sign will be either absent or a plus, the significand will be either a plus (or optionally blank) or minus. The second part of the test section prints 2 groups of small numbers with negative exrad signs.

On output, if the sign of the significand of any of the numbers is positive then a space is printed. The positive signs to the significand are omitted. Although the sample output maintains trailing zeroes in the significand, the standard allows trailing zeroes to be omitted in the fractional part of the significand. Leading zeroes may be omitted in the exrad. There is to be no spacing allowed in the exrad. The standard does not specify the output sign of the exrad. It can be either a + or no sign, but as indicated above no spaces are allowed in the exrad since this would violate the rule that spaces are not allowed in numeric constants.

The output is displayed as follows: After the test title a standard and an optional form is given based upon $d=6$ and $e=2$. Below these initial numbers, two columns of numbers should appear. All the numbers should be equal to each other and be equal to one of the allowed forms. Of course in the case that $d$ is greater than 6 digits, extra zeroes in the significand of the actual system output may appear or be deleted. The first group of columns will have a positive signed significand in both columns. The exrad will be signed in the second column in the source code. The numbers used in the source code are various forms of implcit and explicit print scaled versions of the same number. 
In the second set, two columns of numbers as in the first set will be printed. These will be generated by numbers having an unsigned significand and either signed or unsigned exrads.

The group three numbers will be the same as the previous two groups except that a minus sign in front of the significand.

The fourth set will have only one standard form but there will be two columns of output below it. In this case there will be an unsigned significand and negative signed exrad.

Finally the fifth group will have one column of output and one standard form. Both significand and exrad will have negative signs.

In summary, then, for the positive significand and positive exrad there are the following sign combination input cases: signed significand, unsigned exrad; signed significand, signed exrad; unsigned significand, unsigned exrad; unsigned significand, signed exrad. For the positive significand and negative exrad there are only two cases: signed and unsigned significand. For the negative significand and negative exrad there is only one case.

\subsection{Printing of Some General NR3 Constants}

This test is a continuation of test 5.1, part II. The object here is simply to print a selection of NR3 numbers without attempting to consider the many possible configurations of the same number. Columns one and two are allowed optional graphical representation. Column three contains the values generated by the test systern.

\subsection{NR3 Constants Separated by Commas}

The objective of this test is similar to that of test 1.2.6. In this test, however, the print-items in the print-list are numeric constants in NR3 form. On output there is a string of digits as column counters. This string of digits should be followed by two lines of numbers. The numbers in the first line should be $1.00000 \mathrm{E} 30,-9.87000 \mathrm{E}-37$, and $1.23456 \mathrm{E} 32$ in their respective print zones. The second 1 ine of numbers should be $-1.23456 \mathrm{E} 32$, $1.786500 \mathrm{E} 36$ and $5.00000 \mathrm{E}-20$ in their respective print zones. 


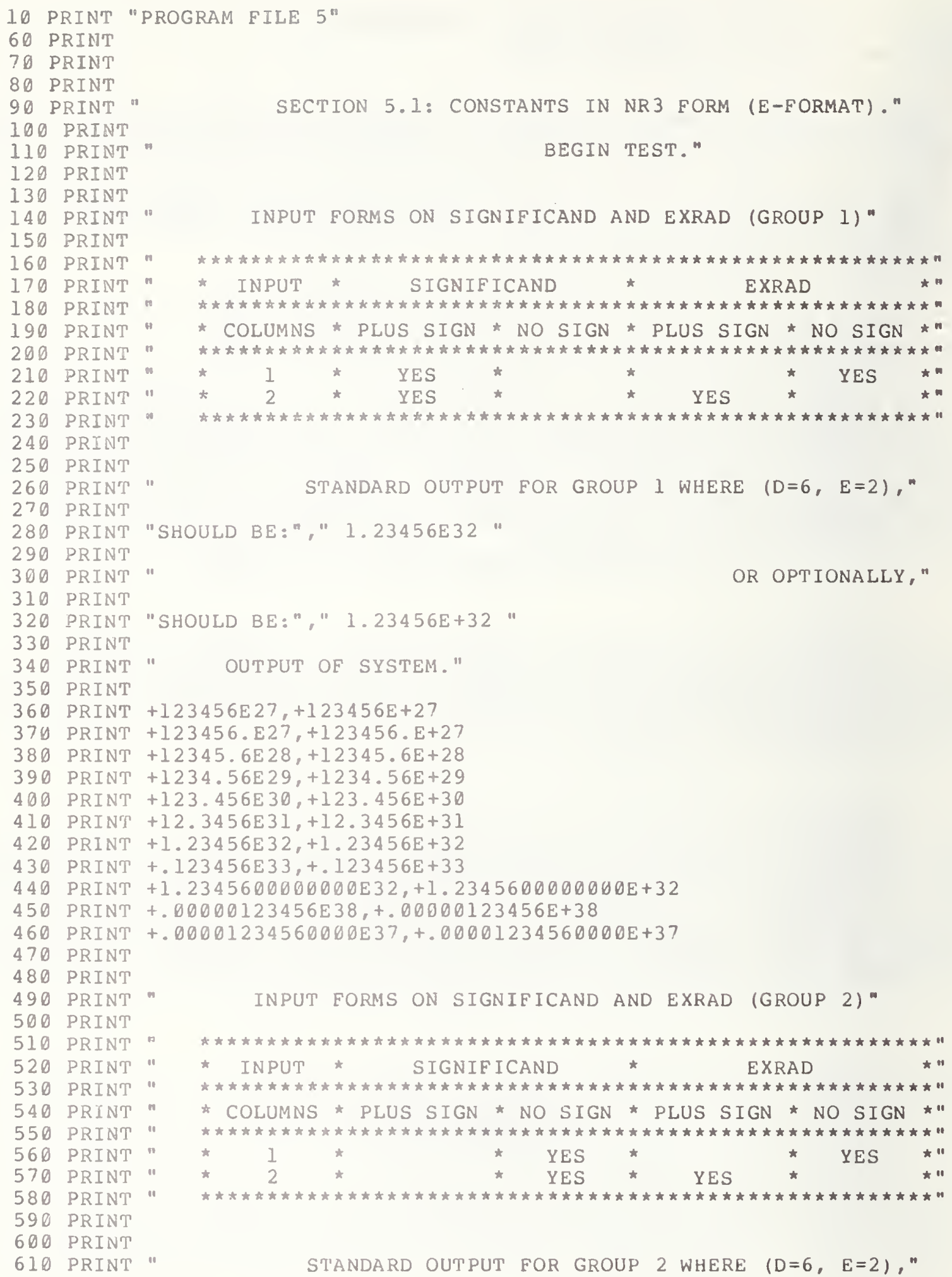




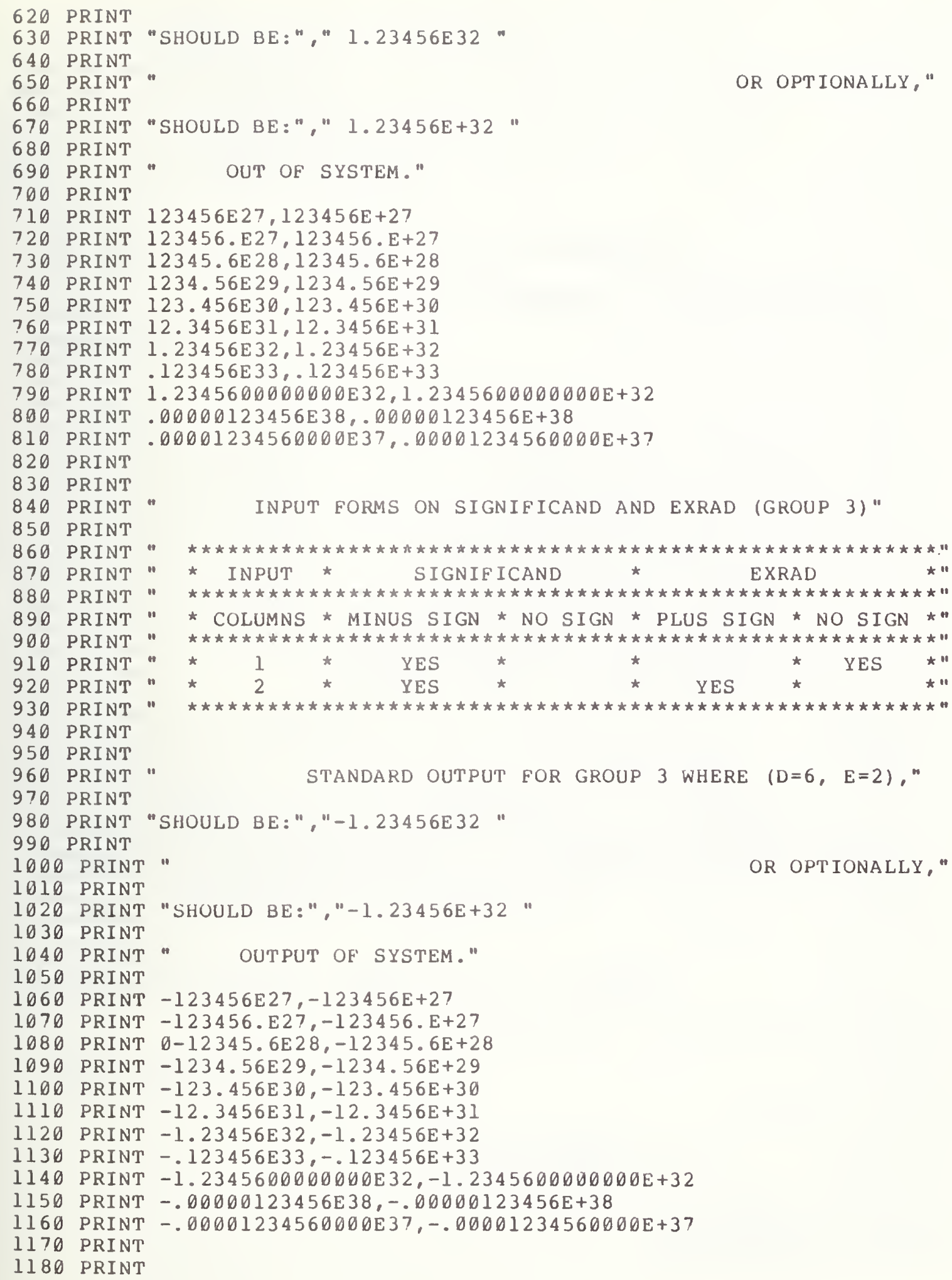




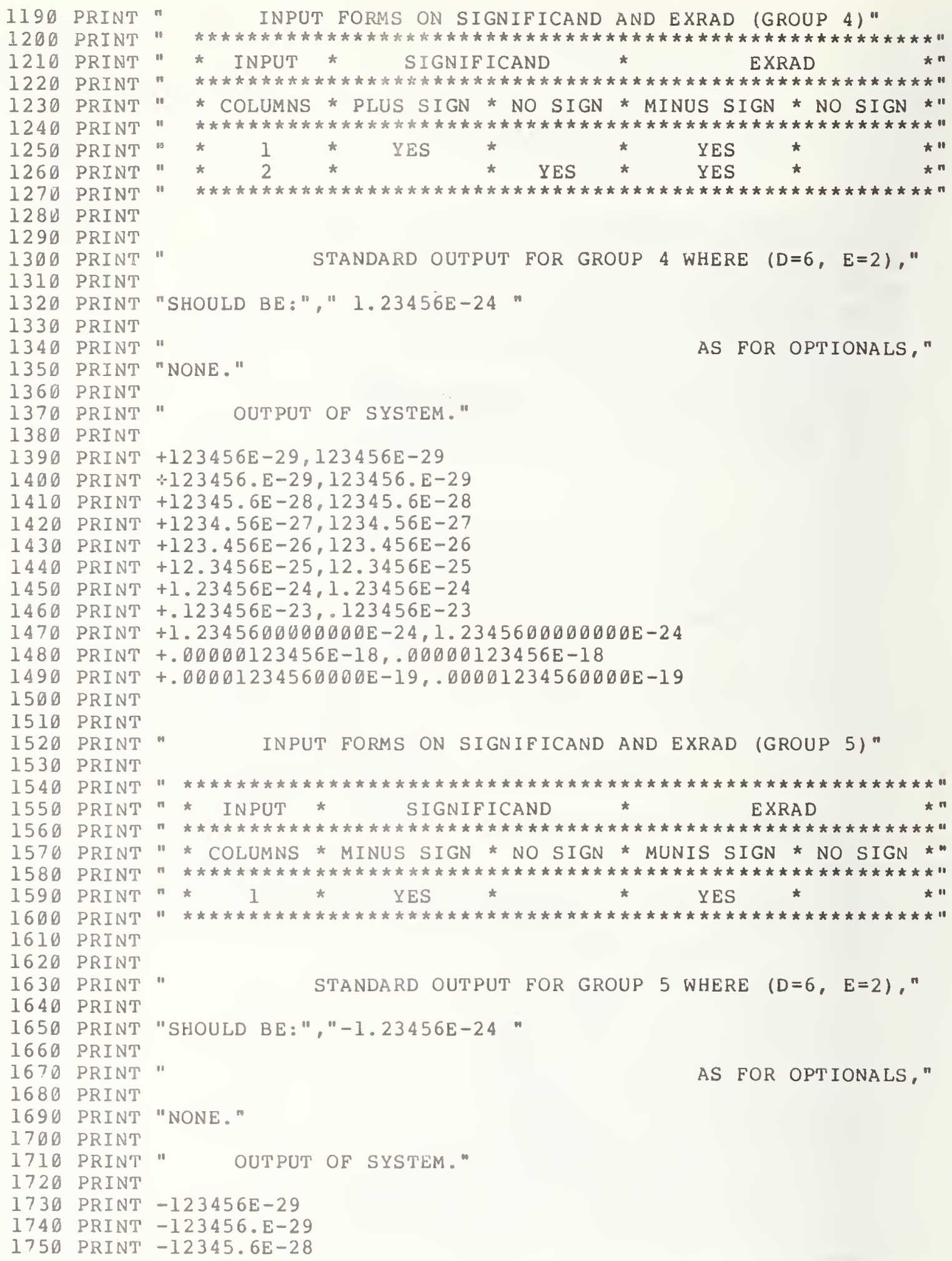




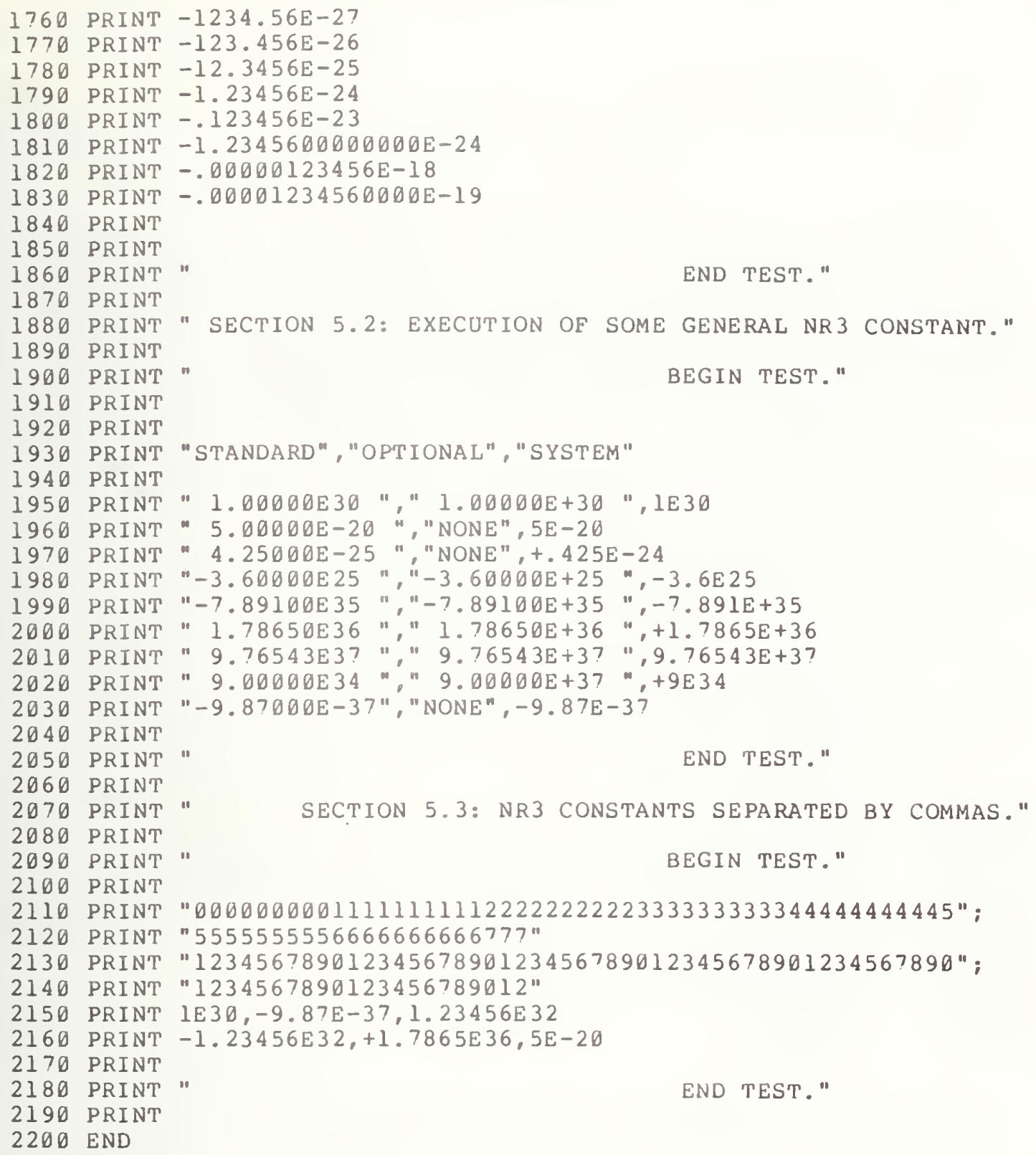

END TEST."

SECTION 5.3: NR3 CONSTANTS SEPARATED BY COMMAS." BEGIN TEST." 
PROGRAM FILE 5

SECTION 5.1: CONSTANTS IN NR3 FORM (E-FORMAT).

BEGIN TEST.

INPUT FORMS ON SIGNIFICAND AND EXRAD (GROUP 1)

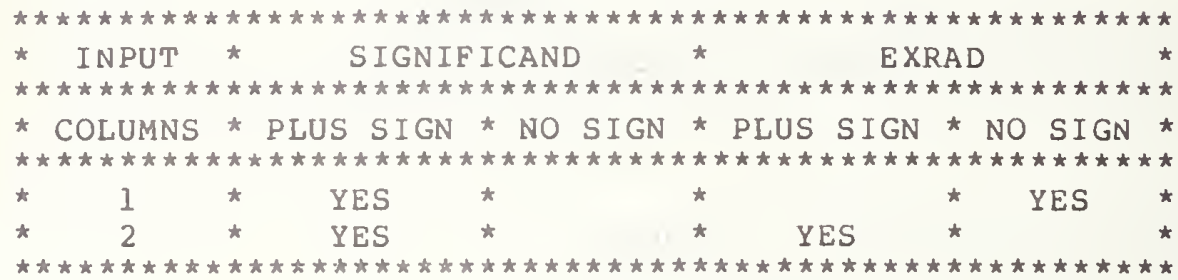

STANDARD OUTPUT FOR GROUP 1 WHERE $(D=6, E=2)$,

SHOULD BE: $\quad 1.23456 E 32$

OR OPTIONALLY,

SHOULD BE: $\quad 1.23456 \mathrm{E}+32$

OUTPUT OF SYSTEM.

$1.23456 \mathrm{E}+32$

1. $23456 \mathrm{E}+32$

$1.23456 \mathrm{E}+32$

1. $23456 \mathrm{E}+32$

1. $23456 \mathrm{E}+32$

1. $23456 \mathrm{E}+32$

1. $23456 \mathrm{E}+32$

1. $23456 \mathrm{E}+32$

$1.23456 \mathrm{E}+32$

1. $23456 \mathrm{E}+32$

1. $23456 \mathrm{E}+32$

l. $23456 \mathrm{E}+32$

1. $23456 \mathrm{E}+32$

1. $23456 \mathrm{E}+32$

1. $23456 \mathrm{E}+32$

1. $23456 E+32$

1. $23456 \mathrm{E}+32$

1. $23456 \mathrm{E}+32$

1. $23456 \mathrm{E}+32$

1. $23456 \mathrm{E}+32$

1. $23456 \mathrm{E}+32$

1. $23456 \mathrm{E}+32$

INPUT FORMS ON SIGNIFICAND AND EXRAD (GROUP 2)

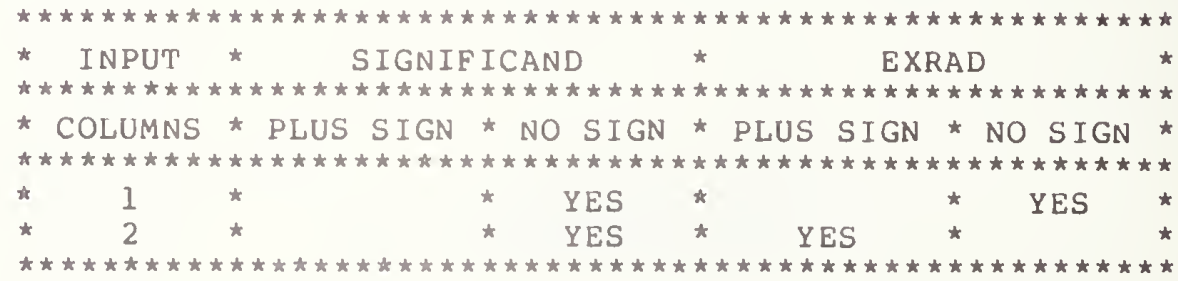

STANDARD OUTPUT FOR GROUP 2 WHERE $(D=6, E=2)$, 

SHOULD BE:
$1.23456 \mathrm{E} 32$

$\begin{array}{cc}\text { SHOULD BE: } & 1.23456 \mathrm{E}+32 \\ \text { OUT OF } & \text { SYSTEM. } \\ 1.23456 \mathrm{E}+32 & 1.23456 \mathrm{E}+32 \\ 1.23456 \mathrm{E}+32 & 1.23456 \mathrm{E}+32 \\ 1.23456 \mathrm{E}+32 & 1.23456 \mathrm{E}+32 \\ 1.23456 \mathrm{E}+32 & 1.23456 \mathrm{E}+32 \\ 1.23456 \mathrm{E}+32 & 1.23456 \mathrm{E}+32 \\ 1.23456 \mathrm{E}+32 & 1.23456 \mathrm{E}+32 \\ 1.23456 \mathrm{E}+32 & 1.23456 \mathrm{E}+32 \\ 1.23456 \mathrm{E}+32 & 1.23456 \mathrm{E}+32 \\ 1.23456 \mathrm{E}+32 & 1.23456 \mathrm{E}+32 \\ 1.23456 \mathrm{E}+32 & 1.23456 \mathrm{E}+32 \\ 1.23456 \mathrm{E}+32 & 1.23456 \mathrm{E}+32\end{array}$

OR OPTIONALLY,

INPUT FORMS ON SIGNIFICAND AND EXRAD (GROUP 3)

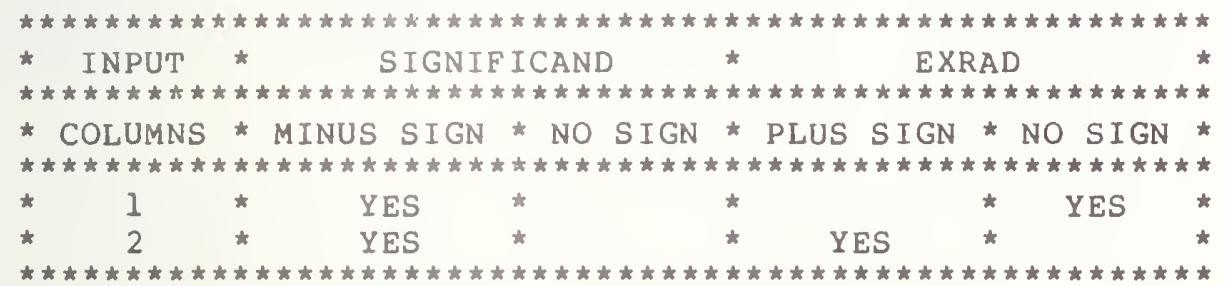

STANDARD OUTPUT FOR GROUP 3 WHERE $(D=6, E=2)$,

SHOULD BE: $\quad-1.23456 \mathrm{E} 32$

OR OPTIONALLY,

SHOULD BE: $\quad-1.23456 E+32$

OUTPUT OF SYSTEM.

$-1.23456 \mathrm{E}+32-1.23456 \mathrm{E}+32$

$-1.23456 \mathrm{E}+32-1.23456 \mathrm{E}+32$

$-1.23456 \mathrm{E}+32-1.23456 \mathrm{E}+32$

$-1.23456 \mathrm{E}+32-1.23456 \mathrm{E}+32$

$-1.23456 \mathrm{E}+32-1.23456 \mathrm{E}+32$

$-1.23456 \mathrm{E}+32-1.23456 \mathrm{E}+32$

$-1.23456 \mathrm{E}+32-1.23456 \mathrm{E}+32$

$-1.23456 \mathrm{E}+32-1.23456 \mathrm{E}+32$

$-1.23456 \mathrm{E}+32-1.23456 \mathrm{E}+32$

$-1.23456 \mathrm{E}+32-1.23456 \mathrm{~s}+32$

$-1.23456 \mathrm{E}+32-1.23456 \mathrm{E}+32$

INPUT FORMS ON SIGNIFICAND AND EXRAD (GROUP 4) 


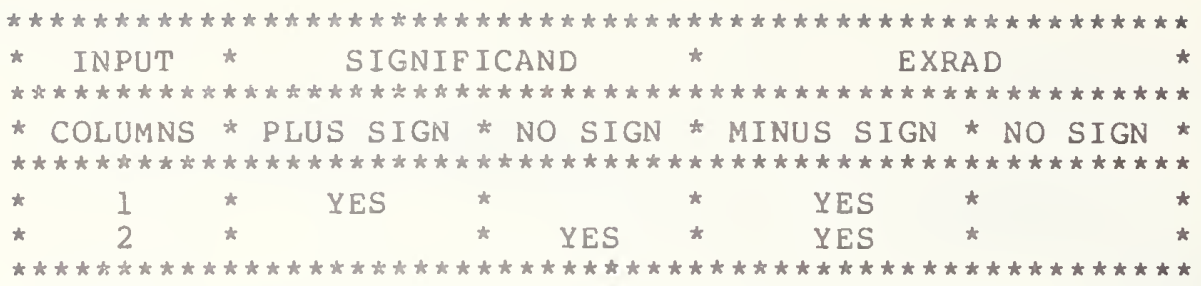

\section{STANDARD OUTPUT FOR GROUP 4 WHERE $(D=6, E=2)$,}

SHOULD BE: $\quad$ 1.23456E-24

AS FOR OPTIONALS,

NONE.

OUTPUT OF SYSTEM.

$\begin{array}{ll}1.23456 \mathrm{E}-24 & 1.23456 \mathrm{E}-24 \\ 1.23456 \mathrm{E}-24 & 1.23456 \mathrm{E}-24 \\ 1.23456 \mathrm{E}-24 & 1.23456 \mathrm{E}-24 \\ 1.23456 \mathrm{E}-24 & 1.23456 \mathrm{E}-24 \\ 1.23456 \mathrm{E}-24 & 1.23456 \mathrm{E}-24 \\ 1.23456 \mathrm{E}-24 & 1.23456 \mathrm{E}-24 \\ 1.23456 \mathrm{E}-24 & 1.23456 \mathrm{E}-24 \\ 1.23456 \mathrm{E}-24 & 1.23456 \mathrm{E}-24 \\ 1.23456 \mathrm{E}-24 & 1.23456 \mathrm{E}-24 \\ 1.23456 \mathrm{E}-24 & 1.23456 \mathrm{E}-24 \\ 1.23456 \mathrm{E}-24 & 1.23456 \mathrm{E}-24\end{array}$

INPUT FORMS ON SIGNIFICAND AND EXRAD (GROUP 5)

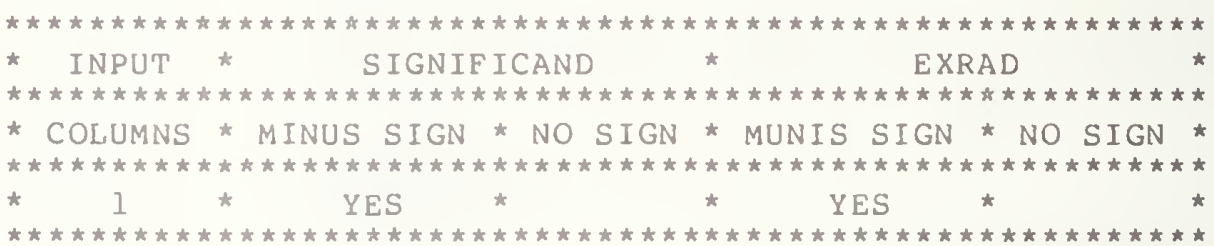

STANDARD OUTPUT FOR GROUP 5 WHERE (D=6, E=2),

SHOULD BE: $\quad-1.23456 \mathrm{E}-24$

AS FOR OPTIONALS,

NONE .

OUTPUT OF SYSTEM.

$-1.23456 \mathrm{E}-24$

$-1.23456 \mathrm{E}-24$

$-1.23456 \mathrm{E}-24$

$-1.23456 \mathrm{E}-24$ 
$-1.23456 \mathrm{E}-24$

$-1.23456 \mathrm{E}-24$

$-1.23456 \mathrm{E}-24$

$-1.23456 E-24$

END TEST.

SECTION 5.2: EXECUTION OF SOME GENERAL NR3 CONSTANT.

BEGIN TEST.

STANDARD

1. $00000 \mathrm{E} 30$

$5.00000 E-20$

4. $25000 \mathrm{E}-25$

$-3.60000 \mathrm{E} 25$

$-7.89100 \mathrm{E} 35$

1. $78650 E 36$

$9.76543 E 37$

9.00000E 34

$-9.87000 E-37$
OPTIONAL

1. $00000 E+30$

NONE

NONE

$-3.60000 E+25$

$-7.89100 E+35$

$1.78650 \mathrm{E}+36$

$9.76543 \mathrm{E}+37$

$9.00000 E+37$

NONE
SYSTEM

$$
\begin{array}{r}
1.00000 E+30 \\
5.00000 E-20 \\
4.25000 E-25 \\
-3.60000 E+25 \\
-7.89100 E+35 \\
1.78650 E+36 \\
9.76543 E+37 \\
9.00000 E+34 \\
-9.87000 E-37
\end{array}
$$

END TEST.

SECTION 5.3: NR3 CONSTANTS SEPARATED BY COMMAS.

BEGIN TEST.

๑00000000111111111122222222223333333333444444444455555555556666666666777 123456789012345678901234567890123456789012345678901234567890123456789012 $1.00000 E+30 \quad-9.87000 E-37 \quad 1.23456 E+32$

$-1.23456 \mathrm{E}+32 \quad 1.78650 \mathrm{E}+36 \quad 5.00000 \mathrm{E}-20$

END TEST. 


\title{
6. 0 PRINTING OF FLOATING POINT NUMBERS (CONTINUED) AND ASSIGNMENT OF INTEGER AND FIXED POINT VALUES
}

In this section we complete the task of evaluating the format of the NR3 constants separated by semicolon delimiters on output and begin the task of assigning the previous numeric constant types to simple variables and printing those variables. Again trailing zeroes in the significand are optional. The user is referred to section 5, 6, 9 and 12 of BSR X3.60

for specifications.

\subsection{Printing NR3 Numbers with Semicolon Delimiters}

\subsubsection{Space Allotment (E-Format) in Compact Form}

The objective of this test is similar to that of previous semicolon separation tests. The representation of NR3 numbers requires exactly d+e+5 characters. Therefore, several NR3 numbers will be given, bracketed by asterisks to delineate the number of characters allocated for an NR3 number. The characters allow space for at most two signs, a period, the "E", and a trailing space.

\subsubsection{NR3 Constants Separated by Semicolons}

The objective of this test is the same as that of test 4.1.4. However, for this test NR3 constants are being used as the print items. There should be output similar to that of test 4.1 .4 except for the numbers.

\subsection{Assignment of Numeric Constants to Simple Variables}

\begin{abstract}
Numeric variables are named by either a single letter or a letter and a digit. Numeric variables may be either simple variables, which refer to single values, or they may refer to elements of one or two dimensional arrays. Such references are called subscripted variables. As indicated above simple numeric variables consist of a letter followed by an optional digit. Arrays will not be considered in this set of tests. They will be deferred until after the Dimension statement has been introduced. Variables can also be assigned to other variables. This is the first primitive assignment of numeric expressions beyond assigning constants to variables. There are 286 possible simple numeric variables.
\end{abstract}

\subsubsection{Assignment of NRI Constants}

The objective of this test is to verify that signed as well as unsigned NRI constants can be assigned to simple variables. It also verifies that an assigned NRI constant can be assigned from one simple variable to another.

\subsubsection{Unsigned Constants}


The objective of this test is to verify that the positive sign is optional when representing NRI constants. Therefore, this test determines whether not having a plus sign with a number when it is assigned to a simple variable causes any discrepancy. On output there should be two columns of numbers. The first column of numbers represents the desired numbers, which can be compared with those outputted in the second column as the evaluated representations of the system.

\section{2 .1 .2 Signed Constants}

The objective of this test is the same as that of test 6.2 .1 .1 except that this test uses signed NRI constants assigned to the simple variables. The test has an output format similar to that of test 6.2.1.1.

\section{2 .1 .3 Cross Assignment}

The objective of this test is to determine whether repeated assignments of an NRI constant between several different simple variables will modify the value of that constant, thus verifying another phase of assigning numeric expressions to simple variables. The test uses 26 of the simple variables, A through 2 . The simple variable $A$ is initially assigned an NRI constant and then the content of $A$ is assigned to $B$, and then $B$ to $C$, and then $C$ to $D$; and this sequence is con tinued through $Z$. The output represents the value of $\mathrm{Z}$ which should be the value of the original NRI constant assigned to $A$.

\subsubsection{Assignment of NR2 Constants}

The objective of this test is to verify that signed as well as unsigned NR2 constants can be assigned to simple variables. Also, it verifies whether an assigned NR2 can be assigned from one simple variable to another.

\subsubsection{Unsigned Constants}

The objective of this test is to verify that the positive sign is op tional when representing NR2 constants. Therefore, this test determines whether there will be any modification in the numerical representation if an unsigned NR2 constant is assigned to a simple variable. On output there should be two columns of numbers. The first column of numbers represents the desired numbers that can be compared with those outputted in the second column as the evaluated representations of the system.

\subsubsection{Signed Constants}

The objective of this test is the same as that of test 2.2.2.1 except that this test uses signed NR2 constants in the assignment made to the simple variables. The test has a similar output format.

\section{2 .2 .3 Cross Assignment.}


The objective of this test is to determine whether repeated assignments of an NR2 constant between several different simple variables will modify the value of that constant. The test uses 26 of the simple variables, $A \theta$ through 20. The simple variable $A \theta$ is initially assigned the NR2 constant and then the content of $A \theta$ is assigned to $B \theta$, and then $B \theta$ to $C \theta$, and then $C \theta$ to $D \theta$; and this sequence of assigning is continued through $2 \theta$. The output represents the value of $z \emptyset$ which should be the value of the original NR2 constant assigned to $A \theta$.

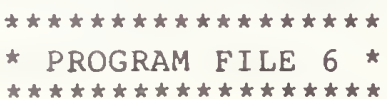

10 PRINT "PROGRAM EILE 6"

20 PRINT

30 PRINT

40 PRINT

90 PRINT " SECTION 6.1.1: SPACE ALLOTMENT (E-FORMAT), COMPACT FORM."

100 PRINT

110 PRINT

120 PRINT

130 PRINT "日0000000011111111112222222222333333333344444444445";

140 PRINT" 5555555556666666666777 "

150 PRINT " $12345678901234567890123456789012345678901234567890 "$;

160 PRINT " 1234567890123456789012 "

170 PRINT

180 PRINT

190 PRINT

200 PRINT

210 PRINT

* STANDARD* * *

OPTIONAL" ; "

SYSTEM"

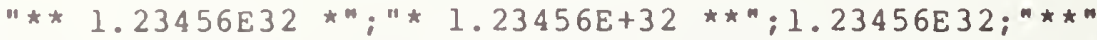

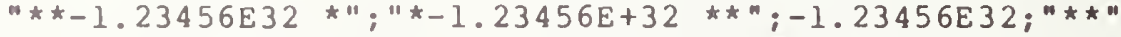

220 PRINT

230 PRINT

240 PRINT

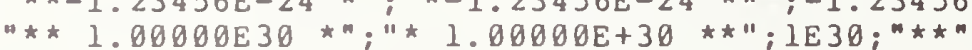

$" \star \star-9.87000 \mathrm{E}-37 \star " ; " \star-9.87000 \mathrm{E}-37 \star \star * ;-9.87 \mathrm{E}-37 ; " \star \star * "$

250 PRINT

260 PRINT

270 PRINT

280 PRINT

290 PRINT

300 PRINT

310 PRINT

320 PRINT

330 PRINT

340 PRINT

"00000000011111111112222222222333333333344444444445"

" $5555555556666666666777 "$

350 PRINT

" 12345678901234567890123456789012345678901234567890 " ;

360 PRINT $1 E 30 ;-9.87 \mathrm{E}-37 ; 1.23456 \mathrm{E} 32$
370 PRINT $-1.23456 \mathrm{E} 32 ;+1.7895 \mathrm{E} 36 ; 5 \mathrm{E}-20$

380 PRINT

390 PRINT "

END TEST."

490 PRINT

END TEST."

SECTION 6.1.2: NR3 CONSTANTS SEPARATED BY SEMICOLONS."

BEGIN TEST."

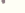




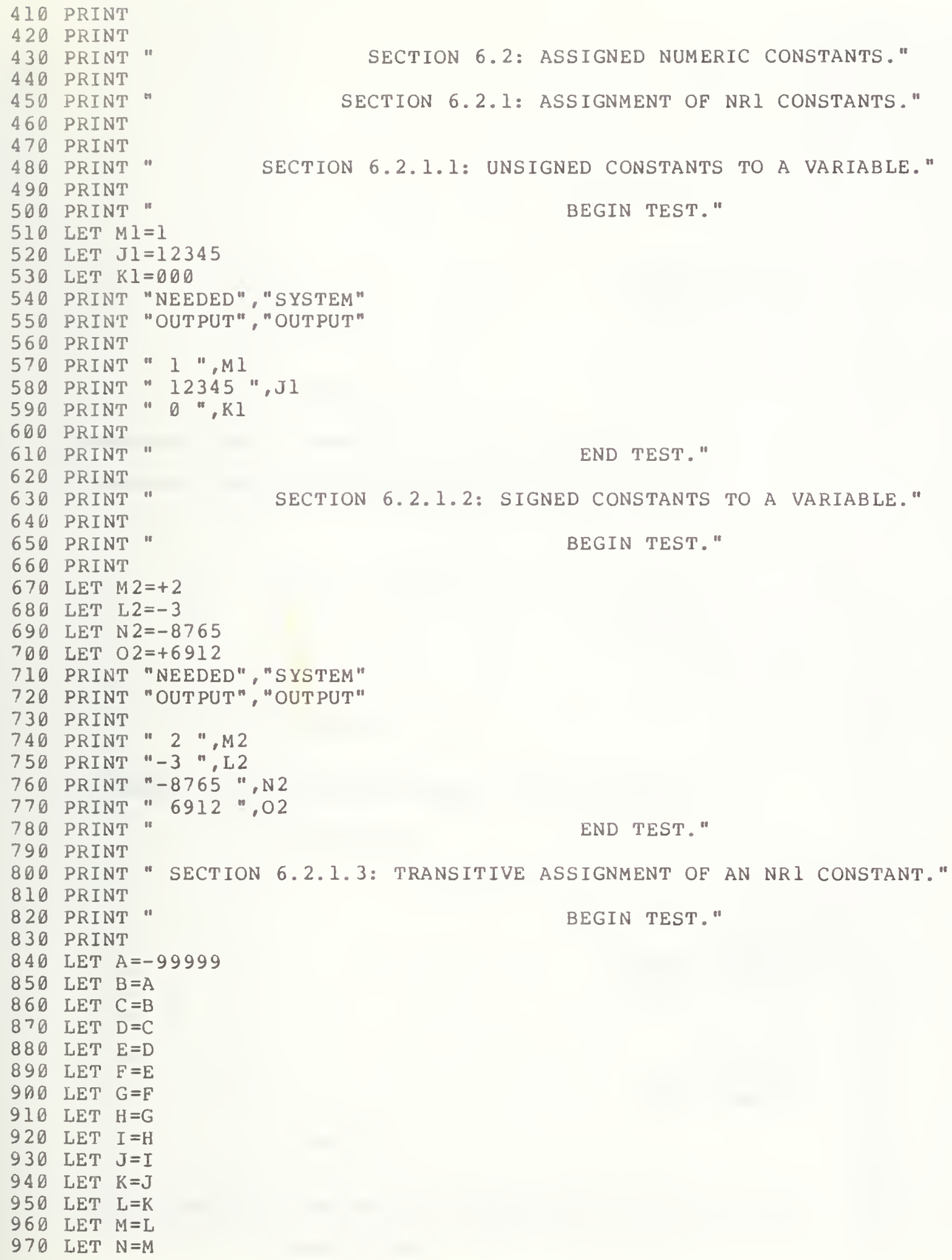




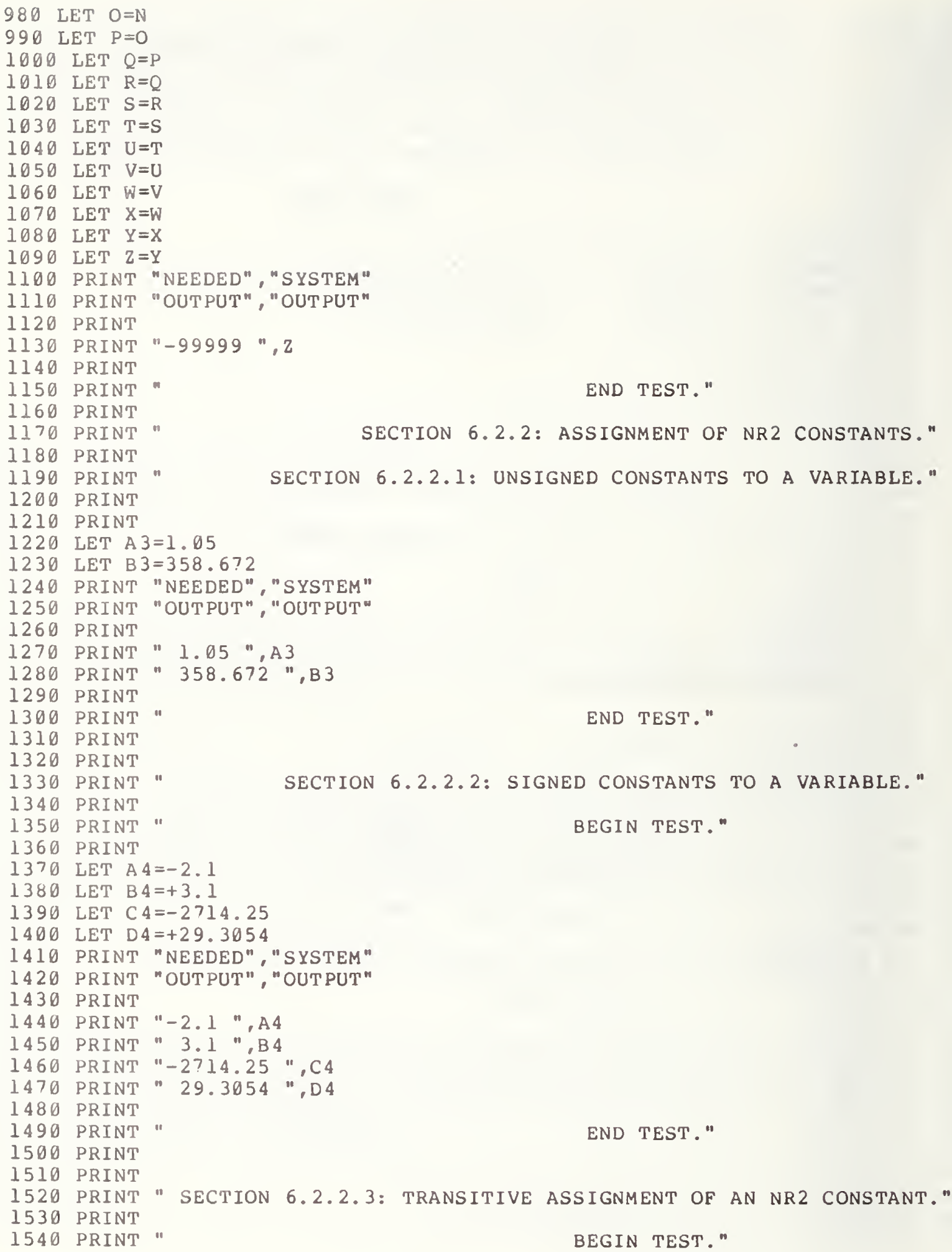




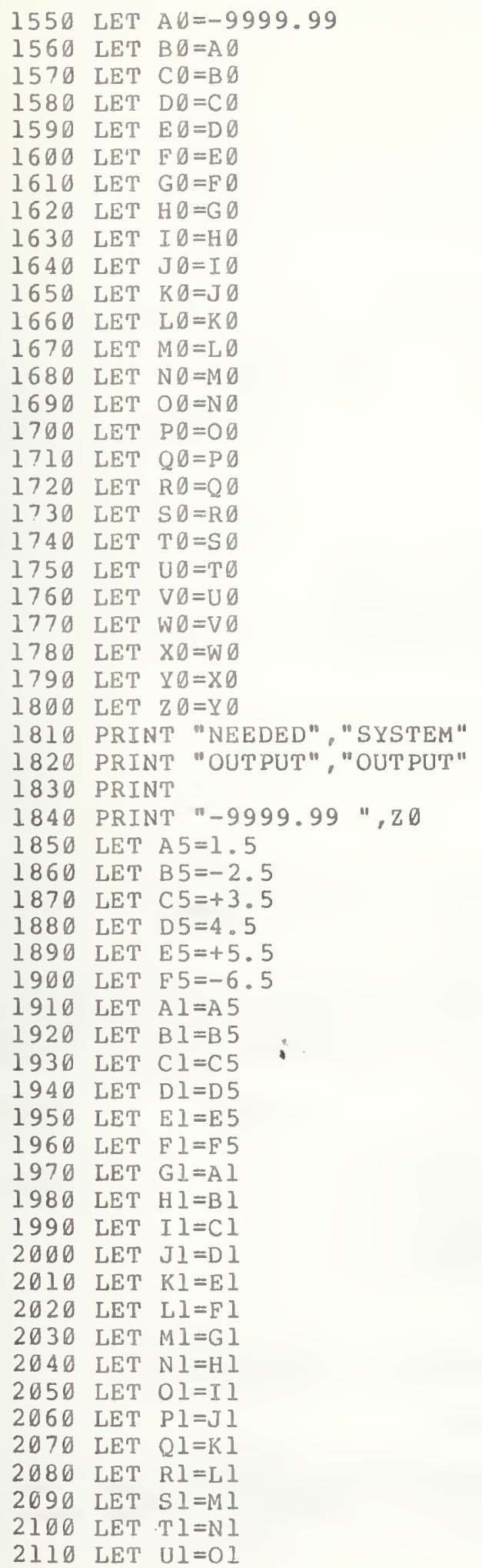



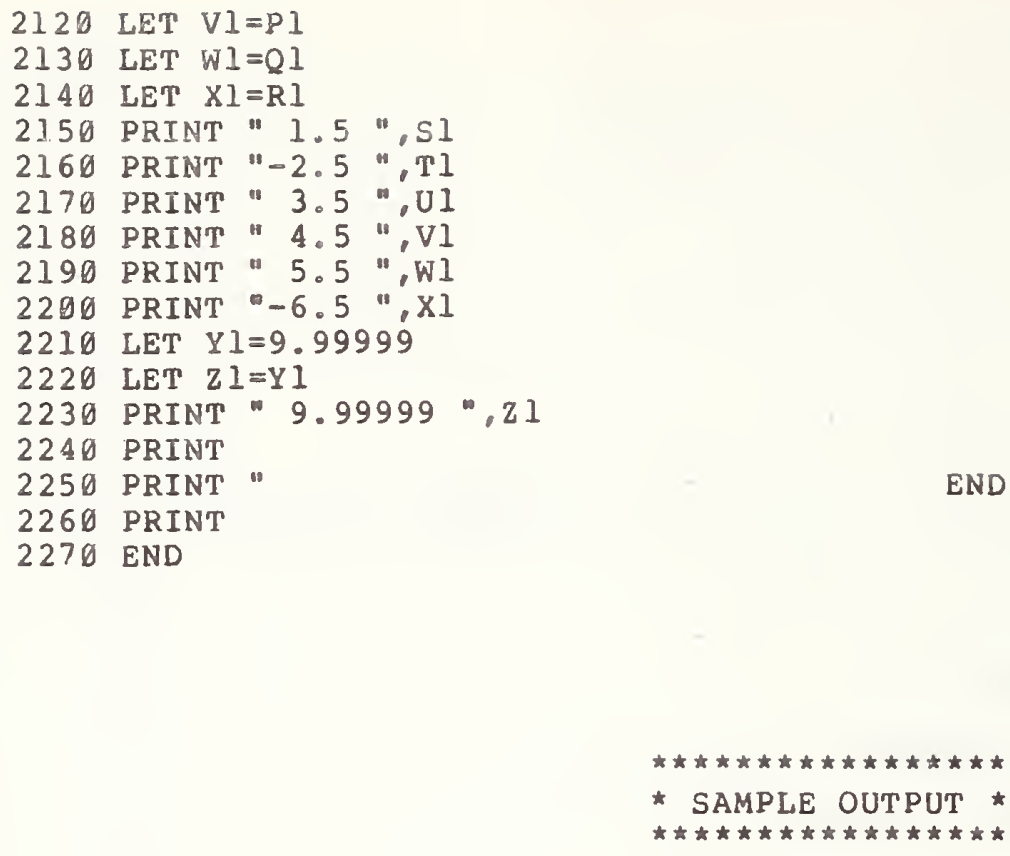

PROGRAM F'ILE 6

SECTION 6.1.1: SPACE ALLOTMENT (E-FORMAT), COMPACT FORM.

BEGIN TEST.

000000000111111111122222222223333333333444444444455555555556666666666777 123456789012345678901234567890123456789012345678901234567890123456789012

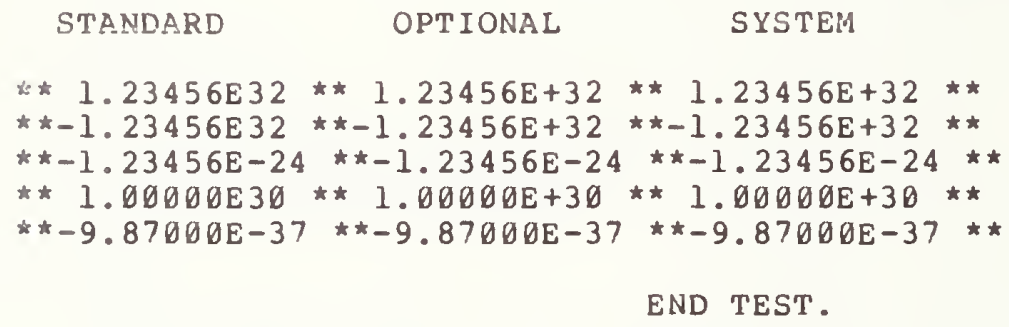




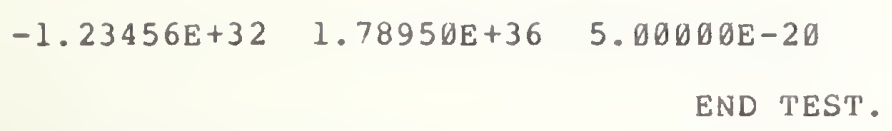

SECTION 6.2: ASSIGNED NUMERIC CONSTANTS. SECTION 6.2.1: ASSIGNMENT OF NRI CONSTANTS. SECTION 6.2.1.1: UNSIGNED CONSTANTS TO A VARIABLE.

$\begin{array}{ll}\text { NEEDED } & \text { SYSTEM } \\ \text { OUTPUT } & \text { OUTPUT } \\ 1 & 1 \\ 12345 & 12345 \\ 0 & 0\end{array}$

BEGIN TEST.

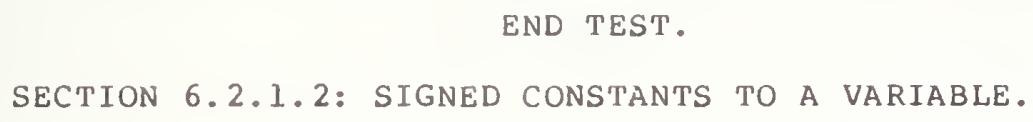

SECTION 6.2.1.3: TRANSITIVE ASSIGNMENT OF AN NRI CONSTANT. BEGIN TEST.

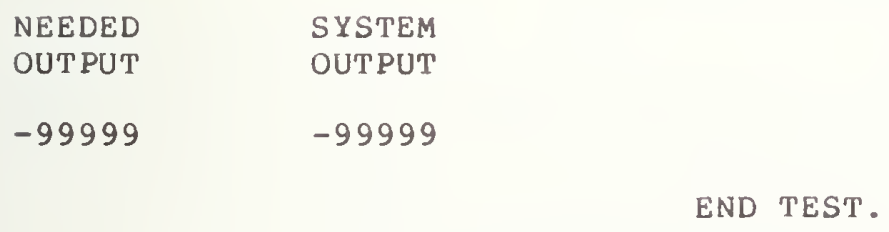


END TEST.

SECTION 6.2.2.2: SIGNED CONSTANTS TO A VARIABLE.

BEGIN TEST.

$\begin{array}{ll}\text { NEEDED } & \text { SYSTEM } \\ \text { OUTPUT } & \text { OUTPUT } \\ -2.1 & -2.1 \\ 3.1 & 3.1 \\ -2714.25 & -2714.25 \\ 29.3654 & 29.3054\end{array}$

END TEST.

SECTION 6.2.2.3: TRANSITIVE ASSIGNMENT OF AN NR2 CONSTANT.

$\begin{array}{lc}\text { NEEDED } & \text { SYSTEM } \\ \text { OUTPUT } & \text { OUTPUT } \\ -9999.99 & -9999.99 \\ 1.5 & 1.5 \\ -2.5 & -2.5 \\ 3.5 & 3.5 \\ 4.5 & 4.5 \\ 5.5 & 5.5 \\ -6.5 & -6.5 \\ 9.99999 & 9.99999\end{array}$

BEGIN TEST.

END TEST. 


\subsection{ASSIGNMENT OF FLOATING POINT CONSTANTS}

This test verifies that signed as well as unsigned NR3 constants can be assigned to simple variables. It also verifies that the assigned value of an NR3 constant can be cross assigned from one simple variable to another. The user should refer to section $5,6,9$, and 12 of BSR X3.60 and observe that trailing zeroes in the significand are optional.

7.l Using NR3 Form to Assign NRI and NR2

Constants, both Signed and Unsigned

This test verifies that the NR3 form of constants can be used to represent numerical constants used in Minimal BASIC program. That is, all numerical constants should be acceptable in NR3 form as program constants but on output should be printed in their appropriate form as either NRI or NR2 constants. The test also verifies that a positive number in NR3 form with or without a preceding plus sign can be assigned to a simple variable without modifying the value of that constant. On output there should be two columns of numbers. The first column of numbers represents the desired numbers which can be compared with those outputted in the second column as the evaluated representation of the system.

\subsection{Using NR3 Form to Assign NR3 Constants, both Signed and Unsigned}

The objective of this test is to verify that the positive sign is optional when representing NR3 constants which cannot be represented in any other form except NR3. Therefore, this section tests whether there will be any modification in the numerical representation regardless of whether a plus sign is in front of the assigned NR3 number. On output there should be two columns of numbers. The first column of numbers represents the desired numbers which can be compared with those outputted in the second column as the evaluated representation of the system.

\subsection{Cross Assignment of an NR3 Constant}

The objective of this test is to sample a number of the allowed representations for a simple variable to determine that cross assignments of an NR3 constant will not modify the value of that constant. The test uses 33 of the simple variables: A2, B2, C2, D2, C3, D3, A6, B6, C6, D6, E2, E3, E4, $\mathrm{E} 6, \mathrm{~F} 2, \mathrm{~F} 3, \mathrm{~F} 4, \mathrm{~F} 6, \mathrm{G} 2, \mathrm{G3}, \mathrm{G} 4, \mathrm{G} 5, \mathrm{G} 6, \mathrm{H} 2, \mathrm{H} 3, \mathrm{H} 4, \mathrm{H} 5, \mathrm{H} 6, \mathrm{I} 2$, I $3, \mathrm{I} 4, \mathrm{I} 5$, and I6. The simple variable $A 2$ is initially assigned the NR3 constant and then the content of A2 is assigned to B2, and then B2 to C2, and then C2 to D 2; and this form assigning continues sequentially through the list of variables above through I6. The final printed output represents the value of I6 which should be the value of the original NR3 constant assigned to A2. 
10 PRINT "PROGRAM EILE 7"

60 PRINT

70 PRINT

80 PRINT

96 PRINT"

100 PRINT

110 PRINT

120 PRINT"

SECTION 7. : ASSIGNMENT OF NR3 CONSTANTS."

130 PRINT

140 PRINT"

150 PRINT

160 PRINT

170 PRINT

180 PRINT

190 PRINT

200 LET $A 7=1.05 E 02$

210 LET B $7=-7.6 \mathrm{El}$

220 LET $C 7=+332.4 \mathrm{EO}$

230 LET D $7=51.32 \mathrm{E}-1$

$24 D$ LET E $7=+5.34 E-3$

250 LET $E 7=-14.19 E-2$

260 LET G7 $=-9.9 \mathrm{E}+2$

270 LET $\mathrm{H} 7=+10.5210 \mathrm{E}+3$

280 LET I $7=4.56 \mathrm{E}+1$

290 PRINT "NEEDED" " SYSTEM"

300 PRINT "OUTPUT" "OUTPUT"

310 PRINT

320 PRINT" 105 "A7

330 PRINT "-76",B 7

340 PRINT" 332.4 ",C7

350 PRINT " 5.132 ",D7

360 PRINT" .00534",E7

370 PRINT "-.1419",E7

380 PRINT "-990",G7

390 PRINT " 10521 ",H7

400 PRINT " 45.6 ", I 7

410 PRINT

420 PRINT

430 PRINT

440 PRINT

450 PRINT"

USING NR3 FORM TO ASSIGN NRI AND NR2 CONSTANTS," BOTH SIGNED AND UNSIGNED."

BEGIN TEST."

460 PRINT

470 PRINT"

480 PRINT"

END TEST."

490 PRINT

500 PRINT

510 PRINT"

SECTION 7.1:"

520 PRINT

530 LET $A 8=1 . E 30$

540 LET $B 8=+123$. E 20

\author{
SECTION 7.2:" \\ USING NR3 FORM TO ASSIGN NR3 CONSTANTS ONLY," \\ BOTH SIGNED AND UNSIGNED."
}

BEGIN TEST." 


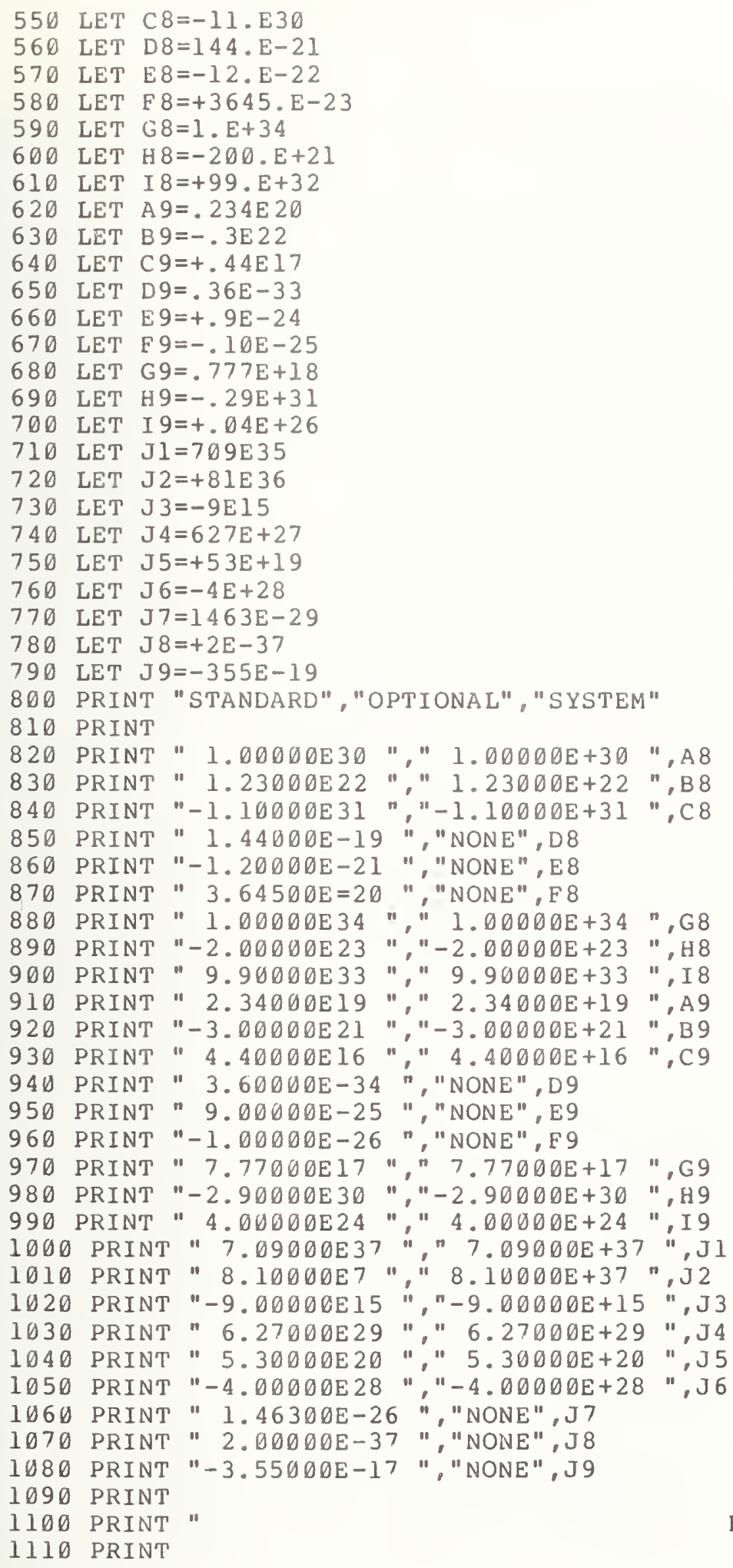




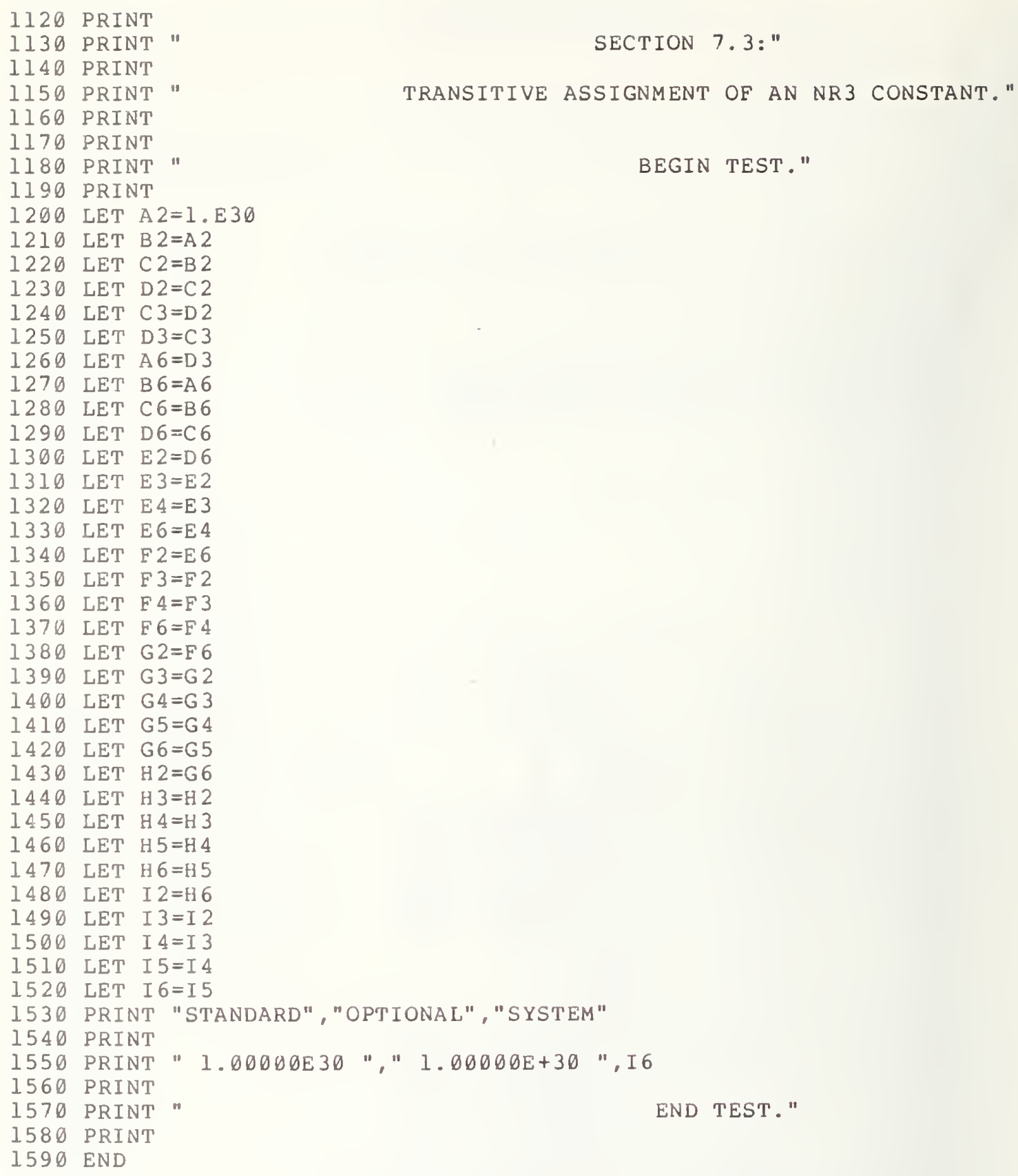




\author{
SECTION 7.1: \\ USING NR3 FORM TO ASSIGN NRI AND NR2 CONSTANTS, \\ BOTH SIGNED AND UNSIGNED.
}

BEGIN TEST.

$\begin{array}{cc}\text { NEEDED } & \text { SYSTEM } \\ \text { OUTPUT } & \text { OUTPUT } \\ 105 & 105 \\ -76 & -76 \\ 332.4 & 332.4 \\ 5.132 & 5.132 \\ .00534 & .00534 \\ -.1419 & -.1419 \\ -990 & -990 \\ 10521 & 10521 \\ 45.6 & 45.6\end{array}$

END TEST.

SECTION 7.2:

USING NR3 FORM TO ASSIGN NR3 CONSTANTS ONLY, BOTH SIGNED AND UNSIGNED.

STANDARD

$1.00000 \mathrm{E} 30$

$1.23000 \mathrm{E} 22$

$-1.10000 \mathrm{E} 31$

$1.44000 \mathrm{E}-19$

$-1.20000 \mathrm{E}-21$

$3.64500 \mathrm{E}=20$

$1.00000 \mathrm{E} 34$

$-2.00000 \mathrm{E} 23$

$9.90000 \mathrm{E} 33$

2. $34000 \mathrm{E} 19$

$-3.00000 \mathrm{E} 21$

$4.40000 \mathrm{E} 16$

$3.60000 \mathrm{E}-34$

$9.00000 \mathrm{E}-25$

$-1.00000 \mathrm{E}-26$

$7.77000 \mathrm{E} 1$ ?

\section{BEGIN TEST .}

OPT IONAL

SYSTEM

$$
1.00000 \mathrm{E}+30
$$

1. $23000 \mathrm{E}+22$

$-1.10000 \mathrm{E}+31$

NONE

NONE

NONE

$1.00000 \mathrm{E}+34$

$-2.00000 \mathrm{E}+23$

$9.90000 \mathrm{E}+33$

2. $34000 \mathrm{E}+19$

$-3.00000 \mathrm{E}+21$

$4.40000 \mathrm{E}+16$

NONE

NONE

NONE

$7.77000 \mathrm{E}+17$

$$
\begin{array}{r}
1.00000 \mathrm{E}+30 \\
1.23000 \mathrm{E}+22 \\
-1.10000 \mathrm{E}+31 \\
1.44000 \mathrm{E}-19 \\
-1.20000 \mathrm{E}-21 \\
3.64500 \mathrm{E}-20 \\
1.00000 \mathrm{E}+34 \\
-2.00000 \mathrm{E}+23 \\
9.90000 \mathrm{E}+33 \\
2.34000 \mathrm{E}+19 \\
-3.00000 \mathrm{E}+21 \\
4.40000 \mathrm{E}+16 \\
3.60000 \mathrm{E}-34 \\
9.00000 \mathrm{E}-25 \\
-1.00000 \mathrm{E}-26 \\
7.77000 \mathrm{E}+17
\end{array}
$$




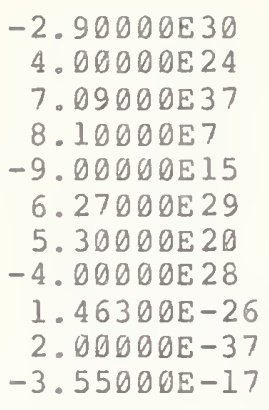
$-2.90000 E+30$
$4.00000 E+24$
$7.09000 \mathrm{E}+37$
8. $10000 \mathrm{E}+37$
$-9.00000 \mathrm{E}+15$
6. $27000 \mathrm{E}+29$
5. $30000 \mathrm{E}+20$
$-4.00000 \mathrm{E}+28$
NONE
NOINE
NONE

$-2.90000 E+30$

$4.00000 \mathrm{E}+24$

$7.09000 \mathrm{E}+37$

8. $10000 \mathrm{E}+3$ ?

$-9.00000 \mathrm{E}+15$

$6.27000 \mathrm{E}+29$

5. $30000 \mathrm{E}+20$

$-4.00000 \mathrm{E}+28$

1. $46300 \mathrm{E}-26$

$2.00000 E-37$

$-3.55000 \mathrm{E}-17$

END TEST.

SECTION 7.3:

TRANSITIVE ASSIGNMENT OF AN NR3 CONSTANT.

BEGIN TEST.

STANDARD

OPTIONAL

SYSTEM

$1.00000 \mathrm{E} 30$

$1.00000 \mathrm{E}+30$

$1.00000 \mathrm{E}+30$

END TEST . 
The objective of this test is to determine whether nonzero numbers of six significant digits with absolute values near the endpoints of the interval $1 E-38$ to $1 E 38$, can be used as print items in the form of numerical constants or be assigned to simple variables. The standard specifies that although constants can have an arbitrary number of digits in the exrad, the implementation-defined range shall be at least $1 E-38$ to $1 E+38$ (see section 5.4 of BSR X3.60). Nonzero constants, whose magnitudes are outside of the implementation-defined range, are to be diagnosed as errors. There will be specific error diagnostic tests in later sections. This section concentrates on keeping within the range lE-38 to lE38.

\subsection{Printing NR3 Constants of Six Significant Digits} That Are Near the Endpoints of: 1 E38 to $1 E-38$

The objective of this subsection is to verify that NR3 constants with absolute values near the endpoints $1 E-38$ or $1 E 38$ can be used as print-items.

\subsubsection{Positive Exponent}

The objective of this test is to print constants that, in absolute value, are near the endpoint 1E38. The test uses both positively and negatively signed NR3 constants. On output there should be three columns of numbers. The first column should be headed "Standard Form". This heads a list of numbers that should also be printed in the third column, which is headed "Form of System". Column two is a list of optional output forms for the NR3 constants.

\subsubsection{Negative Exponent}

The objective of this test is to execute the printing of NR3 constants that, in absolute value, are near the endpoint 1E-38. The output of this test is in the same format as that of test 8.1.1.

\section{2 Assigning NR3 Constants of Six Significant Digits}

That Are Near the Endpoints of: 1 E38 to $1 \mathrm{E}-38$

The objective of this test is to verify that NR3 constants, whose absolute values are close to the magnitude of the endpoints $1 E-38$ and $1 E 38$, can be assigned to simple variables. These simple variables are then used as print-items.

\section{2.l Positive Exponent}

The objective of this test is the same as that of test 8.1 .1 , except that for this test the NR3 constants are assigned to simple variables. The structures of the two tests are basically the same, except for the simple variables used. On output, the format should be the same for this test as 
for test 8.1 .1 .

\subsubsection{Negative Exponent}

The objective of this test is the same as that of test 8.1.2, except that for this test the NR3 constants are assigned to simple variables which are the print-items used. The structure and output of this test are the same as those of test 8.2 .1 .

\section{3 Printing and Assigning the Extreme Values $1 E+38$ and $1 E-38$ \\ 8.3.1 As a Print-Item in Numerical Form}

The objective of this test is to execute as print-items, in NR3 constant form, both the positive and negative cases of $1 E-38$ and $1 E 38$. The test uses a three column formatted output. The first column, titled "standard Form", illustrates the expected standard conforming E-formatted output. The second column, titled "Optional Form", gives another acceptable standard conforming output for E-formatted constants. Column three, titled "Form of system", gives the output form used by the system being tested.

\subsubsection{As Print-Items which Have Been Numerically Assigned}

The objective of this test is the same as that of test 8.3.1, except that for this test the positive and negative cases of the endpoints, $1 E-38$ and IE38, are first assigned to simple numeric variables, and then those simple variables are used as the print-items. The structure of the test is the same as that of test 8.3.1. The output format for this test is the same as the output format for test 8.3.1.

10 PRINT "PROGRAM FILE 8"

60 PRINT

70 PRINT

80 PRINT

90 PRINT " SECTION 8. B: "TES'TING THE MAGNITUDE OF NUMERICAL CONSTANTS"

100 PRINT" "WITHIN MINIMAL LIMITS OF 1 E-38 AND IE38."

110 PRINT

120 PRINT "SECTION 8.1: PRINTING NR3 CONSTANTS OF 6 SIGNIFICANT DI-"

130 PRINT" GITS WHICH ARE NEAR THE MAGNITUDE OF:"

140 PRINT

150 PRINT"

$1 \mathrm{E} 38^{\prime \prime}$ 
160 PRINT

170 PRINT "

180 PRINT

190 PRINT

200 PRINT

210 PRINT

220 PRINT

230 PRINT

240 PRINT

250 PRINT

260 PRINT

270 PRINT

280 PRINT

290 PRINT

300 PRINT

310 PRINT

320 PRINT

330 PRINT

340 PRINT

350 PRINT

360 PRINT

370 PRINT

380 PRINT

390 PRINT

400 PRINT

410 PRINT

420 PRINT

430 PRINT

440 PRINT

450 PRINT

460 PRINT

470 PRINT

480 PRINT

490 PRINT

500 PRINT

510 PRINT

520 PRINT

530 PRINT

540 PRINT

550 PRINT

$\begin{array}{ll}560 & \text { PRINT } \\ 570 & \text { PRINT }\end{array}$

580 PRINT

590 PRINT

600 PRINT

610 PRINT

620 PRINT

630 PRINT

640 PRINT

650 PRINT

660 PRINT

670 PRINT

680 PRINT

690 PRINT

700 PRINT

710 PRINT

720 PRINT
OR"

IE-38."

SECTION $8.1 .1 "$

(POSITIVE EXPONENT.)"

BEGIN TEST."

"STANDARD"," "OPTIONAL" ", FORM "

"FORM "," FOR ", "SYSTEM"

$"-9.99999 E 30 ",-9.99999 E+30 ",-9.99999 E 30$

" $9.99999 E 31$ ", $9.99999 E+31 ",+9.99999 E 31$

$"-9.99999 E 32 ",-9.99999 E+32 ",-9.99999 E+32$

" $9.99999 E 33$ ", 9.99999E+33 ",9.99999E33

"-9.99999E 34 ","-9.99999E+34 ", -9.99999E 34

"9.99999E35 "," 9.99999E+35 ", +9.99999E+35

"-9.99999E36 ", "-9.99999E+36 ",-9.99999E+36

" $9.99999 \mathrm{E} 37$ ", $9.99999 \mathrm{E}+37$ ",9.99999E37

$"$

END TEST."

SECTION $8.1 .2 "$

(NEGATIVE EXPONENT.) "

BEGIN TEST."

" ", " " FORM "

"STANDARD", "OPTIONAL"," OF"

FORM "," FORM ", "SYSTEM"

$"-9.99999 E-30 ", " N O N E ",-9.99999 E-30$

" $9.99999 E-31$ ","NONE", +9.99999E-31

"-9.99999E-32 ", "NONE", $-9.99999 E-32$

" $9.99999 E-33$ ", "NONE", $9.99999 E-33$

"-9.99999E-34" "NONE", -9.99999E-34

" $9.99999 \mathrm{E}-35$ ", "NONE", +9.99999E-35

"-9.99999E-36" "NONE", $-9.99999 E-36$

" $9.99999 E-37 ", " N O N E ", 9.99999 E-37$

END TEST."

"SECTION 8.2: ASSIGNING NR3 CONSTANTS OF 6 SIGNIFICANT DI-" GITS WHICH ARE NEAR THE MAGNITUDE OF:"

lE $38 "$ 


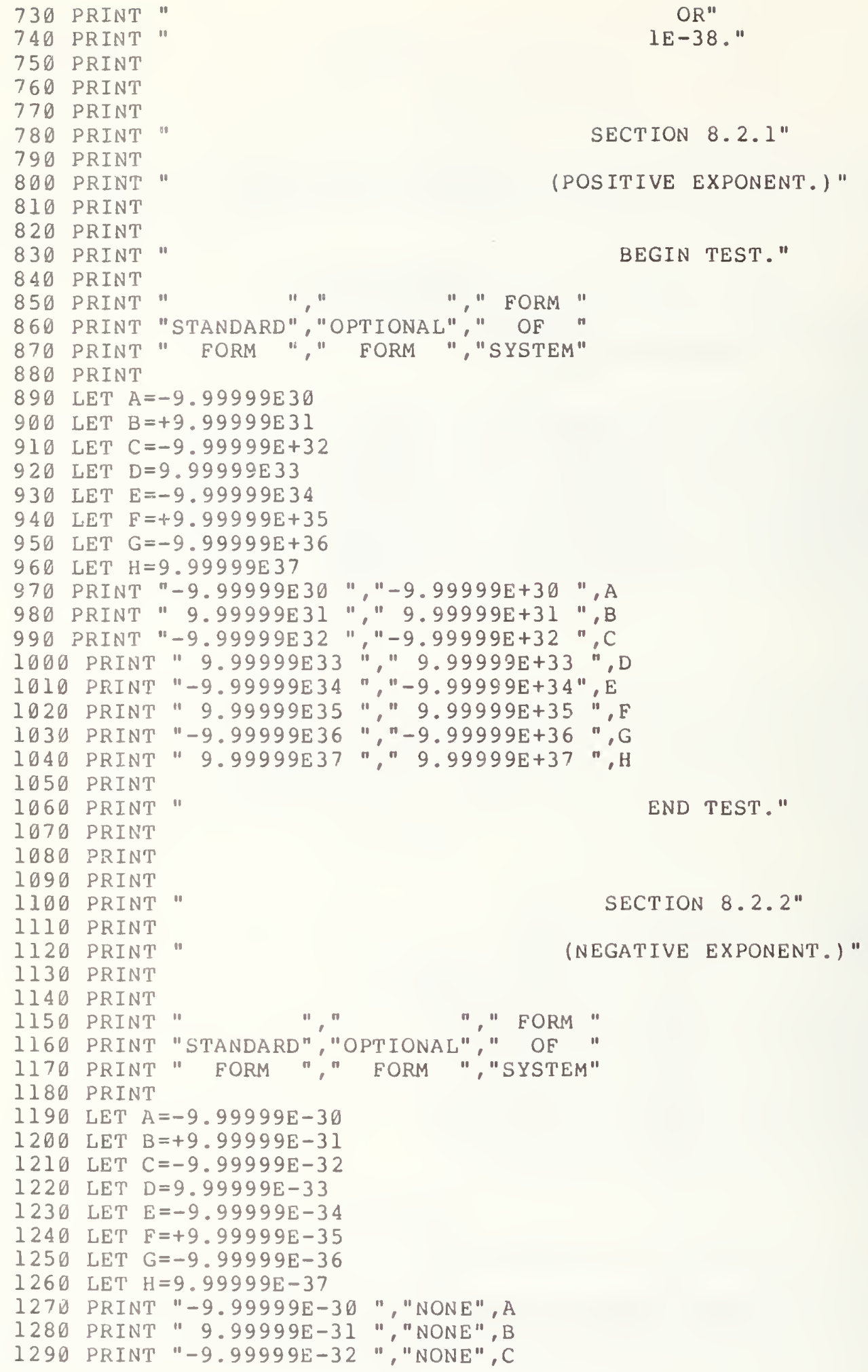




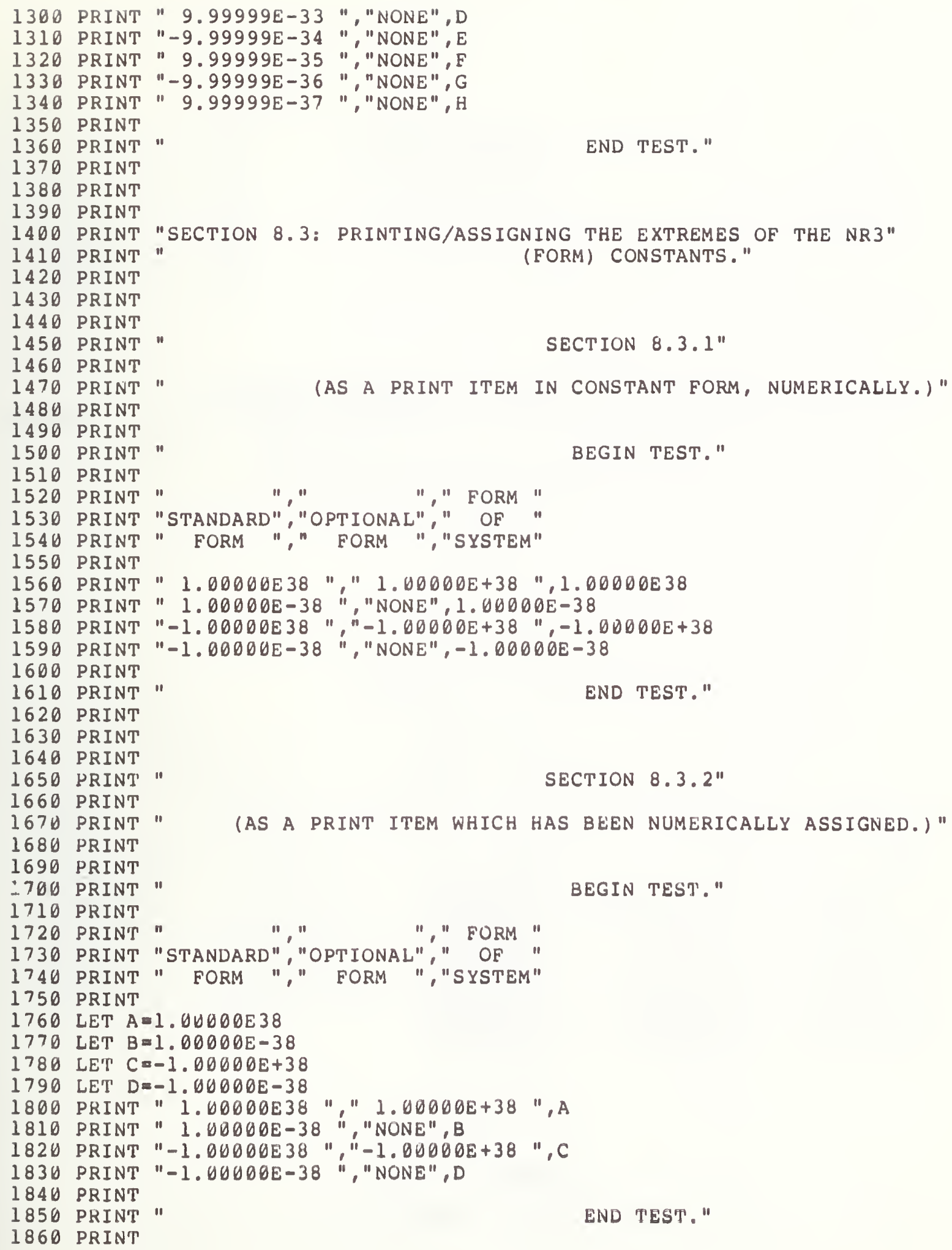


PROGRAM FILE 8

SECTION 8.0: TESTING THE MAGNITUDE OF NUMERICAL CONSTANTS WITHIN MINIMAL LIMITS OF IE-38 AND IE38.

SECTION 8.1: PRINTING NR3 CONSTANTS OF 6 SIGNIFICANT DIGITS WHICH ARE NEAR THE MAGNITUDE OF :

IE 38
OR
$1 E-38$

\author{
SECTION 8.1 .1 \\ (POSITIVE EXPONENT.)
}

BEGIN TEST.

FORM

OF

SYST'EM

$-9.99999 E 30$

9.99999E 31

$-9.99999 E 32$

$9.99999 E 33$

$-9.99999 \mathrm{E} 34$

9.99999E 35

$-9.99999 \mathrm{E} 36$

9. $99999 \mathrm{E} 37$
OPT IONAL FOR

$$
\begin{array}{r}
-9.99999 E+30 \\
9.99999 E+31 \\
-9.99999 E+32 \\
9.99999 E+33 \\
-9.99999 E+34 \\
9.99999 E+35 \\
-9.99999 E+36 \\
9.99999 E+37
\end{array}
$$

$-9.99999 E+36$

9. $99999 E+31$

$-9.99999 E+32$

$9.99999 E+33$

$-9.99999 E+34$

$9.99999 E+35$

$-9.99999 E+36$

$9.99999 E+37$

END TEST.

SECTION 8.1 .2

(NEGATIVE EXPONENT.) 
BEGIN TEST.

\begin{tabular}{rlr} 
STANDARD & OPTIONAL & \multicolumn{1}{c}{ FORM } \\
FORM & FORM & SYSTEM \\
$-9.99999 E-30$ & NONE & $-9.99999 E-30$ \\
$9.99999 E-31$ & NONE & $9.99999 E-31$ \\
$-9.99999 E-32$ & NONE & $-9.99999 E-32$ \\
$9.99999 E-33$ & NONE & $9.99999 E-33$ \\
$-9.99999 E-34$ & NONE & $-9.99999 E-34$ \\
$9.99999 E-35$ & NONE & $9.99999 E-35$ \\
$-9.99999 E-36$ & NONE & $-9.99999 E-36$ \\
$9.99999 E-37$ & NONE & $9.99999 E-37$ \\
& & END TEST.
\end{tabular}

SECTION 8.2: ASSIGNING NR3 CONSTANTS OF 6 SIGNIFICANT DIGITS WHICH ARE NEAR THE MAGNITUDE OF:

\author{
1 E 38 \\ OR \\ $1 \mathrm{E}-38$.
}

SEC'TION B.2.1

(POSITIVE EXPONENT.)

STANDARD

OPTIONAL FORM

BEGIN TEST.

FORM

$-9.99999 \mathrm{E} 30$

$9.99999 \mathrm{E} 31$

$-9.99999 E 32$

$9.99999 \mathrm{E} 33$

$-9.99999 E 34$

$9.99999 \mathrm{E} 35$

$-9.99999 \mathrm{E} 36$

9.99999E37

$-9.99999 E+3 b$
$9.99999 E+31$
$-9.99999 E+32$
$9.99999 E+33$
$-9.99999 E+34$
$9.99999 E+35$
$-9.99999 E+36$
$9.99999 E+37$

FORM

OF

SYSTEM

$-9.99999 E+30$
$9.99999 E+31$
$-9.99999 E+32$
$9.99999 E+33$
$-9.99999 E+34$
$9.99999 E+35$
$-9.99999 E+36$
$9.99999 E+37$

END TEST .

SECTION 8.2 .2

(NEGATIVE EXPONENT.) 


\begin{tabular}{rr}
\multicolumn{1}{l}{$\begin{array}{l}\text { STANDARD } \\
\text { FORM }\end{array}$} & OPTIO \\
& FORM \\
$-9.99999 \mathrm{E}-30$ & NONE \\
$9.99999 \mathrm{E}-31$ & NONE \\
$-9.99999 \mathrm{E}-32$ & NONE \\
$9.99999 \mathrm{E}-33$ & NONE \\
$-9.99999 \mathrm{E}-34$ & NONE \\
$9.99999 \mathrm{E}-35$ & NONE \\
$-9.99999 \mathrm{E}-36$ & NONE \\
$9.99999 \mathrm{E}-37$ & NONE
\end{tabular}

FORM

OF

SYSTEM

$-9.99999 \mathrm{E}-30$

$9.99999 \mathrm{E}-31$

$-9.99999 \mathrm{E}-32$

$9.99999 \mathrm{E}-33$

$-9.99999 E-34$

$9.99999 \mathrm{E}-35$

$-9.99999 E-36$

$9.99999 \mathrm{E}-37$

END TEST.

SECTION 8.3: PRINTING/ASSIGNING THE EXTREMES OF THE NR3 (FORM) CONSTANTS.

SECTION 8.3 .1

(AS A PRINT ITEM IN CONSTANT FORM, NUMERICALLY.)

BEGIN TEST .

FORM

$\begin{array}{ccc}\text { STANDARD } & \text { OPTIONAL } & \text { OF } \\ \text { FORM } & \text { FORM } & \text { SYSTEM }\end{array}$

$\begin{array}{lll}1.00000 \mathrm{E} 38 & 1.00000 \mathrm{E}+38 \quad 1.00000 \mathrm{E}+38\end{array}$

$1.00000 \mathrm{E}-38$ NONE $1.00000 \mathrm{E}-38$

$-1.00000 \mathrm{E} 38 \quad-1.00000 \mathrm{E}+38-1.00000 \mathrm{E}+38$

$-1.00000 \mathrm{E}-38$ NONE $-1.00000 \mathrm{E}-38$

END TEST .

SECTION 8.3 .2

(AS A PRINT ITEM WHICH HAS BEEN NUMERICALLY ASSIGNED.)

BEGIN TEST.

$\begin{array}{cll}\begin{array}{c}\text { STANDARD } \\ \text { FORM }\end{array} & \begin{array}{c}\text { OPTIONAL } \\ \text { FORM }\end{array} & \begin{array}{c}\text { FORM } \\ \text { OF } \\ \text { SYSTEM }\end{array} \\ 1.00000 \mathrm{E} 38 & 1.00000 \mathrm{E}+38 & 1.00000 \mathrm{E}+38 \\ 1.00000 \mathrm{E}-38 & \text { NONE } & 1.00000 \mathrm{E}-38 \\ -1.00000 \mathrm{E} 38 & -1.00000 \mathrm{E}+38 & -1.00000 \mathrm{E}+38 \\ -1.00000 \mathrm{E}-38 & \text { NONE } & -1.00000 \mathrm{E}-38\end{array}$


END TEST. 


\subsection{THE REM AND GOTO STATEMENTS}

The objectives of this test are two-fold in that they test the REM and GoTo-statements both separately and together. The REM statement is tested for the requirement that it allow the use of any characters in the ASCII character set for BASIC in its REM-string. The GOTO-statement is tested for its unconditional transferability. This section begins the evaluation of the host system's control structure with the most primitive BASIC control statement. The user should refex here to sections 10 and 18 and the syntax of a remark-string in section 3.2 of BSR $\times 3.60$.

\section{I REM-Statement as a Program Annotator}

The objective of this test is to use all of the ASCII allowed Minimal BASIC string-characters within a remark-string. This character set consists of the set of upper-case Roman letters referenced by the ASCII character set in positions $4 / 1$ through $5 / 10$, the set of Arabic digits referenced by the ASCII character set in positions $3 / 0$ through $3 / 9$ and the remaining string-characters. The remaining string-characters consist of the following characters: space, exclamation-point, number-sign, dollar, percent, ampersand, quote, apostrophe, open-parenthesis, close-parenthesis, asterisk, plus, comma, minus, period, slant, colon, semicolon, less-than, equals, greater-than, question-mark, circumflex, and underline. The test uses each of the characters described above in REM strings. On output, there must be only one printed statement between the beginning of the test and its end with two blank lines above it and one below it.

\subsection{GOTO Statement with a Single Space Between GO and TO}

The objective of this test is to test the transfer capability of the unconditional GoTo-statement. This transfer capability is tested for both forward and backward transferring. In testing the forward and backward transferring capabilities of the GOTO-statements, the transfers are made to both adjacent and non-adjacent line numbers. Along with these transfers there is also a test of the capability of the GOTO-statement to carry with its transfers any numeric values that may be requested, i.e. there is a test to verify that assigned variables are global. In this test section, only a single space is used between the GO and TO in the keyword. On output there should be numerically ordered printing of the digits $1,2, \ldots, 8$ for each successful transfer by the GOTO-statements. There are also error traps in the test. Should a transfer be unsuccessful, with no diagnostic and execution continuing at the next statement, then a printout of the attempted line transfer, just prior to the halting of execution, will appear.

\subsection{GOTO Statement with Many Spaces Between GO and TO}

The objective here is to test the use of an arbitrary number of spaces within the keyword between the GO and the TO of the GOTO-statement. The test also verifies that although the REM-statement has no effect when executed, it can serve as a statement to which control is transferred. 
The output for this test should be the same as for test 9.2. Error traps are also a part of this test for any faulty transfer attempts. The printout for any errors will be the same as specified for test 9.2.

\section{4 GOTO statement with a Transfer to a GOTO}

The objective of this test is to verify further the unconditional transfer capability of the GoTo-statement, which in this test transfers to another GOTO-statement. The test has error messages printed if there are any incorrect transfers. These messages will indicate which transfers were requested, but failed. On output there should be a statement to the user on the status of the test.

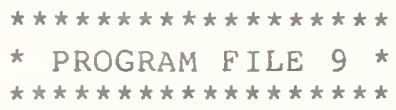

1 PRINT "PROGRAM FILE 9"

2 PRINT

3 PRINT

4 PRINT

30 PRINT"

SECTION 9.1: REM-STATEMENT, AN ANNOTATOR."

40 PRINT

50 PRINT

BEGIN TEST."

60 PRINT

7D REM THIS TEST SECTION TESTS THE REM STATEMENT.

80 REM ALL THE MINIMAL BASIC CHARACTER SET OF THE ASCII CHARACTER

90 REM SET ARE GIVEN BELOW.

100 REM

110 REM ABCDEFGHIJKLMNOPQRSTUVWXYZ * () \&

120 REM ? $123456789^{\prime \prime ! ~ \# \$ \& '+,-. /: ;<=! ~}$

130 REM

140 REM THE PROGRAM FLOW SHOULD NOT BE ALTERED BY REM STATEMENTS.

150 REM

160 PRINT

170 PRINT "

180 PRINT

190 PRINT"

200 PRINT

210 PRINT"

220 PRINT

230 PRINT"

END TEST."

240 PRINT

250 PRINT"

260 GO TO 430

270 PRINT"

280 LET $M=3$

290 PRINT TAB $(30) ; M$ 
300 PRINT " IF A FOUR FOLLOWS THIS LINE, FORWARD TRANSFER PERFORMED."

310 GO TO 580

320 PRINT"

ERROR, TRANSFER FROM LINE 310 TO 580 IMPROPER."

330 LET $M=$ ?

340 PRINT TAB (30);M

350 PRINT "IF AN EIGHT FOLLOWS THIS LINE, FORWARD TRANSFER PERFORMED."

360 GO TO 480

370 PRINT " ERROR, TRANSFER FROM LUNE 360 TO 480 IMPROPER."

380 LET $M=2$

390 PRINT TAB (30);M

400 PRINT " IF A THREE FOLLOWS THIS LINE, BACKWARD TRANSFER PERFORMED."

410 GO TO 280

420 PRINT" $"$ ERROR, TRANSFER FROM LINE 410 TO 280 IMPROPER."

430 LET $M=1$

440 PRINT TAB (30);M

450 PRINT " IF A TWO FOLLOWS THIS LINE, BACKWARD TRANSFER PERFORMED."

460 GO TO 380

470 PRINT" $\quad$ ERROR, TRANSTER FROM LINE 460 TO 380 IMPROPER."

480 LET $M=8$

490 PRINT TAB $(30) ; M$

500 PRINT " IF A MESSAGE ON OUTPUT SHOULD FOLLOW THIS PARAGRAPH,"

505 PRINT "THEN FORWARD TRANSFER PERFORMED."

510 GO TO 680

520 PRINT"

ERROR, TRANSFER FROM LINE 510 TO 680 IMPROPER."

530 LET $M=6$

540 PRINT TAB (30);M

550 PRINT " IF A SEVEN FOLLOWS THIS LINE, BACKWARD TRANSFER PERFORMED."

560 GO TO 330

570 PRINT "

580 LET $M=4$

590 PRINT TAB $(30) ; M$

600 PRINT " IF A FIVE FOLLOWS THIS LINE, FORWARD TRANSFER PERFORMED."

610 GO TO 630

620 PRINT"

630 LET $M=5$

640 PRINT TAB (30);M

650 PRINT " IF A SIX FOLLOWS THIS LINE, BACKWARD TRANSFER PERFORMED."

660 GO TO 530

670 PRINT "

680 PRINT "

690 PRINT

700 PRINT "

ERROR, TRANSFER FROM LINE 560 TO 330 IMPROPER."

710 PRINT

720 PRINT "

730 PRINT

740 PRINT "

ERROR, TRANSFER FROM LINE 610 TO 630 IMPROPER."

750 PRINT

760 PRINT "

770 GOTO 970

780 PRINT"

ERROR, TRANSFER FROM LINE 660 TO 530 IMPROPER."

790 REM CONTROL TRANSFERED BACKWARDS TO THIS STATEMENT.

800 LET $M=3$

810 PRINT TAB (30);M

820 PRINT " IF A FOUR FOLLOWS THIS LINE, FORWARD TRANSFER PERFORMED." 830 GO TO 1150

840 PRINT" " ERROR, TRANSEER EROM LINE 830 TO 1150 IMPROPER. 850 REM CONTROL TRANSFERED BACKWARDS TO THIS STATEMENT. 
860 LET $M=7$

870 PRINT TAB (30);M

880 PRINT "IF AN EIGHT FOLLOWS THIS LINE, FORWARD TRANSFER PERFORMED." 890 GO TO 1030

$9 \emptyset \emptyset$ PRINT " ERROR, TRANSFER FROM LINE 890 TO 1030 IMPROPER."

910 REM CONTROL TRANSFERED BACKWARDS TO THIS STATEMENT."

920 LET $M=2$

930 PRINT TAB (30);M

940 PRINT "IF A THREE FOLLOWS THIS LINE, BACKWARD TRANSFER PERFORMED."

950 GO TO 790

960 PRINT" $\quad$ ERROR, TRANSFER FROM LINE 950 TO 790 IMPROPER."

970 REM CONTROL TRANSFERED FORWARD TO THIS STATEMENT.

980 LET $M=1$

990 PRINT TAB (30);M

1000 PRINT " IF A TWO FOLLOWS THIS LINE, BACKWARD TRANSFER PERFORMED." 1010 GO TO 910

1020 PRINT " ERROR, TRANSFER FROM LINE 1010 TO 910 IMPROPER."

1030 REM CONTROL TRANSFERED FORWARD TO THIS STATEMENT.

1040 LET $M=8$

1050 PRINT TAB (30);M

1060 PRINT " IF A MESSAGE ON OUTPUT SHOULD FOLLOW THIS PARAGRAPH,"

1065 PRINT "THEN FORWARD TRANSFER PERFORMED."

1070 GO TO 1270

1080 PRINT" $\quad$ ERROR, TRANSFER FROM LINE 1070 TO 1270 IMPROPER."

1090 REM CONTROL TRANSFERED BACKWARDS TO THIS STATEMENT.

1100 LET $M=6$

1110 PRINT TAB (30);M

1120 PRINT " IF A SEVEN FOLLOWS THIS LINE, BACKWARD TRANSFER PERFORMED." 1130 GO TO 850

1140 PRINT" $\quad$ ERROR, TRANSFER FROM LINE 1130 TO 850 IMPROPER."

1150 REM CONTROL TRANSFERED FORWARD TO THIS STATEMENT.

1160 LET $M=4$

1170 PRINT TAB (30);M

1180 PRINT " IF A FIVE FOLLOWS THIS LINE, FORWARD TRANSFER PERFORMED." 1190 GO TO 1210

1200 PRINT" $\quad$ ERROR, TRANSFER FROM LINE 1190 TO 1210 IMPROPER."

1210 REM CONTROL TRANSFERED FORWARD TO THIS STATEMENT.

1220 LET $M=5$

1230 PRINT TAB (30);M

1240 PRINT " IF A SIX FOLLOWS THIS LINE, BACKWARD TRANSFER PERFORMED." 1250 GO TO 1090

1260 PRINT" $\quad$ ERROR, TRANSFER FROM LINE 1250 TO 1090 IMPROPER."

1276 REM CONTROL TRANSFERED FORWARD TO THIS STATEMENT.

1280 PRINT" THE ABOVE PRINTOUT SHOULD BE IN THE ORDER $1,2, \ldots, 8 . "$

1290 PRINT

1300 PRINT"

END TEST."

1310 PRINT

1320 PRINT

1330 PRINT"

1340 PRINT

1350 PRINT"

1360 PRINT

1370 GO TO 1440

1380 PRINT"

1390 PRINT"

1400 GO TO 1460

1410 PRINT"

SECTION 9.4: GOTO-STATEMENT, TRANSFER TO A GOTO." BEGIN TEST."

ERROR, TRANSFER FROM LINE 1370 TO 1440 IMPROPER." IF NO ERROR MESSAGES, TEST PASSED."

ERROR, TRANSFER FROM LINE 1400 TO 1460 IMPROPER." 
1420 GO TO 1390

1430 PRINT "

1440 GO TO 1420

1450 PRINT

1460 PRINT

1470 PRINT "

1480 PRINT

1500 END
ERROR, TRANSFER FROM LINE 1420 TO 1390 IMPROPER." ERROR, TRANSFER FROM LINE 1440 TO 1420 IMPROPER." END TEST."

PROGRAM FILE 9

SECTION 9.1: REM-STATEMENT, AN ANNOTATOR.

BEGIN TEST.

IF THIS LINE ONLY PRINT, REM TEST PASSES.

END TEST.

SECTION 9.2: GOTO-STATEMENT, SINGLE SPACED.

BEGIN TEST.

IF A ONE FOLLOWS THIS LINE, FORWARD TRANSFER PERFORMED. 1

IF A TWO FULLOWS THIS LINE, BACKWARD TRANSEER PERFORMED. 2

IF A THREE FOLLOWS THIS LINE, BACKWARD TRANSFER PERFORMED. 3

IF A FOUR FOLLOWS THIS LINE, FORWARD TRANSFER PERFORMED. 4

IF A EIVE FOLLOWS THIS LINE, FORWARD TRANSFER PEREORMED.

6 C 6 .

IE A SEVEN FOLLOWS THIS LINE, BACKWARD TRANSEER PERFORMED.

IF AN EIGHT FOLLOWS THIS LINE, FORWARD TRANSFER PERFORMED. IF A MESSAGE ON OUTPUT SHOULD EOLLOW THIS PARAGRAPH, THEN FORWARD TRANSEER PERFORMED.

THE ABOVE PRINTOU'T SHOULD BE IN THE ORDER $1,2, \ldots, 8$. 
END TEST.

SECTION 9.3: GOTO-STATEMENT, ANY SPACE/REM.

BEGIN TEST.

IF A ONE FOLLOWS THIS LINE, FORWARD TRANSFER PERFORMED.

IF A TWO FOLLOWS THIS LINE, BACKWARD TRANSFER PERFORMED. 2

IF A THREE FOLLOWS THIS LINE, BACKWARD TRANSFER PERFORMED. 3

IF A FOUR FOLLOWS THIS LINE, FORWARD TRANSFER PERFORMED. 4

IF A FIVE FOLLOWS THIS LINE, FORWARD TRANSFER PERFORMED.

IF A SIX FOLLOWS THIS LINE, $\begin{gathered}6 \\ 6\end{gathered}$

IF A SEVEN FULLOWS THIS LINE, BACKWARD TRANSFER PERFORMED.

IF AN EIGHT FOLLOWS THIS LINE, FORWARD TRANSFER PERFORMED. IF A MESSAGE ON OUTPUT SHOULD FOLLOW THIS PARAGRAPH,

THEN FORWARD TRANSFER PERFORMED.

THE ABOVE PRINTOUT SHOULD BE IN THE ORDER $1,2, \ldots, 8$.

END TEST.

SECTION 9.4: GOTO-STATEMENT, TRANSFER TO A GOTO.

BEGIN TEST .

IF NO ERROR MESSAGES, TEST PASSED.

END TEST. 
The objective of this test is to verify that the execution of a GOTO-statement, which refers to a non-existent line, will cause program execution to be suspended by the system. As specified in section 10.4 of BSR $\times 3.60$ all line-numbers in control statemerits must refer to 1 ines in the program. In order to continue, this program will require some user-oriented restart procedure but this would be implementation dependent. The structure of this test is specifically constructed with a GOTO-transfer to a non-existent line number in order to determine whether the system implementation detects and processes this error. There should be some form of implementation defined diagnostic printed upon execution attempt of this program.

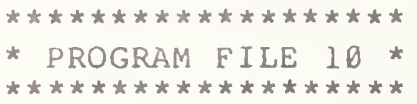

10 PRINT "PROGRAM FILE 10"

60 PRINT

70 PRINT

80 PRINT

90 PRINT "

100 PRINT

110 PRINT

120 PRINT

130 PRINT

140 PRINT

150 PRINT

$16 \mathrm{~V}$ PRINT

170 PRINT

180 PRINT

190 PRINT

200 PRINT

210 PRINT"

220 FRINT

230 GOTO 89

240 PRINT "SYSTEM EAILED TEST."

250 PRINT

260 PRINT "

270 PRINT

\author{
SECTION 10.0: FATAL ERROR CHECK ON GOTO-STATEMENT."
}

280 END

BEGIN TEST."

END TEST." 
This program requires a diagnostic. Since these are implementation dependent no universal diagnostic statement can be illustrated. However the following message illustrates the problem in the program and is given here only as an example:

? UNDEFINED LINE NUMBER 89 IN LINE 230 


\section{0 THE IF-THEN STATEMENT USED TO COMPARE POSITIVE NUMERICAL CONSTANTS}

This test not only performs standard conforming executions of the IF-THEN statement, but also tests the relation operations. The IF-THEN statement allows interruption of the normal sequence of execution of statements. It causes execution to continue at a specified line, rather than at the one with the next higher line number. The syntax of the IF-THEN statement has the general form: IF expl rel exp2 THEN line-number. Expl and exp2 are numeric expressions or string expressions. Rel is any of the following relational operators: $\langle,\langle=,=,\langle\rangle\rangle=$,, or $>$. Equaljty in this test means strict equality rather than "approximate equality." Each test of the relation between expl and exp2 is designed to test both the true and false case of the IF- THEN statement. This is done by: (1) testing the IF-THEN statement against known true cases, and (2) against known false cases. Since there is no collating sequence specified by the standard, string comparisons are made only for $=$ and \langle\rangle .

All output for the IF-THEN test is formatted as a truth table. There are three headings for the output of each test. The first heading, "Assigned Values", labels the column of numbers that are being assigned to variables for comparison. The second heading, "Comparison of", labels the column of illustrative comparisons used in the IF-THEN statements. The third heading, "Truth Table", labels the symbols $=,\langle\rangle,\langle\rangle,\rangle=$, and $\langle=$ used in the IF-THEN comparisons. Each of these symbols forms a column of comparative results in the truth table by the system's evaluations of the If-THEN comparisons. The entries in the truth table are ejther $T, F$, or $X$, where $x$ means that a comparison failed to yield the proper truth result. The truth table output is used in the next several tests. The user should refer to section lo of BSR X3.60-**** for the proper specifications.

\section{I GO TO Transfer to an IF-THEN}

The objective of this test is to extend the capability of the Goro-statement. In fact the test requires the processor to perform a transfer to an IF-THEN statement by a GOTO-statement. Only a fail message can be printed. No other output will be generated if the transfer is performed.

\subsection{IF-THEN Comparison of a Posjtive Numerjcal Constant} with a Positive Numerical Constant

The objectives of the next two tests are simply to compare the values of positive numbers.

\subsubsection{Equal Case}

This test shows that the comparison of a positive numerjcal value with itself will be properly assigned a truth value by the IF- THEN statement for each of the relation symbols $=,\langle\rangle,\langle\rangle,\rangle=$, and $\langle=$. This test prints three possible outputs in the truth table. An "F" or a "T" indicates that the IF-THEN statement has made a correct evaluation where appropriate and performed the proper transfer. An " $x$ " indicates that an incorrect evaluation 
has been made and program flow continued at the next higher line number. For this test the program supplies the truth values in the first row of the truth table in the sample output for PROGRAM FILE 11.

\subsubsection{Unequal Case}

The objective of this test is to show that the comparison of a positive numerical value with another positive value, not of equal magnitude, will be properly made by the IF-THEN statement for each of the relation symbols: =, $\langle\rangle,,\langle>\rangle=$,, and $\langle=$. This test supplies the information needed in the second row of the table in the sample output.

11.3 If-THEN Comparison of a Positive Number with a Negative Number

The objective of this test is to show that the comparison of a positive numerical value with a negative value, of the same absolute value, will be properly made by the IF-THEN statement for each of the relation symbols $=$, $<$, \rangle,$\langle>\rangle=$,, and $\langle=$. The output for this test is in the third row of the truth table in the sample output.

11. 4 IF-THEN Comparison of a Negative Number with a Positive Number

The objective of this test is to show that the comparison of a negative numerical value with a positive value, not of the same absolute value, will be properly made by the IF-THEN statement for each of the relation symbols =, $\langle\rangle,\langle\rangle,\rangle=$, and $\langle=$. This test prints output in the fourth row of the truth table.

11.5 IF-THEN Comparison of a Positive Number with Zero

The objective of this test is to show that the comparison of a positive numerical value with zero will be properly made by each of the relation symbols $=,\langle\rangle,\langle\rangle,\rangle=$, and $\langle=$. This test prints its results in the fifth row of the truth table.

11.6 IF-THEN Comparison of Zero with a Positive Number

The objective of this test is to show that the comparison of zero when compared with a positive value will be properly made for each of the relation symbols $=,\langle\rangle,\langle\rangle,\rangle=$, and $\langle=$. The test output lies in the sixth row of the truth table.

\subsection{IF-THEN Comparison of Zero with Zero}

The objective of this test is to show that the comparison of zero itself with zero will be properly made by the IF-THEN statement for each of the relation symbols $=,\langle\rangle,\langle\rangle,\rangle=$, and $\langle=$. The test output lies in the seventh row of the truth table. 
10 PRINT "PROGRAM FILE 11 "

60 PRINT

70 PRINT

80 PRINT

90 PRINT"

100 PRINT

110 LET $A \$="="$

120 LET $B \$=^{m}<"$

130 LET $C \$=">"$

140 LET D $\$="\langle>n$

150 LET ES $=">="$

160 LET F $\$="<="$

170 LET $A=1$

180 LET $B=2$

190 LET $\mathrm{C}=3$

200 LET $L=-1$

210 LET $x=-2$

220 LET $Y=3$

230 LET $\mathrm{Z}=0$

240 PRINT "ASSIGNED";TAB (20); "COMPARISON OF" ; TAB (54); "TRUTH TABLE"

250 PRINT "VALUES ";TAB (44);A\$;TAB (49);B\$;TAB (54);C\$;TAB (59);D\$;

260 PRINT TAB (65);E\$;TAB(70);E\$

270 PRINT

280 REM

290 REM

300 REM

310 REM

320 REM

3.30 REM

340 GOTO 420

350 PRINT"

360 PRIN'T"

370 PRINT "CONTINUED TEST OF IF-THEN, MAY HAVE INVALID ERROR MESSAGES."

380 REM

390 REM

400 REM

410 REM

420 IF $4=4$ THEN 510

430 LET $A S=" X "$

440 GOTO 520

450 LET B $\$=" X "$

460 GOTO 580

470 LET C $\$=" X "$

480 GOTO 600

490 LET D\$ = $X "$

500 GOTO 670

510 LET $A \$=" T "$

520 IF $4<=4$ THEN 630

530 LET $F \$=" X "$
BEGIN TEST."
SECTION 11.2: IF-THEN/POS. VS. POS.

SECTION 11.2.1: EQUAL CASE. 


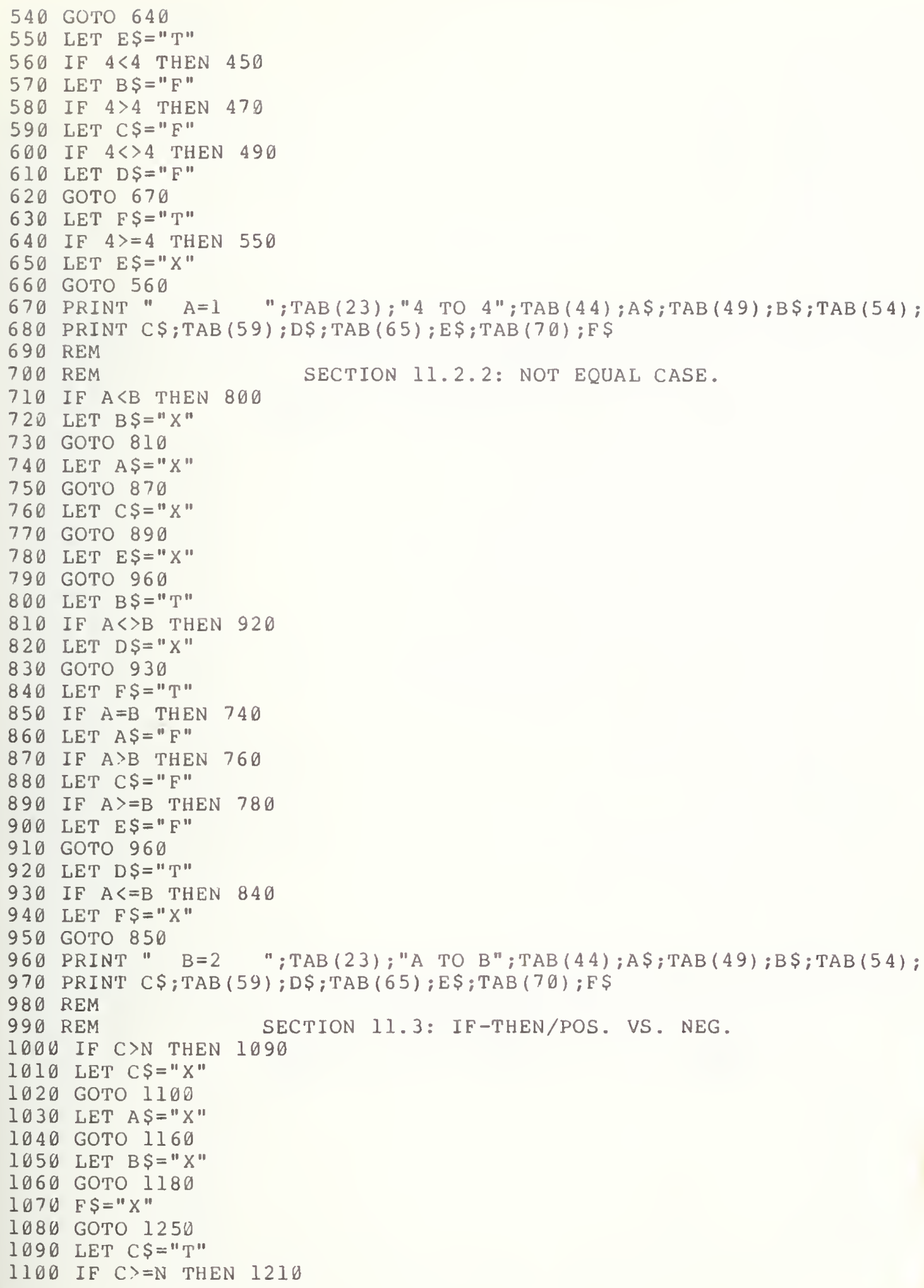




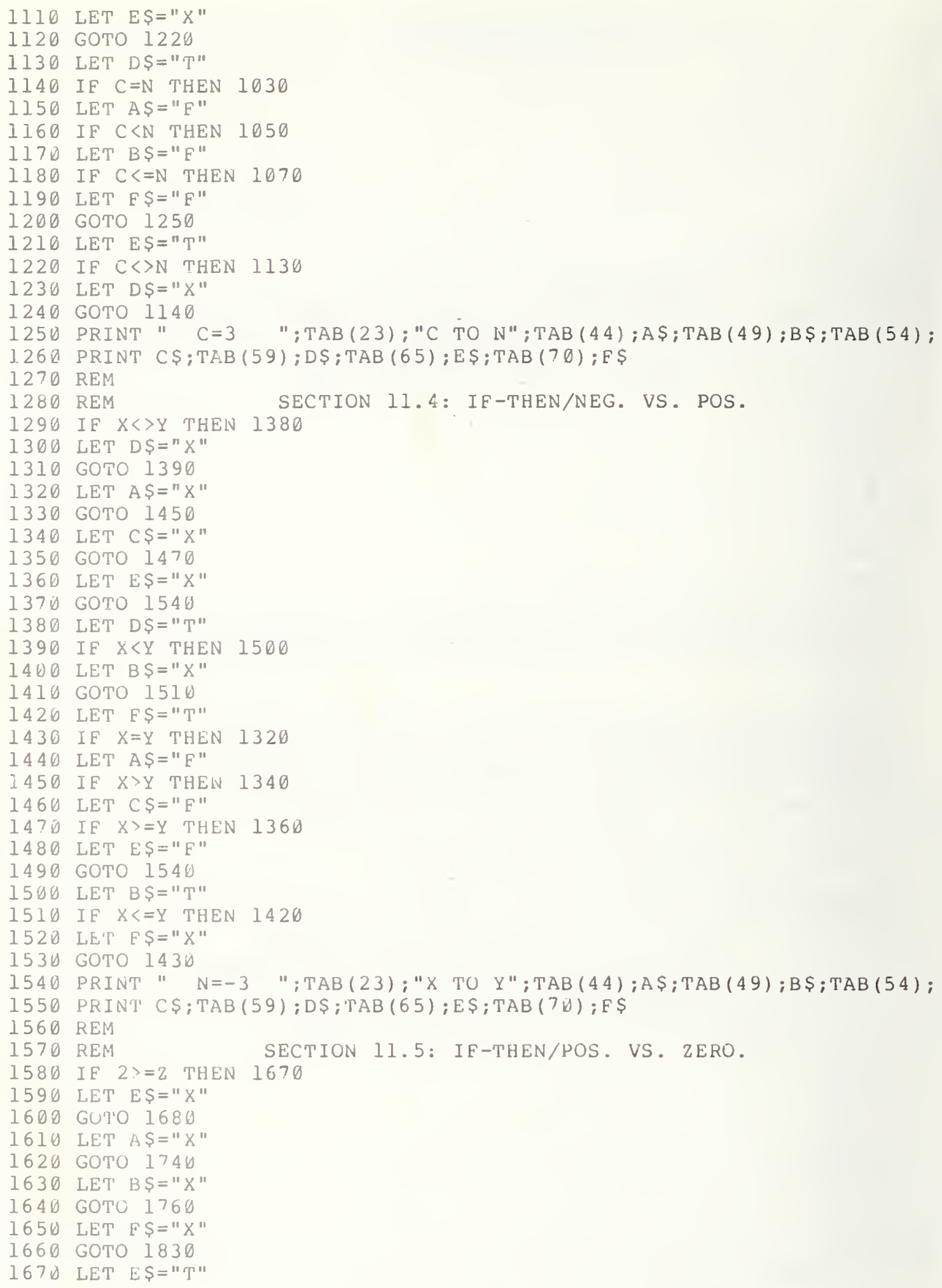


1680 IF 2>Z THEN 1790

1690 LET $C \$=" X "$

1700 GOTO 1800

1710 LET $D \$=" T "$

1720 IF $2=2$ THEN 1610

1730 LET AS="E"

1740 IF $2<2$ THEN 1630

1750 LET $B \$=" F "$

1766 IF $2<=2$ THEN 1650

1770 LET $F \$=" F "$

1780 GOTO 1830

1790 LET $C \$=" T "$

1800 IF $2<>Z$ THEN 1710

1810 LET $D S=" X "$

1820 GOTO 1720

1830 PRINT" $\quad X=-2 \quad$ "TAB (23);"2 TO $2 " ; T A B(44) ; A \$ ; T A B(49) ; B \$ ; T A B(54)$;

1840 PRINT C\$;TAB (59);D\$;TAB (65);E\$;TAB (70);E\$

1850 REM

1860 REM SECTION 11.6: IF-THEN/ZERO VS. POS.

1870 IF $0<=A$ THEN 1960

1880 LET $F \$=" X "$

1890 GOTO 1970

1900 LET AS="X"

1910 GOTO 2030

1920 LET $C \$=" X "$

1930 GOTO 2050

1940 LET E\$=" $X "$

1950 GOTO 2120

1960 LET $F \$=" T "$

1970 IF $\emptyset<A$ THEN 2080

1980 LET $B S=" X "$

1990 GOTO 2090

$20 \square 0$ LET $D S=" T "$

2010 IF $\emptyset=A$ THEN 1900

2020 LET $A \$=" F "$

2030 IF $0>A$ THEN 1920

2040 LET $C \$=" F "$

2050 IF $\theta>=A$ THEN 1940

2060 LET $E S=" F "$

2070 GOTO 2120

2080 LET BS="T"

2090 IF $\theta<>A$ THEN 2000

2100 LET $D S=" X "$

2110 GOTO 2010

2120 PRINT " Y=3 ";TAB (23);"D TO A";TAB (44);A\$;TAB (49);B\$;TAB (54);

2130 PRINT C\$;TAB(59);D\$;TAB (65);E\$;TAB (70);F\$

2140 REM

2150 REM

2160 IF $2=0$ THEN 2250

2170 LET AS="X"

2180 GOTO 2260

2190 LET B\$="X"

2200 GOTO 2320

2210 LET $C \$=" X "$

2220 GOTO 2340

2230 LET D $\$=" X "$

2240 GOTO 2410 


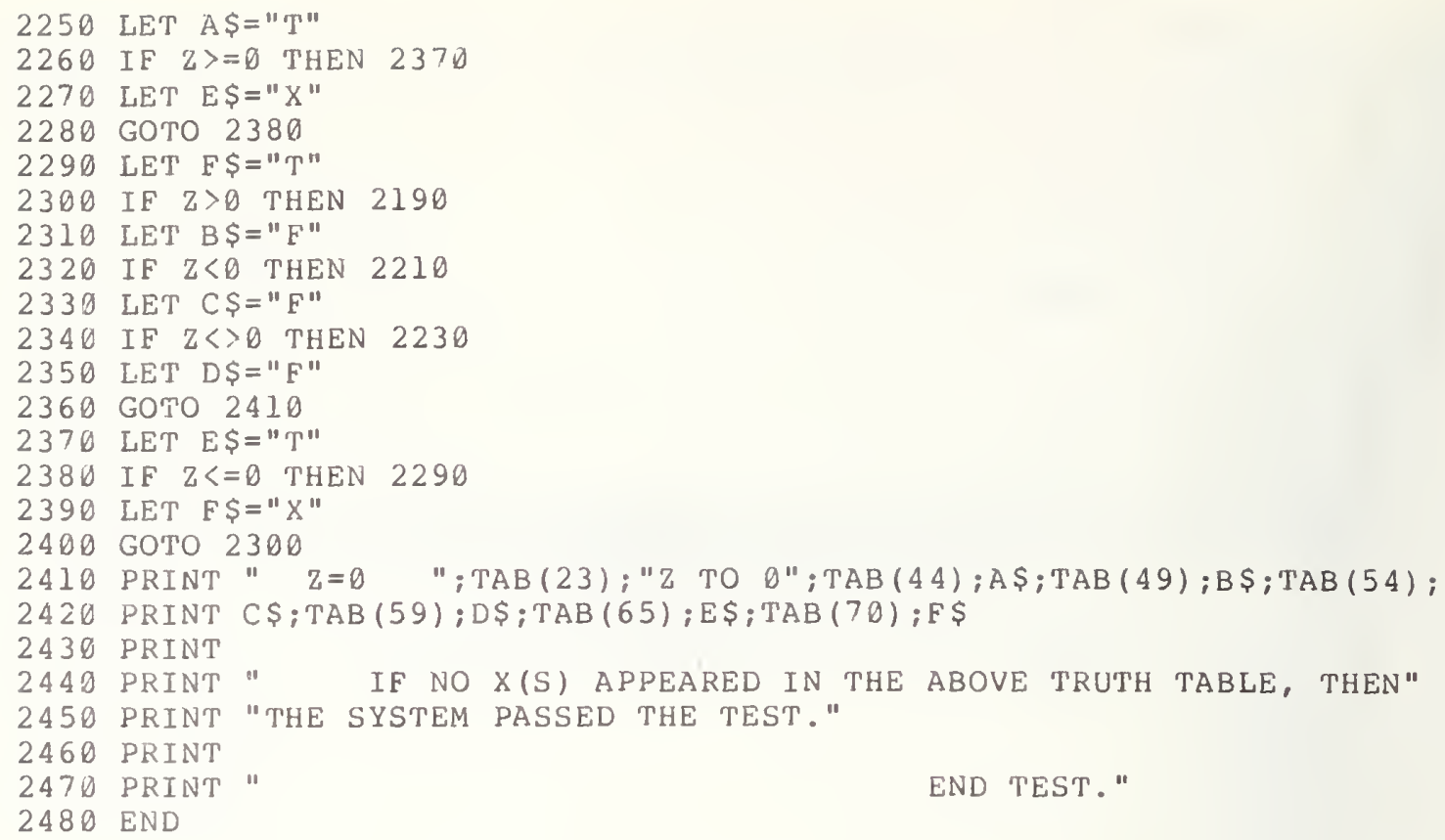

PROGRAM FILE 11

BEGIN TEST.

\begin{tabular}{|c|c|c|c|c|c|c|c|}
\hline ASS IGNED & COMPARISON OF & & & & $\mathrm{T}$ & & \\
\hline VALUES & & $=$ & $<$ & $y$ & $\langle>$ & $>=$ & $<=$ \\
\hline$A=1$ & 4 Tо 4 & $T$ & F & F & F & $\mathrm{T}$ & $T$ \\
\hline$B=2$ & A TO B & F & $\mathrm{T}$ & F & $T$ & $\mathrm{~F}$ & $\mathrm{~T}$ \\
\hline$C=3$ & C TO $\mathrm{N}$ & F & $\mathbf{F}$ & $\mathrm{T}$ & $\mathrm{T}$ & $\mathrm{T}$ & F \\
\hline$N=-3$ & $X$ TO Y & F & $\mathrm{T}$ & F & $\mathrm{T}$ & $\mathrm{F}$ & $\mathrm{T}$ \\
\hline$x=-2$ & 2 TO Z & F & $\mathrm{F}$ & $\mathrm{T}$ & $\mathrm{T}$ & $\mathrm{T}$ & $\mathrm{F}$ \\
\hline$Y=3$ & D TO A & $\mathrm{F}$ & $T$ & $\mathrm{~F}$ & $T$ & F & $\mathrm{T}$ \\
\hline$Z=0$ & 2 TO 0 & $\mathrm{~T}$ & $\mathrm{~F}$ & F & F & $\mathrm{T}$ & $T$ \\
\hline
\end{tabular}

IE NO $X(S)$ APPEARED IN THE ABOVE TRUTH TABLE, THEN THE SYSTEM PASSED THE TEST. 
END TEST. 


\subsection{THE IF-THEN STATEMENT USED TO COMPARE NEGATIVE} NUMERICAL CONSTANTS

\subsection{If-THEN Comparison of a Negative Number with a Negative Number}

The objective of this subsection is to compare two negative numerical values by the IF-THEN statement (see section 10 of BSR X3.60).

$$
\text { 12.1.1 Equal Case }
$$

The objective of this test is to show that the proper comparison of a negative numerical value with itself will be made by the IF-THEN statement for each of the relation symbols $=,\langle\rangle,\langle\rangle,\rangle=$, and $\langle=$. The test output is in the first row of the truth table in the sample output for PROGRAM FILE 12 .

\subsubsection{Unequal Case}

The objective of this test is to show that the proper comparison of a negative numerical value with another negative value, not of the same magnitude, will be made by the IF-THEN statement for each of the relation symbols $=,\langle\rangle,\langle\rangle,\rangle=$, and $\langle=$. The test output is in the second row of the truth table.

\subsection{IF-THEN Comparison of Zero with a Negative Number}

The objective of this test is to show that the proper comparison of zero with a negative value will be made by the IF-THEN statement for each of the relation symbols $=,\langle\rangle,,\langle>\rangle=$,, and $\langle=$. The test output is in the third row of the truth table.

\subsection{IF-THEN Comparison of a Negative Number with Zero}

The objective of this test is to show that the proper comparison of a negative numerical value with zero will be made by the IF-THEN statement for each of the relation symbols $=,\langle\rangle,,\langle>\rangle=$,, and $<=$. The test output is in the fourth row of the truth table.

\subsection{IF-THEN Comparison of Positive with the Negation of a Negative, Using Parentheses}

'The objective of this test is to show that the proper comparison of a positive numerical value with a numerical value that is enclosed in parentheses will be made. The constant enclosed in the parentheses represents the negative of a negative numerical value of equal magnitude to the original positive value. The comparison will be made by the IF-THEN statement for each of the relation symbols $=,\langle\rangle,,\langle>\rangle=$,, and $\langle=$. The test output is in the fifth row of the truth table.

\subsection{IF-THEN Comparison of Negative with a}


The objective of this test is to show that a proper comparison of a negative numerical value with a numerical value enclosed in parentheses will be made. The value in parentheses represents the negative of a positive numerical value of equal magnitude to the original negative value. The comparison will be made by an IF-THEN statement for each of the relation symbols $=,\langle\rangle,\langle\rangle,\rangle=$, and $\langle=$. The test output is in the sixth row in the truth table.

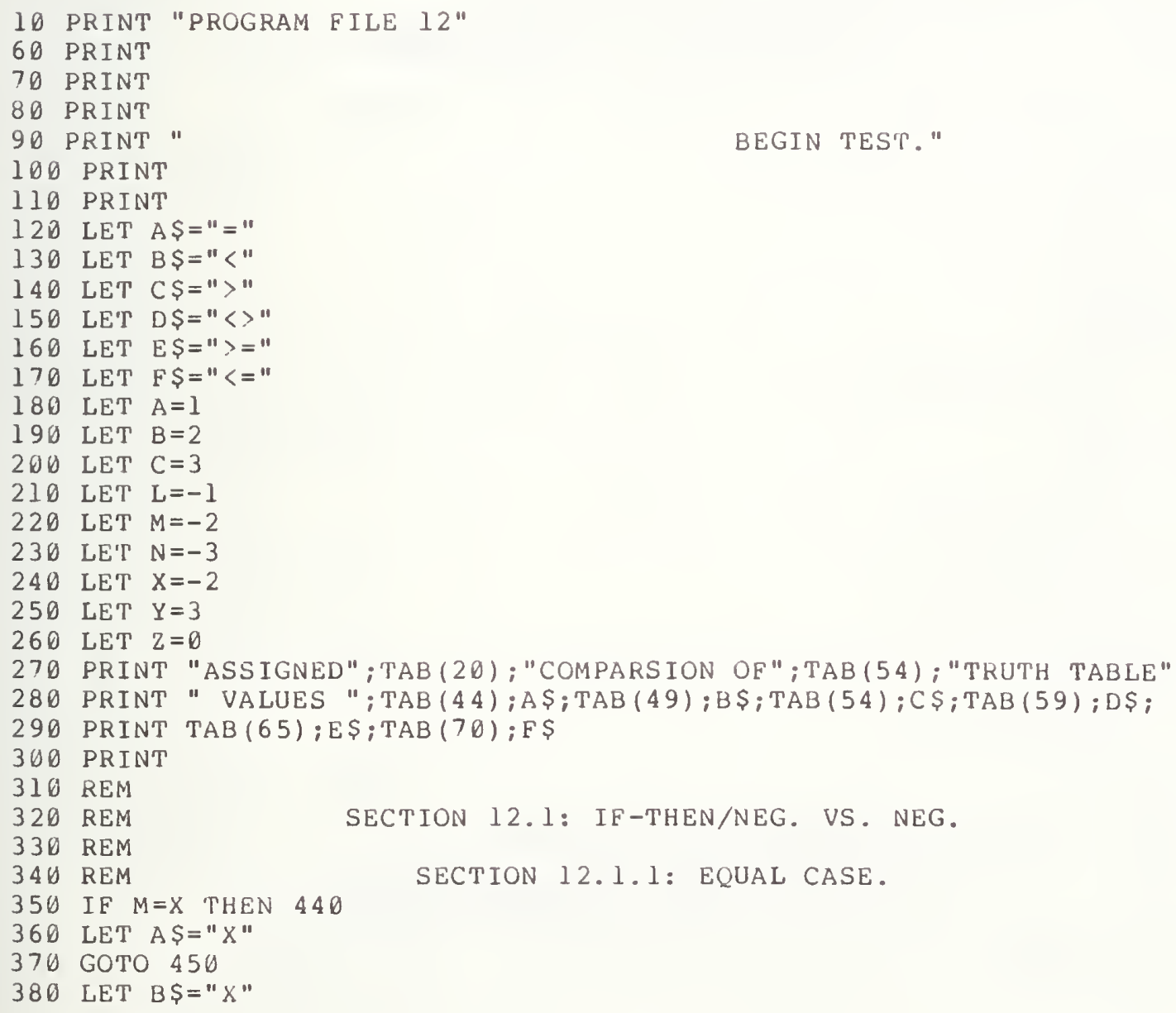




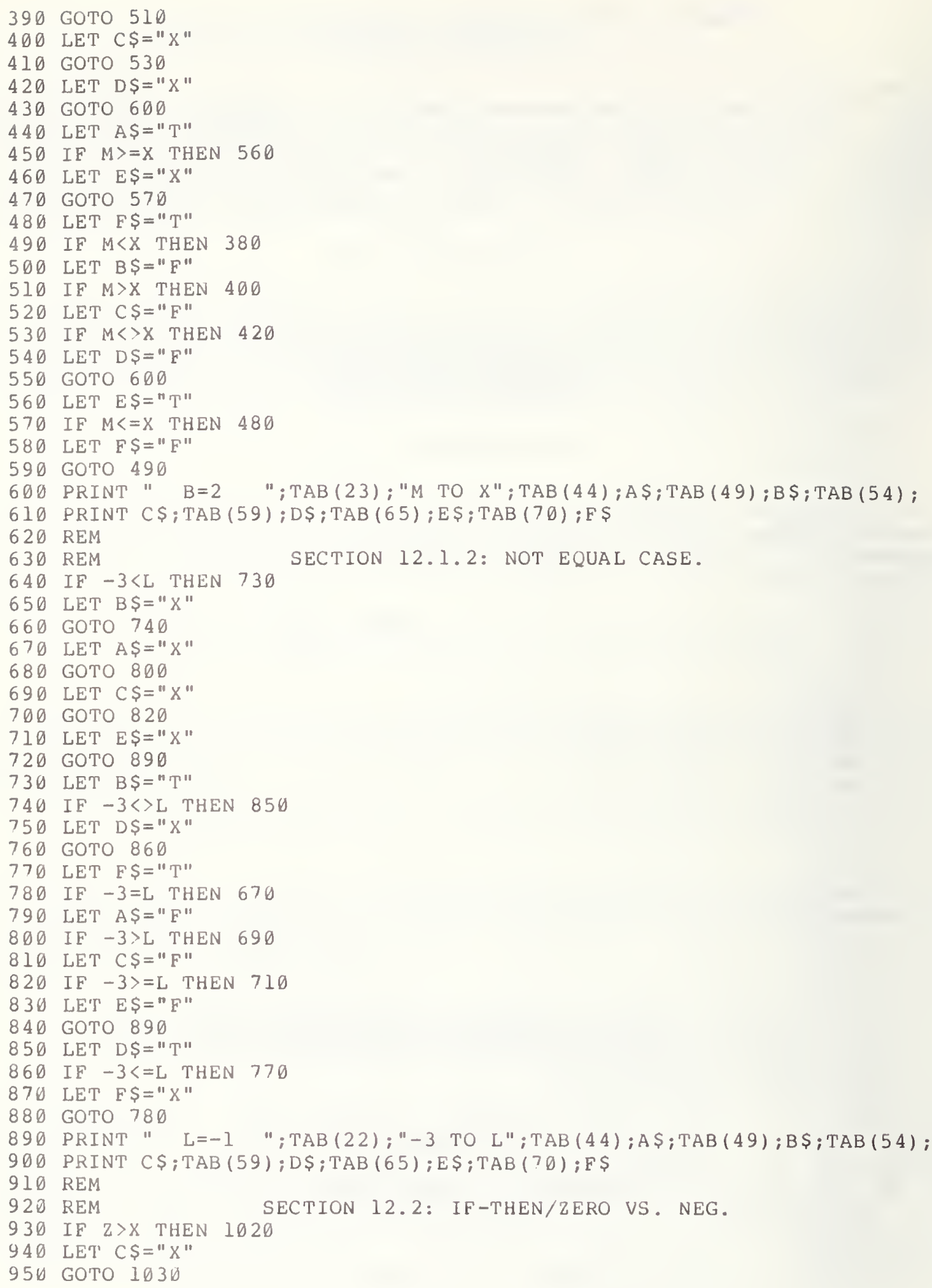




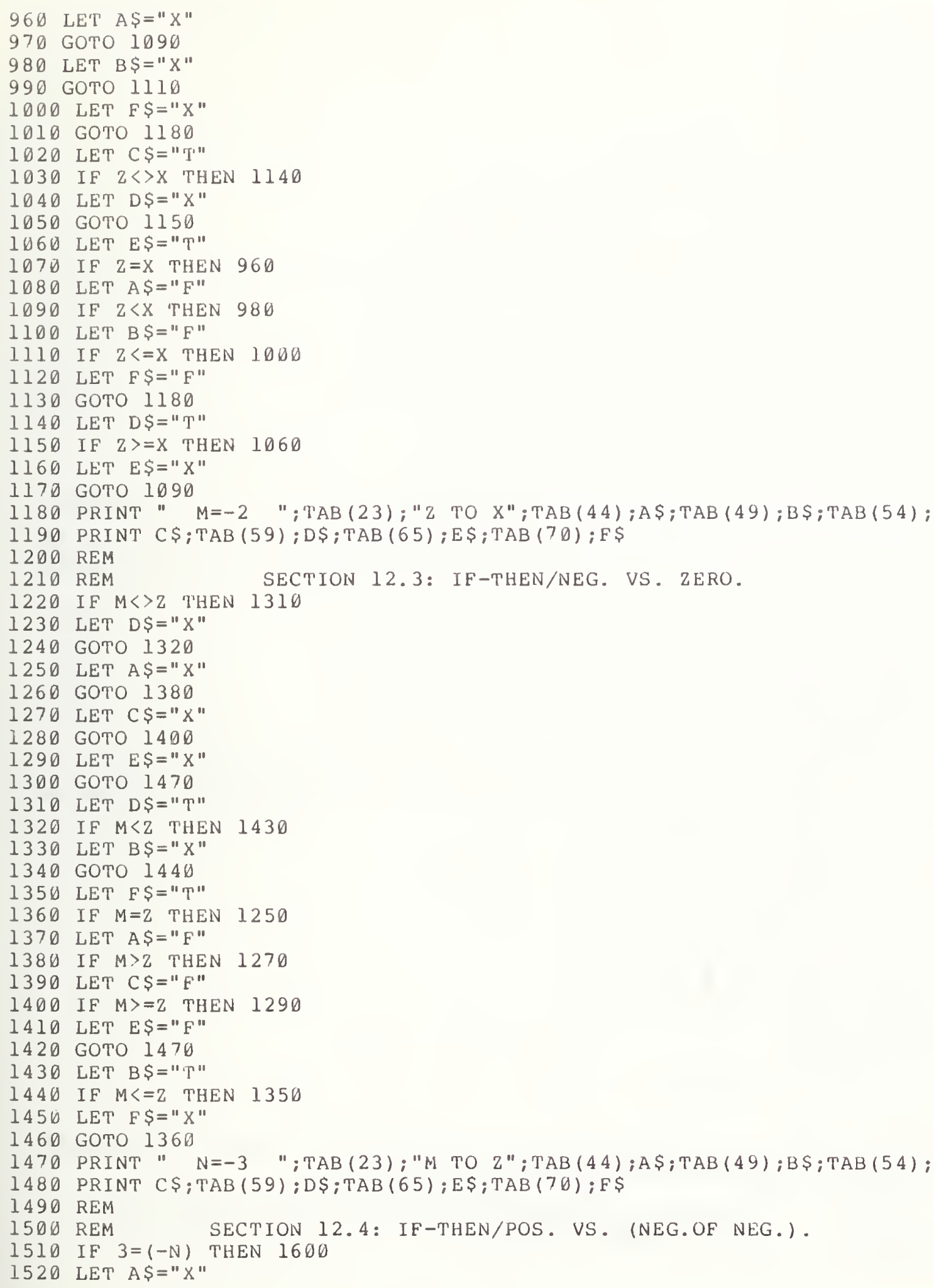




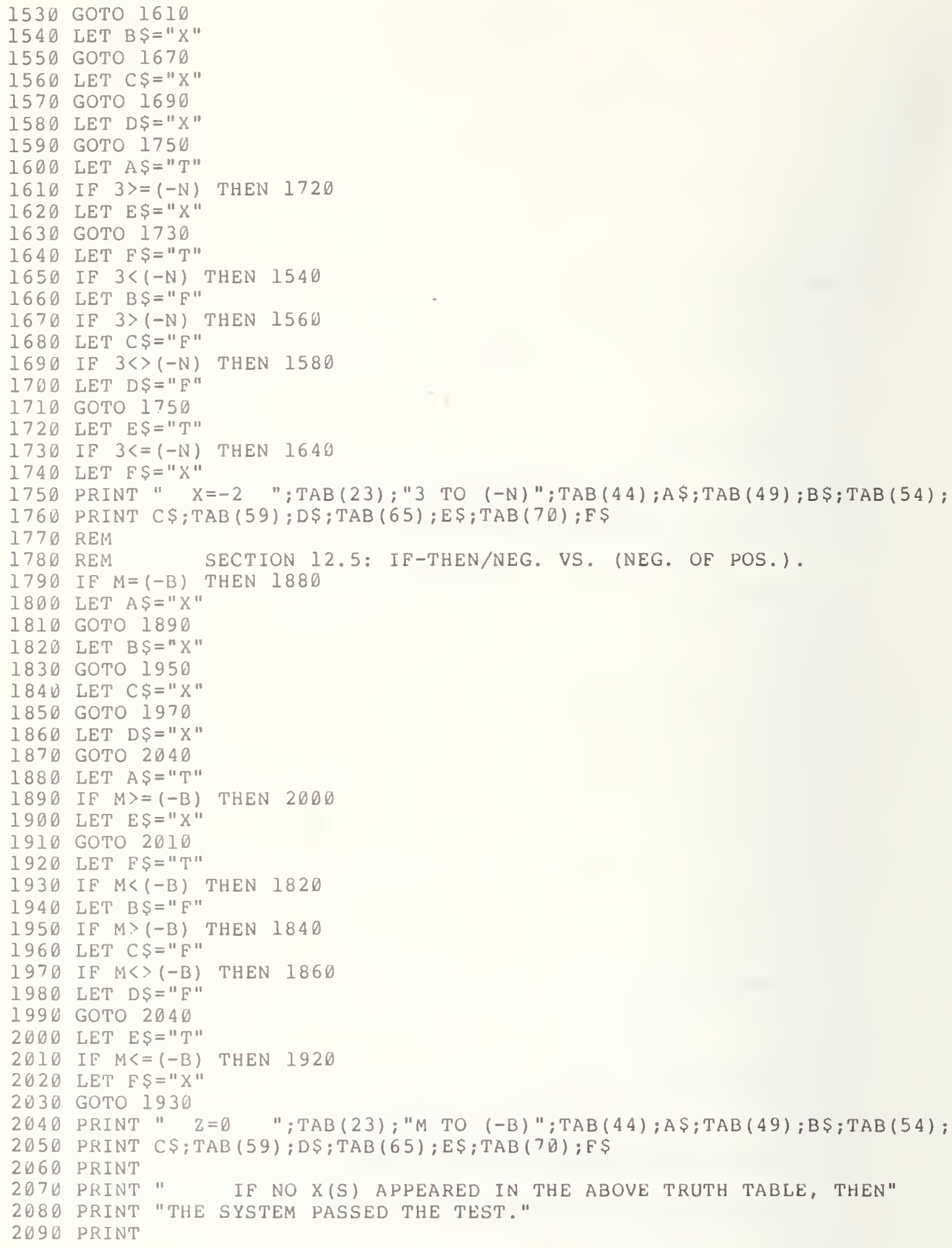


2100 PRINT

2110 PRINT"

2120 PRINT

2130 END
END TEST."

$\star$ SAMPLE OU'TPUT $\star$

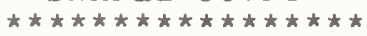

PROGRAM FILE 12

BEGIN TEST.

\begin{tabular}{|c|c|c|c|c|c|c|c|}
\hline ASSIGNED & \multirow[t]{2}{*}{ COMPARSION OF } & \multicolumn{6}{|c|}{ TRUTH TABLE } \\
\hline VALUES & & $=$ & $<$ & $>$ & $\langle>$ & $>=$ & $<=$ \\
\hline$B=2$ & $M$ TO X & $\mathrm{T}$ & $\mathrm{F}$ & $\mathrm{F}$ & $\mathrm{F}$ & $T$ & $\mathrm{~T}$ \\
\hline$L=-1$ & -3 TO L & $\mathrm{F}$ & $\mathrm{T}$ & $\mathrm{F}$ & $\mathrm{T}$ & F & $T$ \\
\hline$M=-2$ & z To X & $\mathrm{F}$ & $\mathrm{F}$ & $\mathrm{T}$ & $T$ & $T$ & $\mathrm{~F}$ \\
\hline$N=-3$ & M TO Z & E & $\mathrm{T}$ & F & $\mathrm{T}$ & $\mathrm{F}$ & $\mathrm{T}$ \\
\hline$x=-2$ & 3 TO $(-N)$ & $\mathrm{T}$ & F & $\mathrm{F}$ & $\mathrm{F}$ & $T$ & $T$ \\
\hline $\mathrm{Z}=0$ & M TO $(-B)$ & $T$ & $\mathrm{~F}$ & $\mathrm{~F}$ & $\mathrm{~F}$ & $\mathrm{~T}$ & T \\
\hline
\end{tabular}

IF NO $X(S)$ APPEARED IN THE ABOVE TRUTH TABLE, THEN

THE SYSTEM PASSED THE TEST.

END TEST. 


\subsection{IF-THEN COMPARISON OF NEGATIVE CONSTANTS (CONT) AND VARIABLES AVOIDING PARENTHESES}

This section continues a case-by-case analysis of the IF-THEN control statement that began in section 1l. The emphasis in this section will be on comparing assigned numeric variables. The user is referred to section 6 and 10 in BSR $\times 3.60$.

\section{I IF-THEN Comparison of an Assigned Negative with a Negative Constant, Without Parentheses}

The objective of this test is to show that the proper comparison of a negative numerical value assigned to a simple variable against another negative value not assigned to a simple variable or enclosed in parentheses will be made by the IF-THEN statement for each of the relation symbols $=$, $<$, $>,\langle\rangle,\rangle=$, and $\langle=$. The test output falls in the first row of the truth table output for PROGRAM FILE 13.

\subsection{IF-THEN Comparison of a Negative Variable with a Negative Constant, wi thout Parentheses}

The objective of this test is to show that the proper comparison of the negative of a variable, assigned a positive numerical value, with a negative value not assigned to a simple variable or enclosed in parentheses, will be made by the IF-THEN statement for each of the relation symbols $=,\langle\rangle,\langle\rangle$, , $>=$, and $<=$. The test output falls in the second row of the truth table.

\subsection{IF-THEN Comparison of Positive Variable with Negative Variable, without Parentheses}

The objective of this test is to show that the proper comparison of a variable, assigned a positive value, with the negative of a variable assigned a value of the same magnitude as the positjve value, will be made by the IE-THEN statement for each of the relation symbols $=,\langle\rangle,\langle\rangle,\rangle=$, and $\langle=$. The test output falls in the third row of the truth table.

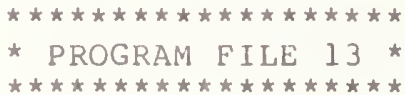

1 PRINT "PROGRAM FILE I3"

20 PRINT

3i) PRINT 


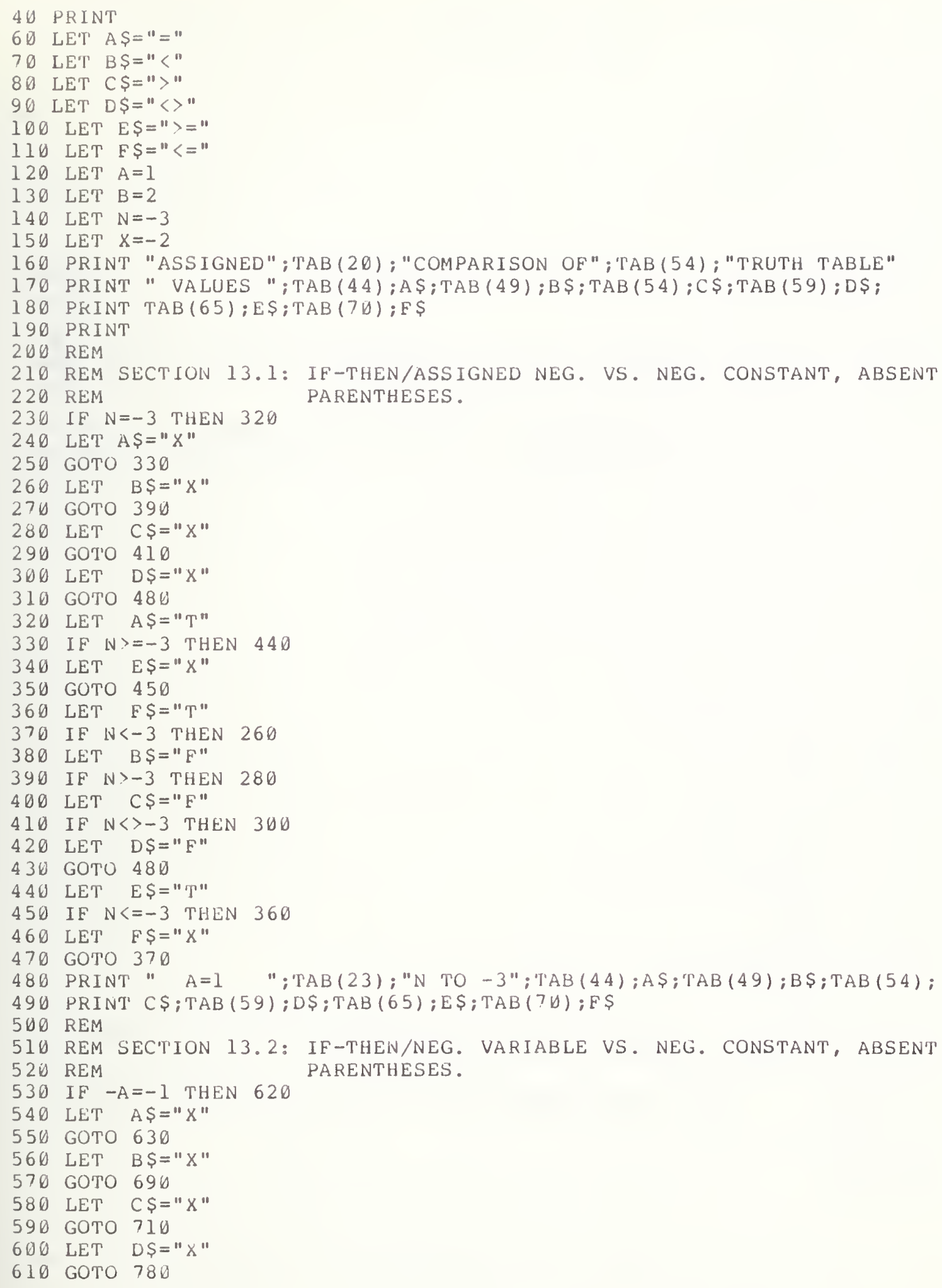




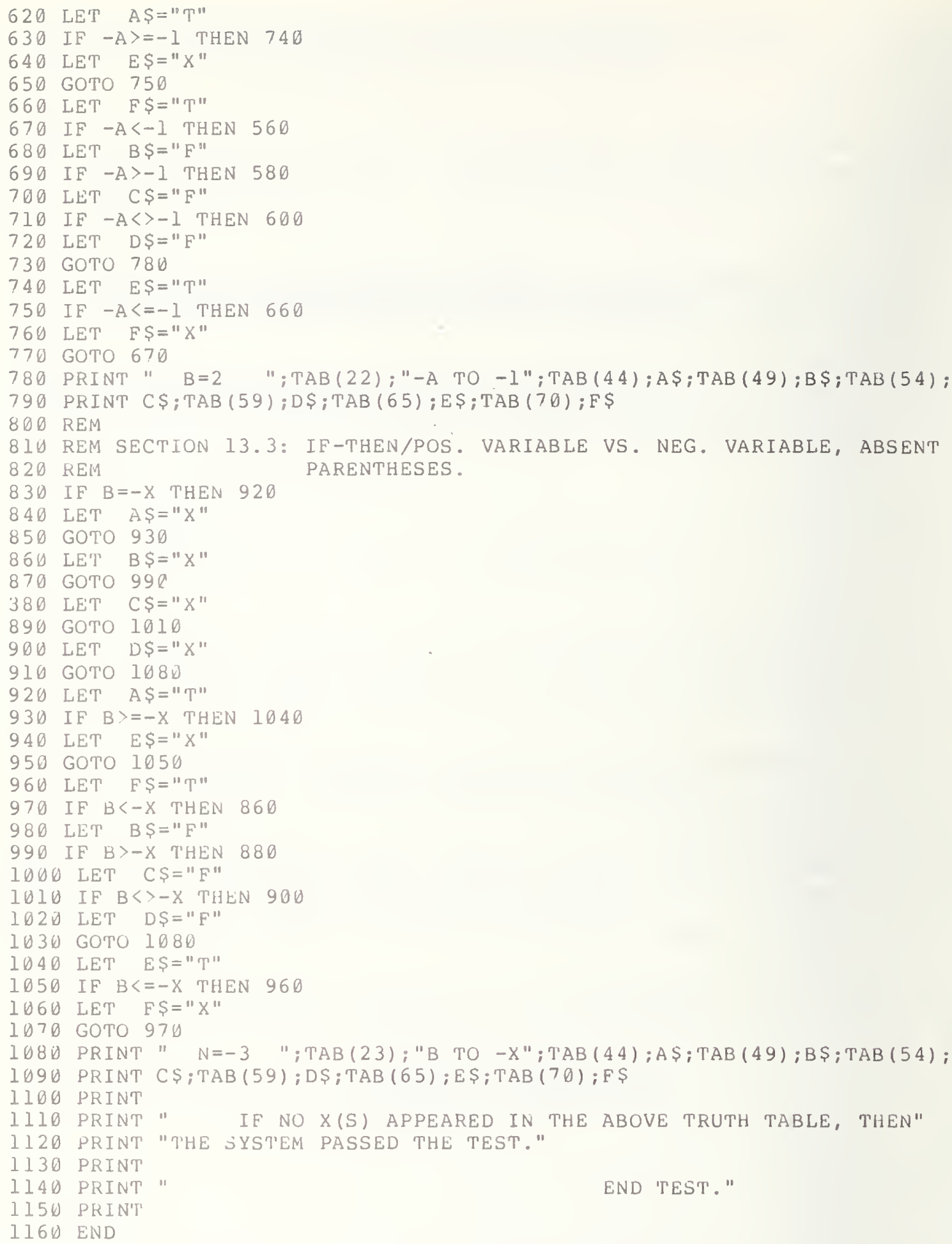




\begin{tabular}{|c|c|c|c|c|c|c|c|}
\hline ASSIGNED & COMPARISON OF & \multicolumn{6}{|c|}{ TRUTH TABLE } \\
\hline VALUES & & $=$ & $<$ & $>$ & $\langle>$ & $>=$ & $<=$ \\
\hline$A=1$ & $\mathrm{~N}$ TO -3 & $\mathrm{~T}$ & F & $\mathrm{F}$ & $\mathrm{F}$ & $\mathrm{T}$ & $\mathrm{T}$ \\
\hline$B=2$ & -A TO & $\mathrm{T}$ & $\mathbf{F}$ & $\mathbf{F}$ & $\mathrm{F}$ & $\mathrm{T}$ & $\mathrm{T}$ \\
\hline$N=-3$ & B TO $-x$ & $\mathrm{~T}$ & F & F & $\mathrm{F}$ & $\mathrm{T}$ & $\mathrm{T}$ \\
\hline
\end{tabular}

IF NO $X(S)$ APPEARED IN THE ABOVE TRUTH TABLE, THEN THE SYSTEM PASSED THE TEST.

END TEST. 


\subsection{COMPARING QUOTED STRINGS AND STRING VARIABLES}

The program for this test prints four columns. The first column prints the names of certain string variables used in the program. The second column lists the strings assigned to these variables, within the program, to the string variables in the first column. The third column lists the comparisons made and whether they are between string constants or assigned string variables. The last column prints the truth table for this test program. The user need only look for X's printed in the table. If there are none the system has passed the test.

The standard states that string comparisons can only be made for equality $(=)$ and inequality $(\langle>)$ (see section 10.2 and 10.4 of BSR $\times 3.60$ ). Tests of collating sequences are inapplicable for Minimal BASIC.

\section{1 Comparing Identical Strings}

The objective of this test is to show that a comparison of two strings having the same sequential order of characters will be made by the IF-THEN statement. This test generates the values in the first row as the column four truth table output in the sample output for this section.

\subsection{Strings of Equal Length but Different Characters}

The objective of this test is to show that a comparison of two different strings having the same number of characters will be made by the IF-THEN statement. This test outputs the values in the second row of the truth table.

\subsection{Strings of the Same Length which have the Same Characters} but not in the Same Sequential Order

The objective of this test is to show that a comparison of two strings, having the same character set, but not in the same sequential order, will be made by the IF-THEN statement. The output for this test lies in the third row of the truth table.

\section{4 Leading Spaces}

The objective of this test is to show that a proper comparison of two strings having the same non-space characters in the same sequential order, but with leading spaces for one of the strings, will be performed. The output for this test 1 ies in the fourth row of the truth table. According to the standard these strings are not equal since spaces within quoted strings are considered significant.

\subsection{Trailing Spaces}


The objective of this test is to show that a proper comparison of two strings having the same non-space characters in the same sequential order, but with trailing spaces used in one of the strings, will also be performed. The output for this test lies in the fifth row of the truth table. Again, these two quoted strings are not equal.

\subsection{Leading and Trailing Spaces}

The objective of this test is to show the effect of using both leading and trailing spaces in the comparison of two strings. The strings in this test appear the same except for the leading and trailing spaces in one of them. The result should be that the two strings are not equal since spaces in strings are significant. The output for this test lies in the sixth row of the truth table.

\subsection{A Variety of Unequal String}

The objective of this test is to further verify that the relation of equality holds between two strings if and only if the two strings have the same length and contain identical sequences of characters. This test compares various strings of different characters as well as of different lengths. The output for this test lies in the seventh through ninth rows of the truth table.

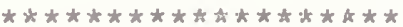

* PROGRAM FILE 14 *

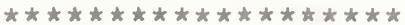

10 PRINT "PROGRAM EILE 14 "

60 PRINT

70 PRINT

80 PRINT

90 LET D $\$="="$

100 LET G\$=" $\langle>"$

110 LET A\$=" ZONE"

120 LET $B S=$ "NESTING"

130 LET CS=" IMPLEMENTATION"

140 LET L $\$=" N E S T "$

150 LET $M \$=" K E Y W O R D "$

160 LET N\$= "MARGIN"

170 LET Y\$="LINE"

180 PRINT

190 PRINT" IN THE COMPARISON COLUMN BELOW, THE UNDERLINE CHARAC-"

200 PRINT "TER IS USED TO REPRESENT THE SPACE CHARACTER."

210 PRINT

220 PRINT

230 PRINT" STRING "TAB (23); "ASSIGNED";TAB (44); "COMPARS ION"; TAB (64); 


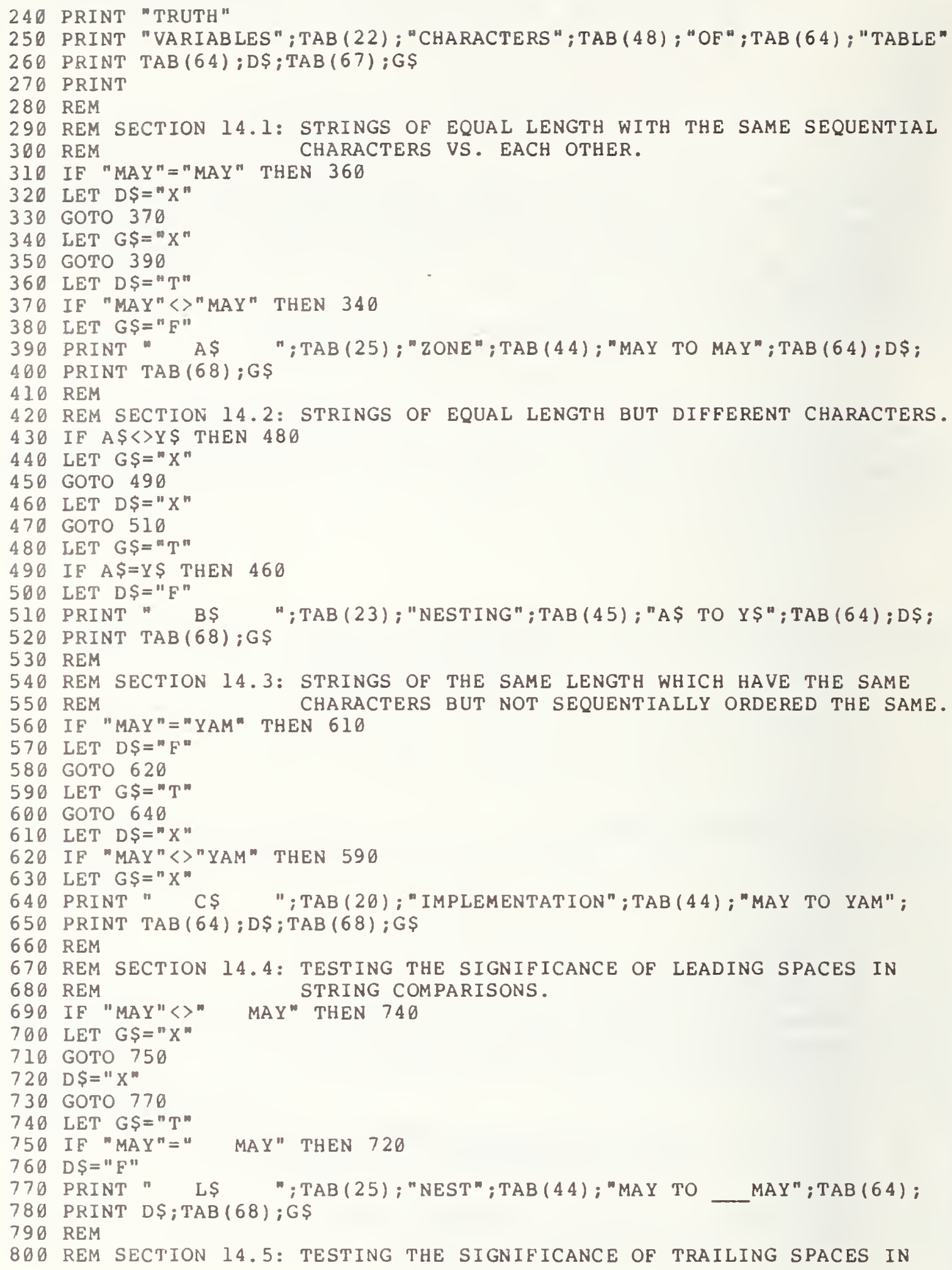


810 REM

820 IF "MAY" = "MAY

830 LET D $\$=" F "$

840 GOTO 860

850 LET $D \$=" X "$

860 IF "MAY"<>"MAY " THEN 890

870 LET G\$ $=" \mathrm{X} "$

880 GOTO 900

890 LET G\$="T"

900 PRINT " MS

910 PRINT TAB $(64) ; D \$$; TAB $(68) ; G \$$

920 REM

930 REM SECTION 14.6: TESTING LEADING AND TRAILING SPACES TOGETHER IN 940 REM

950 IF "MAY" $<>"$ MAY

960 LET GS=" $X "$

970 GOTO 1010

980 LET $D \$=" X "$

990 GOTO 1030

1000 LET G\$="T"

1010 IF "MAY"="

1020 LET $D \$=" F "$

1030 PRINT " N

1040 PRINT TAB (64);D\$;TAB (68);G\$

1050 REM

1060 REM SECTION 14.7: TESTING A VARIETY OF UNEQUAL STRINGS OF LENGTH

1070 REM

1080 IF $C \$=B \$$ THEN 1210

1090 LET $D \$=" F "$

1100 GOTO 1220

1110 LET $G \$=" T "$

1120 IF $C \$<>N \$$ THEN 1250

1130 LET $E \$=" X "$

1140 GOTO 1260

1150 LET $F \$=" X "$

1160 GOTO 1280

1170 LET HS="T"

1180 IF "KEY"=M\$ THEN 1310

1190 LET I $\$=" \mathrm{~F} "$

1200 GOTO 1320

1210 LET $D S=" X "$

1220 IF L\$ $<>B S$ THEN 1110

1230 LET G\$=" $\mathrm{X}$ "

1240 GOTO 1120

1250 LET E\$= "T"

1260 ]: $C \$=N \$$ THEN 1150

1270 LET $F \$=" F "$

1280 IF "KEY" $>M \$$ THEN 1170

1290 LET $H \$=" X "$

1300 GOTO 1180

1310 LET I $\$=" X "$

1320 PRINT " Y\$ "; TAB (25); "LINE";TAB (45); "LS TO B\$"; TAB (64);D\$;

1330 PRINT TAB (68);G\$

1340 PRINT TAB (45);"C\$ TO N\$";TAB (64);D\$;TAB (68);G\$

1350 PRINT TAB (44);"KEY TO MS";TAB (64);D\$;TAB (68);GS

1360 PRINT

1370 PRINT "

IF NO $X(S)$ APPEARED IN THE ABOVE TRUTH TABLE, THEN" 
1380 PRINT "THE SYSTEM PASSED THE TEST."

1390 PRINT

1400 PRINT *

END TEST."

1410 PRINT

1420 END

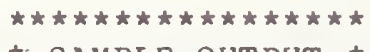

* SAMPLE OUTPUT *

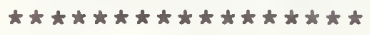

PROGRAM FILE 14

IN THE COMPARISON COLUMN BELOW, THE UNDERLINE CHARACTER IS USE TO REPRESENT THE SPACE CHARACTER.

STRING
VARIABLES

$\begin{array}{cc}\text { A\$ } & \text { 2ONE } \\ \text { B\$ } & \text { NESTING } \\ \text { C\$ } & \text { IMPLEMENTATION } \\ \text { L\$ } & \text { NEST } \\ \text { M\$ } & \text { KEYWORD } \\ \text { N\$ } & \text { MARGIN } \\ \text { Y\$ } & \text { LINE }\end{array}$

$\begin{array}{cc}\text { COM PARSION } & \text { TRUTH } \\ \text { OF } & \text { TABLE } \\ & =\langle\rangle\end{array}$

MAY TO MAY

A\$ TO Y\$

MAY TO YAM

MAY TO MAY

MAY TO $\overline{M A Y}$

MAY TO

L\$ TO B\$

CS TO NS

KEY TO MS
T $\quad F$

F T

F T

F T

F T

F T

F T

F T

F T

IF NO $X(S)$ APPEARED IN THE ABOVE TRUTH TABLE, THEN THE SYSTEM PASSED THE TEST.

END TEST. 


\subsection{TEST OF IF-THEN TRANSFER TO ILLEGAL LINE NUMBER}

The objective of this test is to verify that the execution of an IF-THEN statement, referring to a non-existent, line will cause program execution to be suspended by the system. To continue the program, execution should require some user-directed restart procedures which would be implementation-dependent. In the output for this test there should be an implementation specific diagnostic for an error.

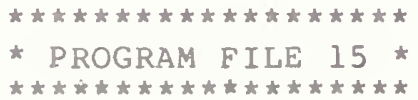

16 PRINT "PROGRAM FILE 15 "

60 PRINT

70 PRINT

80 PRINT

90 PRINT"

100 PRINT

110 PRINT

120 PRINT

130 PRINT " THE OBJECTIVE OF THIS SECTION IS TO USE AN IF-THEN"

140 PRINT "STATEMENT WHICH REEERS TO A NON-EXISTENT LINE-NUMBER. IF"

150 PRINT "THE SYSTEM RECOGNIZES THIS AS A FATAL ERROR (THAT IS, SUS-"

160 PRINT "PENDING PROGRAM EXECTION SUCH THAT USER-DIRECTED RESTART"

170 PRINT "PROCEDURES ARE REQUIRED), THEN THE TEST WILL HAVE PASSED."

180 PRINT

190 PRINT

200 PRINT

210 PRINT

BEGIN TEST. "

220 PRINT

230 LET $A=5$

240 IF $A<>5$ THEN 99

250 PRINT "TEST FAILED."

260 PRINT

270 PRINT "

END TEST."

280 PRINT

290 END 
?UNDEFINED LINE NUMBER 99 IN LINE 240 


\section{LINE LABELS WITH AND WITHOUT LEADING ZEROES}

This unit tests the unique line-number which serves as a label for the statement on the line. The labels at the beginning of each line have the following restrictions: (1) they do not contain and are not preceded by spaces, and (2) they are within the range 1 to 9999 inclusive. Leading zeroes have ho effect (see section 4 of BSR X3.60). These tests are performed with GOTO, IF-THEN, and PRINT statements only. The GOTO statement uses line numbers which may or may not have leading zeroes and these same 1 ine numbers when used as $l$ ine labels may have fewer leading zeroes than in the GOTO statements. The output for this test is in the form of messages to the user that describe the sequence of label tests as they proceed and whether each has passed or failed. A final "passed" or "failed" message is given at the end.

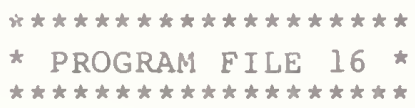

1 PRINT "PROGRAM FILE 16"

16 PRINT

19 PRINT

22 PRINT

25 PRINT

28 PRINT

31 PRINT"

SECTION 16.0: LINE LABELS, WITH/WITHOUT LEADING ZEROES."

34 PRINT

37 LET $M=1$

40 PRINT "

43 GOTO $\square 58$

Dด46 PRINT "

49 LET $Z=N$

52 PRINT "

55 GOTO 0070

58 PRINT "

61 LET $N=M$

64 PRINT "

67 GOTO 46

070 PRINT"

BEGIN TEST."

73 IF $Z=1$ THEN 82

76 PRINT *

79 GOTO 91

82 PRINT "

85 PRINT

88 PRINT "

91 PRINT

9999 END

TEST 1, GOTO USING I LEADING ZEROES ON LABEL."

TEST 2 PASSED, LABEL GAINED 2 LEADING ZEROES."

TEST 3, GOTO USING 2 LEADING ZEROES ON LABEL."

TEST 1 PASSED, LABEL LOST ALL OF ITS LEADING ZEROES."

TEST 2, GOTO USING NO LEADING ZEROES ON LABEL."

TEST 3 PASSED, LABEL LOST 1 OF ITS LEADING ZEROES."

LEADING ZEROES TEST FAILED."

LEADING ZEROES TEST PASSED."

END TEST." 


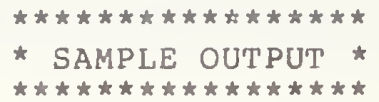

PROGRAM FILE 16

SECTION 16.0: LINE LABELS, WITH/WITHOUT LEADING ZEROES. BEGIN TEST.

TEST 1, GOTO USING I LEADING ZEROES ON LABEL. TEST 1 PASSED, LABEL LOST ALL OF ITS LEADING ZEROES. TEST 2, GOTO USING NO LEADING ZEROES ON LABEL.

TEST 2 PASSED, LABEL GAINED 2 LEADING ZEROES. TEST 3, GOTO USING 2 LEADING ZEROES ON LABEL. TEST 3 PASSED, LABEL LOST 1 OF ITS LEADING 2 EROES. LEADING ZEROES TEST PASSED.

END TEST. 


\subsection{ORDER OF LINES = TWO LINES WITH THE SAME LINE $\overline{\text { NUMBER }}$}

The objective of the next two tests is to determine whether the ordering of line numbers and/or using duplicate line numbers will be recognized by implementations as an error or be adjusted by a local editing facility. In the present test the implementation is asked to accept a program with a duplicate line at 260. There are two possible cases here. First, if the system does not have a program editor, then a diagnostic should be given. If, however, the system does automatically edit programs, then an output to the test program should be given without also giving an error diagnostic.

10 PRINT "PROGRAM FILE 17"

60 PRINT

70 PRINT

80 PRINT

90 PRINT

100 PRINT

110 PRINT

120 PRINT

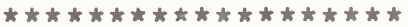

* PROGRAM FILE 17 *

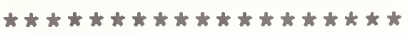

130 PRINT "ALLOW FOR DUPLICATE LINE-NUMBERS AND LINES CONTAINING"

140 PRINT "ONLY A LINE-NUMBER. THIS TEST MAY PRODUCE AN"

150 PRINT "ERROR DIAGNOSTIC ON OTHER SYSTEMS."

160 PRINT

170 PRINT

180 PRINT

230 PRINT

SECTION 17.0: TEST OF LINES WITH SAME NUMBER."

240 PRINT

260 LET $Y=1111$

260 LET $Y=9999$

270 PRINT "Y $="$; $Y$

280 PRINT

290 PRINT

SINCE A VALUE FOR Y HAS BEEN PRINTED IT CAN BE AS-"

300 PRINT "SUMED THAT THIS SYSTEM DOES NOT RECOGNIZE DUPLICATE LINE-"

310 PRINT "NUMBERS AS AN ERROR. IF $Y=9999$ THEN THE LAST LINE"

320 PRINT "260 WAS RETAINED BY THE LOCAL EDITOR."

330 PRINT

340 PRINT

END TEST."

350 PRINT

360 END 
PROGRAM FILE 17

SECTION 17.0: TEST OF LINES WITH SAME NUMBER

NOTE: LOCAL EDITING FACILITIES MAY ALLOW

FOR THE ENTRY OF STATEMENT LINES IN ANY ORDER AND ALSO

ALLOW FOR DUPLICATE LINE-NUMBERS AND LINES CONTAINING

ONLY A LINE-NUMBER. THIS TEST MAY PRODUCE AN

ERROR DIAGNOSTIC ON OTHER SYSTEMS.

BEGIN TEST.

$Y=9999$

SINCE A VALUE FOR Y HAS BEEN PRINTED IT CAN BE ASSUMED THAT THIS SYSTEM DOES NOT RECOGNIZE DUPLICATE LINENUMBERS AS AN ERROR. IE $Y=9999$ THEN THE LAST LINE

260 WAS RETAINED BY THE LOCAL EDITOR.

END TEST. 


\subsection{ORDER OF LINES - LINES OUT OF ORDER}

This test verifies whether the test system will either recognize lines out of order as an error when no local editor is available or have a program editor that reorders the lines (see section 4.6 in BSR X3.60). On output, there should be a diagnostic for systems without editors or two numbers in order $A I=1111$ and $A 2=9999$. If these numbers are produced in reverse order then the local editor did not reorder the lines. The test language processor executed one line after the other without regard to line order.
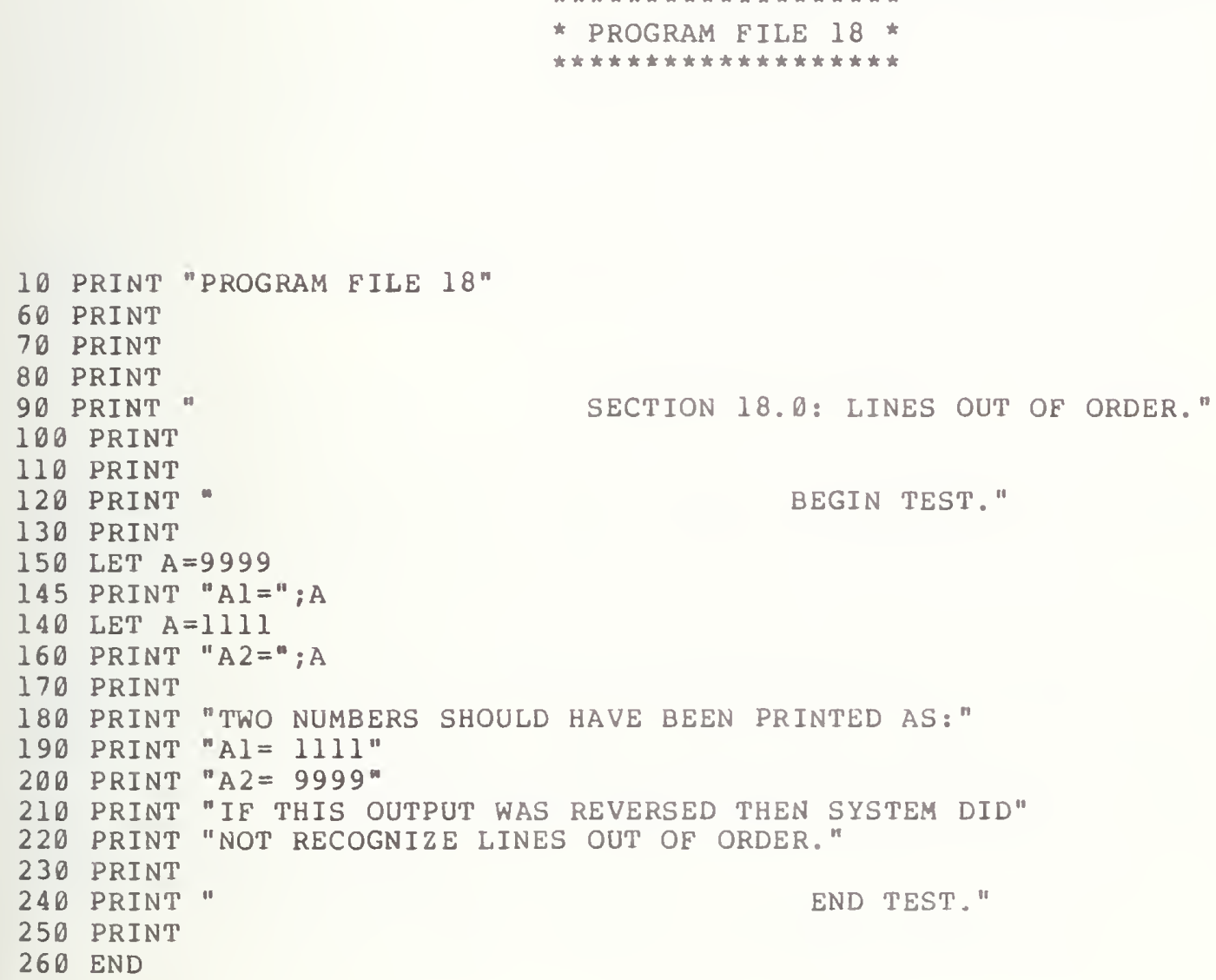

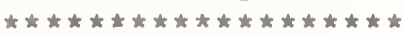

(260 
PROGRAM FILE 18

SECTION 18. 0 : LINES OUT OF ORDER.

BEGIN TEST .

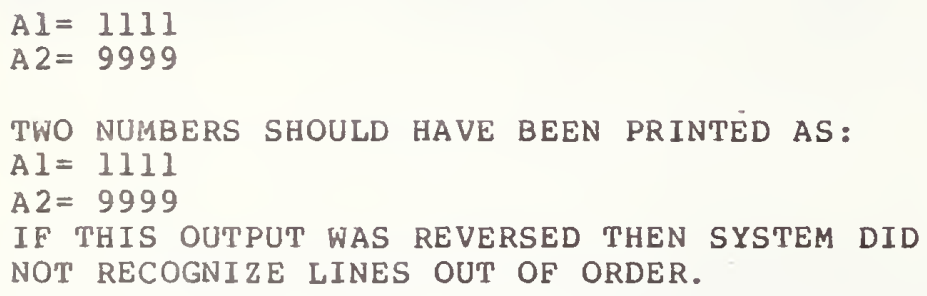

$A 1=1111$

$A 2=9999$

TWO NUMBERS SHOULD HAVE BEEN PRINTED AS:

$A 1=1111$

A $2=9999$

IF THIS OUTPUT WAS REVERSED THEN SYSTEM DID

NOT RECOGNIZE LINES OUT OF ORDER.

END TEST. 


\section{THE ABS EUNCTION AND ELEMENTARY NUMERICAL EXPRESSIONS USING CONSTANTS}

The objective of the next several test sections is to verify that numeric expressions can be constructed from simple variables and constants using the operations of addition, subtraction, multiplication, division, and involution. They further verify that simple variables and constants can be used as arguments for an absolute value function reference. One item the user should be wary of in these tests is that a difference in format of output does not force a test failure. For example, there are numbers that should be printed in NR2 format that some non-conforming systems might print in NR3. The non-conformance would only be in formatting of numbers which would have been tested previously. The user need only check the test output for asterisks after the last ouput column, where numerical errors are printed. At the lowest level, the tests are passed if there are no diagnostics for the ABS function or for the expressions. That is, the host system can evaluate them. However, in order to pass the test entirely, there should be no asterisks. If there are, this means that some operation has generated a result that is out of tolerance. The user should be familiar at this point with sections 7 and 8 of BSR $\times 3.60$.

These tests further extend the capability of the IF-THEN statement, since there is a comparison of the ABS function of an argument against a constant. The successful evaluation of this form of the IF-THEN statement demonstrates that an intrinsic function can be referenced in the branch condition.

\subsection{The ABS Function}

The objective of this test section is to introduce a reference to the absolute value function. The arguments used will be the simplest of the numerical expressions. The expressions will consist of only one term and these terms will consist of only one factor.

Even if two results agree to within six digits, the actual machine representation of the test system may use a register or memory storage location that holds more bits than required for a six digit representation. The errors printed only represent differences between computed results and converted program constants. The only errors flagged are those that differ by a unit or more in the sixth significant digit of the result. Absolute error means the absolute value of the difference between the test system computed result and the comparison result, which is the true result rounded to six significant digits.

\subsubsection{Using Numerical Constants for Arguments}

The objective of this test is to verify that numerical constants can be used as arguments in an absolute value function. This test uses both negative and positive numerical constants as the arguments in an absolute value function reference. That is, both negative and positive NRI, NR2, and NR3 constants are used for the arguments. The output format is in three columns. The first column is labeled "ARGUMENT" and represents the constant used as the argument. The second column is labeled "TRUE EVALUATION", and the third column is labeled "SYSTEM EVALUATION". In the second column we 
list the standard conforming output expected and in the third column we list the evaluations of the absolute value function on the system being tested. An asterisk should appear beside any evaluation that does not conform to the standard.

\subsubsection{Using Assigned Variables for Arguments}

The objective of this test is to verify that simple variables can be used as the arguments for an absolute value function. This test uses both negative and positive numbers assigned to the simple variables. Specifically, both negative and positive NRl, NR2, and NR3 constants have been assigned to the simple variables, and these simple variables are then used as arguments in absolute value function referencing. The test uses the same output format as in test 19.1.1.

\subsection{Primitive Operations}

The remainder of this section and the next two sections are devoted to verifying that numerical expressions can be constructed from two terms (involving addition or subtraction), two factors (involving multiplication or division), or from a base and an exponent (involving involution), using constants only.

\subsection{Using Numerical Constants in Addition}

This test initiates the construction of numerical expressions from numerical constants. This test and the next two proceed through each of the operations of addition, subtraction, multiplication, division, and involution. Each test is structured to use the same type of constants for each operation, that is, NRI constants are not used with NR2 constants, NR2 constants are not used with NR3 constants, etc.

The objective of this test subsection is to verify that the operation of addition between two numerical constants will yield at least six decimal digits of precision. This routine tests the addition of two NRI constants, two NR2 constants and two NR3 constants. The output of this test falls into four columns of which the first column is labeled "lst. ADDEND PLUS 2nd. ADDEND", the second column is labeled "REQUIRED SUM", the third column is labeled "SUM OF SYSTEM", and the fourth column is labeled "ABSOLUTE ERROR". The first column lists the pairs of numerical constants that are added; the second column lists the standard conforming expected output; the third column lists the sums of the constants as evaluated by the system being tested; and the fourth column lists the absolute difference between the expected values and the system generated values. If the implementation did not maintain at least six decimal digits of precision, an asterisk will appear to the right of the fourth column.

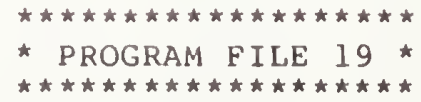




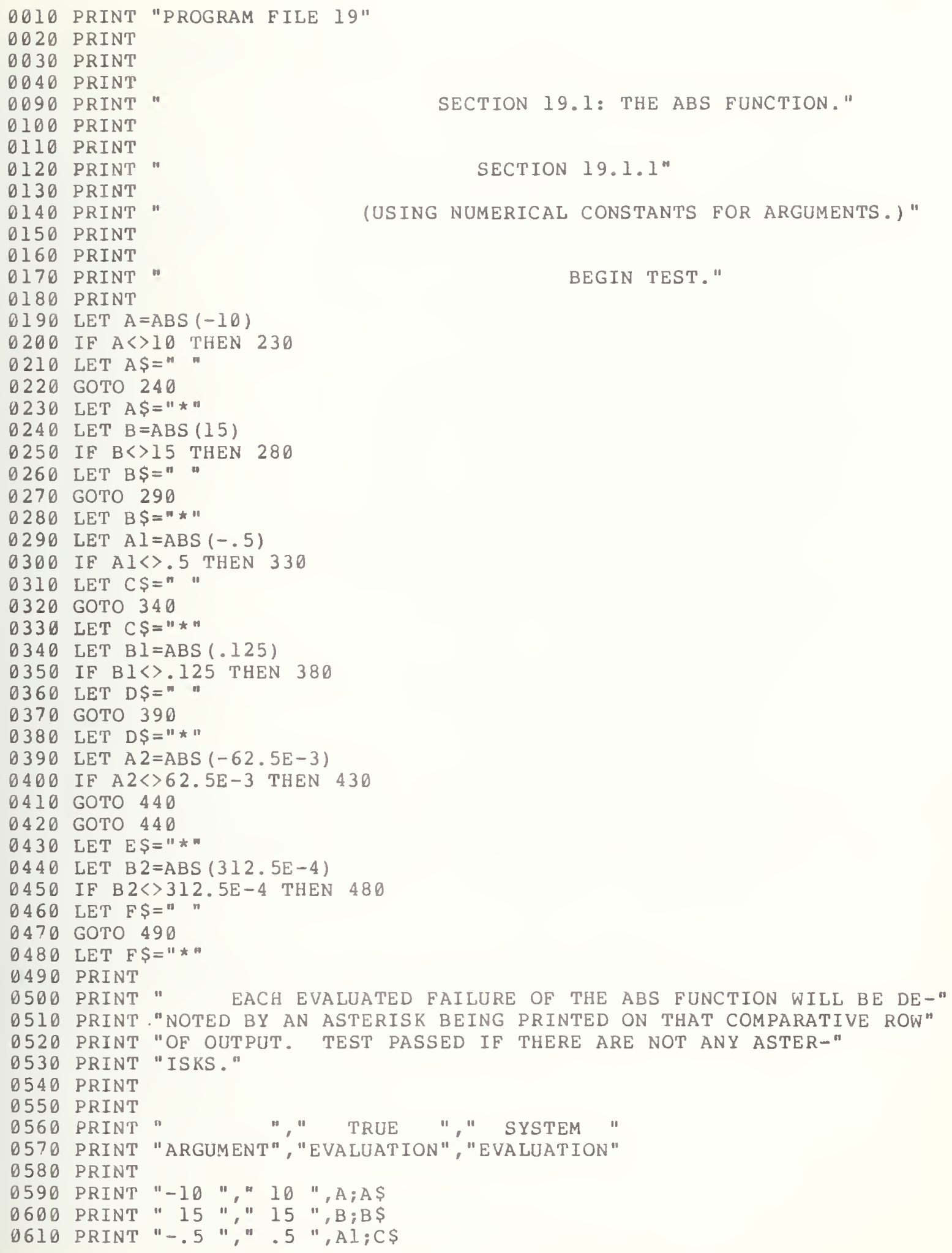

SECTION 19.1: THE ABS FUNCTION."

SECTION 19.1.1"

(USING NUMERICAL CONSTANTS FOR ARGUMENTS.)"

BEGIN TEST." 

1190 PRINT

1200 PRINT

1210 PRINT

1220 PRINT

1230 PRINT

1240 PRINT

1250 PRINT

1260 PRINT

1270 PRINT

1280 PRINT

1290 PRINT

1300 PRINT

1310 PRINT

1320 PRINT

1330 PRINT

1350 PRINT

1360 PRINT

1370 PRINT

1380 PRINT

1390 PRINT

1410 PRINT

1420 PRINT

1430 PRINT

1440 PRINT

1450 PRINT

1460 PRINT

1470 PRINT

1480 PRINT

1490 PRINT

1500 PRINT

1520 PRINT

1530 PRINT

1540 PRINT

1550 PRINT

1560 PRINT

1570 PRINT

1580 PRINT

1590 PRINT

1600 PRINT

1610

162

163

164

1660

167

168

169

170

171

172

1736

1748

175

176

1778

1780

PRINT

"VALUE OF"," TRUE " " SYSTEM "

"ARGUMENT" " "EVA LUATION" " EVA LUATION"

"-10"," $10 ", M 1 ; A S$

" 15 "," 15 ", M2;B\$

" $-.5^{m, " . ~} 5^{\prime \prime}, \mathrm{M} 3 ; \mathrm{CS}$

". 125 ", ". 125 ", M4;DS

"-62.5E-3",".0625", M5:ES

" $312.5 \mathrm{E}-4$ ",". $13125^{\circ, M 6 ; E \$}$

"

END TEST."

SECTION 19.2.1"

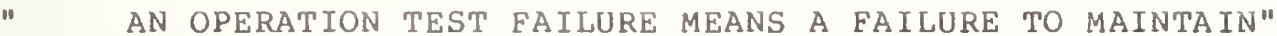
"AT LEAST 6 DIGITS OF PRECISION."

" BEGIN TEST."

n $\quad+t+++++++++$ "

+ ADDITION +"

$++t+t+t+t+n$

" IF NO ASTERISK FOLLOWS ANY VALUE IN THE ABSOLUTE ERROR"

"COLUMN, TEST PASSED. HOWEVER, IF AN ASTERISK FOLLOWS"

"A VALUE IN THE ABSOLUTE ERROR COLUMN, TEST FAILED BE-"

"CAUSE SYSTEM WOULD HAVE FAILED THE ERROR BOUND ROUND-OFF OF"

"SIX PLACE ACCURACY."

"IST. ADDEND"

" PLUS ", "REQUIRED" , "SUM OF" , ABSOLUTE"

"2ND. ADDEND"," SUM ","SYSTEM"," ERROR "

PRINT

PRINT

LET L $2=2+144$

LET $\mathrm{L} 3=(2+144)+(-146)$

IF $A B S(L 3)<=1 \mathrm{E}-3$ THEN 1760

PRINT " 2

PRINT " +

PRINT " 14.4

GOTO 1790

PRINT " 2

PRINT" +

PRINT " 144 


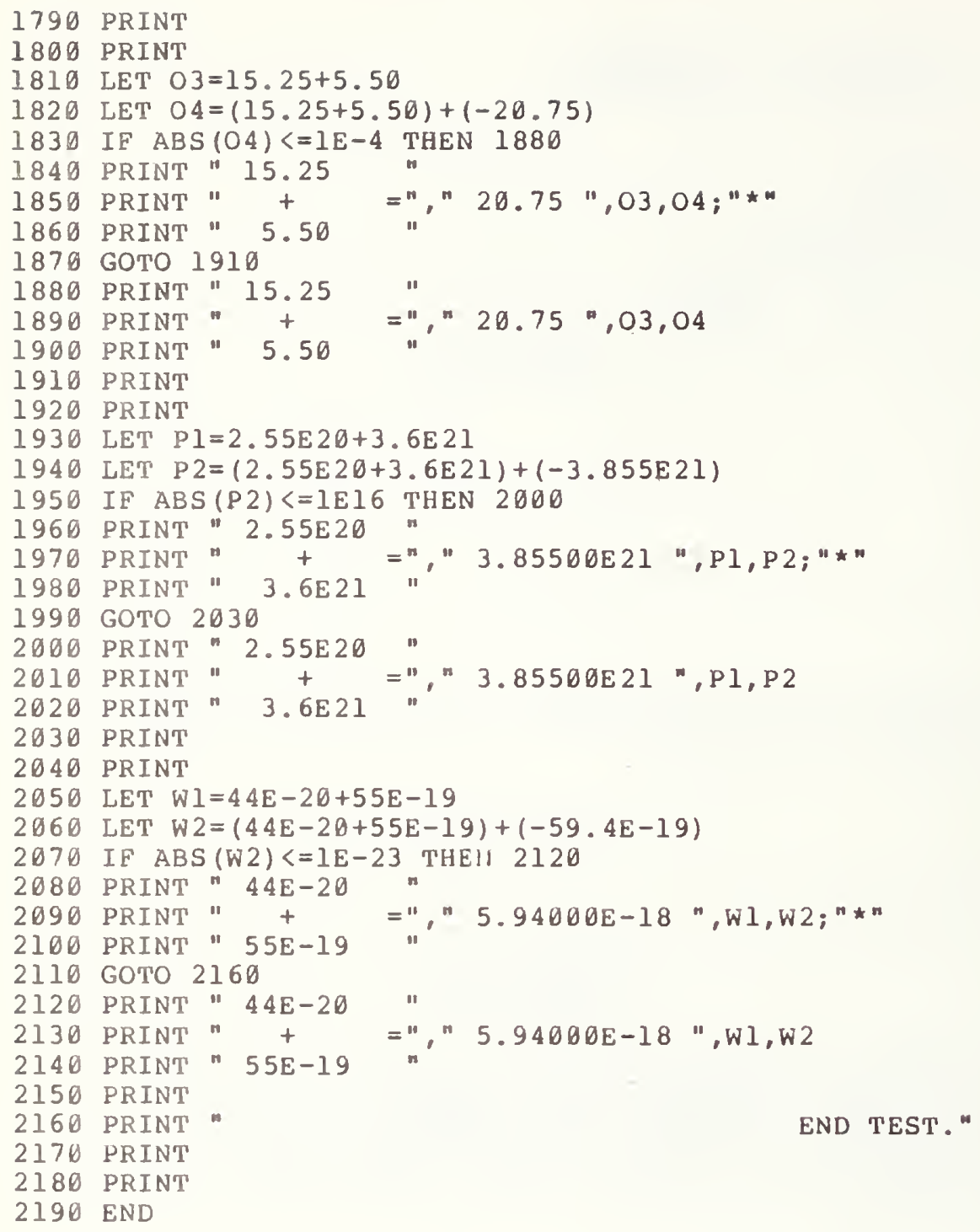


SECTION 19.1: THE ABS FUNCTION.

SECTION 19.1 .1

(USING NUMERICAL CONSTANTS FOR ARGUMENTS.)

BEGIN TEST.

EACH EVALUATED FAILURE OF THE ABS FUNCTION WILL BE DENOTED BY AN ASTERISK BEING PRINTED ON THAT COMPARATIVE ROW OF OUTPUT. TEST PASSED IF THERE ARE NOT ANY ASTERISKS .

$\begin{array}{lll}\text { ARGUMENT } & \begin{array}{c}\text { TRUE } \\ \text { EVALUATION }\end{array} & \begin{array}{c}\text { SYSTEM } \\ \text { EVALUATION }\end{array} \\ -10 & 10 & 10 \\ 15 & 15 & 15 \\ -.5 & .5 & .5 \\ .125 & .125 & .125 \\ -62.5 \mathrm{E}-3 & .0625 & .0625 \\ 312.5 \mathrm{E}-4 & .03125 & .03125 \\ & & \\ & & \text { END TEST. }\end{array}$

SECTION 19.1 .2

(USING ASSIGNED VARIABLES FOR ARGUMENTS.)

BEGIN TEST.

EACH EVALUATED FAILURE OF THE ABS FUNCTION WILL BE DENOTED BY AN ASTERISK BEING PRINTED ON THAT COMPARATIVE ROW OF OUTPUT. CHECK TEST PASSED IF THERE ARE NOT ANY ASTERISKS.

\begin{tabular}{|c|c|c|}
\hline $\begin{array}{l}\text { VALUE OF } \\
\text { ARGUMENT }\end{array}$ & $\begin{array}{c}\text { TRUE } \\
\text { EVA LUATION }\end{array}$ & $\begin{array}{r}\text { SYSTEM } \\
\text { EVALUATI }\end{array}$ \\
\hline $\begin{array}{r}-10 \\
15 \\
-.5 \\
.125 \\
-62.5 E-3 \\
312.5 E-4\end{array}$ & $\begin{array}{l}10 \\
15 \\
.5 \\
.125 \\
.0625 \\
.03125\end{array}$ & $\begin{array}{l}10 \\
15 \\
.5 \\
.125 \\
.0625 \\
.03125\end{array}$ \\
\hline
\end{tabular}

END TEST. 
AN OPERATION TEST FAILURE MEANS A FAILURE TO MAINTAIN AT LEAST 6 DIGITS OF PRECISION.

BEGIN TEST.

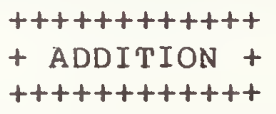

IF NO ASTERISK FOLLOWS ANY VALUE IN THE ABSOLUTE ERROR COLUMN, TEST PASSED. HOWEVER, IF AN ASTERISK FOLLOWS

A VALUE IN THE ABSOLUTE ERROR COLUMN, TEST FAILED BECAUSE SYSTEM WOULD HAVE FAILED THE ERROR BOUND ROUND-OFF OF SIX PLACE ACCURACY.

1ST. ADDEND

PLUS

REQUIRED

SUM OF

SYSTEM

ABSOLUTE

2ND. ADDEND

SUM

ERROR

$\begin{aligned} & 2 \\ & + \\ & 144\end{aligned} \quad=\quad 146 \quad 146$

$\begin{gathered}15.25 \\ +5.50\end{gathered}=20.75 \quad 20.75$

\begin{tabular}{|c|c|c|c|}
\hline $\begin{array}{c}2.55 E 20 \\
+ \\
3.6 E 21\end{array}$ & $=$ & $3.85500 \mathrm{E} 21$ & $3.85500 \mathrm{E}+21$ \\
\hline $\begin{array}{c}44 E-20 \\
+ \\
55 E-19\end{array}$ & $=$ & $5.94000 \mathrm{E}-18$ & $5.94000 \mathrm{E}-18$ \\
\hline
\end{tabular}




\subsection{ELEMENTARY NUMERICAL EXPRESSIONS USING CONSTANTS (CONTINUED)}

\section{1 subtraction}

The objective of this test is to verify that the operation of subtraction of numerical constants will maintain at least six decimal digits of precision. The test forms the difference each of two NRI constants, two NR2 constants, and two NR3 constants. There is again a four column output of which the first column is labeled "MINUEND MINUS SUBTRAHEND", the second column is labeled "REQUIRED DIFFERENCE", the third column is labeled "DIFFERENCE OF SYSTEM", and the fourth column is labeled "ABSOLUTE ERROR". The first column contains the pairs of numerical constants that are subtracted; the second column lists the standard conforming expected output; the third column lists the differences of the constants as evaluated by the system being tested; and the fourth column contains the absolute errors generated in the evaluation. If the implementation did not maintain at least six decimal digits of precision, an asterisk will appear beside any such case to the right of the fourth column.

\subsection{Multiplication}

The objective of this test is to verify that the operation of multiplication of two numerical constants will maintain six significant digits of precision. The test multiplies each of two NRl constants, two NR2 constants, and two NR3 constants. The test outputs four columns of which the first column is labeled "lst FACTOR TIMES 2nd. FACTOR", the second column is labeled "REQUIRED PRODUCT", the third column is labeled "PRODUCT OF SYSTEM", and the fourth column is labeled "ABSOLUTE ERROR". The first column lists the pairs of numerical constants that are multiplied; the second column lists the standard conforming output; the third column lists the products of the constants as evaluated by the system being tested; and the fourth column contains the absolute errors. Again an asterisk will appear to the right of the fourth column for the products not satisfying the six significant digit criteria.

0010 PRINT "PROGRAM FILE 20"

9060 PRINT

0070 PRINT

0080 PRINT

0090 PRINT

0100 PRINT

BEGIN TEST."

0110 PRINT

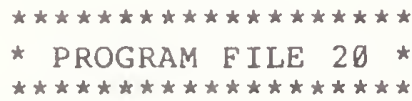

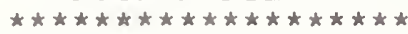




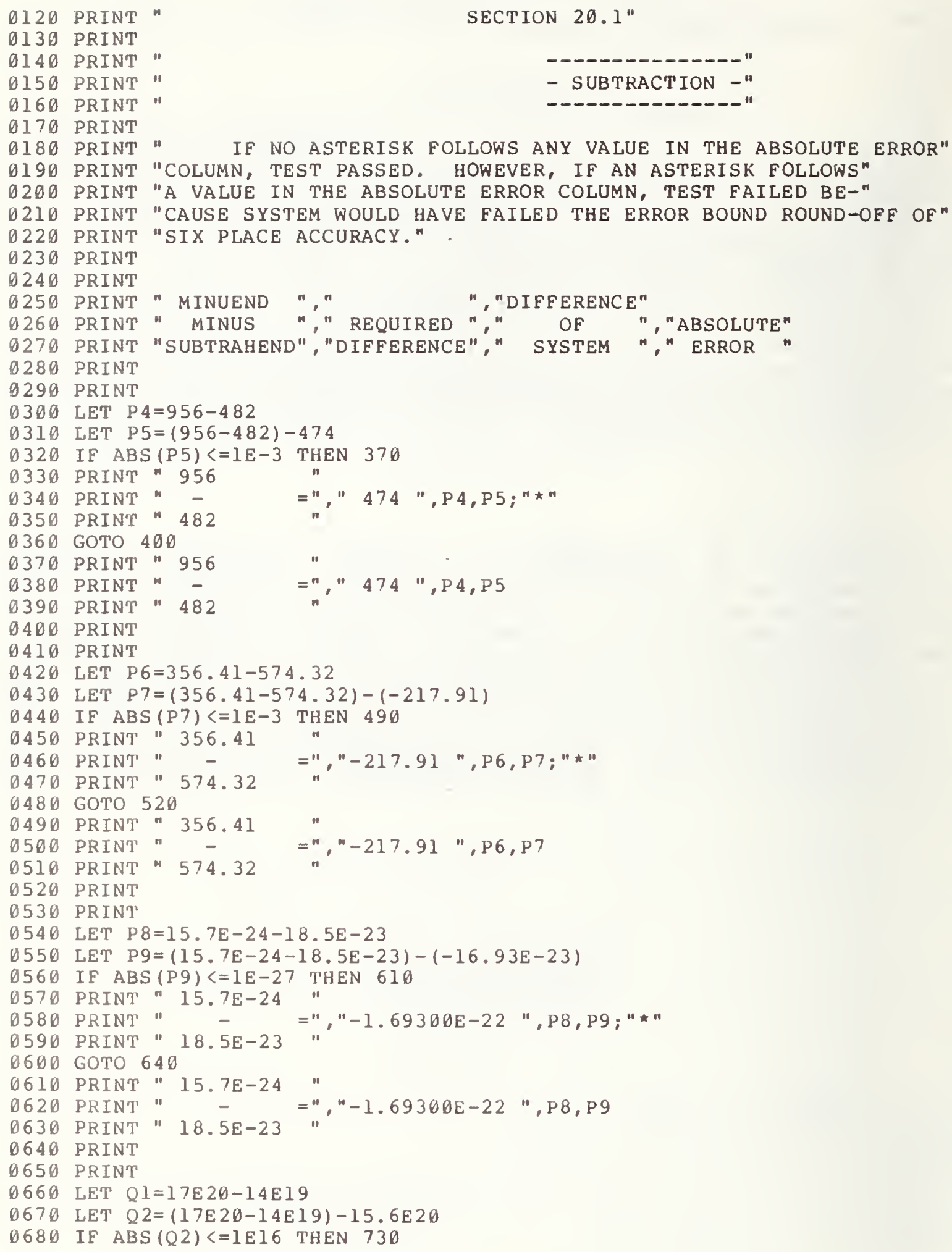

IF NO ASTERISK FOLLOWS ANY VALUE IN THE ABSOLUTE ERROR" "COLUMN, TEST PASSED. HOWEVER, IF AN ASTERISK FOLLOWS" "A VALUE IN THE ABSOLUTE ERROR COLUMN, TEST FAILED BE-" CAUSE SYSTEM WOULD HAVE FAILED THE ERROR BOUND ROUND-OFF OF " MINUEND "," ", "DIFFERENCE" "SUBTRAHEND", "DIFFERENCE"," SYSTEM "," ABSOLUTE" 


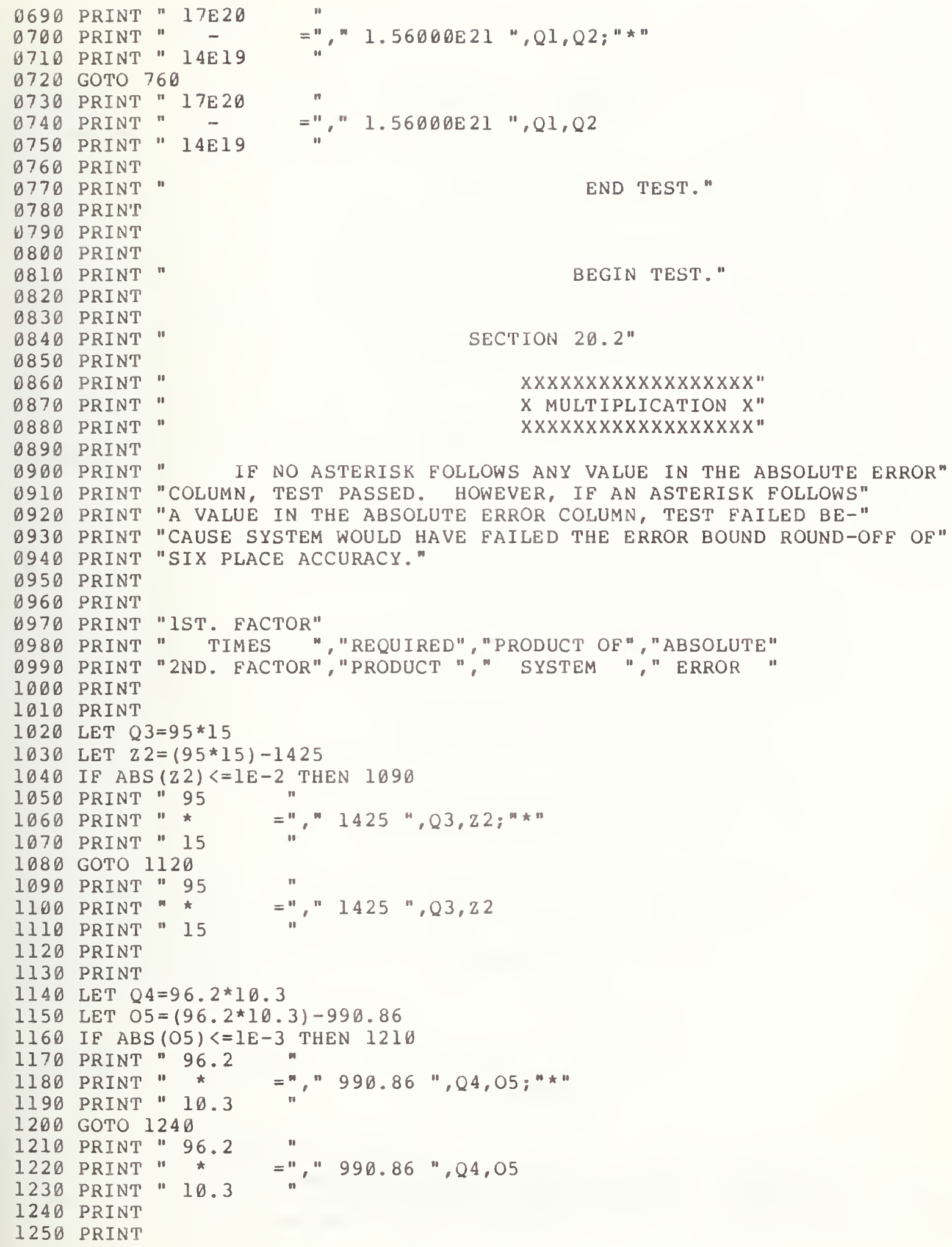



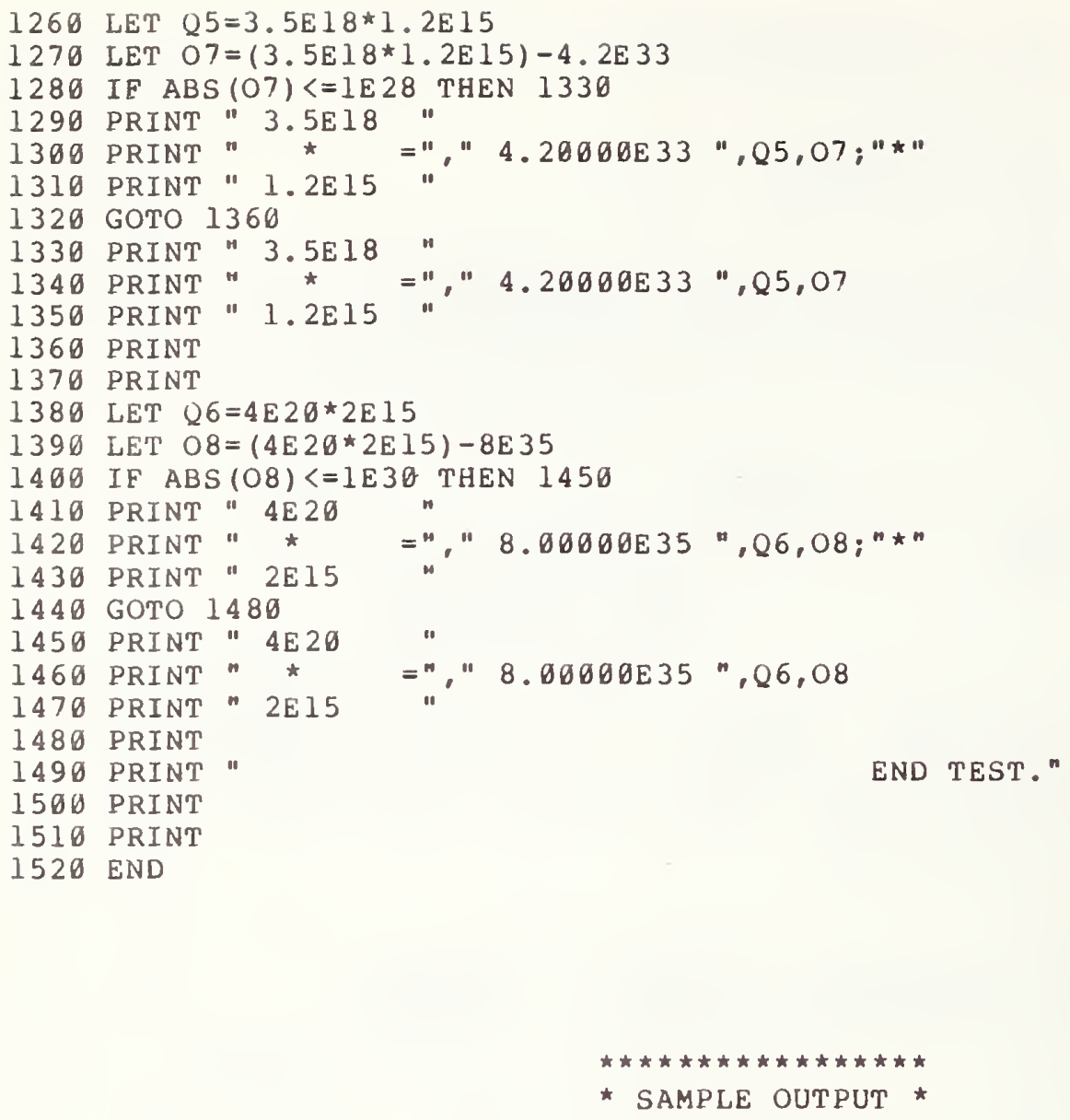

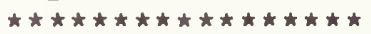

PROGRAM FILE 2ø

BEGIN TEST.

SECTION 20.1

- SUBTRACTION -

IE NO ASTERISK FOLLOWS ANY VALUE IN THE ABSOLUTE ERROR COLUMN, TEST PASSED. HOWEVER, IF AN ASTERISK FOLLOWS A VALUE IN THE ABSOLUTE ERROR COLUMN, TEST FAILED BECAUSE SYSTEM WOULD HAVE FAILED THE ERROR BOUND ROUND-OFF OF 
SIX PLACE ACCURACY.

$\begin{array}{lccc}\begin{array}{c}\text { MINUEND } \\ \text { MINUS }\end{array} & \text { REQUIRED } & \text { DIFFERENCE } & \\ \text { SUBTRAHEND } & \text { OF } & \text { ABSOLUTE } \\ & \text { DIFFERENCE } & \text { SYSTEM } & \text { ERROR } \\ 956 & & & \\ - & & 474 & 0\end{array}$
356.41
$\begin{aligned} & \overline{3} .31 \\ & 57.32\end{aligned}=-217.91 \quad-217.91$

15. $7 \mathrm{E}-24$

$\frac{-}{18.5 E-23}=-1.69300 \mathrm{E}-22-1.69300 \mathrm{E}-22 \quad 0$

$17 \mathrm{E} 20$

$\begin{aligned} & - \\ & 14 \mathrm{E} 19\end{aligned}=1.56000 \mathrm{E} 21 \quad 1.56000 \mathrm{E}+21 \quad 0$

END TEST.

BEGIN TEST.

SECTION 20.2

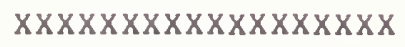

$x$ MULTIPLICATION $X$

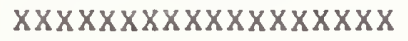

IF NO ASTERISK FOLLOWS ANY VALUE IN THE ABSOLUTE ERROR COLUMN, TEST PASSED. HOWEVER, IF AN ASTERISK FOLLOWS A VALUE IN THE ABSOLUTE ERROR COLUMN, TEST FAILED BECAUSE SYSTEM WOULD HAVE FAILED THE ERROR BOUND ROUND-OFF OF SIX PLACE ACCURACY.

1ST. FACTOR

$2 \mathrm{~N}$

TIMES

2ND. FACTOR

REQUIRED

PRODUCT

$\begin{array}{cc}\text { PRODUCT OF } & \text { ABSOLUTE } \\ \text { SYSTEM } & \text { ERROR }\end{array}$

95

15
$=$

1425

1425

0 
96.2

$\star$

10.3

3. $5 \mathrm{E} 18$

* $=$

1. $2 \mathrm{E} 15$

990.86

990.86

$\emptyset$

4E 20

* $=$

2 E 15

$8.00000 \mathrm{E} 35$

$8.00000 E+35$

$\theta$

END TEST. 


\section{ELEMENTARY NUMERICAL EXPRESSIONS USING CONSTANTS (CONTINUED)}

\subsection{Division}

The objective of this test is to verify that the operation of division between two numerical constants will yield at least six decimal digits of precision. This test computes the quotient of two NRI constants, two NRZ constants, and two NR3 constants. There is $z$ four column output of which the first column is labeled "DIVIDEND DIVIDED BY DIVISOR", the second "olumn is labeled "REQUIRED QUOTIENT", the third column is labeled "QUOTIENT OF SYSTEM", and the fourth column is labeled "ABSOLUTE ERROR".

The first column lists the pairs of numerical constants which enter into the quotient, the second column lists the standard conforming output, the third column lists the quotients as evaluated by the system being tested, and the fourth column contains the absolute errors between the generated quotients and the true quotient. An asterisk to the right would indicate failure to maintain six significant digits.

\subsection{Involution}

The objective of this test is to verify that the operation of involution of numerical constants will yield at least six decimal digits of precision. This test forms the involution of two NRI constants, two NR2 constants, and two NR3 constants. Its output falls in four columns again of which the first column is labeled "BASE " EXPONENT", the second column is labeled "REQUIRED POWER", the third column is labeled "POWER OF SYSTEM", and the fourth column is labeled "ABSOLUTE ERROR".

The first column lists the pairs of numerical constants which should have been involuted, the second column lists the standard conforming output, the third column lists the involution of the constants as generated by the system being tested, and the fourth column contains the absolute errors. An asterisk appears to the right of this column as before for failure to maintain six significant digits.

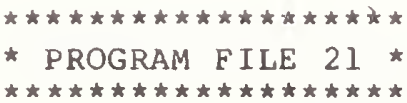

O020 PRINT "PROGRAM FILE 2I"

0070 PRINT

0080 PRINT 


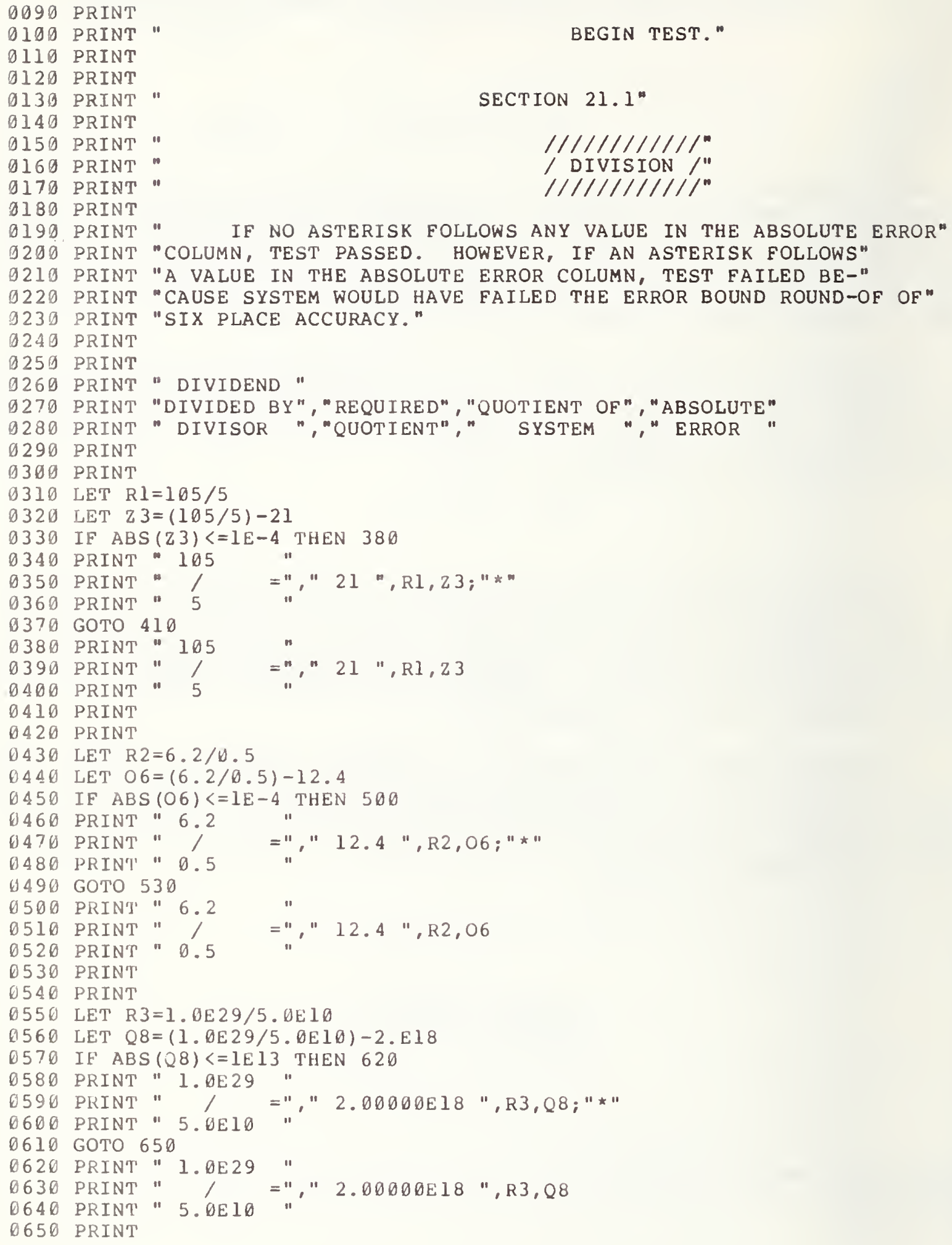


0660 PRINT

0670 LET R4 $=15 \mathrm{E} 30 / 5 \mathrm{E} 15$

0680 LET $O 9=(15 \mathrm{E} 30 / 5 \mathrm{E} 15)-3 \mathrm{E} 15$

0690 IF ABS (09) <=lE 10 THEN 740

$\emptyset 700$ PRINT " 15E30

0710 PRINT" "

0720 PRINT" 5E15

0730 GOTO 770

9740 PRINT " 15E30

0750 PRINT " 9 " =" " 0760 PRINT " $3.00000 \mathrm{E} 15$ ",R4,09

0770 PRINT

0780 PRINT

0790 PRINT

9800 PRINT

0810 PRINT

9820 PRINT

0830 PRINT

9840 PRINT

0850 PRINT

0853 PRINT

0855 PRINT

9860 PRINT

9870 PRINT

$\emptyset 880$ PRINT

0890 PRINT

9900 PRINT

9910 PRINT

0920 PRINT

930 PRINT "CAUSE SYSTEM WOULD HAVE FAILED THE ERROR BOUND ROUND-OFF OF"

PRINT

9950 PRINT

9960 PRINT

9970 PRINT

0980 PRINT

O990 PRINT

1000 PRINT

1010 PRINT

1020 LET R5 $=30^{\wedge} 2$

1030 LET $S 5=\left(3 \theta^{\wedge} 2\right)-900$

1040 IF $A B S(S 5)<=1 E-3$ THEN 1090

1050 PRINT" 30

1060 PRINT" "

1070 PRINT" 2

1080 GOTO 1120

1090 PRINT " 30

1100 PRINT" "

1110 PRINT " 2

SECTION $21.2^{\prime \prime}$

INVOLUT ION ${ }^{a}$

BEGIN TEST."

IF NO ASTERISK FOLLOWS ANY VALUE IN THE ABSOLUTE ERROR"

1120 PRINT

1130 PRINT

1140 LET T $5=\theta^{\wedge} \theta$

1150 LET U $5=\left(\theta^{\wedge} \theta\right)-1$

1160 IF $A B S(U 5)<=1 E-5$ THEN 1210

1170 PRINT " $\theta$

1180 PRINT" "

1190 PRINT" $\theta$

$=", " 900 ", \mathrm{R} 5, \mathrm{~S} 5$; $^{\prime \prime} *$ "

1200 GOTO 1240

$=", " 1 ", \mathrm{~T} 5, \mathrm{U} 5 ; " * "$ 


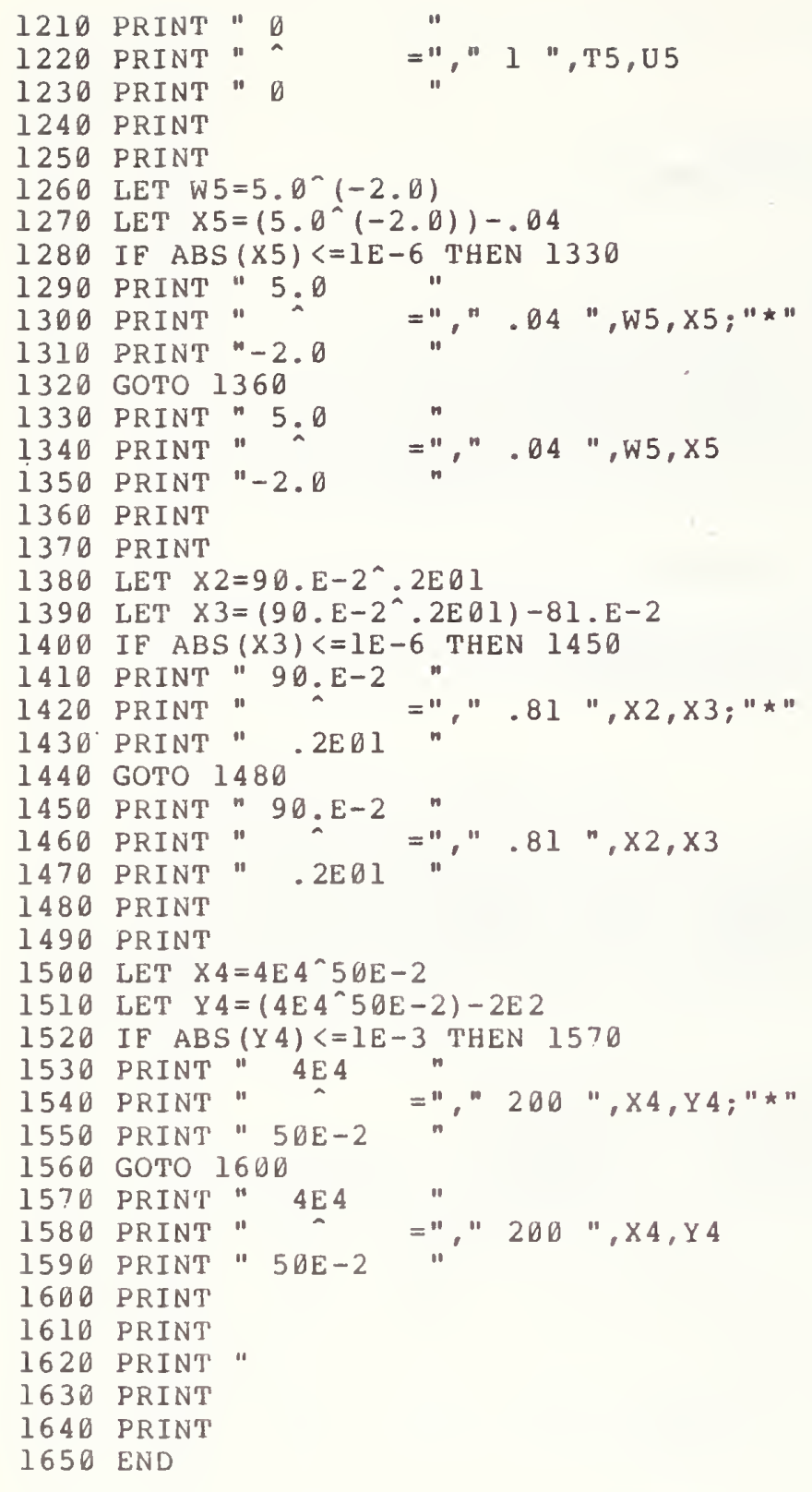


SECTION 21.1

$$
\begin{aligned}
& / / / / / / / / / \\
& / \text { DIVISION } / \\
& / / / / / / / /
\end{aligned}
$$

IF NO ASTERISK FOLLOWS ANY VALUE IN THE ABSOLUTE ERROR COLUMN, TEST PASSED. HOWEVER, IF AN ASTERISK FOLLOWS A VALUE IN THE ABSOLUTE ERROR COLUMN, TEST FAILED BECAUSE SYSTEM WOULD HAVE FAILED THE ERROR BOUND ROUND-OF OF SIX PLACE ACCURACY.

DIVIDEND
DIVIDED BY

DIVISOR

105

$1=$

5

6.2

$1=$

0.5

$1.0 \mathrm{E} 29$

$1=$

$5.0 \mathrm{E} 10$

$15 \mathrm{E} 30$

$1=$

$5 \mathrm{E} 15$
REQU IRED

QUOT IENT

21

21

$\emptyset$

12.4

12.4

0

$2.00000 \mathrm{E} 18 \quad 2.00000 \mathrm{E}+18 \quad 0$

$3.00000 \mathrm{E} 15$

$3.00000 \mathrm{E}+15 \quad 0$

END TEST.

SECTION 21.2

“INVOLUTION ${ }^{\wedge}$

BEGIN TEST . 
IF NO ASTERISK FOLLOWS ANY VALUE IN THE ABSOLUTE ERROR COLUMN, TEST PASSED. HOWEVER, IF AN ASTERISK FOLLOWS A VALUE IN THE ABSOLUTE ERROR COLUMN, TEST FAILED BECAUSE SYSTEM WOULD HAVE FAILED THE ERROR BOUND ROUND-OFF OF SIX PLACE ACCURACY.

\section{BASE}

EXPONENT
REQUIRED

POWER

30

2

$\stackrel{0}{0}=$

5. 0

$-2.0$

$96 \cdot:^{E-2}=$

$.2 E 01$

$4 \mathrm{E} 4$

$50 E-2$
900

1

.04

.81

200
POWER OF

SYSTEM

900

1

b

ABSOLUTE

ERROR

b

$0.04 \quad 0$

$0.81 \quad 0$

$200 . \quad 0$

END TEST. 


\section{D ELEMENTARY EXPRESSIONS USING SIMPLE VARIABLES}

The objective here is to extend the construction process of numerical expressions by using simple numeric variables with the operations of addition, subtraction, multiplication, division, and involution. Each test is constructed to use only simple variables assigned the same type of numerical constants with each other, that is, simple variables that have been assigned NRl constants are not used with simple variables that have been assigned NR2 or NR3 constants, etc.

\subsection{Addition}

The objective of this test is to verify that the operation of addition of two numerically assigned simple variables will yield at least six decimal digits of precision. This test is similar to test 19.3, except for the simple variables and the values of their assigned numerical constants. The labeling of the first column is different in that for this test the first column is labeled "Assignment 1 plus Assignment 2 ". This test generates the same output format as in test 19.3.

\section{2 Subtraction}

The objective of this test is to verify that the operation of subtraction of two numerically assigned simple variables will yield at least six decimal digits of precision. This test is similar to test test 20.1, except for the simple variables and their assigned numerical constants. The labeling of the first column is different, in that, for this test the first column is labeled "Assignment 1 minus Assignment 2". The output format is the same as that in 20.1 .

0010 PRINT "PROGRAM FILE 22"

0060 PRINT

0070 PRINT

0080 PRINT

0140 PRINT

0150 PRINT

0160 PRINT

DI70 PRINT

0180 PRINT

0190 PRINT

0200 PRINT "

BEGIN TEST."

SECTION $22.1^{\prime \prime}$

$+t+t+t+t+t+1$

+ ADDITION +" 


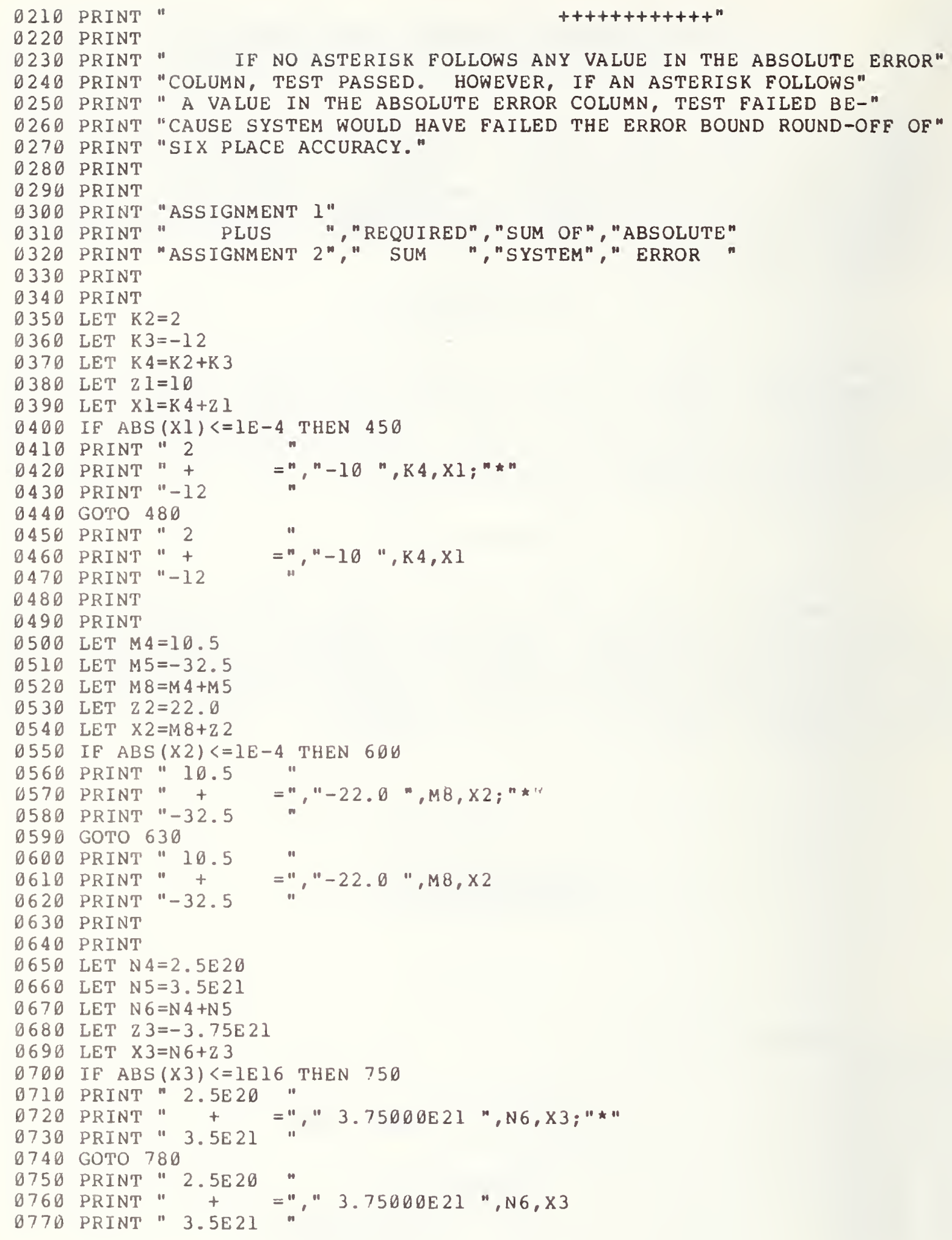




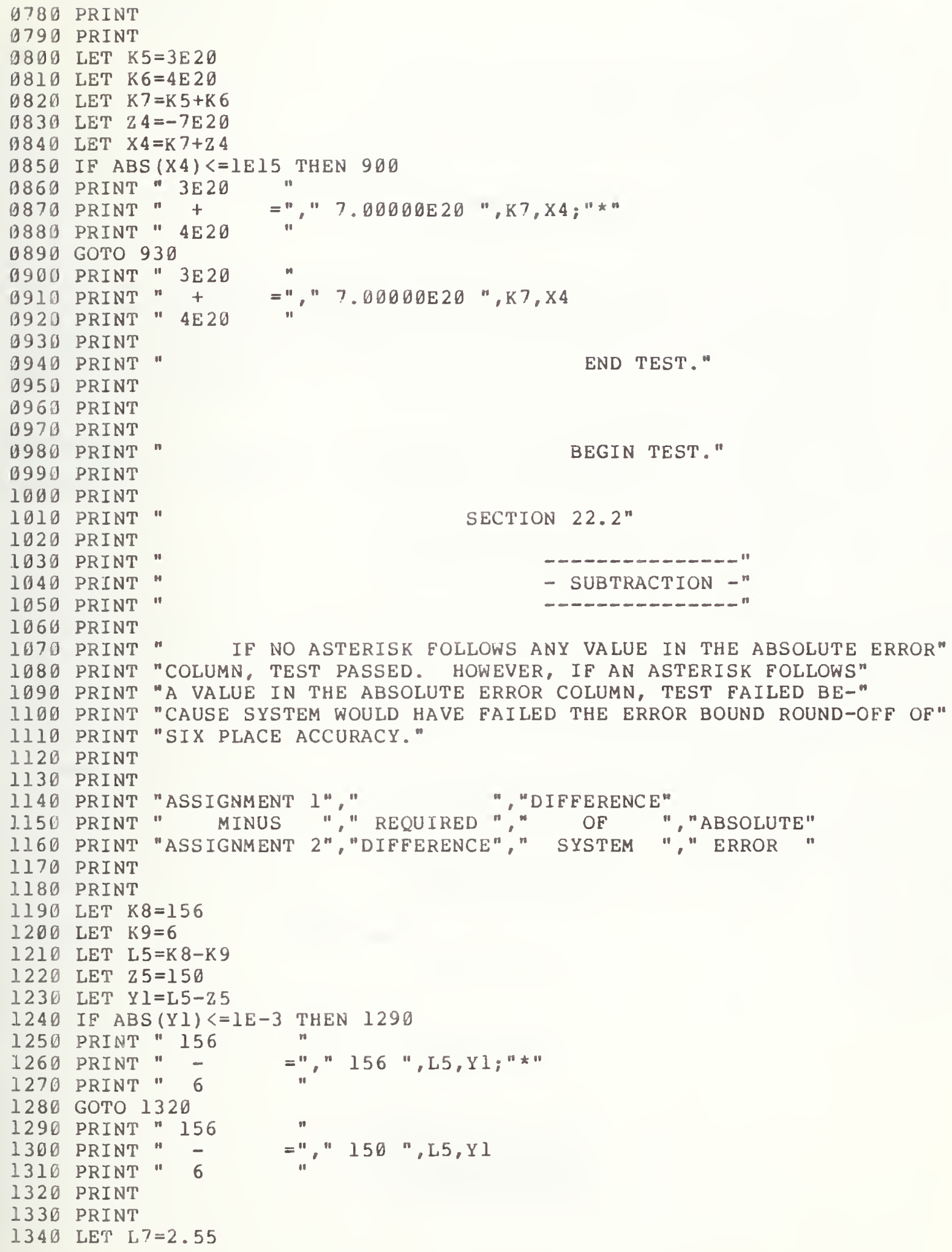




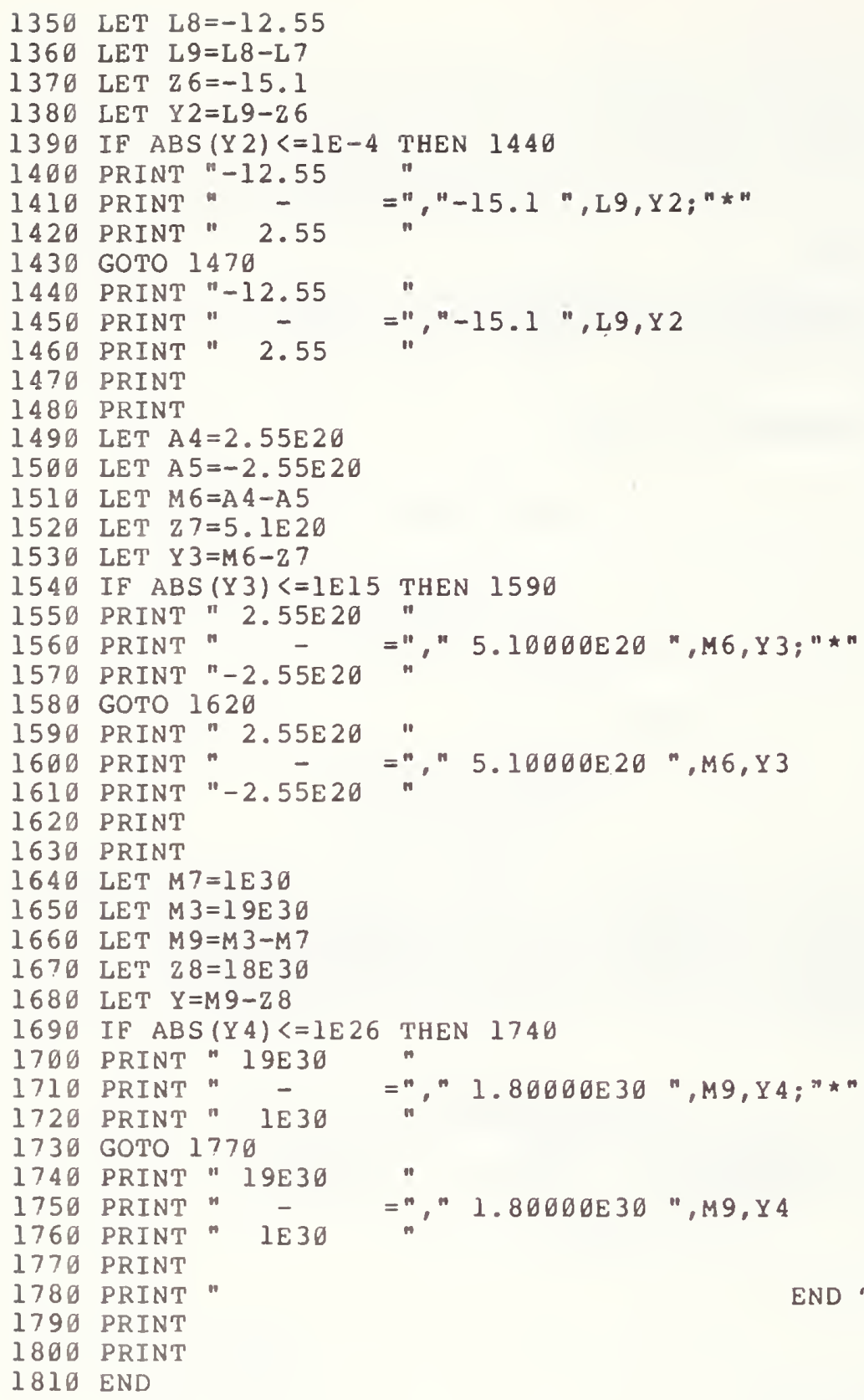




\section{BEGIN TEST.}

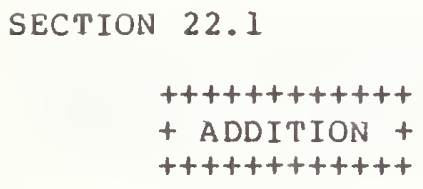

IF NO ASTERISK EOLLOWS ANY VALUE IN THE ABSOLUTE ERROR COLUMN, TEST PASSED. HOWEVER, IF AN ASTERISK FOLLOWS

A VALUE IN THE ABSOLUTE ERROR COLUMN, TEST FAILED BECAUSE SYSTEM WOULD HAVE FAILED THE ERROR BOUND ROUND-OFF OF SIX PLACE ACCURACY.

$\begin{array}{ccccc}\text { ASSIGNMENT } & 1 & & & \\ \text { PLUS } & & \text { REQUIRED } & \text { SUM OF } & \text { ABSOLUTE } \\ \text { ASSIGNMENT } & 2 & \text { SUM } & \text { SYSTEM } & \text { ERROR }\end{array}$

2

$+\quad-10 \quad-10 \quad 0$

$-12$

10.5

$+\quad-22.0 \quad-22 \quad 0$

2. $5 \mathrm{E} 20$

$\underset{3.5 \mathrm{E} 21}{+}=3.75000 \mathrm{E} 21 \quad 3.75000 \mathrm{E}+210$

$3 E 20$

$+$

$4 \mathrm{E} 2 \theta$

$=7.00000020 \quad 7.00000 E+20 \quad 0$

END TEST.

BEGIN TEST.

SECTION 22.2

- SUBTRACTION - 
IF NO ASTERISK FOLLOWS ANY VALUE IN THE ABSOLUTE ERROR COLUMN, TEST PASSED. HOWEVER, IF AN ASTERISK FOLLOWS A VALUE IN THE ABSOLUTE ERROR COLUMN, TEST FAILED BECAUSE SYSTEM WOULD HAVE FAILED THE ERROR BOUND ROUND-OFF OF SIX PLACE ACCURACY.

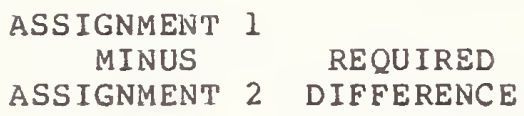

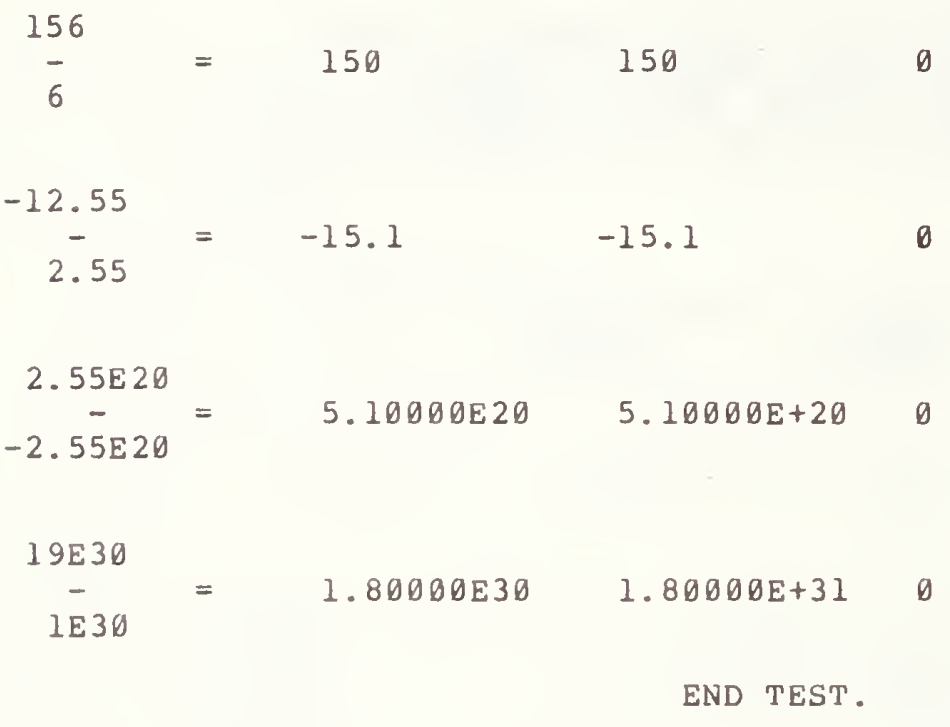




\section{ELEMENTARY EXPRESSIONS USING SIMPLE VARIABLES (CONTINUED)}

\subsection{Multiplication}

The objective of this test is to verify that the operation of multiplication between two numeric assigned simple variables will yield an accuracy of at least six decimal digits of precision. The test is similar to test 20.2, except for the simple variables and the values of their assignea numerical constants. The labeling of the first column is different in that for this test the first column is labeled "Assignrent 1 times Assigninent $2^{*}$. Finally, this test has the same output format as test 20.2 .

\subsection{Division}

The objective of this test is to verify that the operation of division between two numerically assigned simple variables will yield an accuracy of at least six decimal digits of precision. The test is similar to test 21.1 , except for the simple variables and the values of their assigned numerical constants. The labeling of the first column is different in that for this test the first column is labeled "Assignment l divided by Assignment 2." Again, this test has the same output format as test 21.1 .

\subsection{Involution}

The objective of this test is verify that the operation of involution between two numerically assigned simple variables will yield an accuracy of at least six decimal digits of precision. The test is similar to test 21.2, except for the simple variables and the values of their assigned numerical constants. The labeling of the first column is different in that for this test the first column is labeled "Assignment 1 "Assignment 2." Again, this test has the same output format as test 21.2 .

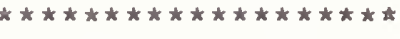

$\star$ PROGRAM FILE $23 \star$

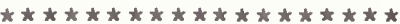

0010 PRINT "PROGRAM FILE 23"
0060 PRINT
0070 PRINT
0080 PRINT
0090 PRINT "
0100 PRINT
0110 PRINT
0120 PRINT "
0130 PRINT

BEGIN TEST."

SECTION $23.1 "$ 


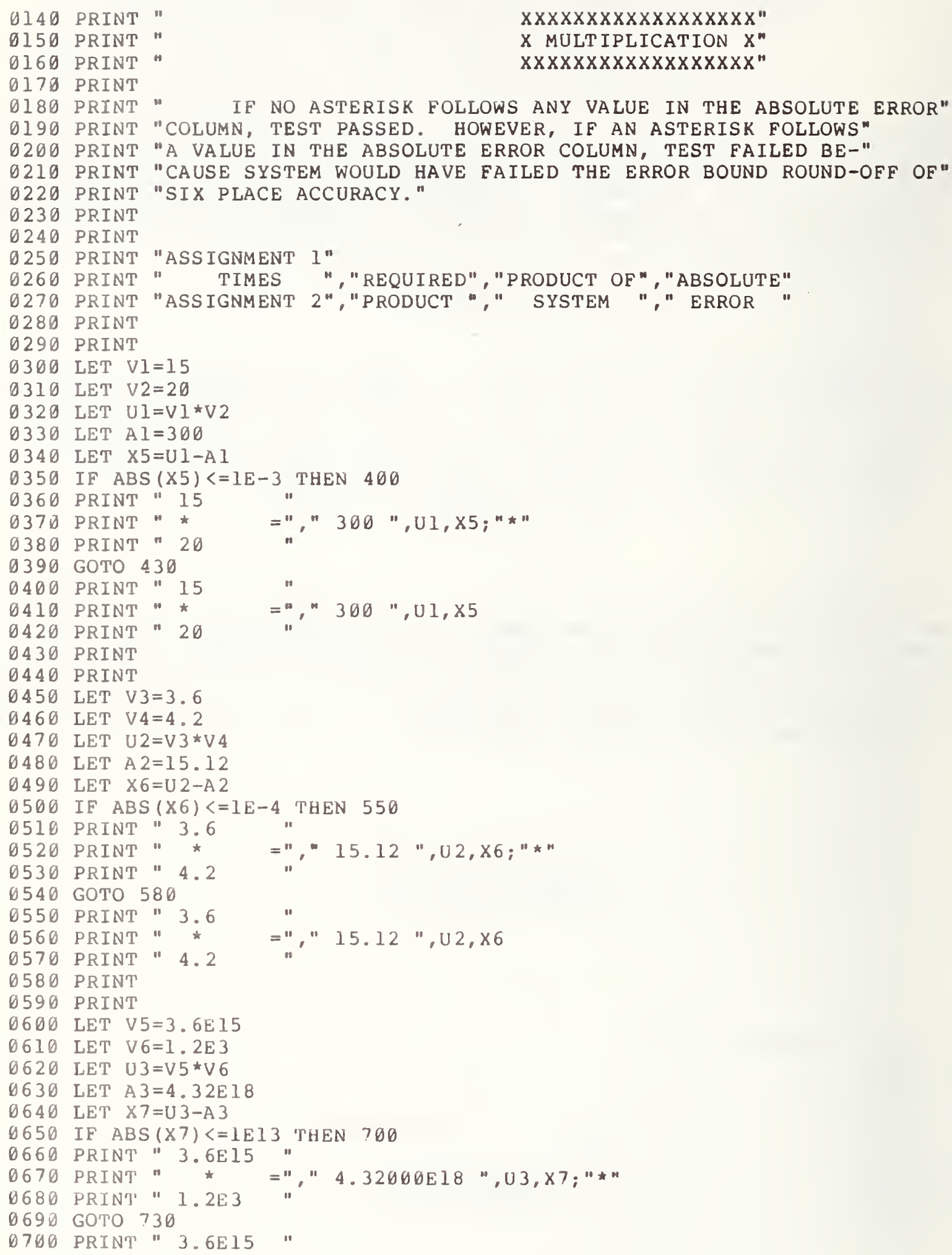
Ø270 PRINT "ASSIGNMENT 2","PRODUCT "," SYSTEM "," ERROR "

\section{$X X X X X X X X X X X X X X X X X "$ $x$ MULTIPLICATION $x^{n}$ XXXXXXXXXXXXXXXXXX"}

IF NO ASTERISK FOLLOWS ANY VALUE IN THE ABSOLUTE ERROR" MN, TEST PASSED. HOWEVER, IF AN ASTERISK FOLLOWS" "A VAlue in the absolute erRor COLUma, test failed be-" "CAUSE SYSTEM WOULD HAVE FAILED THE ERROR BOUND ROUND-OFF OF" "ASSIGNMENT 1 " 


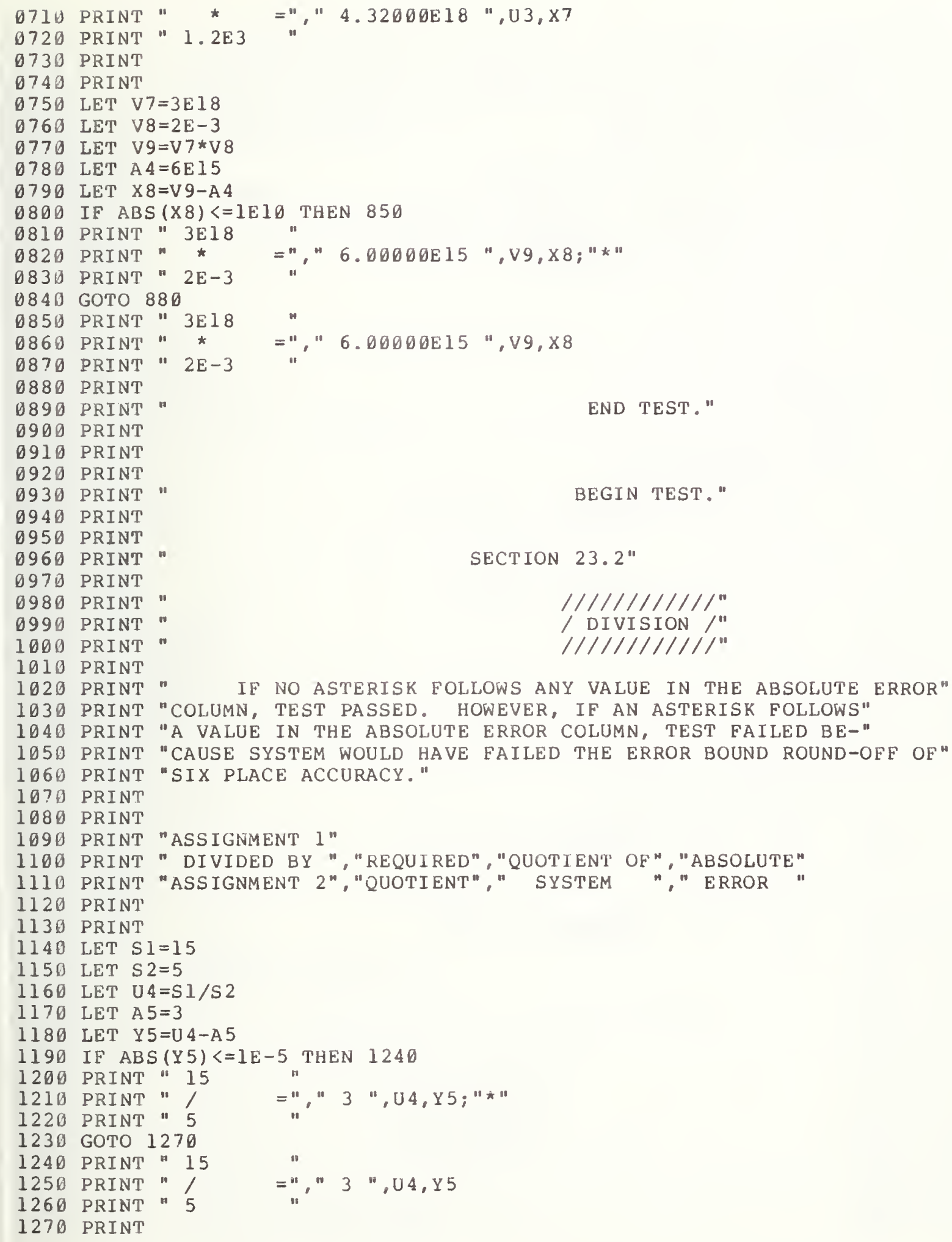




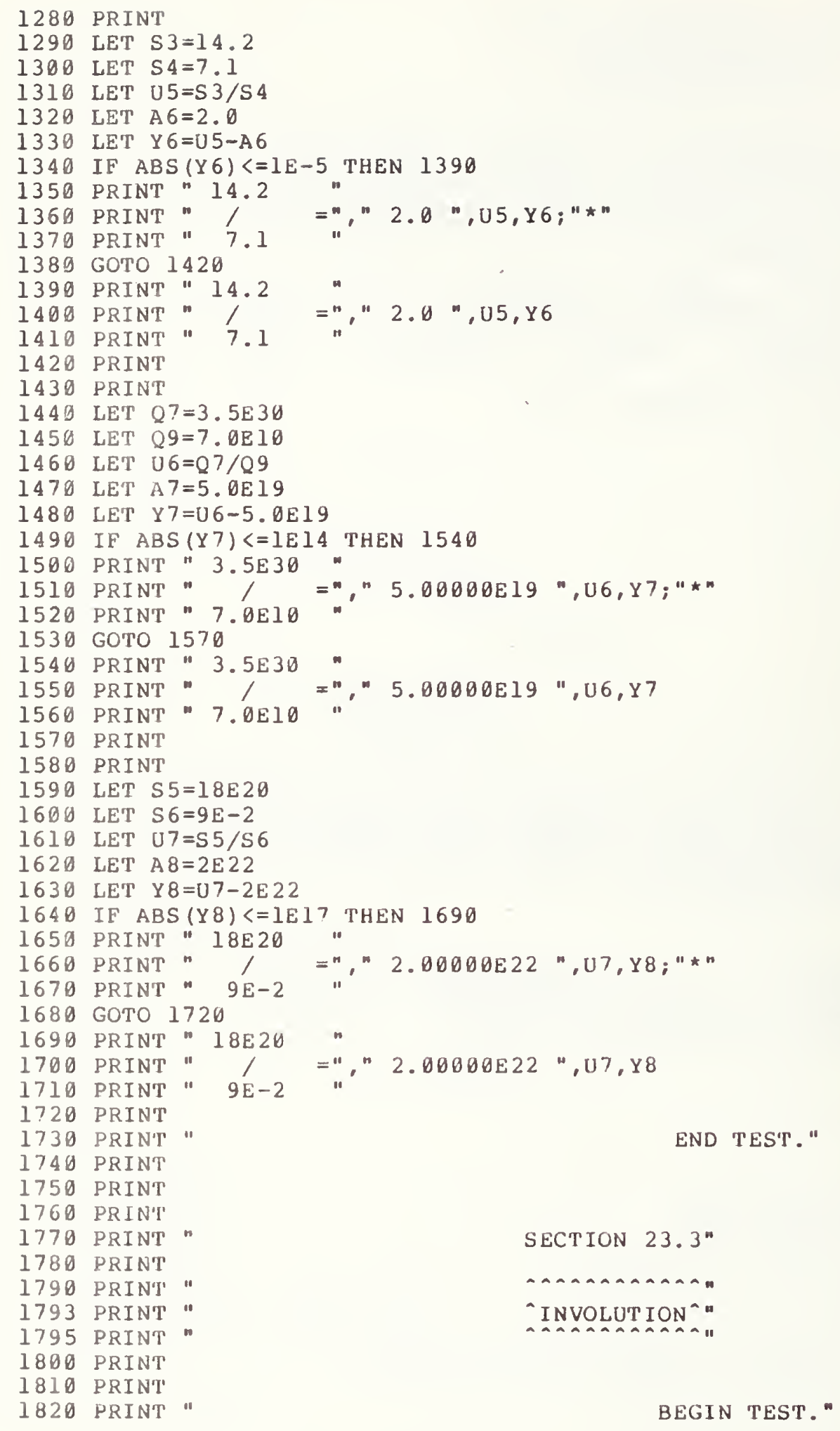


$133)$ PRINT

1341 PRINT

1851 PRINT

IB6I PRINT

1371 SRINT

$138)$ PRINT

$139)$ PRINT

$199)$ PRINT

$131 \%$ PRINT

112 I PRINT

193 ) PRINT

194J PRINT

$195 ! 1$ DRINT

$196 ! 1$ LET $T 6=-5$

19\%" Le? U6=4

$1981 \mathrm{LE}$. $6=\mathrm{T} 6{ }^{\circ} \mathrm{U} 6$

1990 LET B1 $=625$

2\{f। LEI T $7=W 6-B 1$

21) I11 IP ABS (T7) $<=1 \mathrm{E}-3$ THEN 2060

$20: 1$ PRINT " -5

213,31 PRINT "

$2041)$ PRINं" 4

205!) GOTO 2090

206!) DRTNT "-5

20\%() PRINT" "

$2081)$ PRINT " 4

2091) PRINT

$210 ! 1$ PRINT

$2 \pm 11$ LET $\mathrm{R} 6=.625$

22. $2 \mathrm{~S} \mathrm{~S} 6=0.0$

2130 LER X6

2.2.411 T.ES B $2=1.0$

$21515 \mathrm{ES} \mathrm{Y} 6=\mathrm{X} 6-\mathrm{B} 2$

2.6! IF ABS (Y6) $=1 E-5$ THEN 2210

2." iा PRINT" . 625

$218 ! 1$ PRINT

21911 PRINT" 0.0

22011 GONO 2240

221 (I PRINT" .625

22211 PRINT

2.31) PRINT

22.41 PRINT

22.51. PRINT

226 । LET $T 8=-.005 \mathrm{E} 3$

227 I.EI U $7=-200 . E-2$

228 ILT W7=T8 $\mathrm{C}$ ?

2296: I.ET B $3=4.0 E-2$

2306 IET $X 7=W 7-B 3$

231 IF ABS $(X 7)<=1 E-6$ THEN 2360

2326 PRINT "-.0ด5E3

2336 PRINT

2341 PRINT " $-200 . \mathrm{E}-2$

235 GOTO 2390

236 PRINT " $-.005 E 3$

$23 \% 1$ PRINT

2381 PRINT

2396 PRINT
IF NO ASTERISK FOLLOWS ANY VALUE IN THE ABSOLUTE ERROR" TEST PASSED. HOWEVER, IF AN ASTERISK FOLLOWS" CE ACCURACY."

$$
\begin{aligned}
& =", " 625 \text { " } 66, \mathrm{~T} 7 ; " * " \\
& =", " 625 \text { " }, \mathrm{W} 6, \mathrm{~T} 7
\end{aligned}
$$




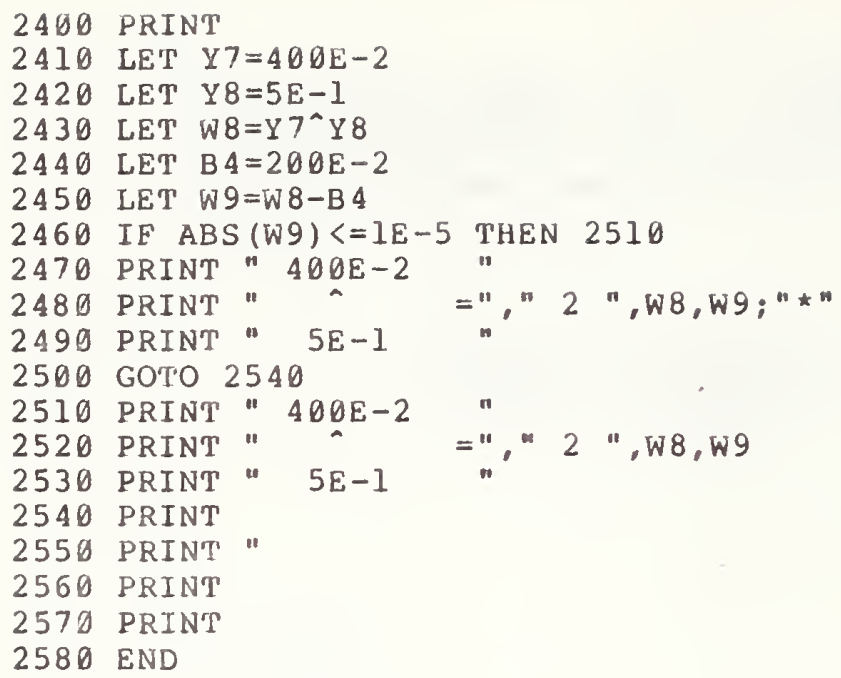

SECTION 23.1

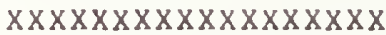
$X$ MULTIPLICATION $X$ XXXXXXXXXXXXXXXXXX

IF NO ASTERISK FOLLOWS ANY VALUE IN THE ABSOLUTE ERROR COLUMN, TEST PASSED. HOWEVER, IF AN ASTERISK FOLLOWS A VALUE IN THE ABSOLUTE ERROR COLUMN, TEST FAILED BECAUSE SYSTEM WOULD HAVE FAILED THE ERROR BOUND ROUND-OFF OF SIX PLACE ACCURACY.

$\begin{array}{cllcc}\text { ASSIGNMENT } & 1 & & & \\ \text { TIMES } & \text { REQUIRED } & \text { PRODUCT OF } & \text { ABSOLUTE } \\ \text { ASSIGNMENT } & 2 & \text { PRODUCT } & \text { SYSTEM } & \text { ERROR }\end{array}$




$$
15
$$

$$
\text { * }
$$$$
=300
$$

300

$\theta$

20
3.6
*
$=$
15.12
15.12
$\theta$
4.2

3. $6 \mathrm{E} 15$

$\star=$

4. $32000 \mathrm{E} 18$

4. $32000 E+18$

b

1. $2 \mathrm{E} 3$

$3 E 18$

* =

$6.00000 \mathrm{E} 15$

$6.00000 E+15$

b

$2 E-3$

\begin{abstract}
END TEST.
\end{abstract}
BEGIN TEST.

\author{
SECTION 23.2 \\ $1 / 1 / 1 / 1 / 1 /$ \\ / DIVISION / \\ //I///I///
}

IF NO ASTERISK FOLLOWS ANY VALUE IN THE ABSOLUTE ERROR COLUMN, TEST PASSED. HOWEVER, IF AN ASTERISK FOLLOWS A VALUE IN THE ABSOLUTE ERROR COLUMN, TEST FAILED BECAUSE SYSTEM WOULD HAVE FAILED THE ERROR BOUND ROUND-OFF OF SIX PLACE ACCURACY.

ASSIGNMENT 1

DIVIDED BY REQUIRED

ASSIGNMENT 2 QUOTIENT

1

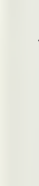
QUOTIENT OF ABSOLUTE SYSTEM ERROR

14.2

7.1

$=2.0$

2

3

3

$\theta$
3. $5 E 30$
I =
5.00000019
$5.00000 \mathrm{E}+19$
0 


$\underset{9 E-2}{18 E 20}=2.00000 \mathrm{E} 22 \quad 2.00000 \mathrm{E}+220$
END TEST.

SECTION 23.3

‘INVOLUTION ${ }^{\wedge}$

BEGIN TEST.

IF NO ASTERISK FOLLOWS ANY VALUE IN THE ABSOLUTE ERROR COLUMN, TEST PASSED. HOWEVER, IF AN ASTERISK FOLLOWS A VALUE IN THE ABSOLUTE ERROR COLUMN, TEST FAILED BECAUSE SYSTEM WOULD HAVE FAILED THE ERROR BOUND ROUND-OFF OF SIX PLACE ACCURACY.

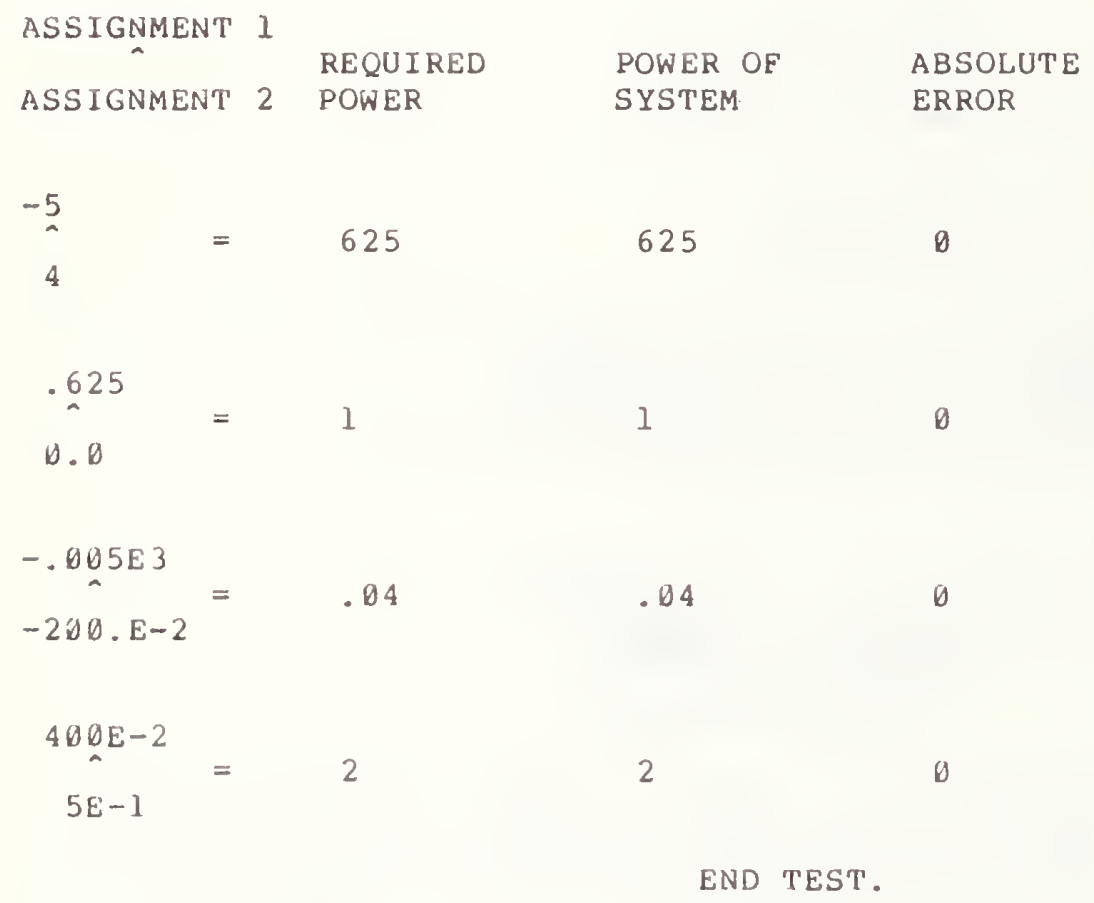




\section{D ELEMENTARY OPERATIONS ON MIXED TYPE CONSTANTS}

The objective of the next few tests is to determine whether the terms of a numerical expression can be of mixed type, that is, whether NRl constants can be added to NR2 or NR3 constants, whether NR1 or NR2 constants can be subtracted from NR3 constants, etc. For this test section, each sub-test will at most use two terms, since expressions with more than two terms will be tested later. The reader should remember that the word type here only refers to graphical form and not to the formal meaning of a typed constant or variable as in FORTRAN, for example. The reader should be familiar with section 7 of BSR $\times 3.60$ at this point.

\section{1 Addition}

The objective of this test is to verify that the operation of addition on two numerical constants that are not of the same type will still yield accuracy of at least six decimal digits of precision. The test is similar to test 19.3, except for the mixing of types and the labeling of the first output column which for this test is labeled "lst Addend plus 2nd Addend". This test has the same output format as test 19.3.

\subsection{Subtraction}

The objective of this test is to verify that the operation of subtraction between two numerical constants, not of the same type, will maintain at least six decimal digits of precision. The test is similar to test 20.1, except for the mixing of types, and the word minus used in labeling of the first column output. Einally this test has the same output format as test 20.1 .

0010 PRINT "PROGRAM EILE $24 "$
0060 PRINT
0070 PRINT
0080 PRINT "
0090 PRINT"
0100 PRINT
0110 PRINT
0120 PRINT
0180 PRINT"
0190 PRINT
0200 PRINT
0210 PRINT"




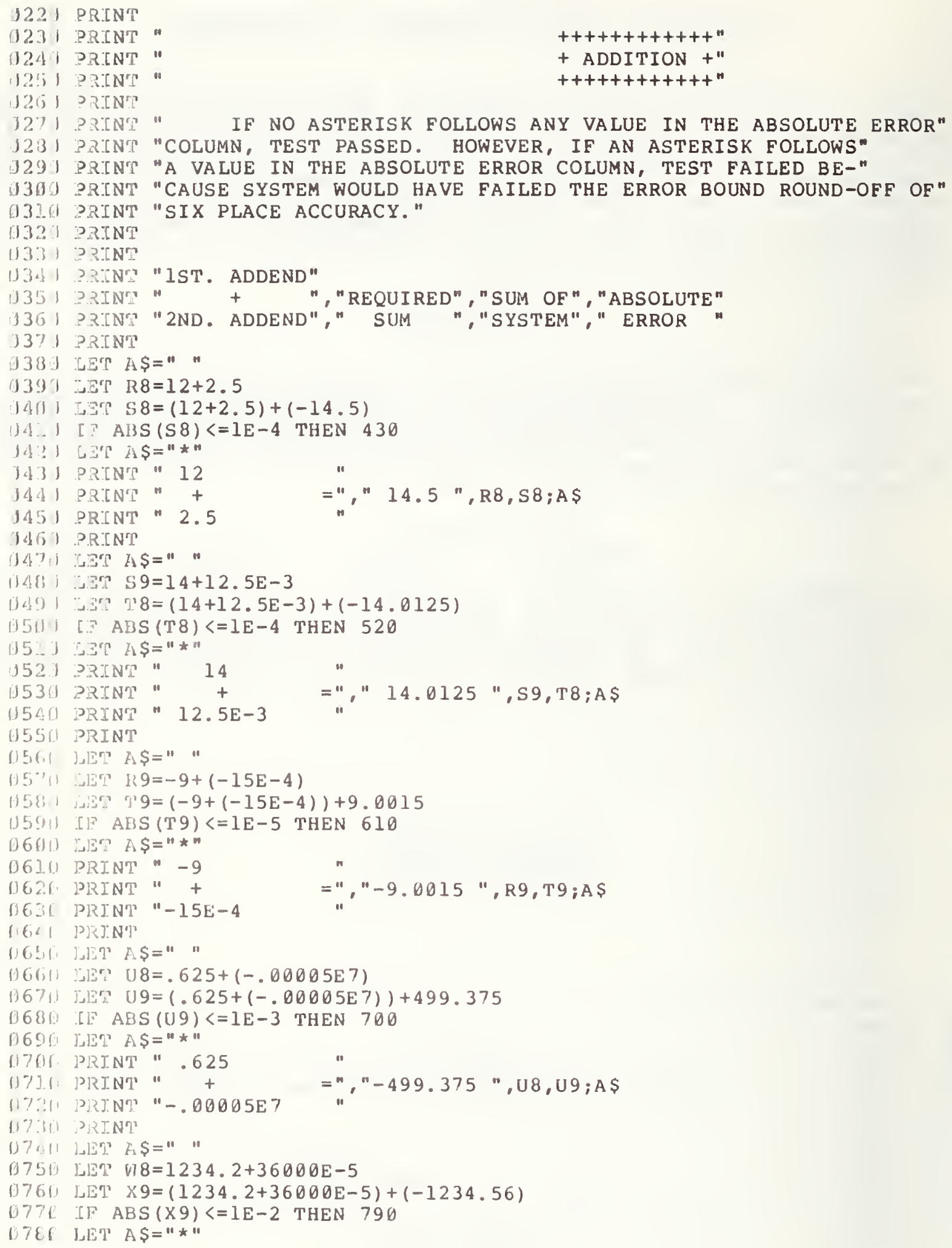




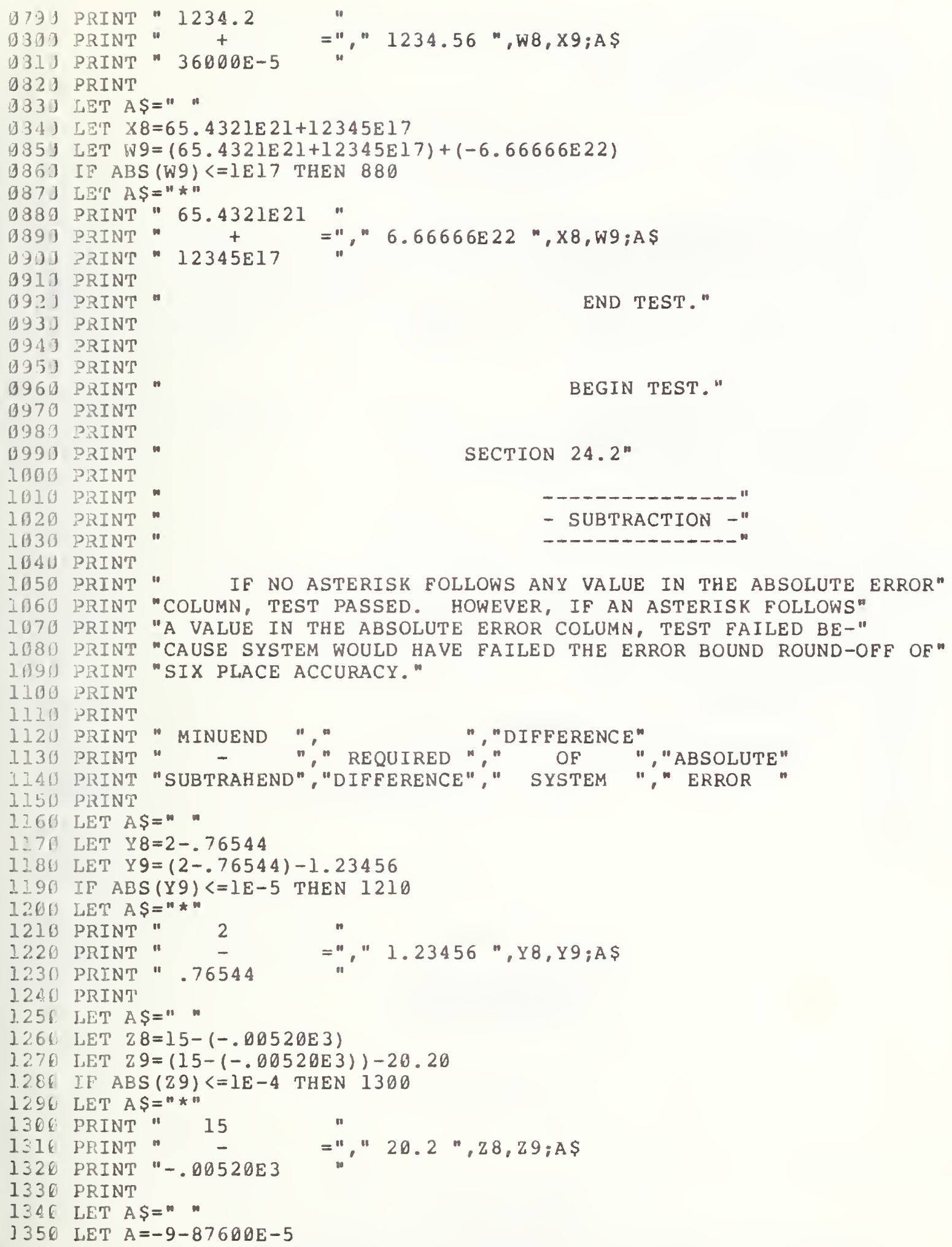



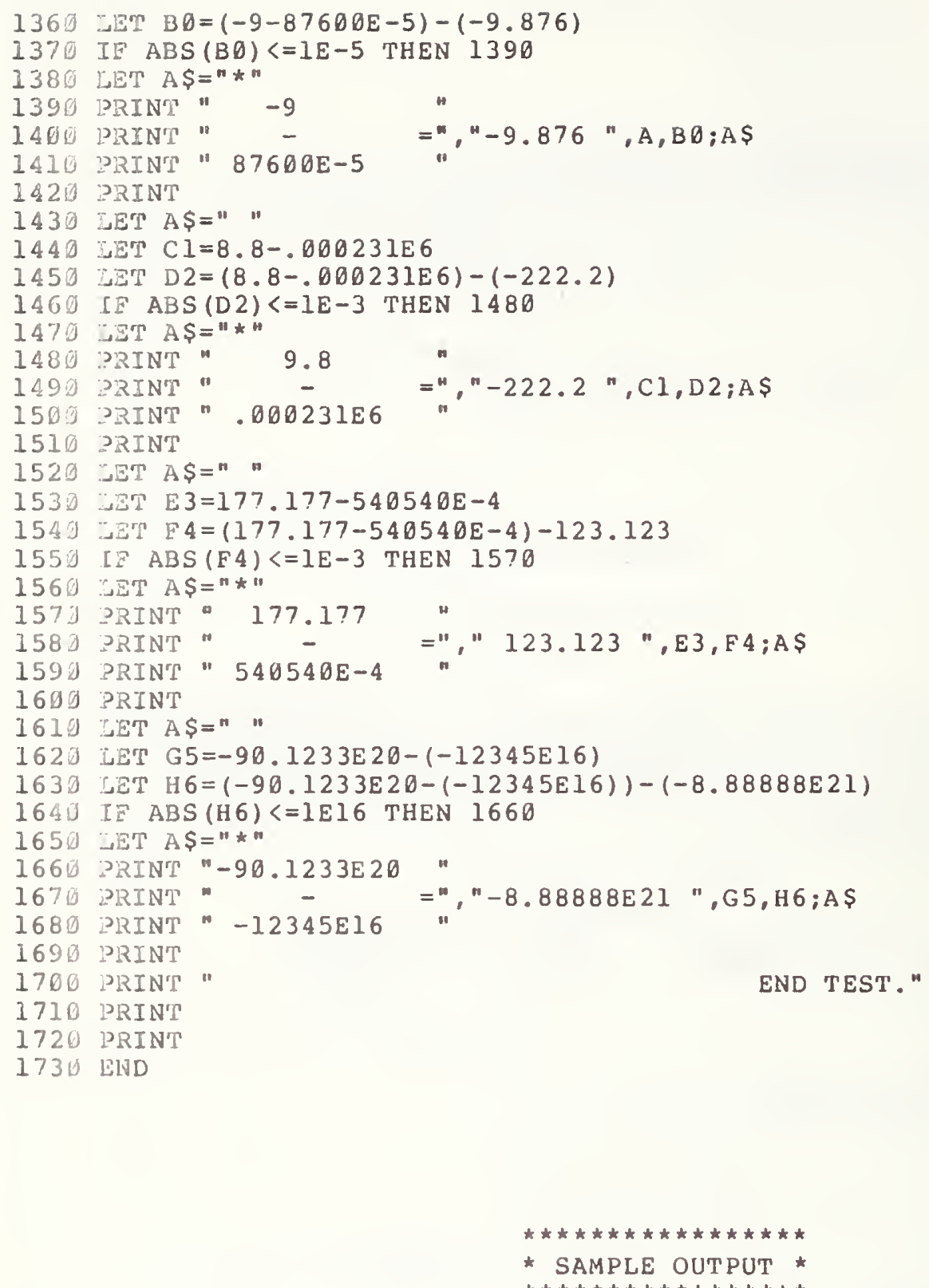

PROGRIM FILE 24

SEC'TION 24.0: PRIMITIVE OPERATIONS ON MIXED MODES. 
BEGIN TEST.

SECTION 24.1

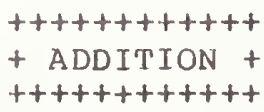

IE NO ASTERISK FOLLOWS ANY VALUE IN THE ABSOLUTE ERROR COI,UMN, TEST PASSED. HOWEVER, IF AN ASTERISK FOLLOWS A VALUE IN THE ABSOLUTE ERROR COLUMN, TEST FAILED BECAUSE SYSTEM WOULD HAVE FAILED THE ERROR BOUND ROUND-OFF OF SIX PLACE ACCURACY.

1ST. ADDEND

$$
+
$$

2ND. ADDEND

REQUIRED SUM OF SUM

$=14.5$

2.5

14

$+$

12. $5 \mathrm{E}-3$

$-9$

$+$

$-15 E-4$

.625

$+$

$-.00005 \mathrm{E} 7$

$=-499 \cdot 375$

$-499.375$

b

1234.2

$+\quad=1234.56$

$36000 \mathrm{E}-5$

$65.4321 E 21$

$1234 \stackrel{+}{5 \mathrm{E}} 17$

$=6.66666 \mathrm{E} 22$

$-9.0015$

$\emptyset$

ABSOLUTE

ERROR

14.5

b

14.0125

b

14.0125

$=-9.0015$

1234.56

l
BEGIN TEST .

END TEST.

$6.66666 \mathrm{E}+22$ 
IF NO ASTERISK FOLLOWS ANY VALUE IN THE ABSOLUTE ERROR COLUMN, CHECK TEST PASSED. HOWEVER, IF AN ASTERISK FOLLOWS A VALUE IN THE ABSOLUTE ERROR COLUMN, CHECK TEST FAILED BECAUSE SYSTEM WOULD HAVE FAILED THE ERROR BOUND ROUND-OFF OF SIX PLACE ACCURACY.

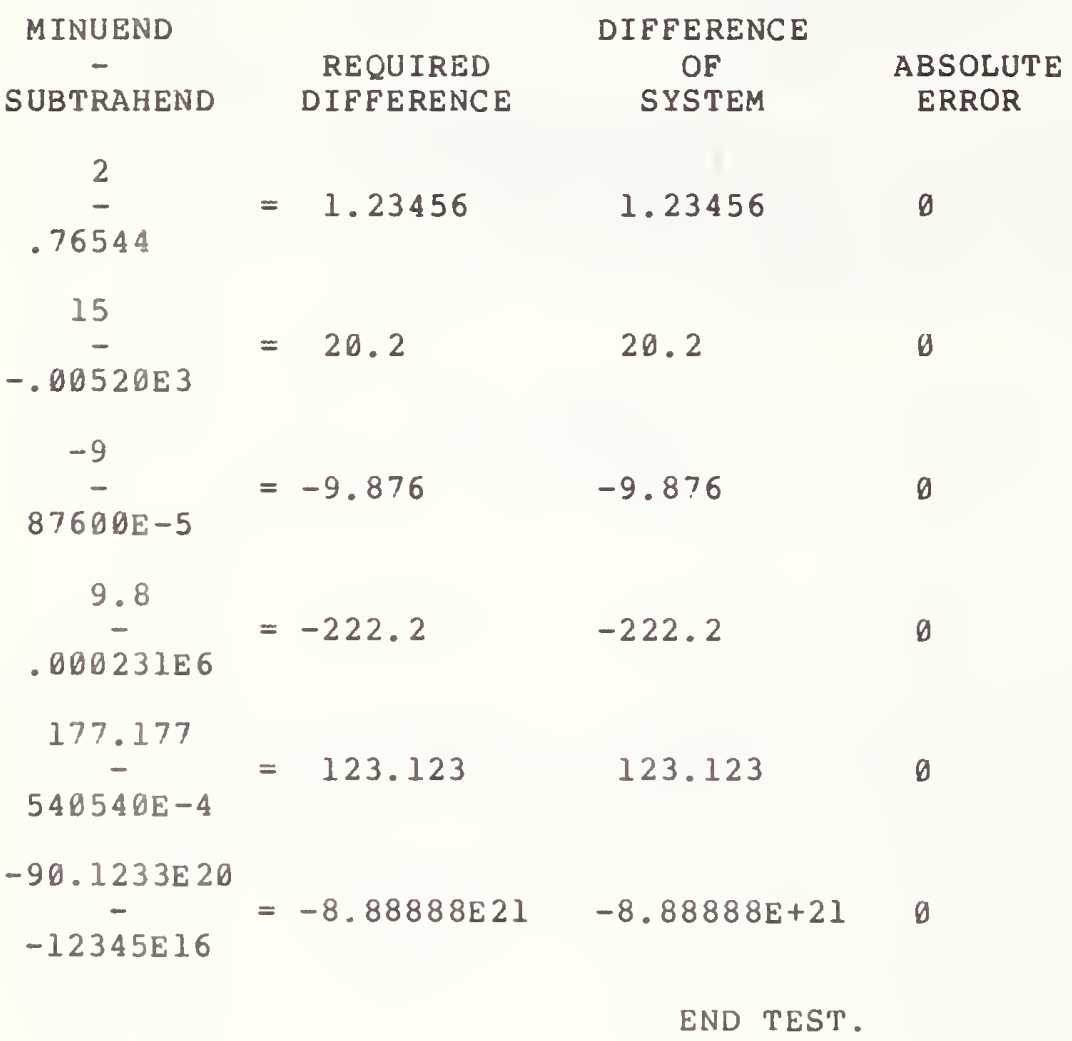




\section{ELEMENTARY OPERATIONS ON MIXED TYPE CONSTANTS (CONTINUED)}

\subsection{Multiplication}

The objective of this test is to verify that the operation of multiplication of two numerical constants that are not of the same type will maintain at least six decimal digits of precision. The test is the same as test 20.3, except for the mixing of types. This test has the same output format as test 20.3 .

\subsection{Division}

The objective of this test is to verify that the operation of division between two numerical constants that are not of the same type will maintain at least six decimal digits of precision. The test is the same in structure as test 21.1 , except for the mixing of types. This test has the same output format as test 21.1 .

\subsection{Involution}

The objective of this test is to verify that the operation of involution between two numerical constants that are not of the same type will maintain at least six decimal digits of precision. The test is the same structurally to test 21.2 , except for the mixing of types. This test has the same output format as test 21.2 .

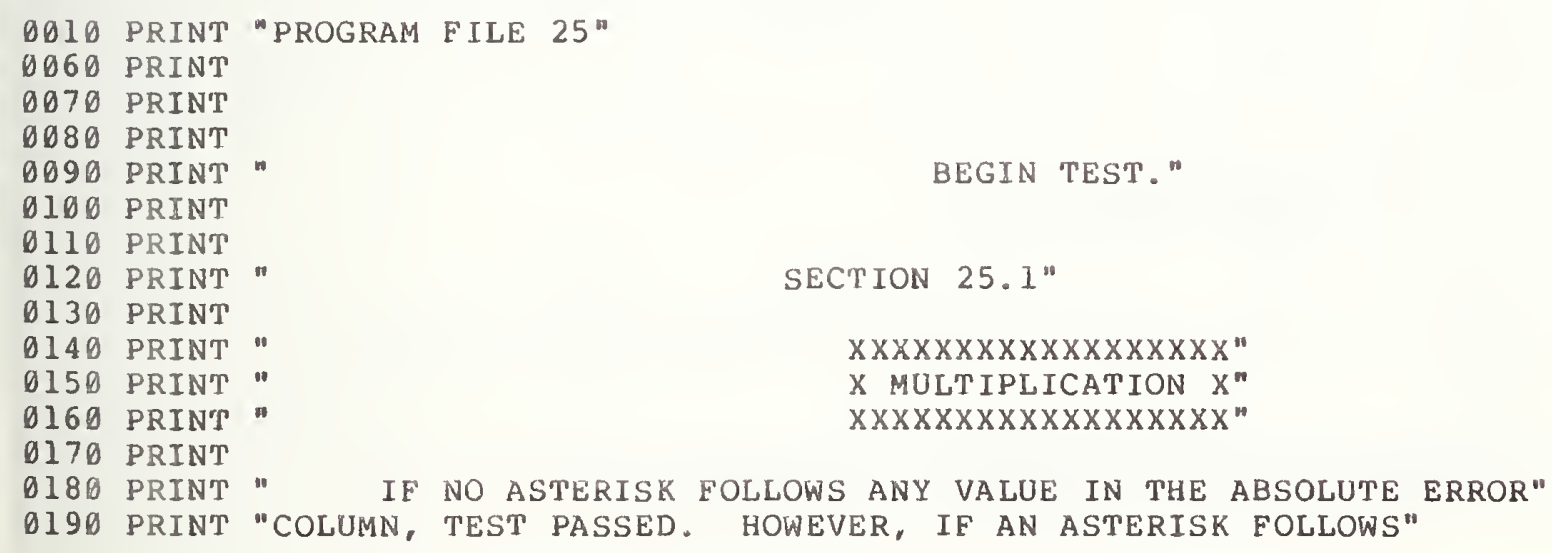




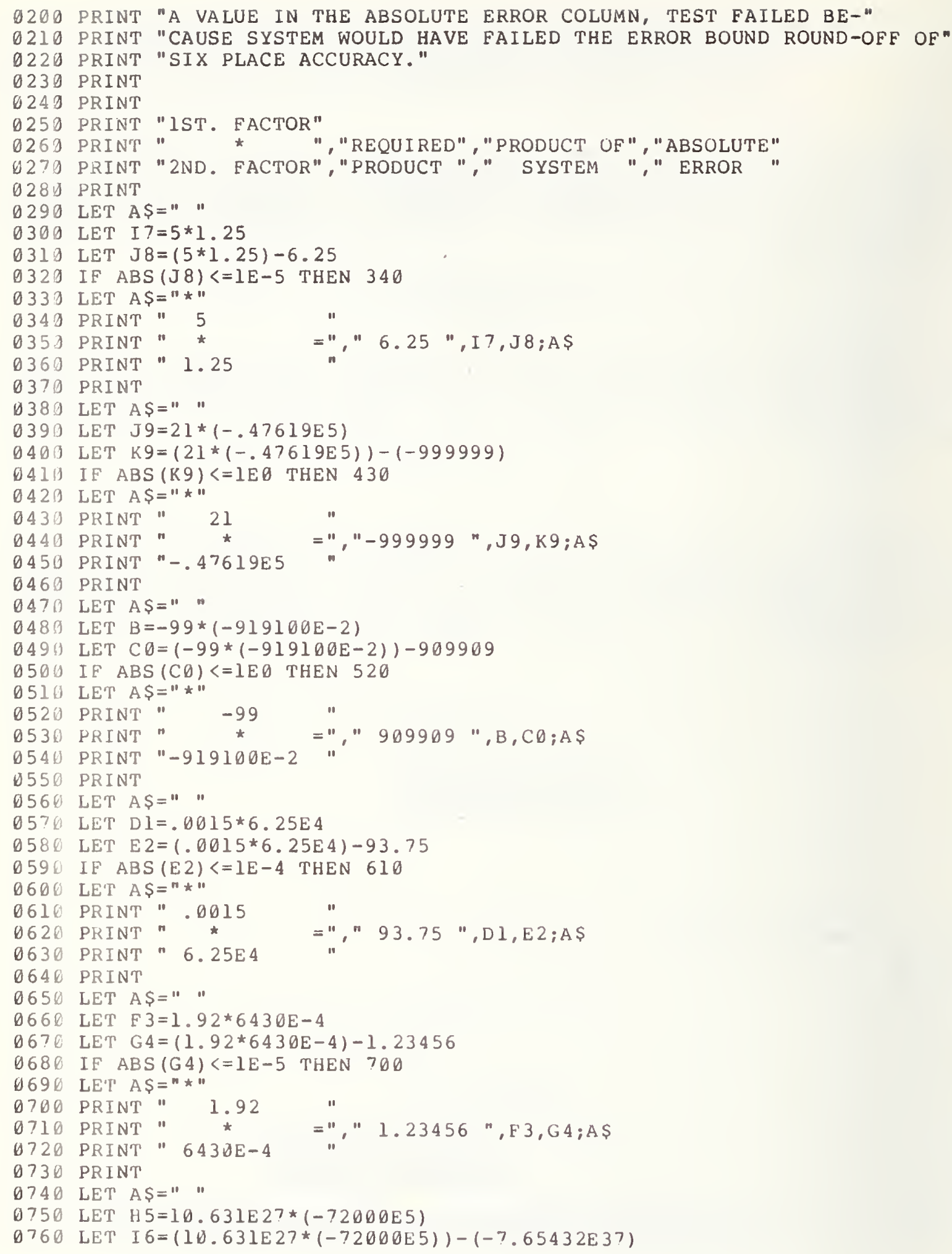




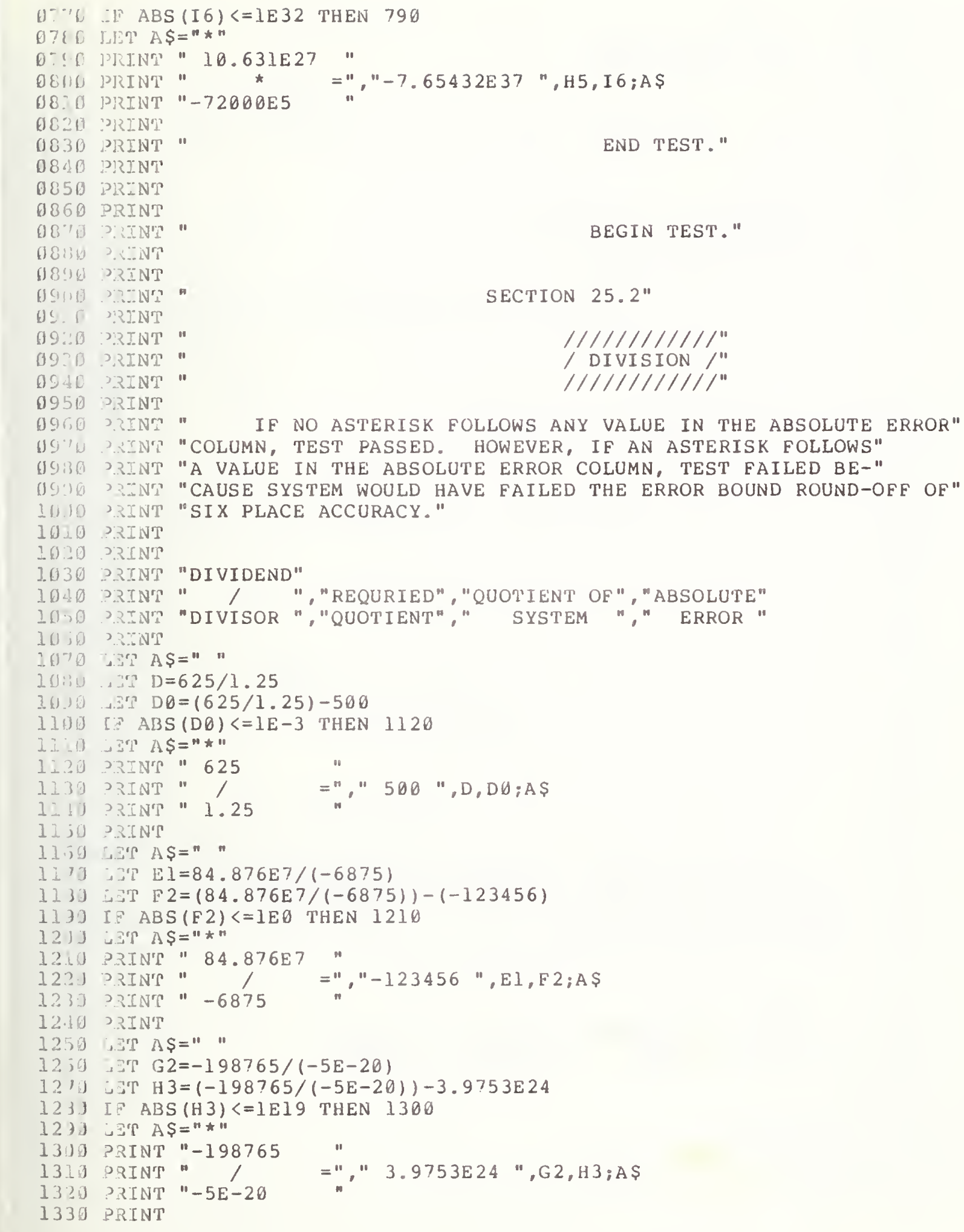




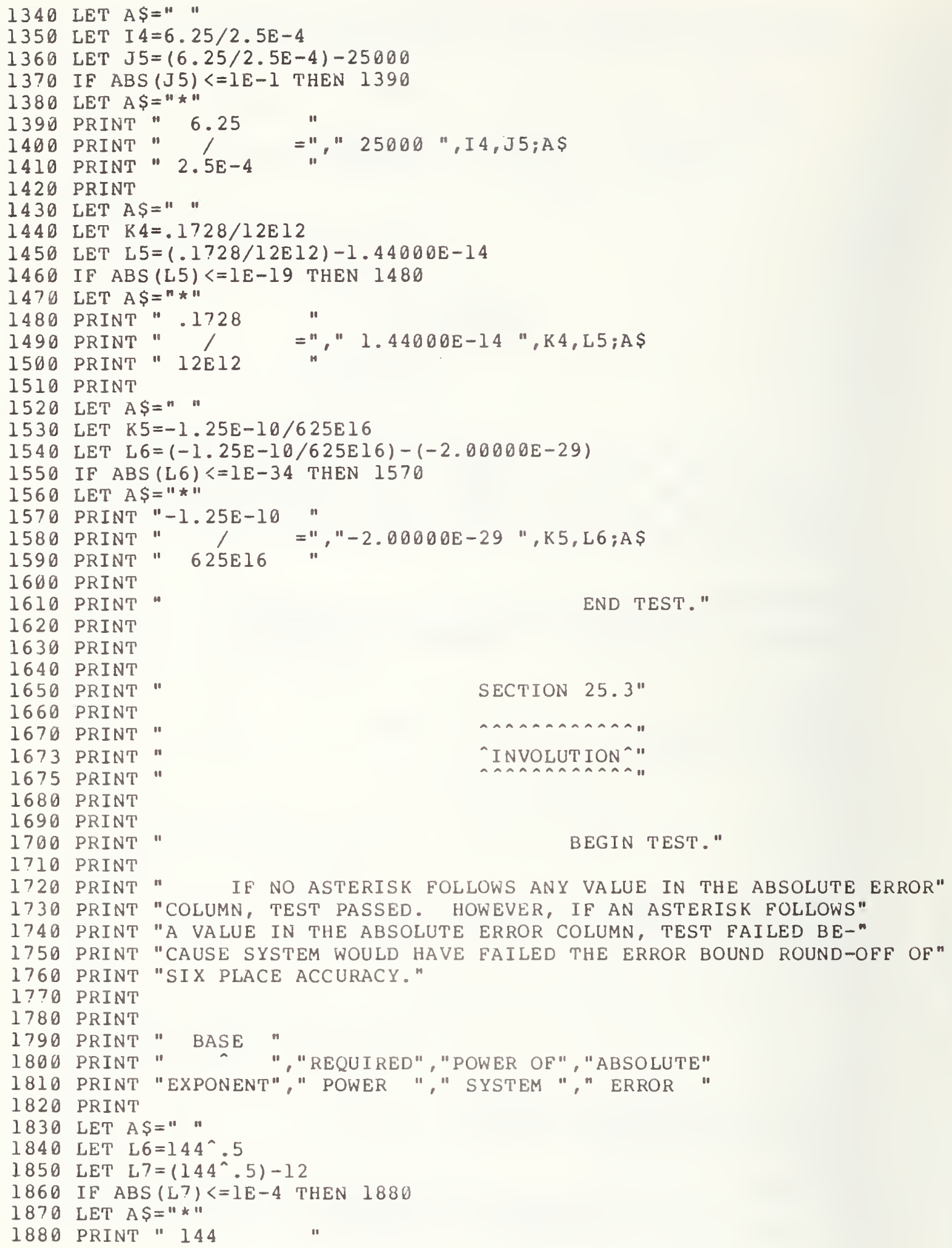

IF NO ASTERISK FOLLOWS ANY VALUE IN THE ABSOLUTE ERROR" "COLUMN, TEST PASSED. HOWEVER, IF AN ASTERISK FOLLOWS" 


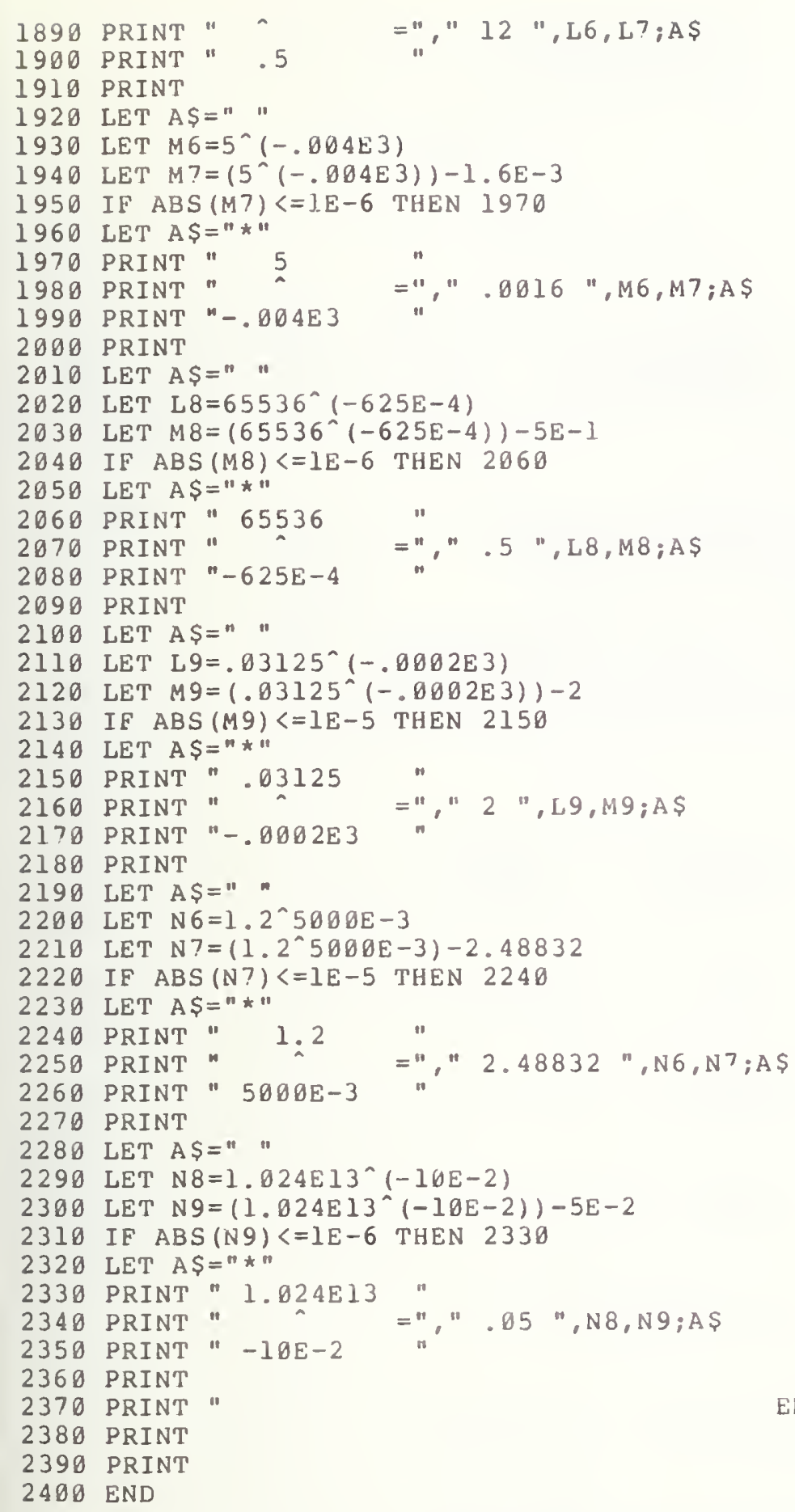




\author{
BEGIN TEST. \\ SECTION 25.1

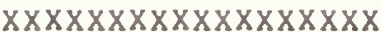 \\ $X$ MULTIPLICATION $x$ \\ XXXXXXXXXXXXXXXXXX
}

IF NO ASTERISK FOLLOWS ANY VALUE IN THE ABSOLUTE ERROR COLUMN, TEST PASSED. HOWEVER, IF AN ASTERISK FOLLOWS A VALUE IN THE ABSOLUTE ERROR COLUMN, TEST FAILED BECAUSE SYSTEM WOULD HAVE FAILED THE ERROR BOUND ROUND-OFF OF SIX PLACE ACCURACY.

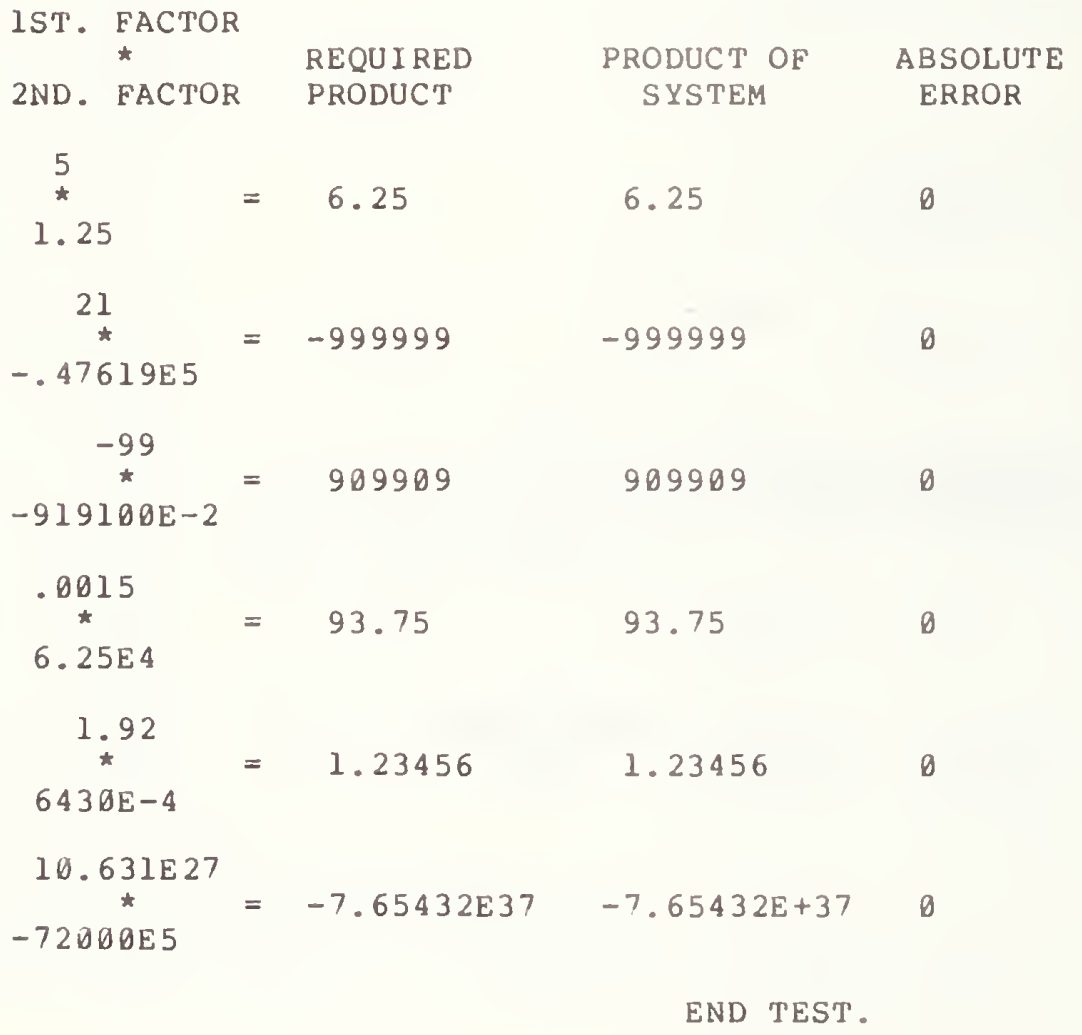


BEGIN TEST .

SECTION 25.2

$$
\begin{aligned}
& 1 / 1 / 1 / 1 / 1 / 1 \\
& \text { / DIVISION / } \\
& \text { ///l/l/l/l }
\end{aligned}
$$

IF NO ASTERISK FOLLOWS ANY VALUE IN THE ABSOLUTE ERROR COLUMN, TEST PASSED. HOWEVER, IF AN ASTERISK FOLLOWS

A VALUE IN THE ABSOLUTE ERROR COLUMN, CHECK TEST FAILED BECAUSE SYSTEM WOULD HAVE FAILED THE ERROR BOUND ROUND-OFF OF SIX PLACE ACCURACY.
DIVIDEND
I ISOR
REQUIRED
QUOTIENT OF
SYSTEM
ABSOLUTE
ERROR

\title{
625
}

I

$=500$

500

$\emptyset$

1.25

$84.876 \mathrm{E} 7$

$-0,875$

$=\quad-123456$

$-123456$

$\emptyset$

$-198765$

$-5 E-20$

$=3.97530 \mathrm{E} 24$

$3.97530 E+24$

$\emptyset$

6.25

$\int_{2.5 E-4}^{6.25}=25000 \quad 25000$

.1728

1

$=1.44000 \mathrm{E}-14$

$1.44000 \mathrm{E}-14 \quad \emptyset$

$12 \mathrm{E} 12$

$-1.25 E-10$

$$
\frac{\prime}{625 E 16}=-2.00000 \mathrm{E}-29 \quad-2.00000 \mathrm{E}-29 \quad 0
$$

\author{
END TEST.
}

SECTION 25.3

INVOLUTION"

BEGIN TEST . 
IF NO ASTERISK FOLLOWS ANY VALUE IN THE ABSOLUTE ERROR COLUMN, TEST PASSED. HOWEVER, IF AN ASTERISK FOLLOWS A VALUE IN THE ABSOLUTE ERROR COLUMN, TEST FAILED BECAUSE SYSTEM WOULD HAVE FAILED THE ERROR BOUND ROUND-OFF OF SIX PLACE ACCURACY.

\begin{tabular}{|c|c|c|c|c|}
\hline EXPONENT & & $\begin{array}{l}\text { REQUIRED } \\
\text { POWER }\end{array}$ & $\begin{array}{l}\text { POWER OF } \\
\text { SYSTEM }\end{array}$ & $\begin{array}{l}\text { ABSOLUTE } \\
\text { ERROR }\end{array}$ \\
\hline $\begin{array}{r}144 \\
.5\end{array}$ & $=$ & 12 & 12 & 0 \\
\hline $\begin{array}{c}5 \\
-.004 E 3\end{array}$ & $=$ & .0016 & .0016 & $\theta$ \\
\hline $\begin{array}{c}65536 \\
-625 E-4\end{array}$ & $=$ & .5 & .5 & 0 \\
\hline $\begin{array}{r}.03125 \\
-.0002 \mathrm{E} 3\end{array}$ & $=$ & 2 & 2 & D \\
\hline $\begin{array}{c}1: 2 \\
5000 E-3\end{array}$ & $=$ & 2.48832 & 2.48832 & $\theta$ \\
\hline $\begin{array}{l}1.024 \mathrm{E} 13 \\
-10 \mathrm{E}-2\end{array}$ & $=$ & .65 & .05 & $\theta$ \\
\hline
\end{tabular}




\section{ELEMENTARY OPERATIONS ON VARIABLES ASSIGNED} MI XED TYPE CONSTANTS

The objective of these tests is to verify further that numerical expressions can be constructed by mixing simple numeric variables that have not been assigned the same type of numeric constant, with the operations of addition subtraction, multiplication, division, and involution.

\section{1 Addition}

The objective of this test is to verify that the operation of addition of two numerically assigned simple variables, that have not been assigned the same type of numeric constants, maintains at least six decimal digits of precision. The test is similar in structure and output format to test 22.1.

\subsection{Subtraction}

The objective of this test is to verify that the operation of subtraction between two numerically assigned simple variables, that have not been assigned the same type constants, maintains at least six decimal digits of precision. The test is similar in structure and output format to test 22.2 .

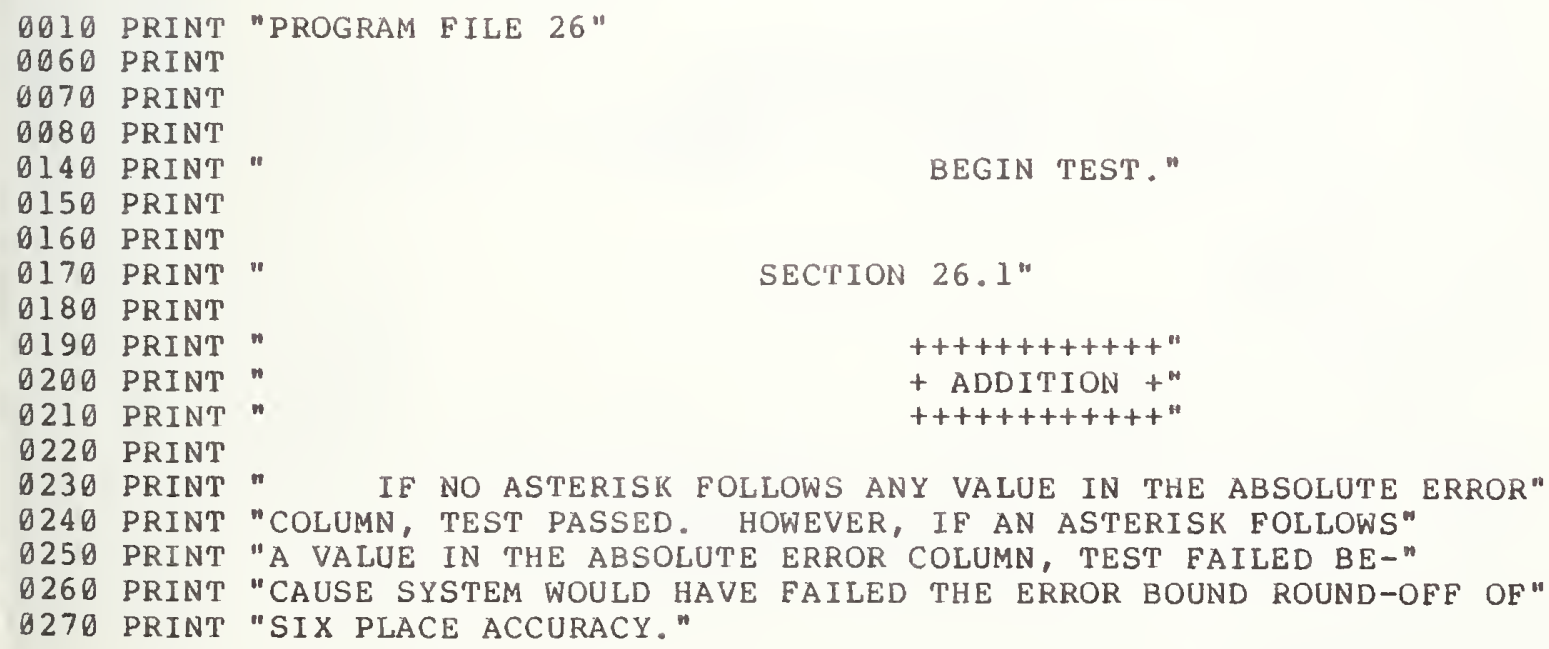




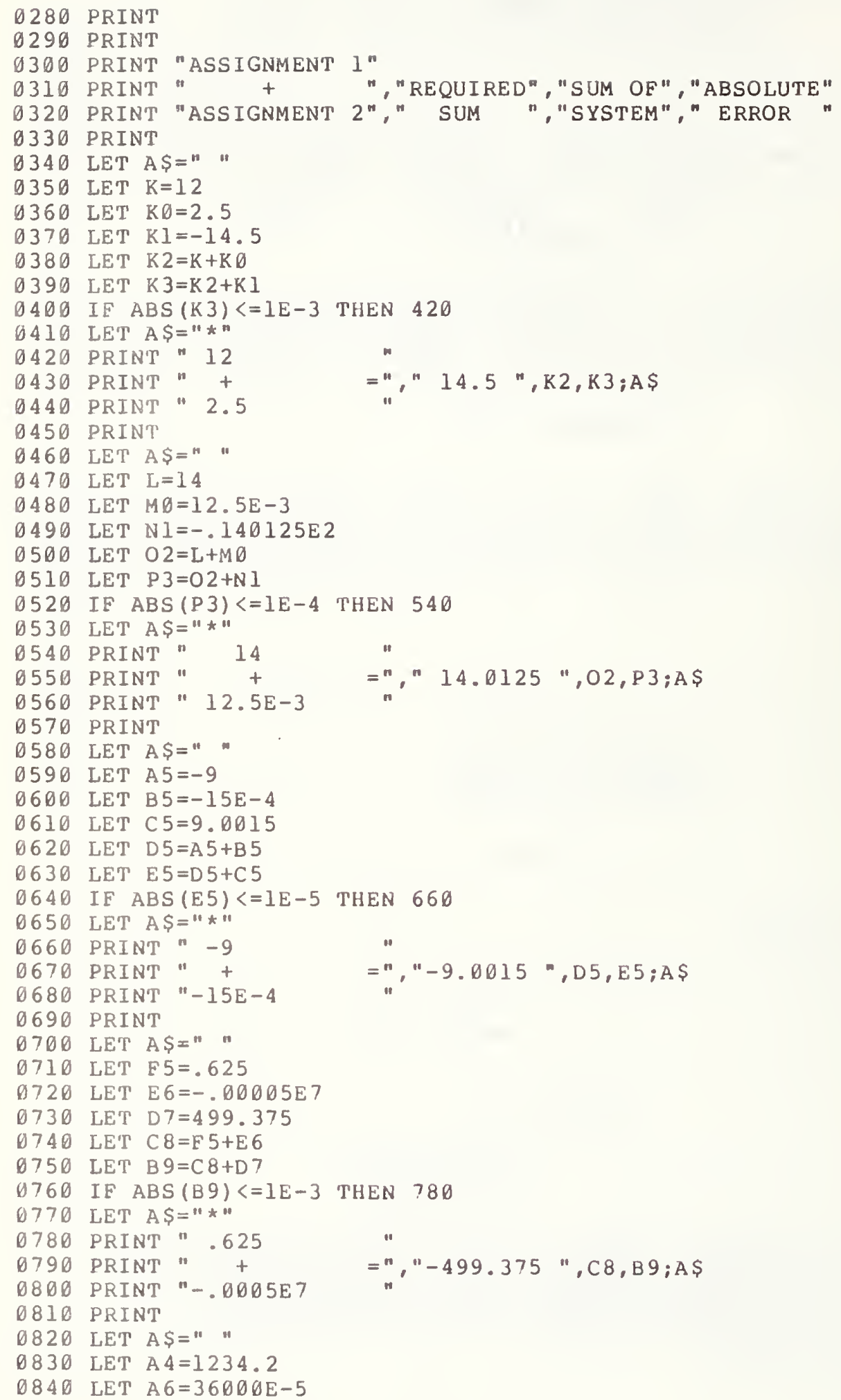




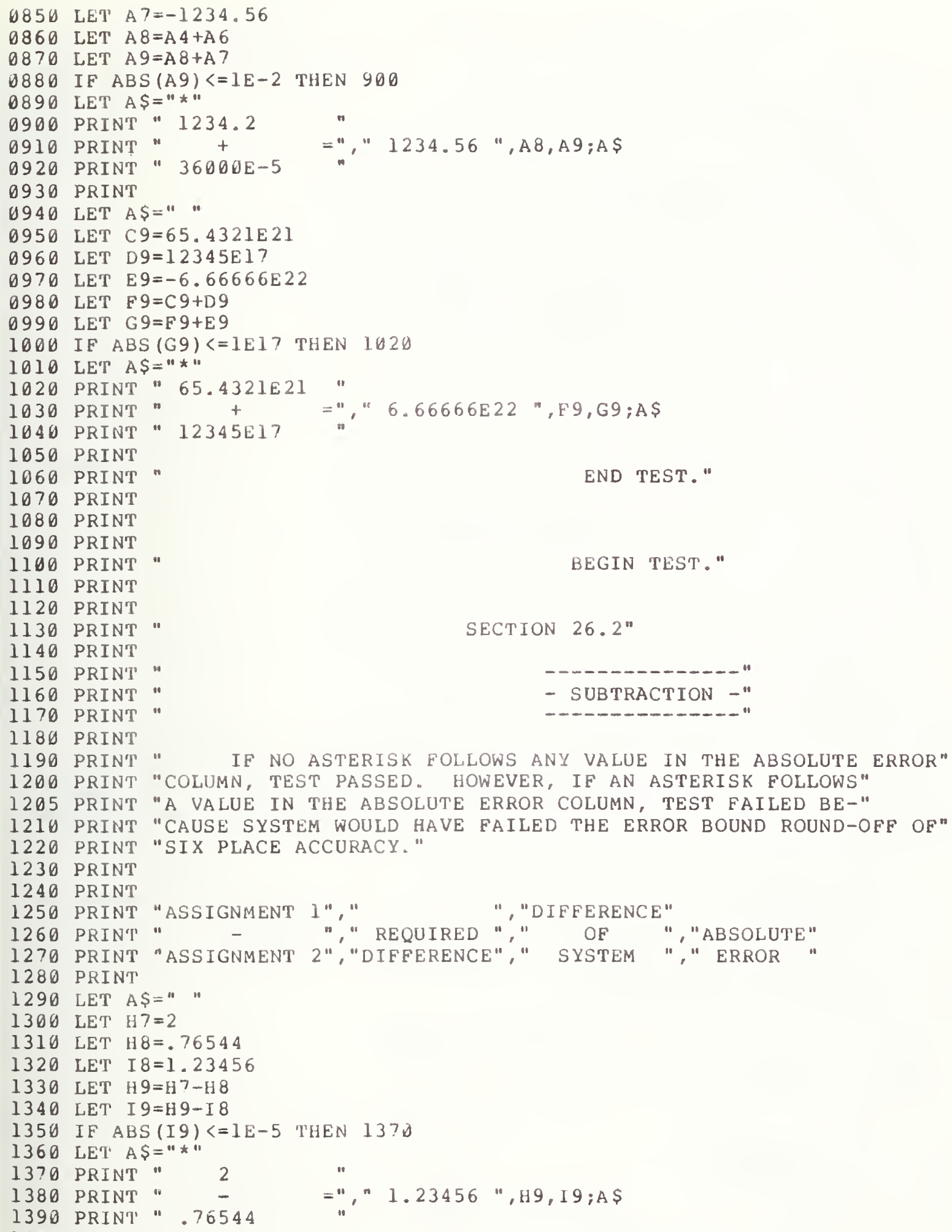




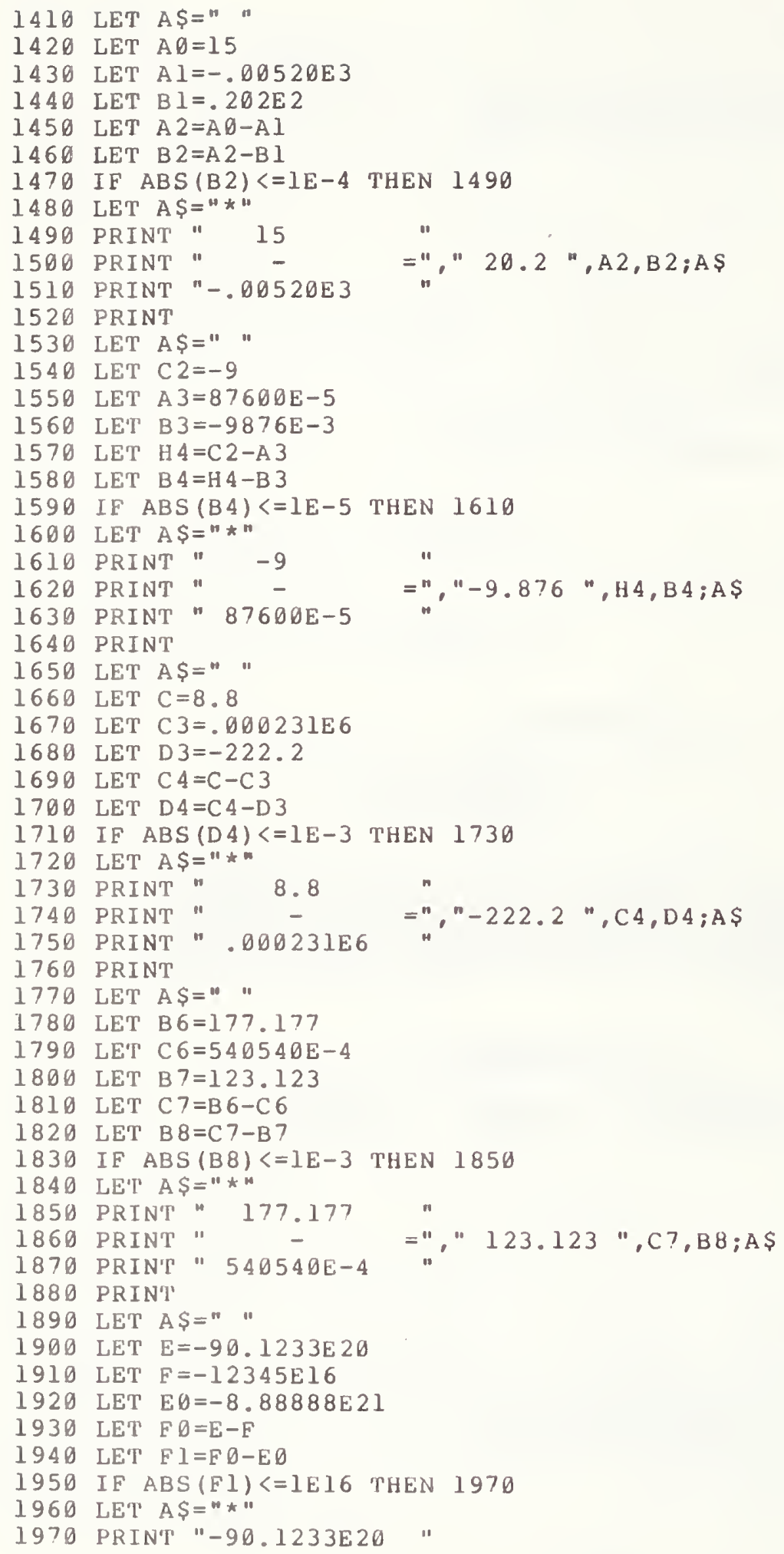




$\begin{array}{lll}\underset{+}{+0005 E 7} & =-499.375 & -499.375 \\ \begin{array}{l}1234.2 \\ + \\ 36000 \mathrm{E}-5 \\ \begin{array}{c}65.4321 \mathrm{E} 21 \\ + \\ 12345 \mathrm{E} 17\end{array}\end{array}=1234.56 & 1234.56\end{array}$

END TEST.

BEGIN TEST.

SECTION 26.2

- SUBTRACTION -

IF NO ASTERISK FOLLOWS ANY VALUE IN THE ABSOLUTE ERROR COLUMN, TEST PASSED. HOWEVER, IF AN ASTERISK FOLLOWS A VALUE IN THE ABSOLUTE ERROR COLUMIN, TEST FAILED BE-

CAUSE SYSTEM WOULD HAVE FAILED THE ERROR BOUND ROUND-OFF OF SIX PLACE ACCURACY.

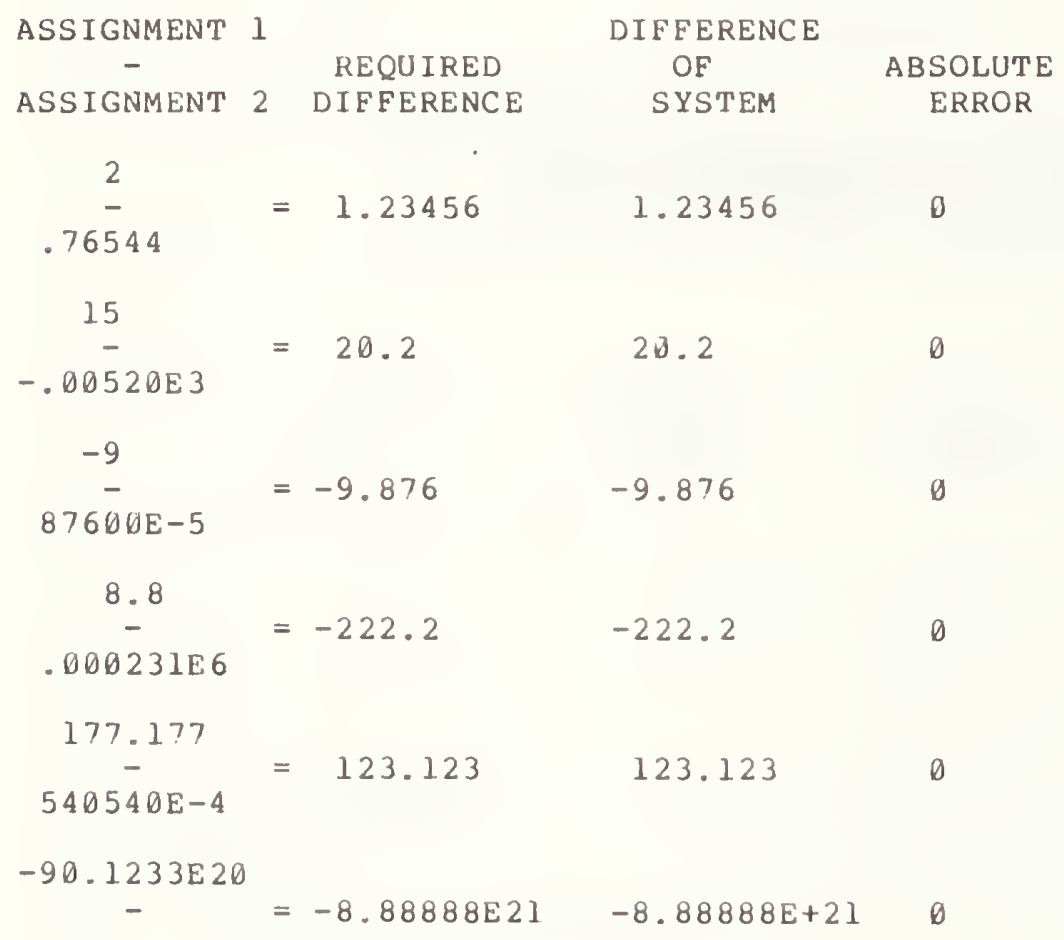


$-12345 E 16$

END TEST. 


\section{ELEMENTARY OPERATIONS ON VARIABLES ASSIGNED MIXED TY $\overline{\mathrm{PE}}$ CONSTANTS (CONTINUED)}

\section{Multiplication}

The objective of this test is to verify that the operation of multiplication of two numerically assigned simple variables, which have not been assigned the same type constants, will maintain at least six decimal digits of precision. This test is similar in structure and output format to test 23.1 .

\section{2 Division}

The objective of this test is to verify that the operation of division between two numerically assigned simple variables, which have not been assigned the same type numeric constants, will maintain at least six decimal digits of precision. The test is similar in structure and output format to test 23.2 .

\subsection{Involution}

The objective of this test is to verify that the operation of involution of two numerically assigned simple variables, which have not been assigned the same type constants, will maintain at least six decimal digits of precision. The test is similar in structure and output format to test 23.3. 


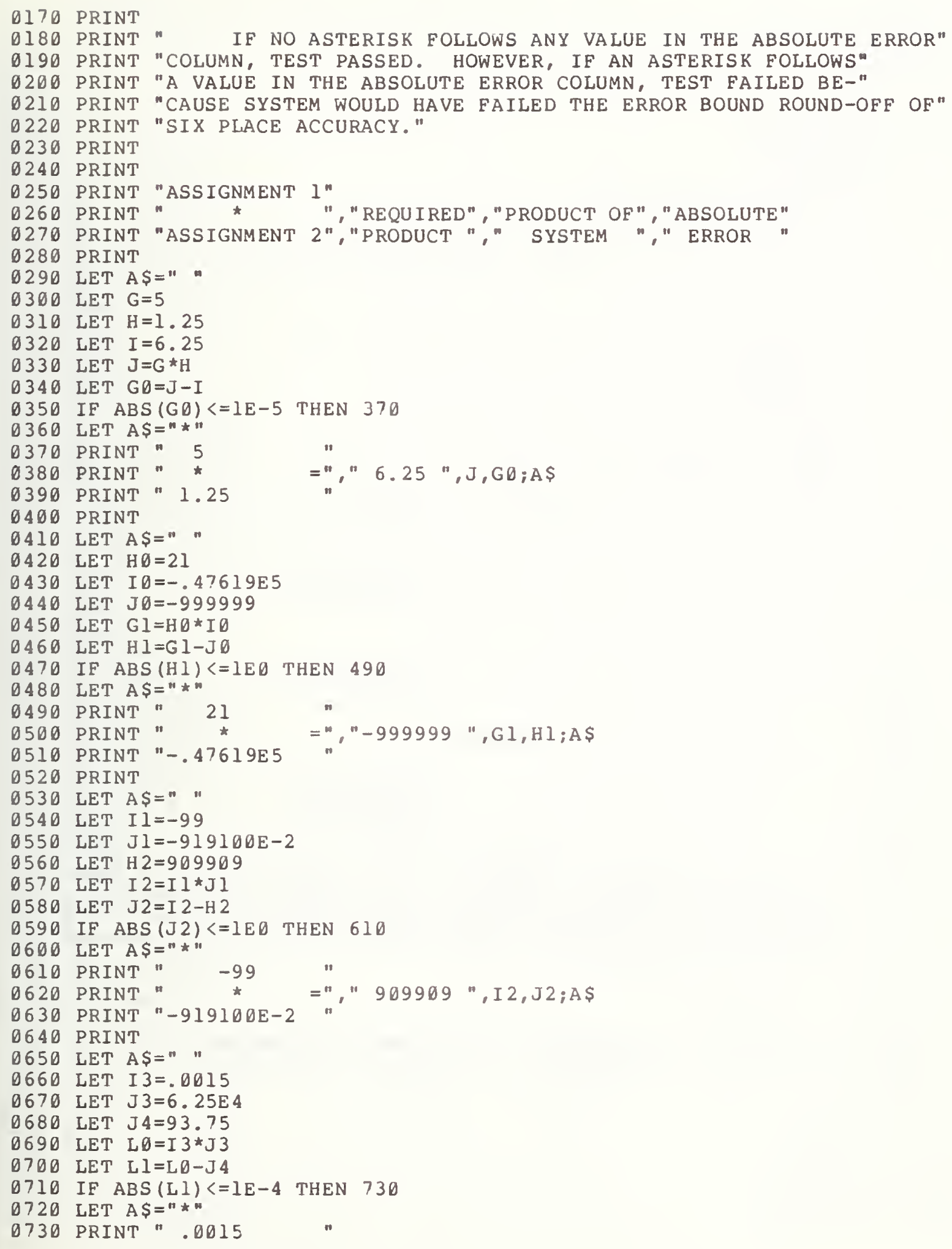




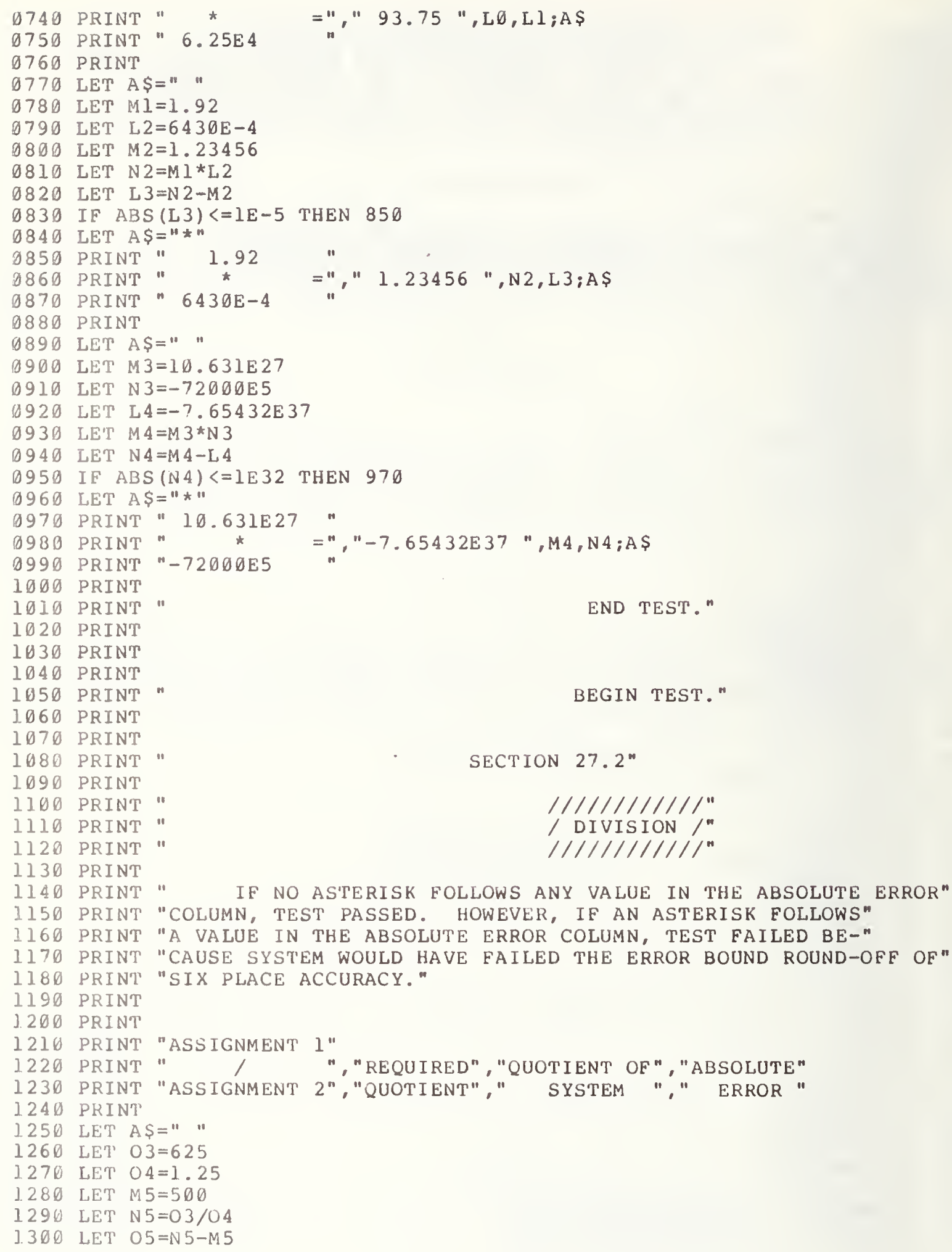


1310 IF ABS (O5) $<=1 E-3$ THEN 1330

1320 LET A $\$=" \star * "$

1330 PRINT " 625

1340 PRINT" /

1350 PRINT " 1.25

$=", " 500 ", N 5,05 ; A S$

1360 PRINT

1370 LET $A \$=" ~ "$

1380 LET $Q 4=84.876 \mathrm{E}$ ?

1390 LET $R 5=-6875$

1400 LET S6 $=-123456$

1410 LET $T 7=04 / R 5$

1420 LET U $8=\Upsilon 7-S 6$

1430 IF ABS (U8) <=1E0 THEN 1450

1440 LET A $\$="$ * "

1450 PRINT " $84.876 E 7$

1460 PRINT " $"$ =","

1470 PRINT " -6875

1480 PRINT

1490 LET A\$=" "

1500 LET P4 $=-198765$

1510 LET P5 $=-5 E-20$

1520 LET Q5 $=39753$ E 20

1530 LET J $6=P 4 / P 5$

1540 LET $\mathrm{K} 6=\mathrm{J} 6-\mathrm{Q} 5$

1550 IF $A B S(K 6)<=1 E 19$ THEN 1570

1560 LET AS="

1570 PRINT " -198765

1580 PRINT " /

1590 PRINT "-5E-20

$=", " 3.9753 E 24 ", J 6, K 6 ; A S$

1600 PRINT

1610 LET A $\$=" ~ "$

1620 LET $\mathrm{T}=6.25$

1630 LET $\mathrm{T} \theta=2.5 \mathrm{E}-4$

1640 LET $\mathrm{T} l=25000.0$

1650 LET $\uparrow 2=\Upsilon / \Upsilon 0$

1660 LET $T 3=T 2-T 1$

1670 IF $A B S(T 3)<=1 E-1$ THEN 1690

1680 LET $A \$=" * "$

1690 PRINT" 6.25

1700 PRINT

1710 PRINT " $2.5 \mathrm{E}-4$

"

1720 PRINT

1730 LET $A \$=" ~ "$

1740 LET $M=.1728$

1750 LET $\mathrm{N}=12 \mathrm{E} 12$

1760 LET $0=144000 \mathrm{E}-19$

1770 LET $P=M / N$

1780 LET $Q=P-O$

1790 IF ABS $(Q)<=1 E-19$ THEN 1810

1800 LET A $\$="$ *"

1810 PRINT " .1728

1820 PRINT " /

1830 PRINT " $12 E 12$

$="$ " $25000 "$ "T2,T3;A\$

1840 PRINT

1850 LET AS=" "

1860 LET $R=-1.25 E-10$

1870 LET $S=625 \mathrm{E} 16$ 


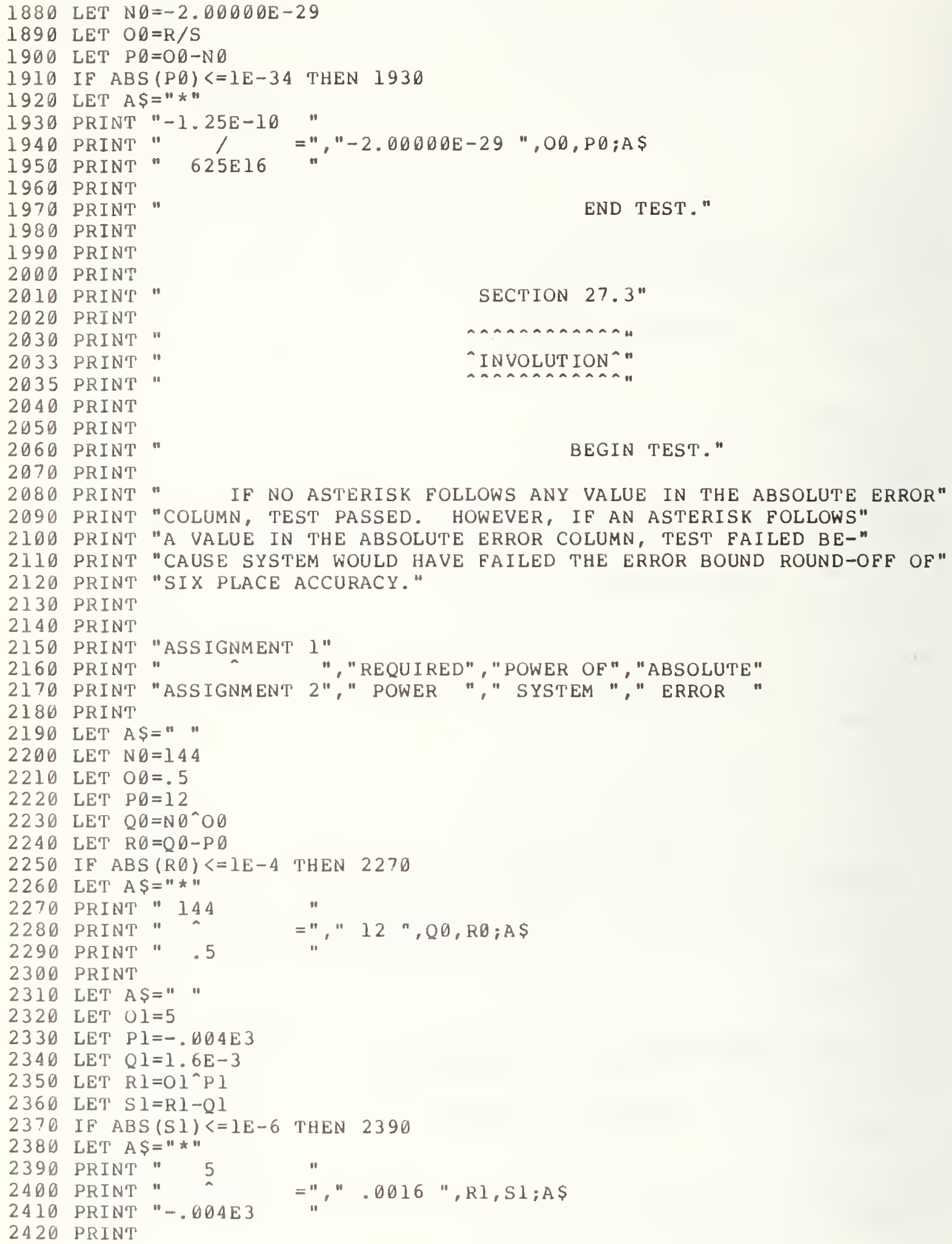

\section{BEGIN TEST."}

IF NO ASTERISK FOLLOWS ANY VALUE IN THE ABSOLUTE ERROR" SECTION $27.3^{\prime \prime}$ 


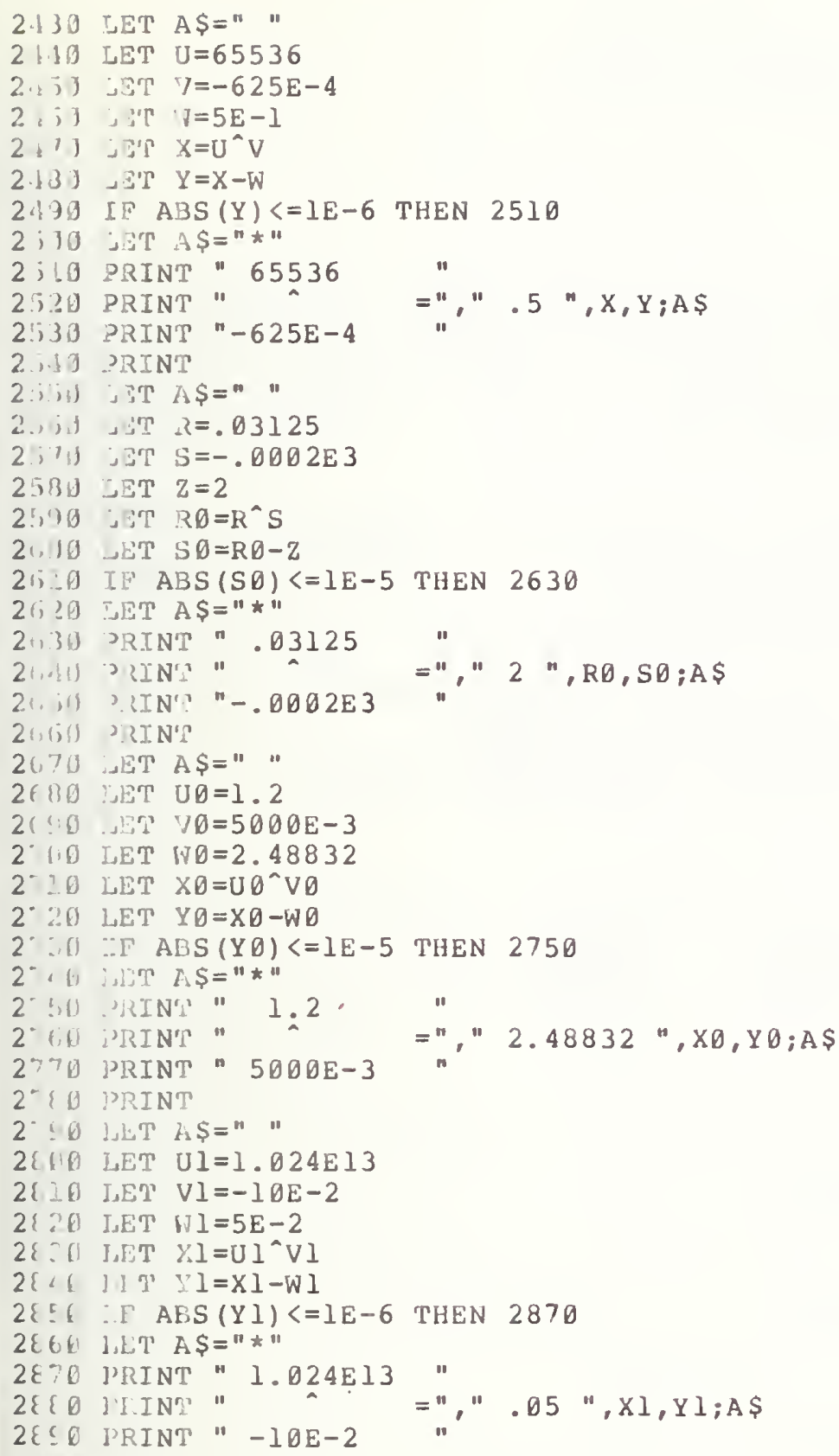




\author{
BEGIN TEST . \\ SECTION 27.1 \\ XXXXXXXXXXXXXXXXXX \\ $X$ MULTIPLICATION $X$

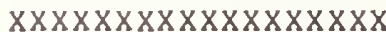

IF NO ASTERISK FOLLOWS ANY VALUE IN THE ABSOLUTE ERROR COLUMN, TEST PASSED. HOWEVER, IF AN ASTERISK FOLLOWS A VALUE IN THE ABSOLUTE ERROR COLUMN, TEST FAILED BECAUSE SYSTEM WOULD HAVE FAILED THE ERROR BOUND ROUND-OFF OF SIX PLACE ACCURACY.

\begin{tabular}{|c|c|c|c|c|}
\hline$\underset{\star}{\text { ASS I GNMENT }}$ & 1 & REQU I RED & PRODUCT OF & ABSOLUTE \\
\hline ASS I GNMENT & 2 & PRODUCT & SYSTEM & ERROR \\
\hline $\begin{array}{l}5 \\
\star \\
1.25\end{array}$ & $=$ & 6.25 & 6.25 & $\theta$ \\
\hline $\begin{array}{c}21 \\
\star \\
-.47619 E 5\end{array}$ & $=$ & -999999 & -999999 & $\theta$ \\
\hline $\begin{array}{c}-99 \\
\star \\
-919100 \mathrm{E}-2\end{array}$ & $=$ & 909909 & 909909 & $\theta$ \\
\hline $\begin{array}{c}.6015 \\
\star \\
6.25 \mathrm{E} 4\end{array}$ & $=$ & 93.75 & 93.75 & $\theta$ \\
\hline $\begin{array}{c}1.92 \\
6 \\
6430 E-4\end{array}$ & $=$ & 1.23456 & 1.23456 & $\theta$ \\
\hline $\begin{array}{c}10.631 \mathrm{E} 27 \\
-72000 \mathrm{E} 5\end{array}$ & $=$ & $-7.65432 \mathrm{E} 37$ & $-7.65432 E+37$ & $\theta$ \\
\hline
\end{tabular}




\section{SECTION 27.2

$$
\begin{aligned}
& / / / / / / / / / \\
& / \text { DIVISION / } \\
& / / / / / / / /
\end{aligned}
$$

IF NO ASTERISK FOLLOWS ANY VALUE IN THE ABSOLUTE ERROR COLUMN, TEST PASSED. HOWEVER, IF AN ASTERISK FOLLOWS

A VALUE IN THE ABSOLUTE ERROR COLUMN, TEST FAILED BECAUSE SYSTEM WOULD HAVE FAILED THE ERROR BOUND ROUND-OFF OF SIX PLACE ACCURACY.

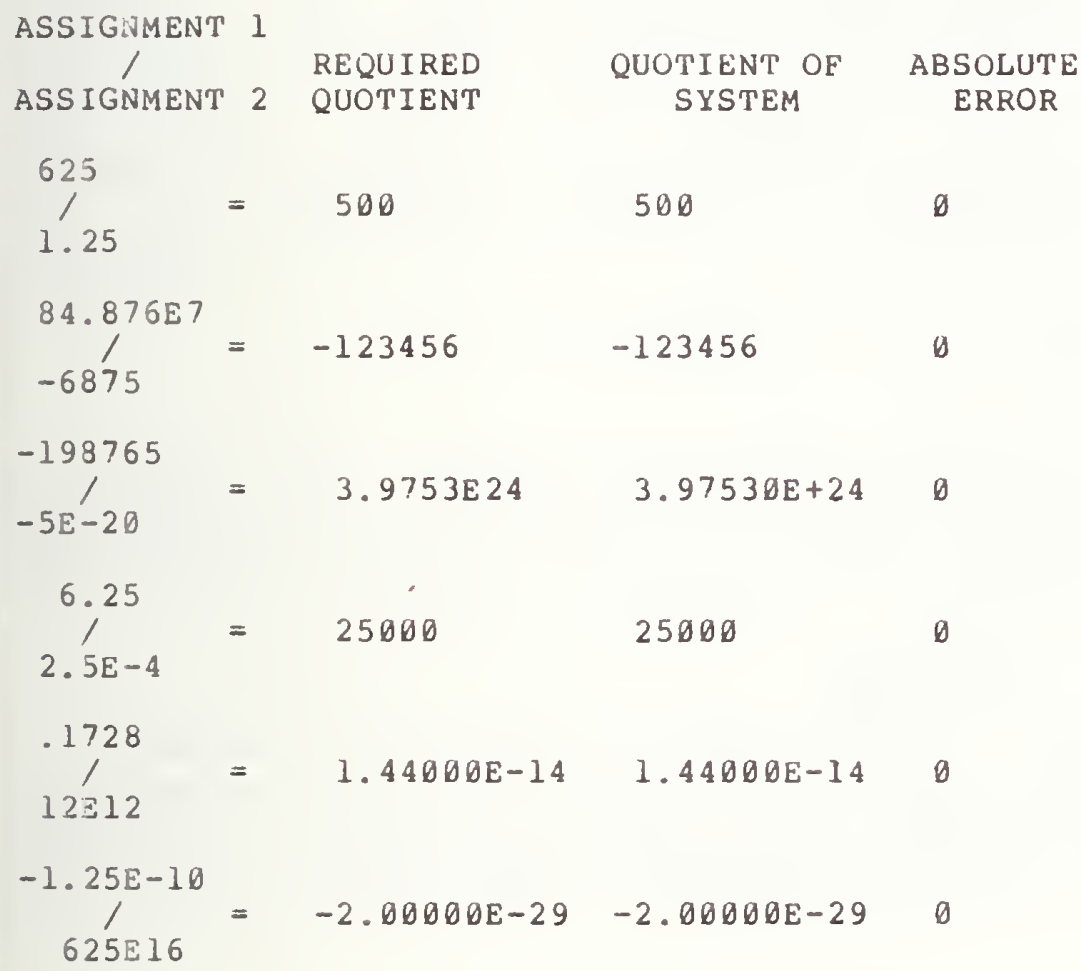

END TEST.

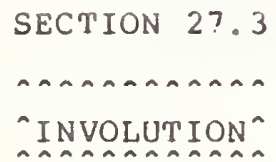

BEGIN TEST. 
IF NO ASTERISK FOLLOWS ANY VALUE IN THE ABSOLUTE ERROR COLUMN, TEST PASSED. HOWEVER, IF AN ASTERISK FOLLOWS A VALUE IN THE ABSOLUTE ERROR COLUMN, TEST FAILED BECAUSE SYSTEM WOULD HAVE FAILED THE ERROR BOUND ROUND-OFF OF SIX PLACE ACCURACY.

\begin{tabular}{|c|c|c|c|c|}
\hline ASSIGNMENT & 2 & $\begin{array}{l}\text { REQUIRED } \\
\text { POWER }\end{array}$ & $\begin{array}{l}\text { POWER OF } \\
\text { SYSTEM }\end{array}$ & $\begin{array}{l}\text { ABSOLUTE } \\
\text { ERROR }\end{array}$ \\
\hline $\begin{array}{r}144 \\
.5\end{array}$ & $=$ & 12 & 12 & $\theta$ \\
\hline $\begin{array}{c}5 \\
-.004 \mathrm{E3}\end{array}$ & $=$ & .0016 & .0016 & $\theta$ \\
\hline $\begin{array}{c}65536 \\
-625 E-4\end{array}$ & $=$ & .5 & .5 & $\theta$ \\
\hline $\begin{array}{r}.03125 \\
-.0002 \mathrm{E} 3\end{array}$ & $=$ & 2 & 2 & 0 \\
\hline $\begin{array}{c}1: 2 \\
5000 \mathrm{E}-3\end{array}$ & $=$ & 2.48832 & 2.48832 & $\theta$ \\
\hline $\begin{array}{l}1.024 \mathrm{E} 13 \\
-10 \mathrm{E}-2\end{array}$ & $=$ & .05 & .05 & $\theta$ \\
\hline
\end{tabular}




\section{0 ADDITION OF THREE OR MORE TERMS}

The objective of this section is to verify that three or more terms can be used in the construction of numerical expressions using the operation of addition.

\section{I Using only Numerical Constants}

The objective of this test is to verify that the operation of addition of three or more numerical constants will maintain at least six decimal digits of precision. The test forms the sum of three or more numerical constants of different type. There are four columns of output of which the first column is labeled "Number of Terms," the second column is labeled "Required Sum," the third column is labeled "Sum of system," and the fourth column is labeled "Absolute Error." The first column lists numbers indicating the number of terms that should have been summed for each row of output; the second column lists a standard conforming output; the third column lists the sums of the constants as evaluated by the system being tested; and the fourth column contains 1 ists of the differences between the expected values and the system generated values. If the implementation did not mainliain at least six decimal digits of precision, an asterisk will appear beside any such case.

\section{2 Using only Numerically Assigned Variables}

The objective of this test is to verify that the operation of addition of three or more numerically assigned simple variables will maintain at least six decimal digits of precision. The test is similar to 28.1 , except for the use of simple variables. The test has the same output format as test 28.1 .

\section{3 Numerical Constants and Assigned Variables, Mixed}

The objective of this test is to construct numerical expressions using both numerical constants and simple variables together. It verifies that the operation of addition of several terms composed of both numerical constants and simple variables will maintain at least six decimal digits of precision. The test is similar, both in structure and output to test 28.1 . 


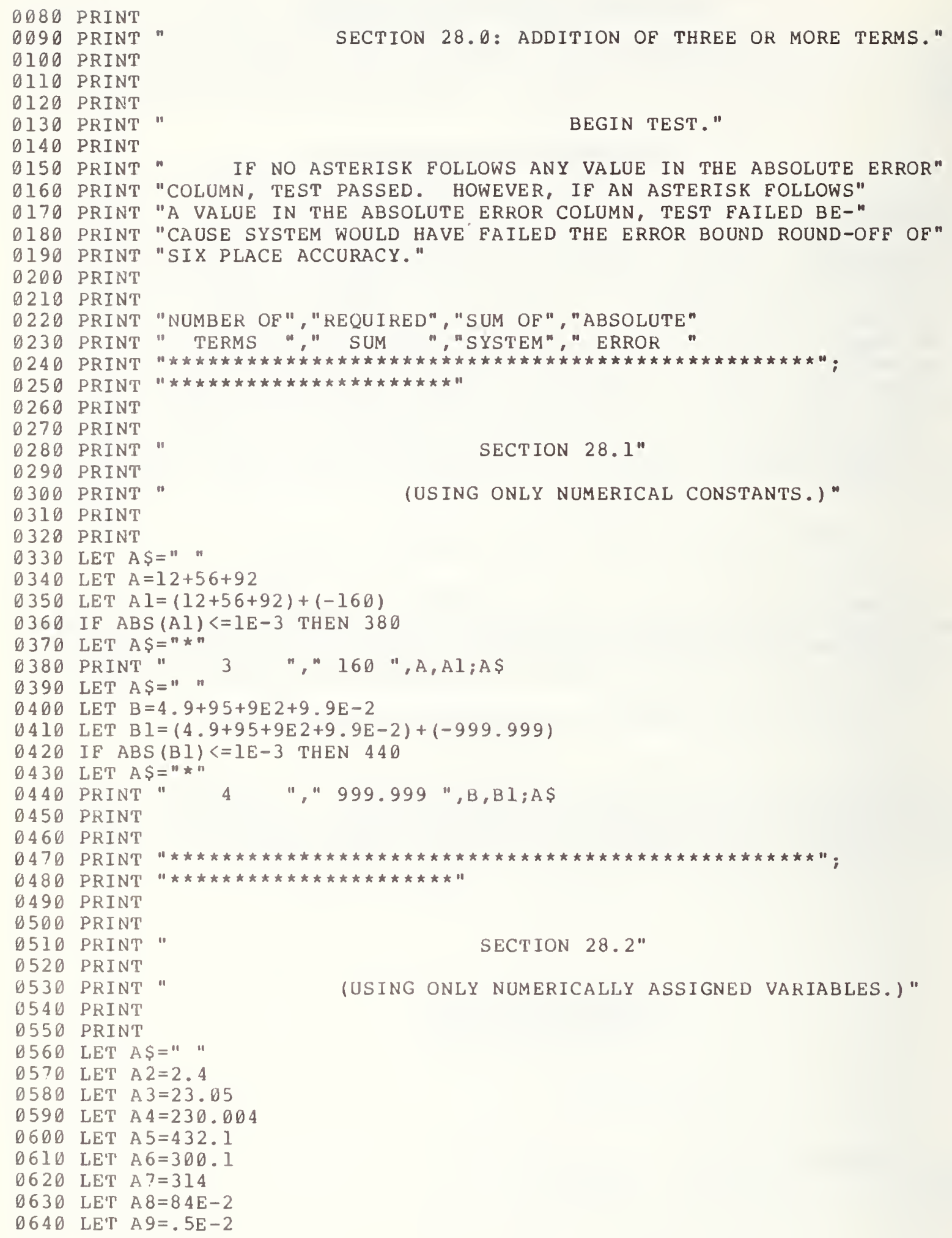

IF NO ASTERISK FOLLOWS ANY VALUE IN THE ABSOLUTE ERROR" "COLUMN, TEST PASSED. HOWEVER, IF AN ASTERISK FOLLOWS" "A VALUE IN THE ABSOLUTE ERROR COLUMN, TEST FAILED BE-" "CAUSE SYSTEM WOULD HAVE FAILED THE ERROR BOUND ROUND-OFF OF" "NUMBER OF", "REQUiRED", "SUM OF", "ABSOlute" 


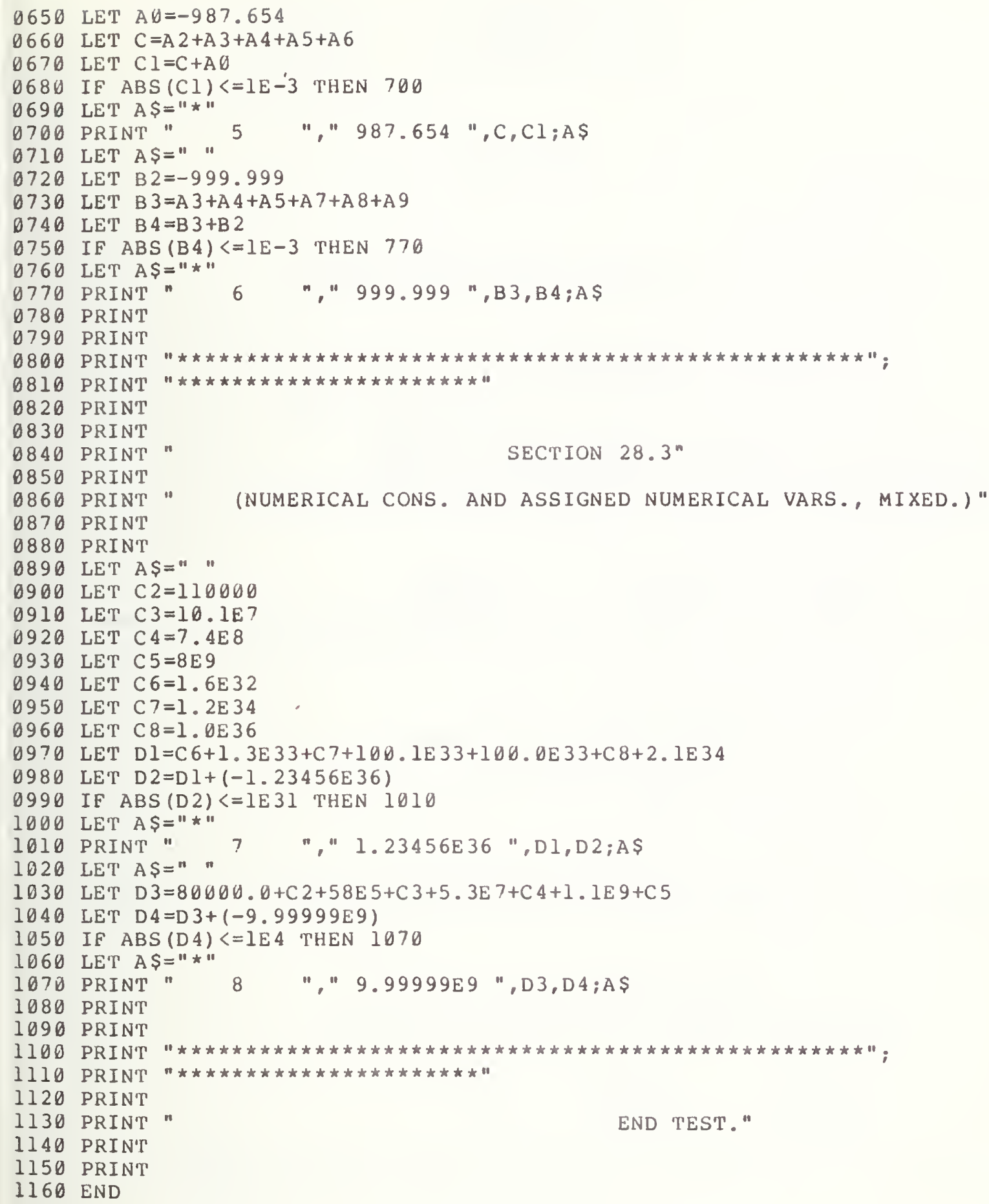




\section{BEGIN TEST.}

IF NO ASTERISK FOLLOWS ANY VALUE IN THE ABSOLUTE ERROR COLUMN, TEST PASSED. HOWEVER, IF AN ASTERISK FOLLOWS A VALUE IN THE ABSOLUTE ERROR COLUMN, TEST FAILED BECAUSE SYSTEM WOULD HAVE FAILED THE ERROR BOUND ROUND-OFF OF SIX PLACE ACCURACY.

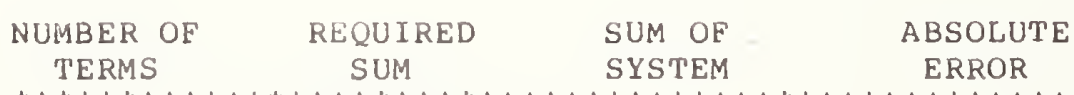

SECTION 28.1

(USING ONLY NUMERICAL CONSTANTS.)

$\begin{array}{llll}3 & 160 & 160 & 0 \\ 4 & 999.999 & 999.999 & 0\end{array}$

SEC'TION 28.2

(USING ONLY NUMERICALLY ASSIGNED VARIABLES.)

$\begin{array}{llll}5 & 987.654 & 987.654 & 0 \\ 6 & 999.999 & 999.999 & 0\end{array}$

SECTION 28.3

(NUMERICAL CONS. AND ASSIGNED NUMERICAL VARS., MIXED.) 
1. $23456 \mathrm{E} 36$

1. $23456 \mathrm{E}+36$

9. $99999 E+9$

$\emptyset$

9. $99999 \mathrm{E} 9$

0

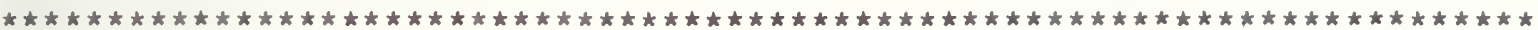

END TEST。 


\subsection{MULTIPLICATION OF THREE OR MORE FACTORS}

The purpose of this section is to show that three or more factors can be used in the construction of numerical expressions using the operation of multiplication.

\subsection{Using Numerical Constants Only}

The objective of this test is to verify that the operation of multiplication of three or more numerical constants will maintain at least six decimal digits of precision. The test forms the products of three or more factors of different types. There are four columns of output, of which the first column is labeled "Number of Terms", the second column is labeled "Required Product", the third column is labeled "Product of system", and the fourth column is labeled "Absolute Error". The first column lists the number of factors that should have been multiplied for each row, the second column lists the standard conforming expected output, the third column lists the products of the constants as evaluated by the system being tested, and the fourth column lists the difference between the expected values and the system generated values. If the implementation did not maintain at least six decimal digits of precision, an asterisk will appear beside any such case.

\section{2 Using Only Assigned Variables}

The objective of this test is to verify that the operation of multiplication of three or more numerically assigned simple variables will maintain at least six decimal digits of precision. The test is simjlar both in structure and output format to test 29.1 .

\subsection{Numerical Constants and Assigned Numerical Variables, Mixed}

The objective of this test is to verify that the operation of multiplication upon several numerical constants and simple variables will maintain at least six decimal digits of precisjon. The test is similar in structure and output to test 29.1 .

OO10 PRINT "PROGRAM FILE 29"

0060 PRINT

0070 PRINT

0080 PRINT 


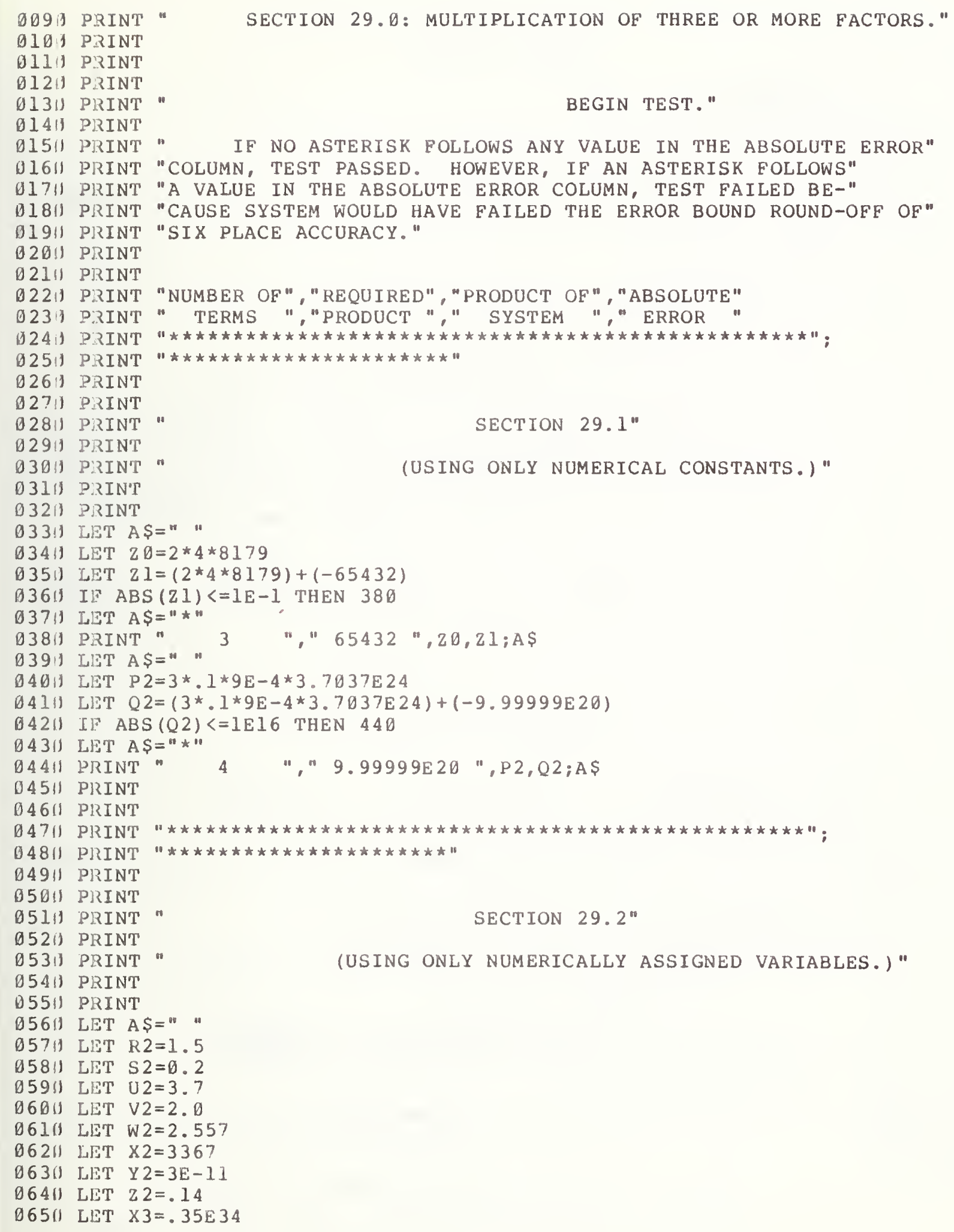




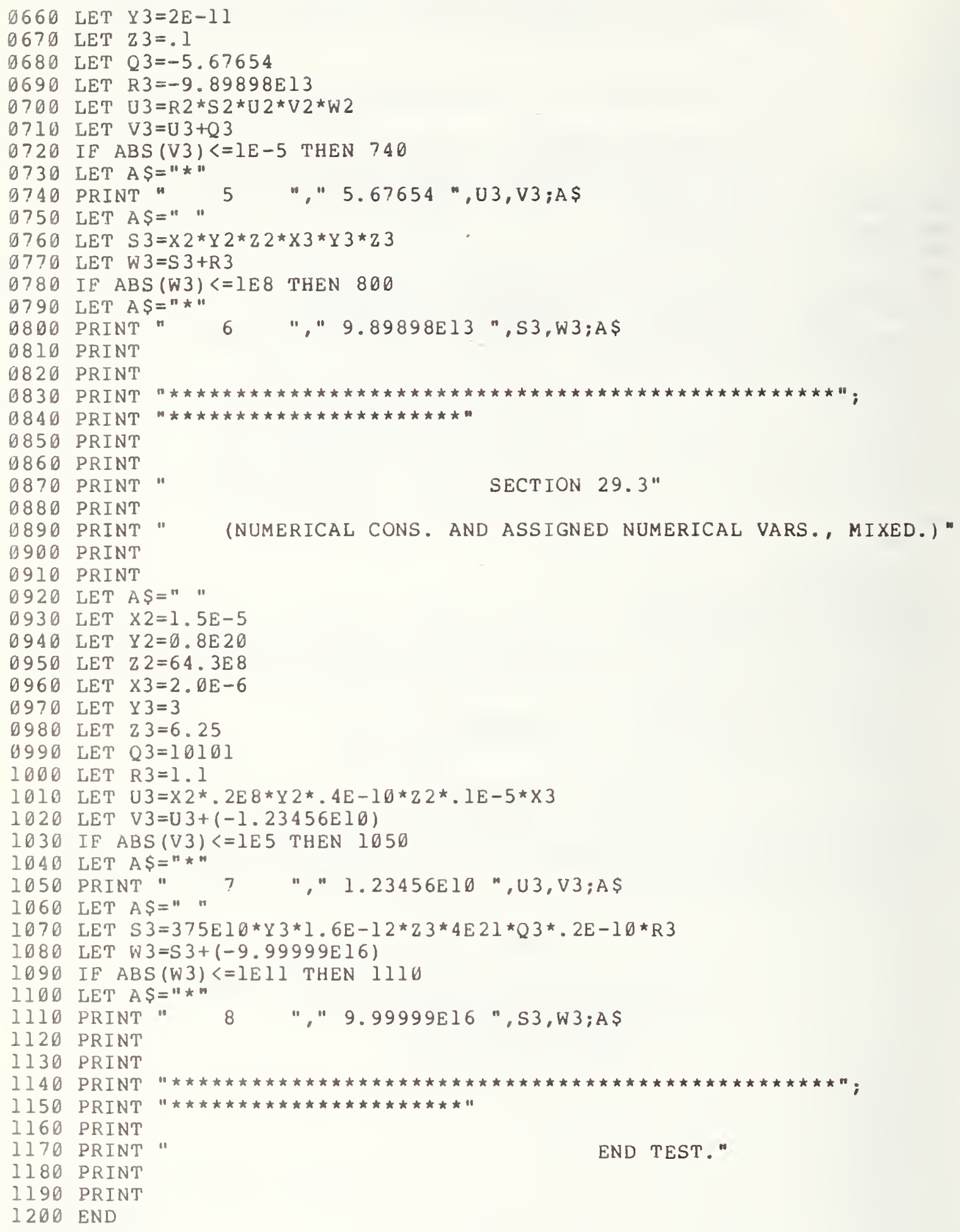




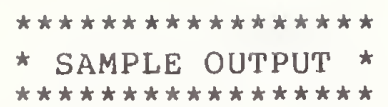

PROGRAM FILE 29

SECTION 29.0: MULTIPLICATION OF THRE OR MORE FACTORS.

\section{BEGIN TEST 。}

IF NO ASTERISK FOLLOWS ANY VALUE IN THE ABSOLUTE ERROR COLUMN, TEST PASSED. HOWEVER, IF AN ASTERISK FOLLOWS A VALUE IN THE ABSOLUTE ERROR COLUMN, TEST FAILED BECAUSE SYSTEM WOULD HAVE FAILED THE ERROR BOUND ROUND-OFF OF SIX PLACE ACCURACY.

$\begin{array}{clc}\text { NUMBER OF } & \text { REQUIRED } & \text { PRODUCT OF } \\ \text { TERMS } & \text { PRSOLUTE }\end{array}$

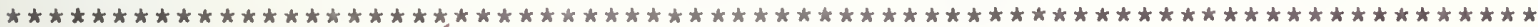

SECTION 29.1

(USING ONLY NUMERICAL CONSTANTS.)

$\begin{array}{llll}3 & 65432 & 65432 & 0 \\ 4 & 9.99999 E 20 & 9.99999 E+20 & 0\end{array}$

SECTION 29.2

(USING ONLY NUMERICALLY ASSIGNED VARIABLES.)

$\begin{array}{llll}5 & 5.67654 & 5.67654 & 0 \\ 6 & 9.89898 \mathrm{E} 13 & 9.89898 \mathrm{E}+13 & 0\end{array}$

SECTION 29.3

(NUMERICAL CONS. AND ASSIGNED NUMERICAL VARS., MIXED.) 


$\begin{array}{llll}7 & 1.23456 \mathrm{E} 10 & 1.23456 \mathrm{E}+10 & 0 \\ 8 & 9.99999 \mathrm{E} 16 & 9.99999 \mathrm{E}+16 & 0\end{array}$

\section{END TEST.}




\section{H HERARCHY OF OPERATIONS AND PARENTHESES}

In this and the succeeding section we verify that for any numerical expression, involutions are performed first, then multiplications and divisions, and finally additions and subtractions (unless parentheses dictate otherwise). Furthermore, in the absence of parentheses, and where it matters mathematically, we determine whether any numerical expression, having operations of the same precedence, is associated to the left. In this section the tests will concentrate on evaluating expression formed from constants. Variables will be introduced in section 31 . The reader should be familiar with the operator precedence specifications in section 7.4 of BSR $\times 3.60$.

\subsection{Expressions with Operators of Equal Priority}

The objective of this test is to verify that in numerical expressions, in which there are no parentheses ordering operations, operators of the same precedence will associate to the left and maintain at least six decimal digits of precision. The test uses only numerical constants in the expressions and the operators of equal precedence are used in the following order: (1) operators are all division symbols, (2) operators are all subtraction symbols, (3) operators are all involution symbols, (4) operators are both subtraction and addition symbols, and (5) operators are both division and multiplication.

There are two columns of output. The first column is labeled "Operator(s) of Expression" and the second column is labeled "Evaluation of System". The first column lists the operator(s) that are used in each numeric expression tested, while the second column lists whether the implementation passed of failed according to the expected values of this test.

30. 2 Expressions with Operators of Different Priorities and no Parenthesis

The objective of this test is to verify that in numerical expressions in which there are no parentheses to dictate the order of operations, operators of different precedence will be performed in the following sequence: first, involutions, then multiplications and divisions, and finally, additions and subtraction. The test also determines whether the expressions maintain at least six decimal digits of precision. The expressions used have only numerical constants in them. Only numerical expressions, in which there are operators of unequal precedence, in different combinations, for the different numeric expressions, are used.

There are two columns of output. The first column is labeled "Priority of Operator" and the second column is labeled "Evaluation of System". The first column lists the operators and their priorities according to their usage in each numeric expression to be tested, while the second column lists whether the implementation passed or failed.

30.3 Expressions with Operators of Different Priorities and Parentheses 
The objective of this test is to verify that numerical expressions, with parentheses to order the operations, will be evaluated properly and maintain at least six decimal digits of precision. The test uses two approaches. First, parentheses are used to alter the evaluation for numeric expressions using operators of equal precedence. Then, parentheses are used to alter the evaluation for numeric expressions using operators of unequal precedence.

There is a two column output of which the first column is labeled "Alteration of Priority by Parentheses", and the second column is labeled "Evaluation of System". The first column lists the classes of numeric expressions which should have been evaluated, while the second column lists whether implementation evaluated each class of expressions successfully or unsuccessfully.

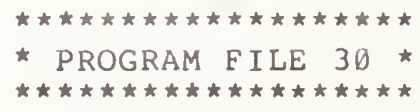

OOI0 PRINT "PROGRAM FILE 30"

$\emptyset 060$ PRINT

Ө07פ PRINT

Oด80 PRINT

OO90 PRINT"

0100 PRINT

0110 PRINT

0120 PRINT

0130 PRINT

O140 PRINT

O150 PRINT

0160 PRINT

0170 PRINT

O 180 PRINT

O190 PRINT

D 200 PRINT

0210 PRINT

0220 PRINT

0230 PRINT

0240 PRINT

6250 PRINT

0260 PRINT

0270 PRINT

0280 PRINT

9290 PRINT

O300 PRINT "

0310 PRINT

0320 PRINT TAB (18); "OPERATOR (S) ";TAB (40); "EVALUATION"

0330 PRINT TAB (18);" OF "TAB(40);" "TAB "

0340 PRINT TAB (18); "EXPRESSION ";TAB (40);" SYSTEM "

0350 PRINT " 


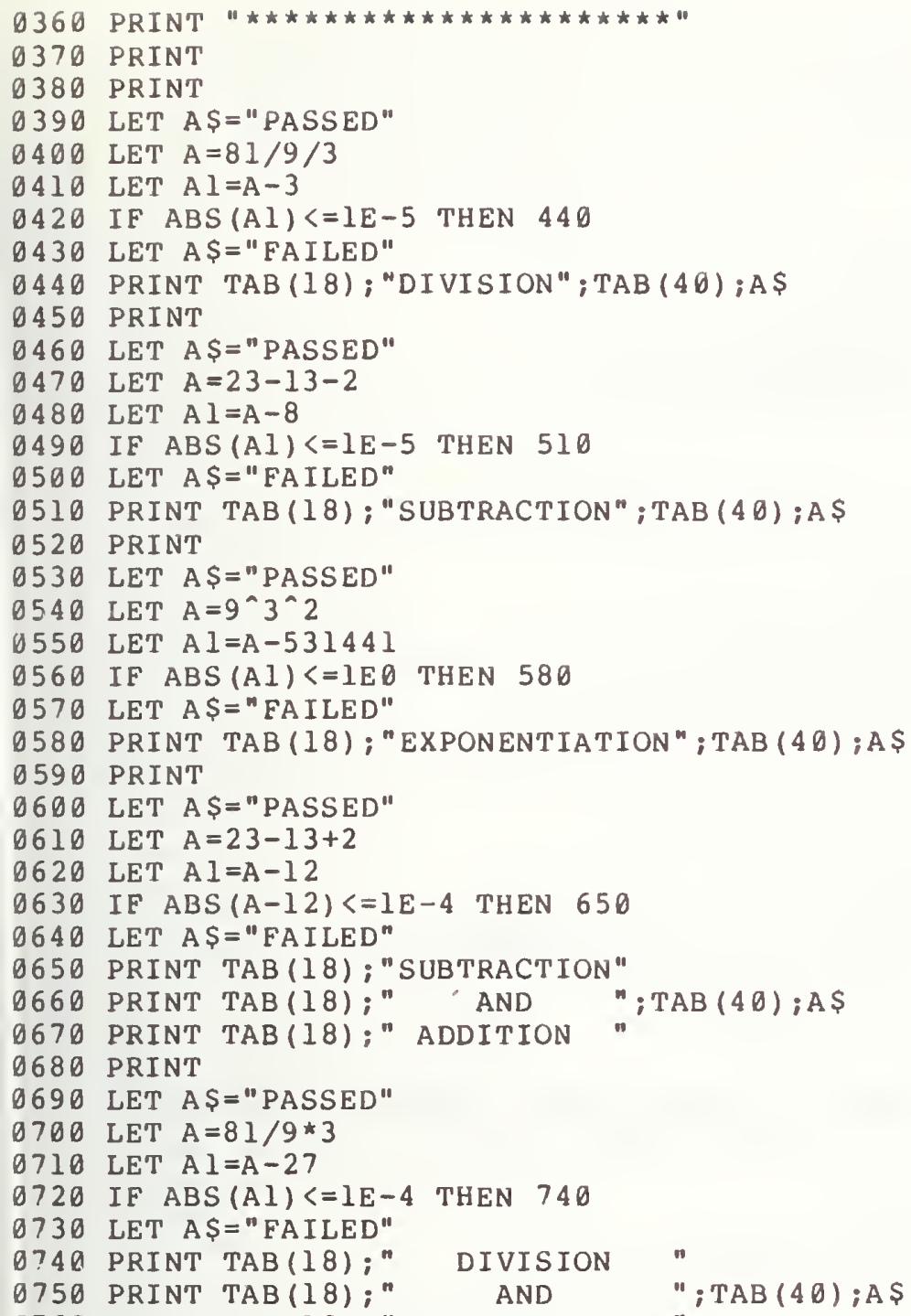

END TEST."

\section{SECTION $30.2^{\prime \prime}$}

EVALUATION OF THE PRECEDENCE OF OPERATORS FOR EXPRES-" "SIONS WHICH CONTAIN OPERATORS OF DIFFERENT PRIORITIES IN" "THE ABSENCE OF PARENTHESES, USING CONSTANTS ONLY."

\section{BEGIN TEST."}




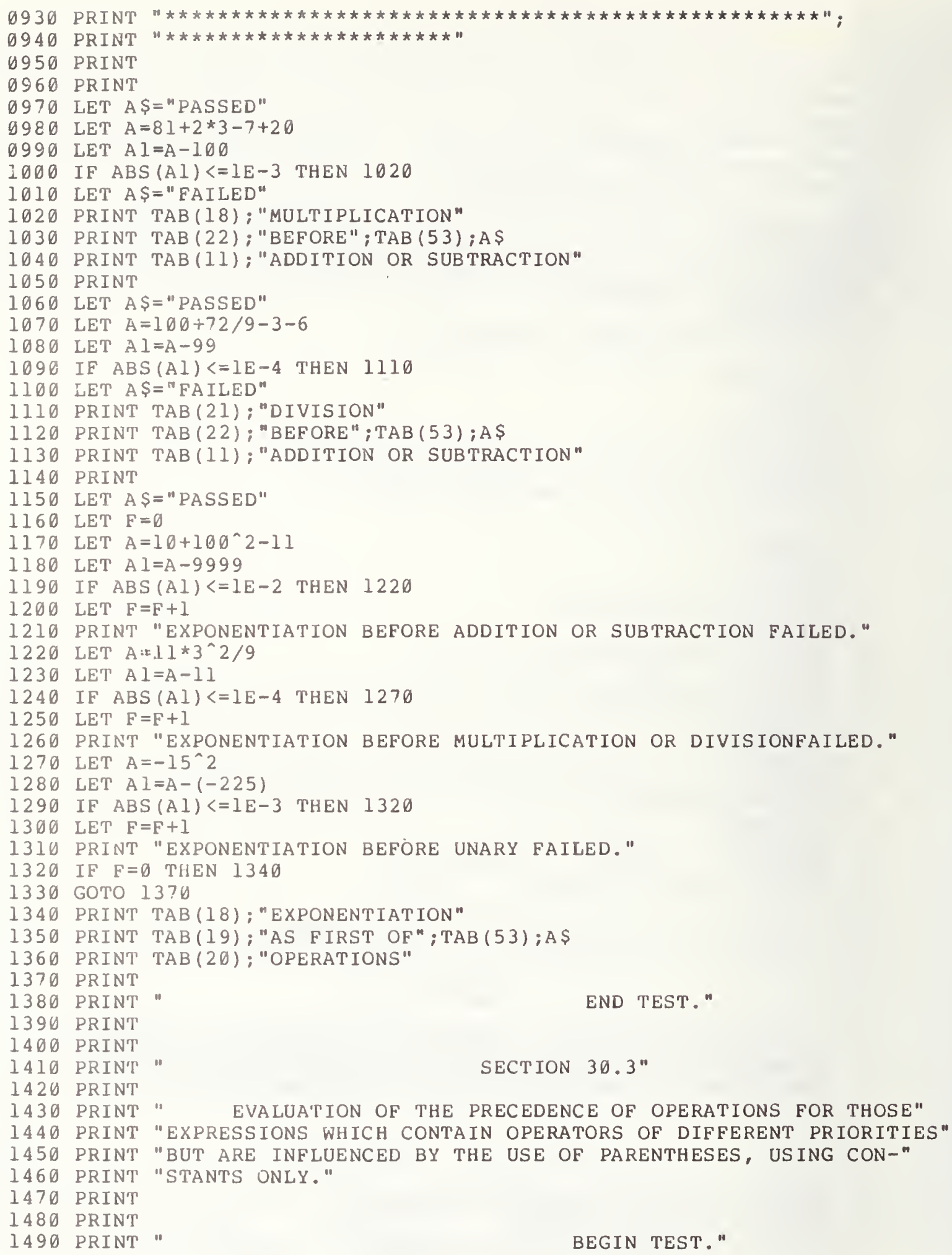




\section{PRINT}

1510 PRINT TAB(14); "ALTERATION OF PRIORITY";TAB(51); "EVALUATION"

1520 PRINT TAB (24); "BY"; TAB (55); "OF"

1530 PRINT TAB (19); "PARENTHESES"; TAB (53); "SYSTEM"

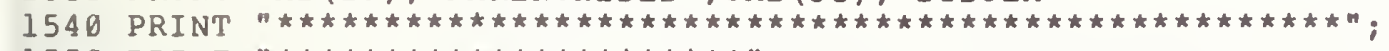

1550 PRINT

1560 PRINT

1570 PRINT

1580 LET $F=0$

1590 LET $A=81 /(9 / 3)$

1600 LET $A I=A-27$

1610 IF ABS $(\mathrm{Al})<=1 \mathrm{E}-4$ THEN 1630

1620 LET $F=1$

1630 LET $A=23-(13-2)$

1640 LET $A I=A-12$

1650 IF $A B S(A I)<=1 E-4$ THEN 1670

1660 LET $F=1$

1670 LET $A=4^{\wedge}\left(3^{\wedge} 2\right)$

1680 LET $A I=A-262144$

1690 IF $\operatorname{ABS}(\mathrm{A} I)<=1 E 0$ THEN 1710

1700 LET $\mathrm{F}=1$

1710 LET $A=23-(13+2)$

1720 LET $A I=A-8$

1730 IF ABS $(A 1)<=1 E-5$ THEN 1750

1740 LET $F=1$

1750 LET $A=81 /(9 * 3)$

1760 LET $A l=A-3$

1770 IF $A B S(A)<=1 E-5$ THEN 1790

1780 LET $F=1$

1790 IF $F=0$ THEN 1820 .

1800 LET A $\$=" U N S U C C E S S F U L "$

1810 GOTO 1830

1820 LET A $\$="$ "SUCCESSFUL"

1830 PRINT TAB (18); "EXPRESSIONS OF"

1840 PRINT TAB (18); "LEFT TO RIGHT";TAB(51);A

1850 PRINT TAB (20); "EVALUATION"

1860 PRINT

1870 LET $F=0$

1880 LET $A=(81+2) *(3-7)+20$

1890 LET $A l=A-(-312)$

1900 IF $A B S(A I)<=1 E-3$ THEN 1920

1910 LET $F=1$

1920 LET $A=(100+92) /(9-3)-6$

1930 LET $A l=A-26$

1940 IF $\operatorname{ABS}(\mathrm{Al})<+1 E-4$ THEN 1960

1950 LET $F=1$

1960 LET $A=(725+274)^{\wedge}(4-2)+1998$

1970 LET Al=A-999999

1980 IF $A B S(A I)<=I E \theta$ THEN 2000

1990 LET $F=1$

2000 LET $A=(11 * 3)^{\wedge}(9 / 3) / 27$

2010 LET $A l=A-1331$

2020 IF ABS $(A 1)<=1 E-2$ THEN 2040

2030 LET $\mathrm{F}=1$

2040 LET $A=(-15)^{\wedge} 2$

2050 LET Al $=A-225$

2060 IF $\operatorname{ABS}(\mathrm{Al})<=1 \mathrm{E}-3$ THEN 2080 
2070 LET $F=1$

2080 IF $F=\emptyset$ THEN 2110

2090 LET A $\$=$ "UNSUCCESSFUL"

2100 GOTO 2120

2110 LET A $\$="$ SUCCESSFUL"

2120 PRINT TAB (14); "EXPRESSIONS EVALUATED"

2130 PRINT TAB (18); "BY PRIORITY OF" ; TAB(51);A

2140 PRINT TAB (19); "THE OPERATOR"

2150 PRINT

2160 PRINT

END TEST."

2170 PRINT

2180 END

PROGRAM FILE 30

SECTION 30.0: HIERACHY OF OPERATORS AND PARENTHESES.

SINCE THIS TEST IS ONLY CONCERNED WITH THE ORDER OF OPERATIONS, THE SELECTED NUMBERS USED FOR THIS TEST ARE IN INTEGER FORM ONLY.

\section{SECTION 30.1}

LEET TO RIGHT EVALUATION FOR EXPRESSIONS WITH OPERATORS OF EQUAL PRIORITY, USING CONSTANTS ONLY.

$\star \star \star \star \star N O T E:$ LEFT TO RIGHT EVALUATION FOR EXPRESSIONS WITH OPERATORS OF ONLY ADDITION OR MULTIPLICATION DOES NOT APPLY, THEREFORE, SUCH EXPRESSIONS ARE NOT TESTED IN

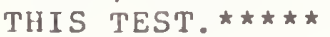

BEGIN TEST.

OPERATOR (S)

OF

EXPRESSION
EVALUATION

OF

SYSTEM 


\begin{tabular}{lc} 
DIVISION & PASSED \\
SUBTRACTION & PASSED \\
EXPONENTIATION & PASSED \\
SUBTRACTION & \\
AND & PASSED \\
ADDITION & \\
DIVISION \\
AND \\
MULTIPLICATION \\
\multicolumn{2}{c}{ PASSED TEST. }
\end{tabular}

SECTION 30.2

EVALUATION OF THE PRECEDENCE OF OPERATORS FOR EXPRESSIONS WHICH CONTAIN OPERATORS OF DIFFERENT PRIORITIES IN THE ABSENCE OF PARENTHESES, USING CONSTANTS ONLY.

\section{BEGIN TEST.}

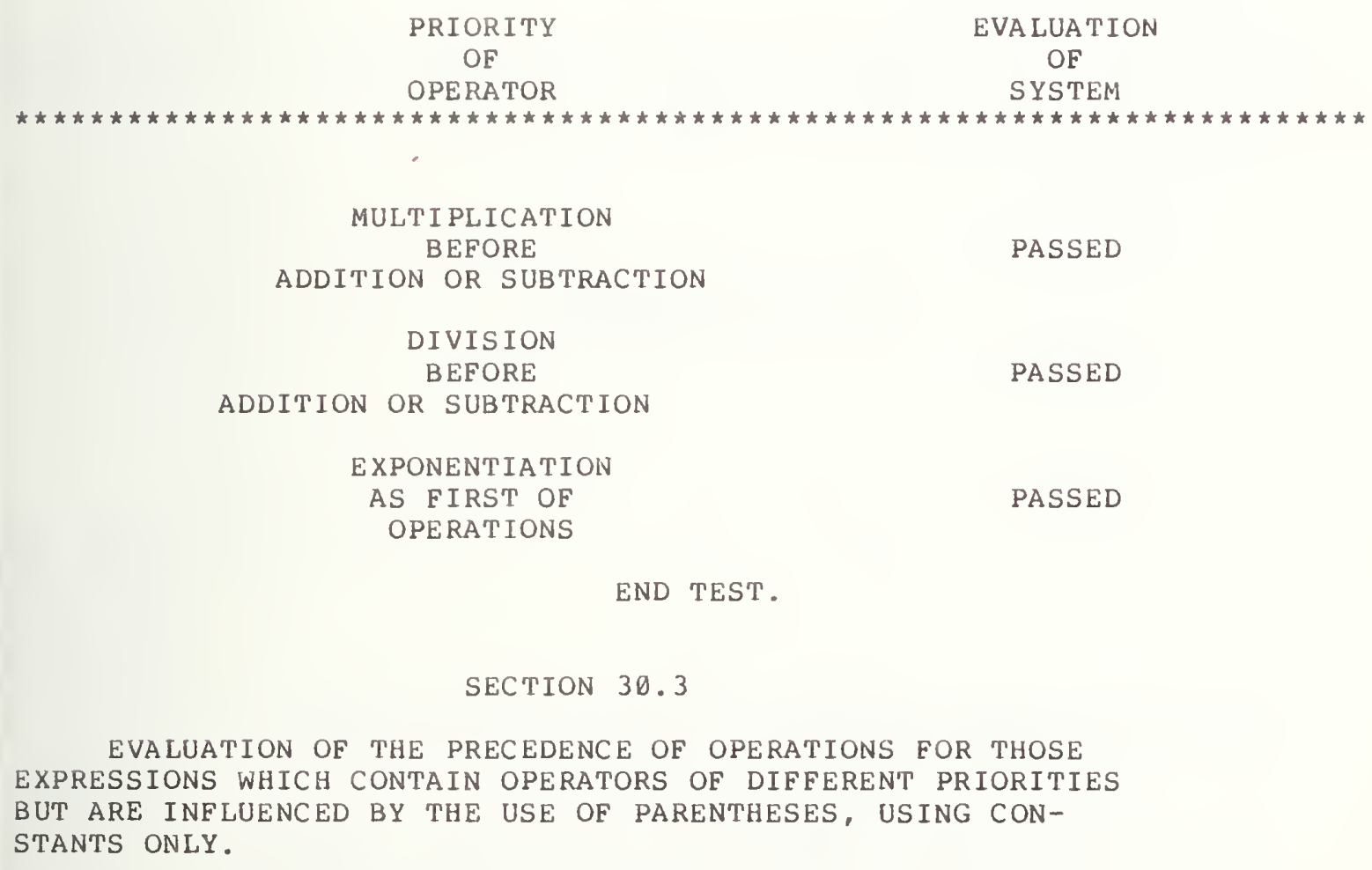

BEGIN TEST. 


$\begin{array}{cc}\text { ALTERATION OF PRIORITY } & \text { EVALUATION } \\ \text { BY } & \text { OF } \\ \text { PARENTHESES } & \text { SYSTEM }\end{array}$

EXPRESSIONS OF

LEFT TO RIGHT

SUCCESSFUL

EVALUATION

EXPRESSIONS EVALUATED

BY PRIORITY OF

THE OPERATOR

END TEST. 
In this section expression will be formed using assigned variables. The test will then consider the two major cases of operations of equal precedence and then of unequal precedence.

$$
\text { 31. I Operators of Equal Priority }
$$

The objective of this test is the same as that in test 30.1. This test uses simple numeric variables in its numerical expressions; otherwise, the test is similar in structure and output format to test 30.1 .

\section{2 Operators of Different Priorities}

The objective of this test is the same as the objective stated for test 30.2. This test uses simple numeric variables in its numerical expressions; otherwise, the test is similar in structure and output format to test 30.2 .

\subsection{Operators of Different Priorities with Parentheses}

The objective of this test is the same as that for 30.3. This test uses simple numeric variables in its numerical expressions; otherwise, this test is similar in structure and output format to 30.3 .

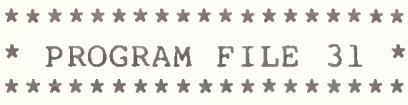

O010 PRINT "PROGRAM FILE 31 "

0060 PRINT

0070 PRINT

0080 PRINT

0090 PRINT

0100 PRINT

0110 PRINT

O120 PRINT

0130 PRINT

OI40 PRINT

OI50 PRINT

OI60 PRINT

0170 PRINT

0180 PRINT

OI90 PRINT

0200 PRINT

SECTION $31.1^{\prime \prime}$

LEFT TO RIGHT EVALUATION FOR EXPRESSIONS WITH OPERA-"

"TORS OF EQUAL PRIORITY, USING ASSIGNED SIMPLE VARIABLES."

$n \star \star \star \star \star N O T E:$ LEFT TO RIGHT EVALUATION FOR EXPRESSIONS WITH"

"OPERATORS OF ONLY ADDITION OR MULTIPLICATION DOES NOT NE-"

"CESSARILY APPLY, THEREFORE, SUCH EXPRESSIONS ARE NOT TESTED"

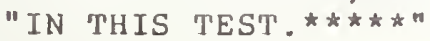




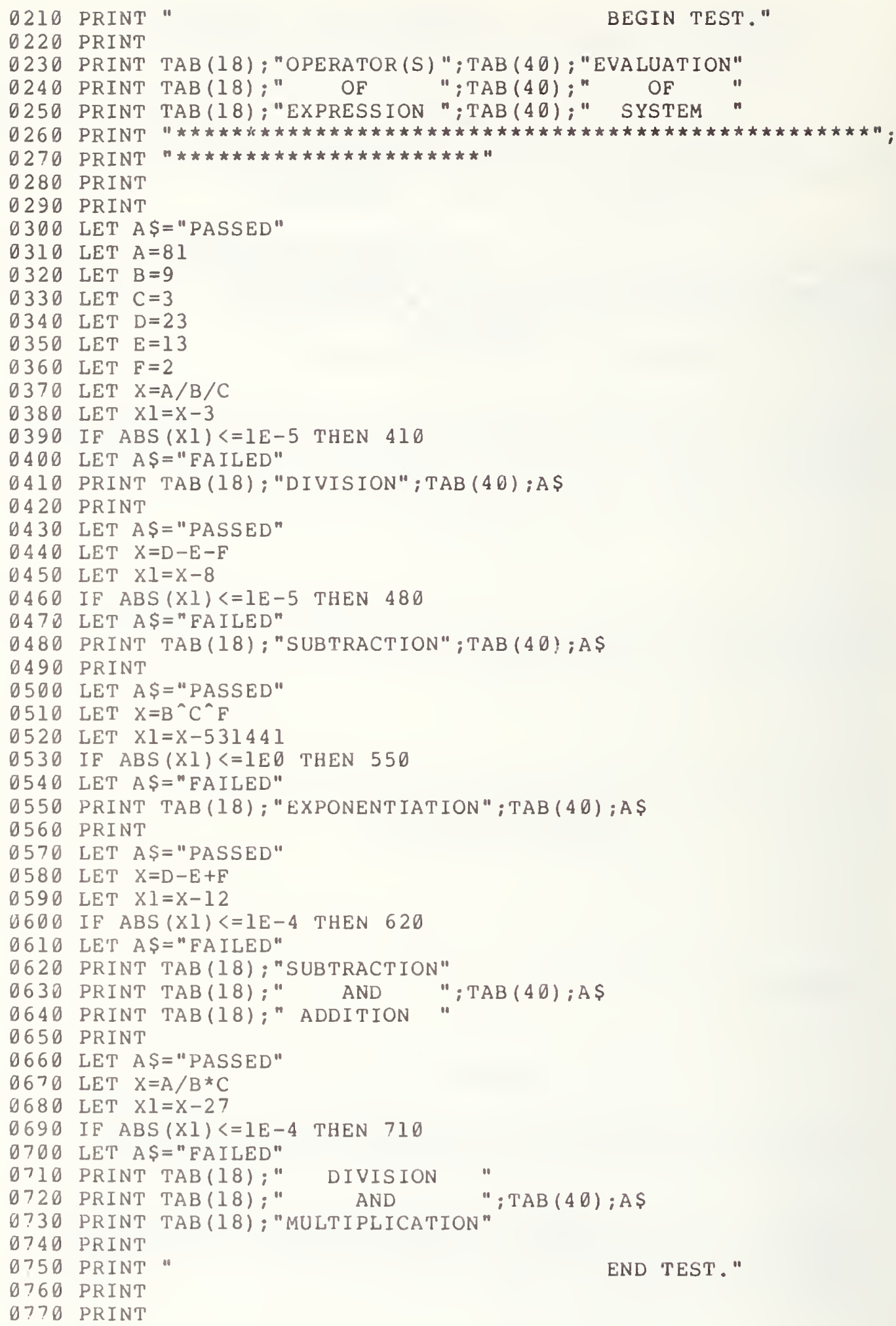




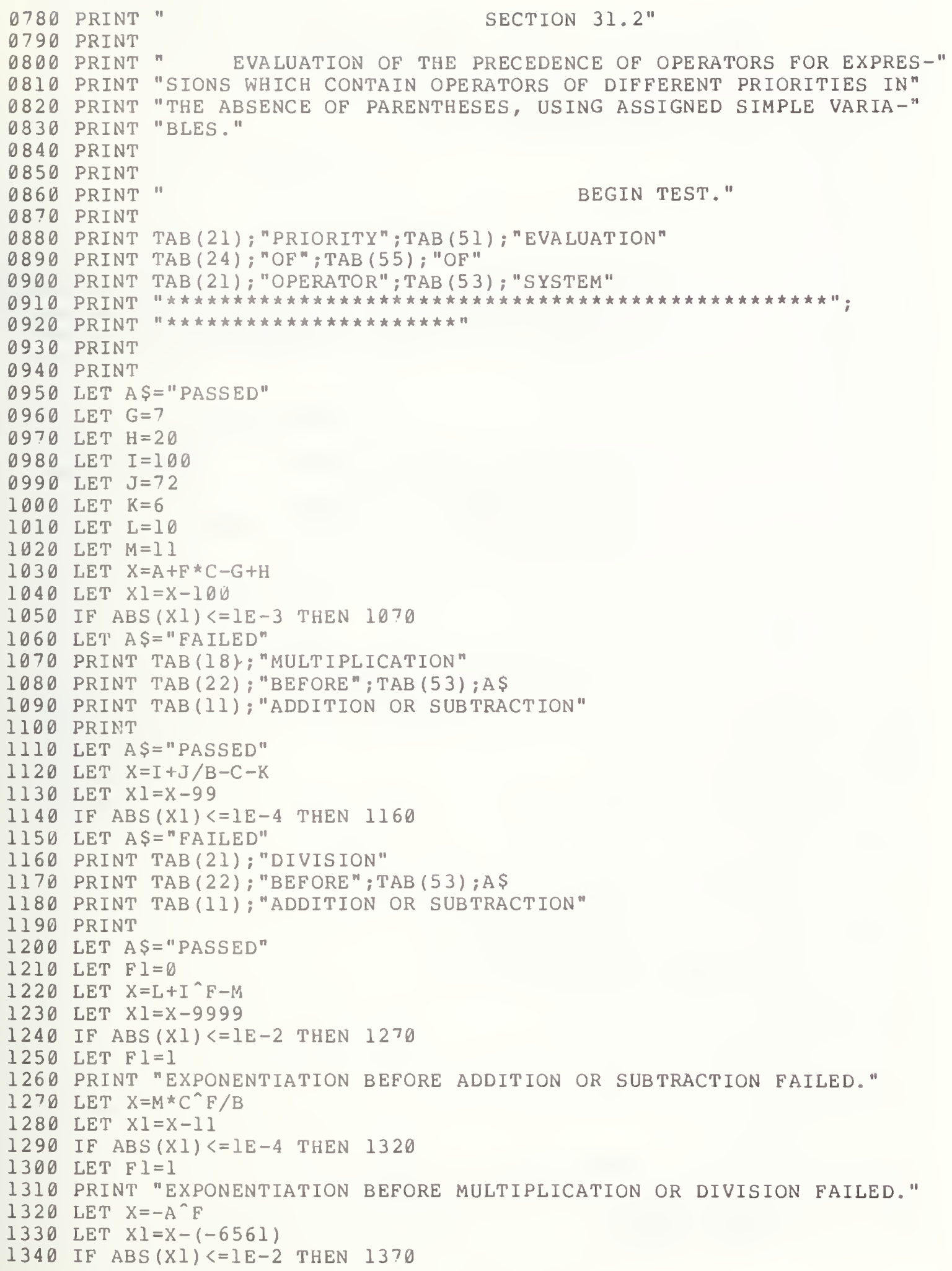




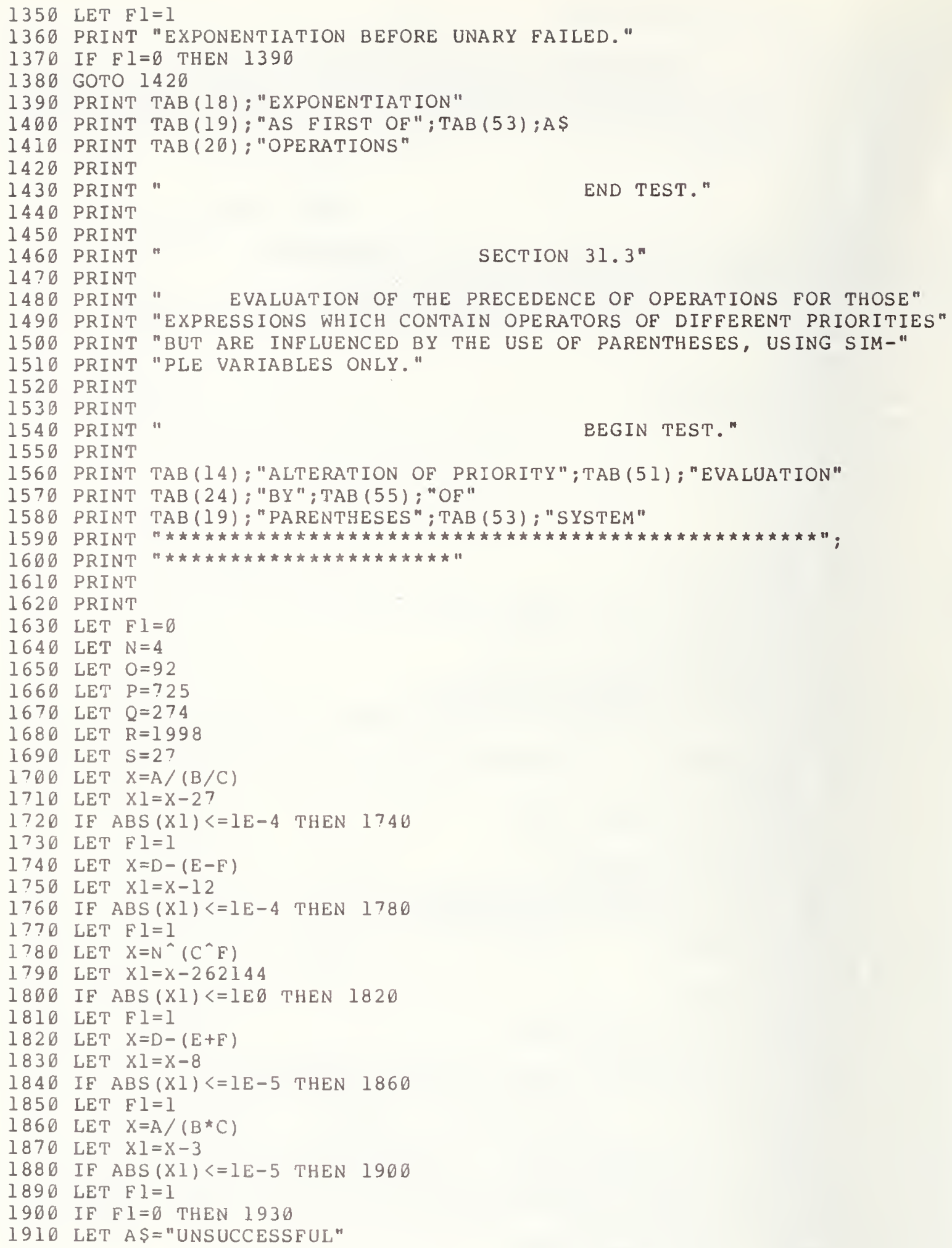




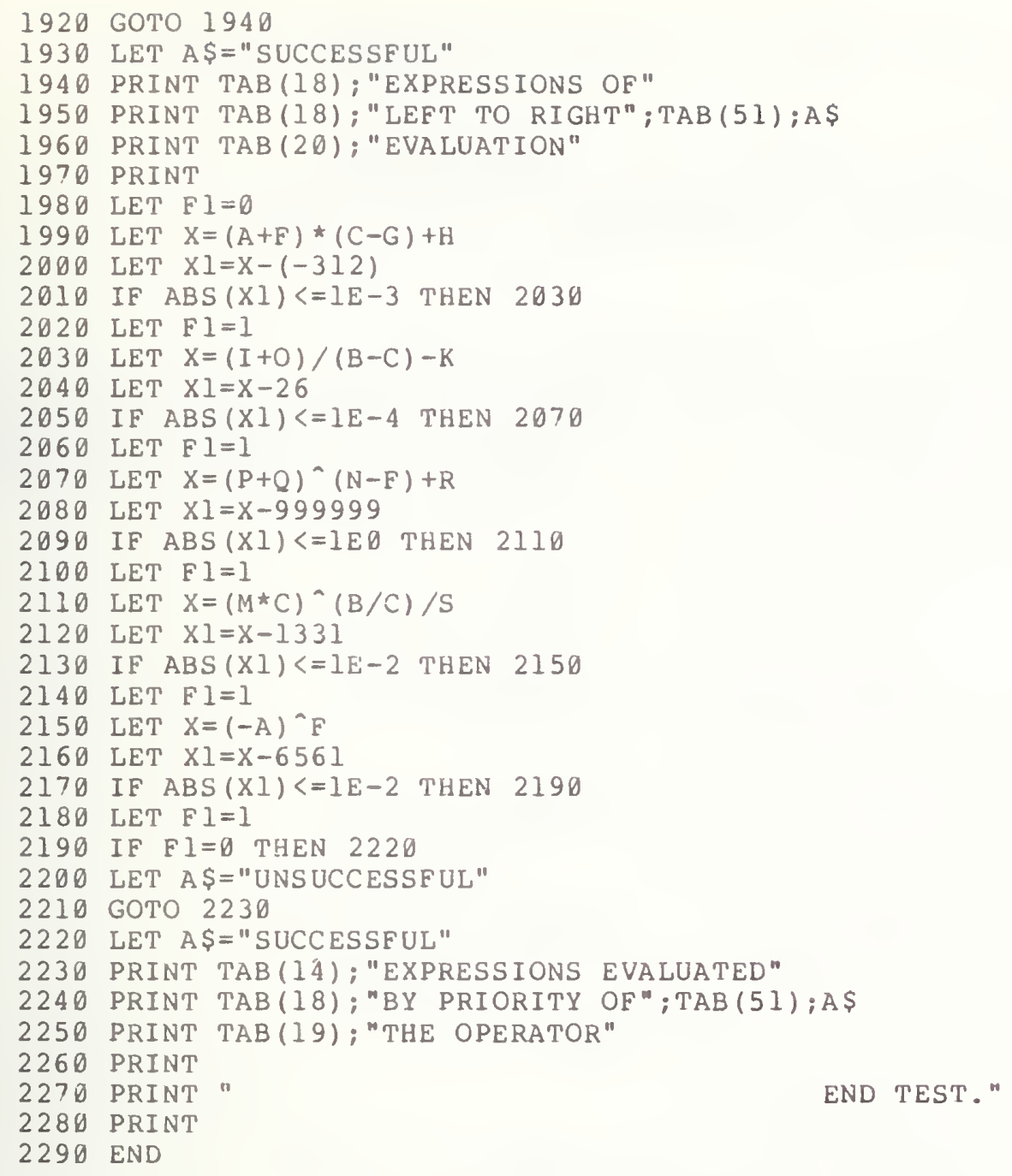

PROGRAM FILE 31 
LEFT TO RIGHT EVALUATION FOR EXPRESSIONS WITH OPERATORS OF EQUAL PRIORITY, USING ASSIGNED SIMPLE VARIABLES.

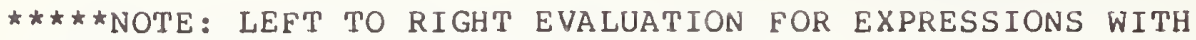
OPERATORS OF ONLY ADDITION OR MULTIPLICATION DOES NOT NECESSARILY APPLY, THEREFORE, SUCH EXPRESSIONS ARE NOT TESTED IN THIS TEST. $* \star \star \star \star *$

BEGIN TEST 。

$\begin{array}{cc}\text { OPERATOR (S) } & \text { EVALUATION } \\ \text { OF } & \text { OF } \\ \text { EXPRESSION } & \text { SYSTEM }\end{array}$

$\begin{array}{lc}\text { DIVISION } & \text { PASSED } \\ \text { SUBTRACTION } & \text { PASSED } \\ \text { EXPONENTIATION } & \text { PASSED } \\ \text { SUBTRACTION } & \\ \text { AND } & \text { PASSED } \\ \text { ADDITION } & \\ \text { DIVISION } & \\ \text { AND } & \text { PASSED } \\ \text { MULTIPLICATION } & \end{array}$

END TEST.

SECTION 31.2

EVALUATION OF THE PRECEDENCE OF OPERATORS FOR EXPRESSIONS WHICH CONTAIN OPERATORS OF DIFFERENT PRIORITIES IN THE ABSENCE OF PARENTHESES, USING ASSIGNED SIMPLE VARIABLES .

\section{BEGIN TEST.}

PRIORITY

$\mathrm{OF}$

OPERATOR
EVALUATION

OF

SYSTEM

MULT I PLICATIOIN

BEFORE

PASSED

ADDITION OR SUBTRACTION

DIVISION
BEFORE

PASSED 
ADDITION OR SUBTRACTION

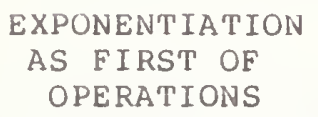

PASSED

END TEST.

SECTION 31.3

EVALUATION OF THE PRECEDENCE OF OPERATIONS FOR THOSE EXPRESSIONS WHICH CONTAIN OPERATORS OF DIFFERENT PRIORITIES BUT ARE INFLUENCED BY THE USE OF PARENTHESES, USING SIM-

PLE VARIABLES ONLY.

$\begin{array}{lc}\text { BEGIN TEST. } & \\ \text { ALTERATION OF PRIORITY } & \text { EVALUATION } \\ \text { BY } & \text { OF } \\ \text { PARENTHESES } & \text { SYSTEM }\end{array}$

EXPRESSIONS OF

LEFT TO RIGHT

EVALUATION

SUCCESSFUL

EXPRESSIONS EVALUATED

BY PRIORITY OF

THE OPERATOR

SUCCESSFUL

END TEST. 


\section{E EVALUATION OF EXPRESSIONS HAVING A VARIETY OE OPERATORS}

The expressions usea are formed from both numerical constants and simple-numeric-variabless. Each expression is characterized by either the absence of parentheses, the use of non-nested parentheses, or the use of nested parentheses. The objective of this test is to verify that numerical expressions can be constructed from both numerical constants and simple-numeric-variables using a combination of operators, with and without parentheses, and that the system will maintain at least six decimal digits of precision. There is a two column output with the first column labeled "Category of Expression", and the second column labeled "Evaluation of system". The first column lists the classes or categories of numeric expressions that are evaluated, while the second indicates whether the implementation evaluated each expression within tolerance, i.e. whether the system passed or failed.

D010 PRINT "PROGRAM FILE 32"

0060 PRINT

O070 PRINT

DO80 PRINT

Ø๑9 PRINT

OIDO PRINT

OII0 PRINT

0120 PRINT

OI30 PRINT

0140 PRINT

O150 PRINT"

OI60 PRINT"

O170 PRINT

$\emptyset 180$ PRINT

OI90 PRINT

Q 210 PRINT

0220 PRINT

0230 PRINT TAB(18);" CATEgORY ":TAB(36); "EVALUATION"

0240 PRINT

0250 PRINT

0260 PRINT

0270 PRINT

TAB (18);" OF ":TAB(36);" OF "

TAB (18); "EXPRESSION" ; TAB $(36) ; "$ SYSTEM

0280 PRINT

0290 PRINT

Q30日 PRIN'T "

$\emptyset 310$ PRINT

SECTION $32.0^{\circ}$

" EVAluation OF EXPREsSions which HAVE A VARIETy OF"

"OPERATORS AND ARE OF ONE OF THREE CATEGORIES:"

" (1) NO PARENTHESES,"

(2) NON-NESTED PARENTHESES, AND"

(3) NESTED PARENTHESES."

"Also, THESE EXPRESSiOns aRe FORMED FROM THE USE OF BOTH" "NUMERICAL CONSTANT'S AND SIMPLE-NUMERIC-VARIABLES."

0320 PRINT

0330 LET $F 1=0$

BEGIN TEST." 


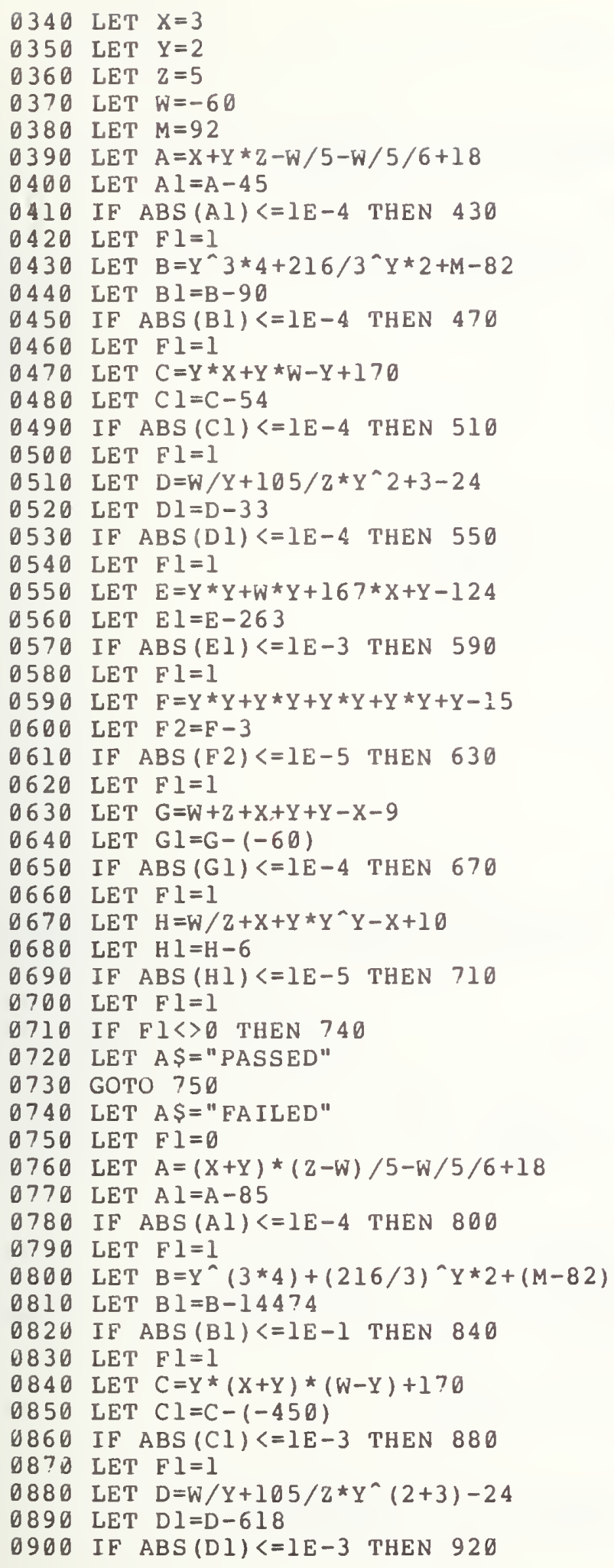




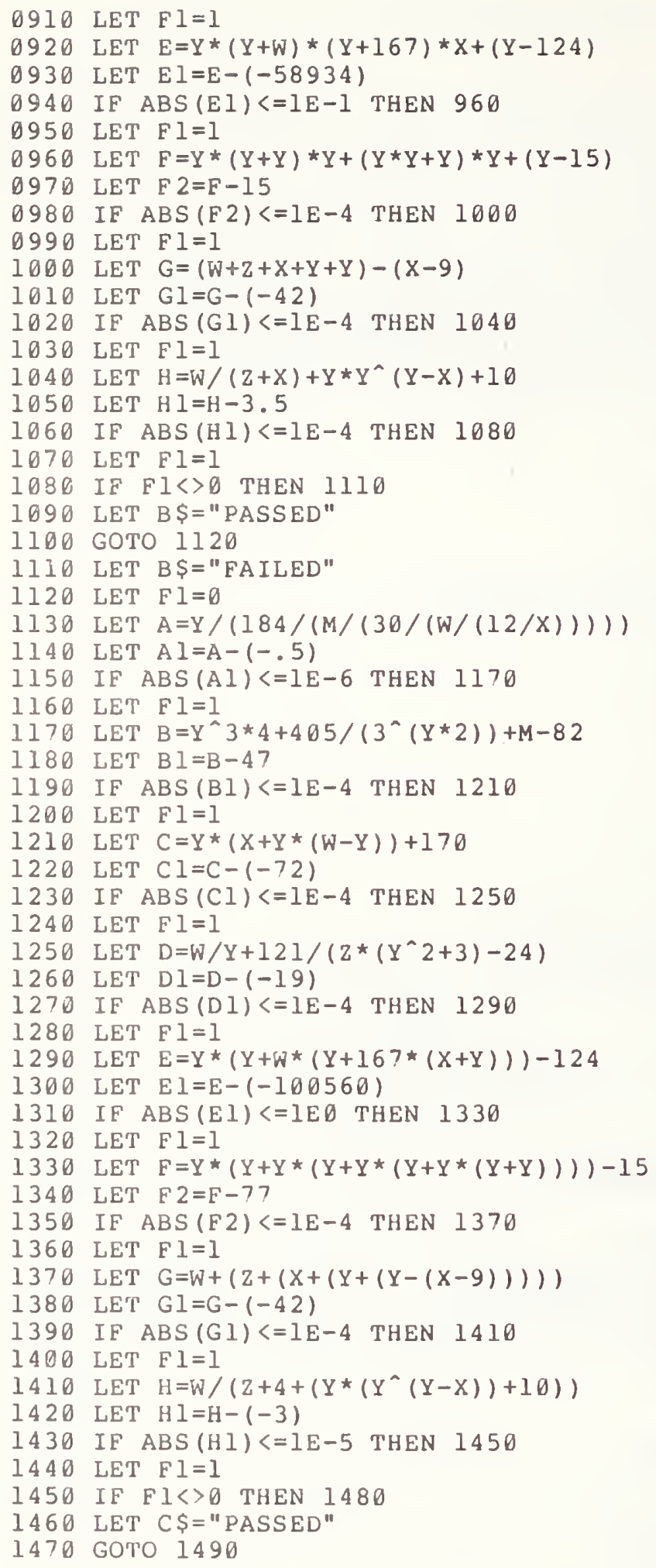


1480 LET C $\$=" F A I L E D "$

1490 PRINT TAB (18):"

NO $"$

1500 PRINT TAB (18); "PARENTHESES";TAB (38);A

1510 PRINT

1520 PRINT TAB(18); "PARENTHESES"

1530 PRINT TAB(18);" BUT ";TAB (38);B\$

1540 PRINT TAB (18);"NON-NESTED "

1550 PRINT

1560 PRINT TAB (18);" NESTED "

1570 PRINT TAB (18); "PARENTHESES";TAB (38);C $\$$

1580 PRINT

1590 PRINT

END TEST."

1600 PRINT

1610 END

PROGRAM FILE 32

SECTION 32.0

EVALUATION OF EXPRESSIONS WHICH HAVE A VARIETY OF OPERATORS AND ARE OF ONE OF THREE CATEGORIES:

(1) NO PARENTHESES,

(2) NON-NESTED PARENTHESES, AND

(3) NESTED PARENTHESES.

ALSO, THESE EXPRESSIONS ARE FORMED FROM THE USE OF BOTH NUMERICAL CONSTANTS AND NUMERICALLY ASSIGNED SIMPLE VARIABLES.

CATEGORY

OF

EXPRESSION
EVALUATION

OF

SYSTEM

\section{BEGIN TEST.}

NO 
PARENTHESES

BUT

PASSED

NON-NESTED

NESTED

PARENTHESES

PASSED

END TEST. 


\section{INSERTION OF SPACES BETWEEN ELEMENTS OF NUMERTC EXPRESSIONS}

This test verifies that spaces are allowed between elements of numeric expressions. This test uses several expressions with varying amounts of space between component elements. On output, a message will indicate that spaces are recognized if the test is successful; otherwise the user should expect some form of syntax diagnostic. If no syntax error is given and the system fails to evaluate the expressions properly a message will indicate that spacing within expressions is not allowed even though it is not diagnosed. For the specifications on spacing within programs the reader is referred to section 3 of BSR X3.60.

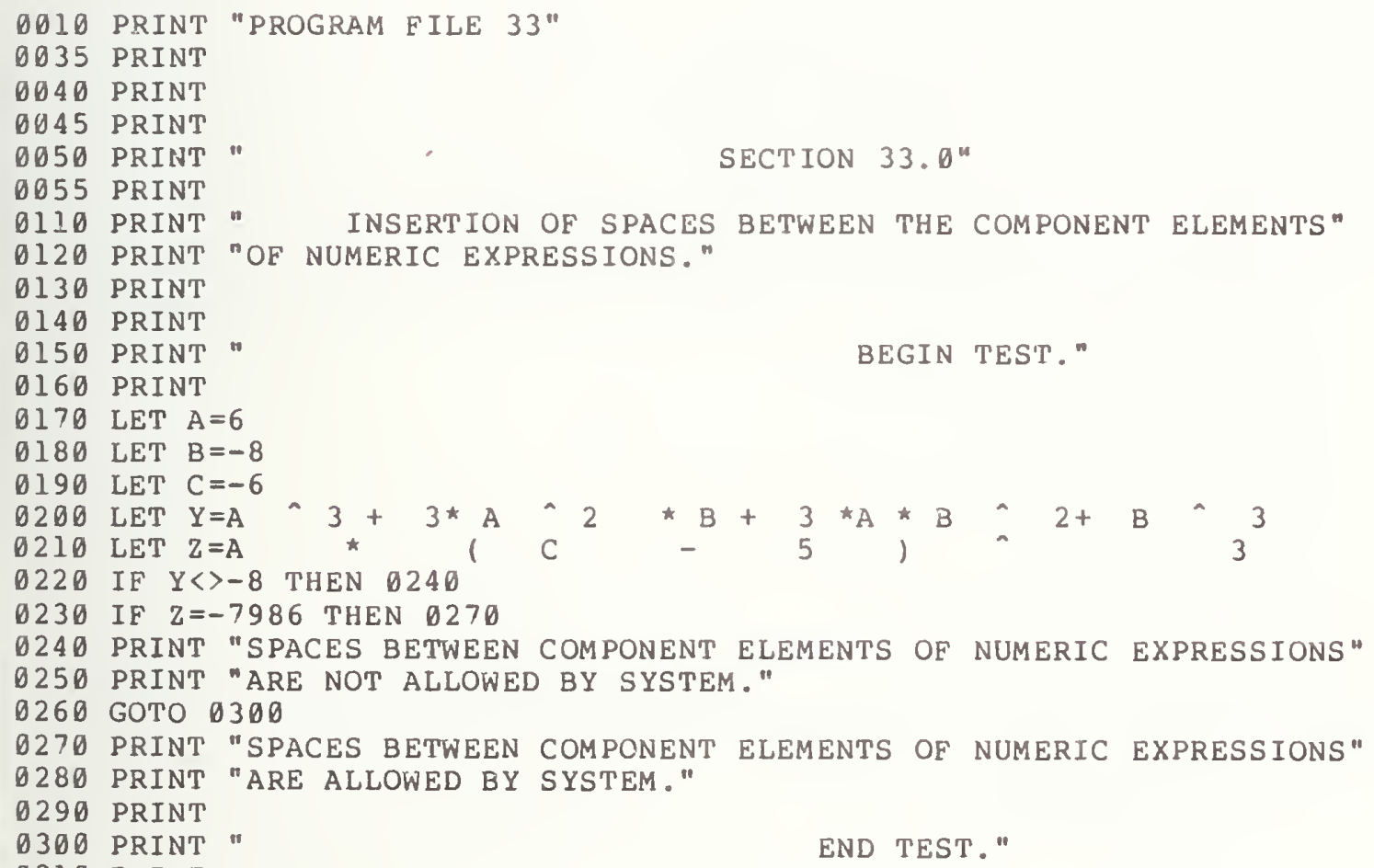

END TEST." 


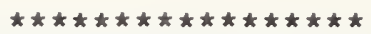

$\star$ SAMPLE OUTPUT *

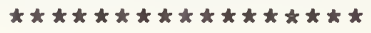

PROGRAM FILE 33

SECTION 33.0

INSERTION OF SPACES BETWEEN THE COMPONENT ELEMENTS OF NUMERIC EXPRESSIONS.

BEGIN TEST.

SPACES BETHEEN COMPONENT ELEMENTS OF NUMERIC EXPRESSIONS ARE ALLOWED BY SYSTEM.

END TEST. 
NBS.114A (REV. 7.73)

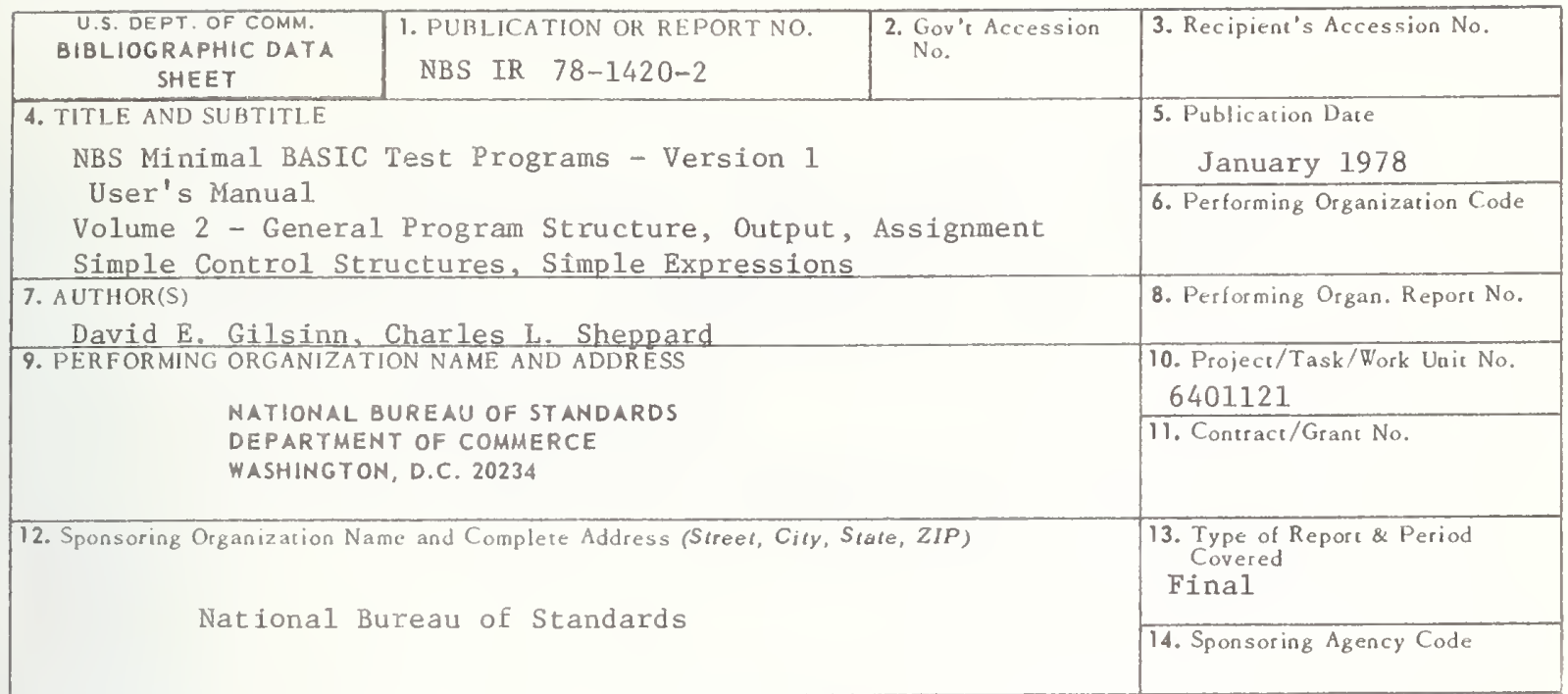

\section{SUPPIEMENTARY NOTES}

16. ABSTRACT (A 200word or less factual summary of most significant informatian. If document includes a significant bibliography or literalure survey, mention it here.)

This volume is the second of four volumes that comprise the user's guide to the NBS Minimal BASIC Test Programs. The programs test whether a BASIC processor accepts the syntactical forms and produces semantically meaningful results according to the specifications given in BSR X3.60 Proposed American National Standard for Minimal BASIC The object of this volume is to introduce elementary variable, control and expression forms and exercise them by using a large sample of variations of the appropriate statements. There are thirty-three programs in this volume. They cover specifically the test for output, simple assignment of varlables, elementary control structures, general program structure, formulating simple expressions, and the hierarchy of operators. The entire set of test programs is available on magnetic tape.

17. KEY WORDS (six to twelve entries; alphabetical order; capitalize only the first letter of the first key word unless a proper name; separated by semicolons)

BASIC; BASIC standard; BASIC validation; compiler validation; computer programming. language; computer standards.

\section{AVAILABILITY}

RFor Offical Distribution. Do Not Release to NTIS

[ Order From Sup. of Doc., U.S. Government Printing (office Washington, D.C. 20.102, SD Cac. No. C.13

I Trder From Narional Techaical Information Service (N1IS) Springfield, Virginia 22151

\begin{tabular}{|l|c|}
\hline $\begin{array}{l}\text { 19. SECURITY CLASS } \\
\text { (THIS REPURT) } \\
\text { UNCLASSIFIED }\end{array}$ & 21. NO. OF PAGES \\
\hline $\begin{array}{l}\text { 20. SECURITY (II.ASS } \\
\text { (THIS PAGE) } \\
\text { UNCLASSIIIEI) }\end{array}$ & 22. Price \\
\hline
\end{tabular}


